\title{
SERVING RESISTANCE ON THE MENU: THE CULTURAL POLITICS OF FILIPINO CUISINE IN WINNIPEG AND OTTAWA
}

\author{
By
}

Gazel Manuel

A thesis submitted to the Faculty of Graduate and Postdoctoral Affairs in partial fulfillment of the requirements for the degree of

\author{
Master of Arts \\ in \\ Sociology
}

Carleton University

Ottawa, Ontario

(C) Gazel Manuel, 2017 


\begin{abstract}
This thesis explores the cultural politics of Filipino cuisine in Canada. Filipinos are the fourth largest visible minority group in Canada yet their cuisine remains underrepresented in the Canadian foodscape compared to other Asian groups. By comparing Winnipeg and Ottawa's contexts, I explore how Filipino cuisine entrepreneurs "do" Filipino cuisine through their establishments. I also examine potential explanations as to why Filipino cuisine is not mainstream. The findings suggest that the underrepresentation of Filipino cuisine can be attributed to structural barriers (colonialism and institutional racism) and the low incidence of Filipino entrepreneurship. Through culinary entrepreneurial practices, Filipino cuisine entrepreneurs engage in a politics of resistance and identity work. For some, the production of Filipino cuisine is implicated in the struggle against cultural assimilation. For others, it is an act of cultural pride and a politics of representation that seeks to disrupt the "hypervisibility" and "invisibility" of Filipino-Canadians and Filipino cuisine.
\end{abstract}




\section{ACKNOWLEDGEMENTS}

Writing this thesis was a transformative and cathartic experience. It has changed the way I think about my Filipino-Canadian identity; although accomplishing this was not easy. Through this research I learned that like so many other 1.5 generation and second generation Filipinos, I exhibited "colonial mentality" - a form of internalised racism among subaltern groups (David 2013; David, Petalio and Sharma 2017). Growing up, I rejected my Filipino heritage and felt no pride in my culture due to negative encounters with members of my extended family and others in Winnipeg's Filipino community. I thought that "all Filipinos are the same" (of course, while excluding myself from that evaluation), leading me to distance myself from the Filipino community.

While conducting my field work, I later discovered from my conversations with other Filipinos that I was not alone in my struggles and negative encounters. This would later lead me to reconsider my negative assessment of Filipino people and Filipino culture. I encountered nothing but kindness and generosity from other Filipinos, which was a stark contrast from what I grew up with. Perhaps, I thought, I was wrong to generalize. Later on, when I became engaged in postcolonial Filipino literature I realised that my negative experiences, along with many others, could be attributed to a larger system of colonialism in the Philippines-it was then I connected my experiences to "colonial mentality." Arriving to this realisation was difficult to accept at first, however, it is necessary to accept painful truths about oneself in order to "decolonize" the mind (Decena 2014). Decolonizing the mind was the first step to re-discovering a part of my identity that I had locked away and buried in the sand for so long.

This thesis has contributed to my growth as an academic and as a person. None of this would have been possible without the help of countless people who were at my side over the past two years and beyond. I would like to thank my participants, mentors, classmates, friends, and loved ones for their continued support during this journey to finishing this thesis.

To my research participants in Winnipeg and Ottawa, thank you all so much working with me on this project. I am forever grateful for your insights, stories, and words of encouragement. This thesis would have not been possible without your participation. Your kindness has truly opened my eyes and has radically changed the way I think about Filipino people and Filipino culture. I will never forget the generosity of those who had graciously 
provided me with hospitality in the form of gifted meals and food - even though it was not at all necessary. Working with you has sparked my resolve and has further motivated me to continue writing about Filipinos in Canada. Salamat sa inyong lahat! I would also like to extend my gratitude to Allan Pineda, who I met through this research project, for catering a beautiful and delicious five-course meal for our wedding in August 2017. You have proved to me that the fruits of research can go beyond the academy and can leave lasting relationships.

I am indebted to my supervisor Dr. Xiaobei Chen for providing her never-ending support and encouragement over the past two years. Even though she has such a busy schedule, she always found the time to provide advice and constructive feedback. Xiaobei is one of the most patient people I know - due to my learning disability (ADHD), I can be challenging to work with. My working style is somewhat disorganized and at times prone to sudden changes and stops. I have the tendency to write long and elaborate e-mails, especially during hours when everybody should be sleeping. Yet, despite my quirks, Xiaobei has graciously worked with me and has kept me grounded and focused through it all, without any judgment. To Xiaobei, you have inspired me to be a better scholar and teacher. I am the luckiest student ever to have a supervisor like you and I look forward to working with you in the next step of my academic journey in the PhD program.

It is not an exaggeration to say that my second reader, Dr. Mike Mopas, has inspired me in a number of ways. To see a successful Filipino-Canadian academic in sociology such as Mike has motivated me to work towards my dreams of becoming a scholar. The inspiration for writing about this topic is also thanks to him. I would have never in a million years thought to write about the Filipino community, much less Filipino cuisine. To Mike, thank you for your feedback, support, patience, and encouragement over the past two years. I know that I can be a bit much with my working style. Thank you for sticking by me and lending me your advice throughout the writing process. Your knowledge on cultural studies and the sociology of food is indispensable!

Even though Dr. Curtis Pankratz is no longer my professor, he still mentors me from afar, even as I continue with my studies in Ottawa. From time to time, he still assists me with brainstorming ideas for projects and providing feedback on my papers. I met Curt during my undergrad at University of Winnipeg and he is the reason why I became a sociologist. While working as a transcriber for Deaf and Hard of Hearing Services, I was assigned to Curt's class by 
chance. Through his approachable teaching style, I fell in love with sociology, so much so that I decided to take his class as a student the following year. As a teacher, he goes above and beyond for his students and if it were not for his help, I would have not mustered the courage and selfconfidence to apply to graduate school. To Curt, as always, I thank you for being such a beacon of support even until now. I also thank you for being such a great role model. I can only hope one day I can inspire my students like you have for me and for countless others.

I would like to thank my peers and classmates for their lending ears and for helping me brainstorm ideas on my thesis. Your feedback, critiques, and second opinions were all very helpful and kept me in check. I would especially like to thank Marie Coligado for being so patient with me and providing critical insights and feedback during the thesis writing process. Marie was especially helpful with our discussions regarding the differences and similarities between the Filipino communities in Winnipeg and Ottawa.

A very large thanks to my friends in Winnipeg and in other parts of the world. Since undergrad, you all encouraged me to pursue sociological studies on critical race and ethnicity studies and food. Throughout the years, my friends would send me articles relating to my research interests through e-mail or social media. I like to extend my gratitude to Joey Felizardo who accompanied me during my participant observations to Filipino restaurants and introduced me to other Filipino restaurants in the city. I would also like to thank Palak Dhiman for her support and attending my thesis defence. Your presence definitely served as a calming effect. Thank you to all my friends who listened to me as I rambled on about my dissertation. Thanks for believing in me and snapping me out of my moments of self-doubt and impostor syndrome.

To my mom, dad, and my brother - thank you for being such a great family unit and for always supporting my studies. I am grateful to my mom and dad for their sacrifices so they could provide for me and Matthew. My mom and dad parented me in a way that fostered my independence and critical thinking, even if it was not easy, and even if their parenting styles were criticized by family members and others. I thank my mom and dad for never giving up on me and for letting me pursue my dreams freely. Mom and dad, your influence has shaped me as a sociologist today. Mom, thank you for lending me your car while I did my field work in Winnipeg and thank you for the delicious Filipino food. As I wrote this thesis, I thought about the meals you made for our family growing up, which were useful frames of reference and 
served as a source of inspiration. Dad, thank you for the great conversations regarding my thesis and for the rich and informative discussions on colonialism and the Philippines.

Lastly, I would like to thank my husband, Gabriel Beaudoin, for his unwavering support for nearly a decade. Thank you Gab, for working so hard while I do my studies. I am very lucky to have a patient and understanding partner like you. You always know how to bring my stress levels down, which is instrumental given that writing a thesis can be very stressful indeed. I appreciate your feedback and insights, as well as keeping me in check (such as reminding me to work on my thesis), all of which keep me grounded and focused. I am also very grateful that you are willing to take the time out of your very busy schedule to listen to me read chapters of my thesis out loud. Thanks so much for driving me around to do my participant observations and interviews. I could go on about all you have done to support me and to make my life easier during the thesis-writing process. For the sake of brevity - thank you for everything. 


\section{LIST OF TABLES}

Table 1. Chart of Filipino Cuisine Establishments Visited ................................................... 49 


\section{LIST OF FIGURES}

Figure 4.0: A photograph of an a-la-carte Filipino cuisine establishment............................... 89

Figure 4.1: A photograph of a buffet Filipino cuisine establishment ..................................... 89

Figure 4.2: A photograph taken from a social media page of a kamayan pop-up dinner with

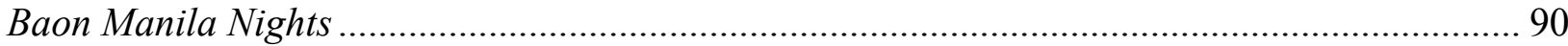

Figure 4.3: A photograph of a carinderia Filipino cuisine establishment .............................. 91

Figure 4.4: A photograph of a turo-turo Filipino cuisine establishment ................................ 92

Figure 4.5: A photograph of a Filipino sari-sari store...................................................... 93

Figure 4.6: A photograph of baked goods at a Filipino bakery ........................................... 94

Figure 4.7: A photograph of baked goods on a shelf at a Filipino bakery ............................... 94

Figure 4.8: A photograph of a food truck Filipino cuisine establishment .............................. 95

Figure 4.9: A photograph of a Filipino food truck with Philippine symbolism as décor ......... 100

Figure 4.10: A photograph of a Pan Asian fusion "Canadian" restaurant decorated with Asian

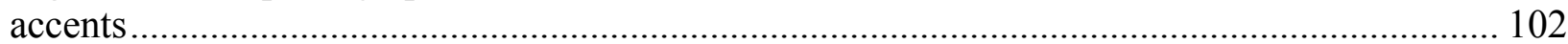

Figure 4.11: A photograph of a kitschy-decorated "traditional" Filipino restaurant ................ 103

Figure 4.12: A photograph of a modern Filipino restaurant stylized as kitsch...................... 105

Figure 4.13: A photograph of a plate of food at one of the "traditional" Filipino restaurants... 106

Figure 4.14: A photograph of a Pan Asian fusion restaurant's interior .................................. 108

Figure 4.15: A photograph of a plate of food at a "modern" Filipino restaurant..................... 111

Figure 5.0: A photograph of a buffet line at a Filipino buffet restaurant.............................. 118

Figure 5.1: A photograph of a Filipino-style breakfast bowl at a Pan Asian fusion restaurant. 121

Figure 5.2ab: Photographs of silog breakfasts in Ottawa (a) and Winnipeg (b) .................... 122

Figure 5.3: A photograph of a Filipino restaurant's silog breakfast menu at a carinderia........ 122

Figure 5.4: A photograph of dried preserved fish at a sari-sari store/turo-turo ...................... 124

Figure 5.5: A photograph of dinuguan, an "ugly" Filipino dish......................................... 127

Figure 5.6: A photograph of a kamayan-style meal at a Filipino restaurant.......................... 129

Figure 5.7: A photograph of kare-kare at a Filipino restaurant .......................................... 130 


\section{TABLE OF CONTENTS}

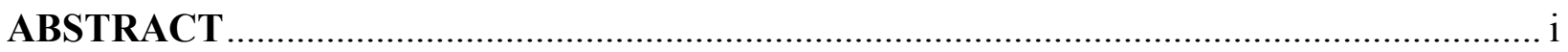

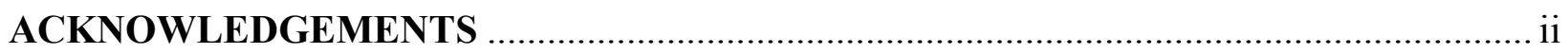

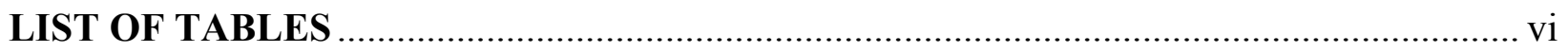

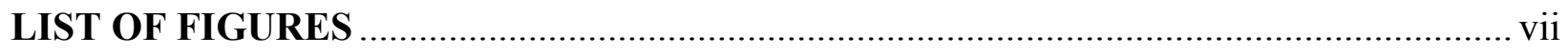

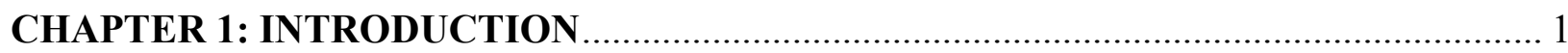

1.1 Empirical Literature on Filipino Cuisine in Diaspora....................................................... 8

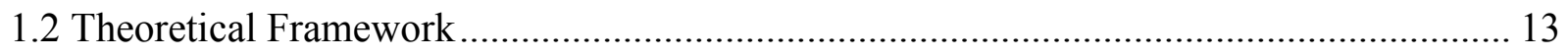

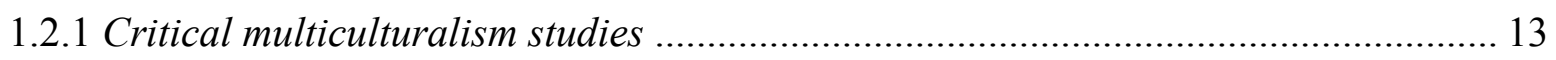

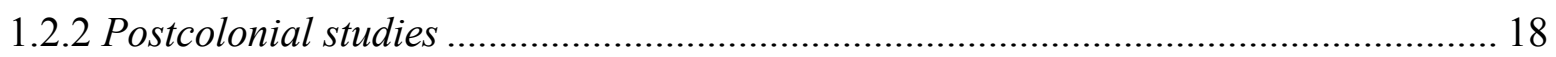

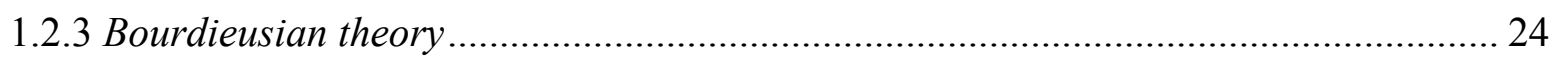

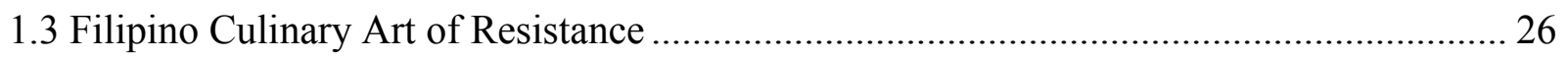

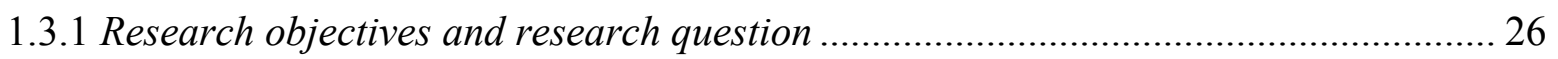

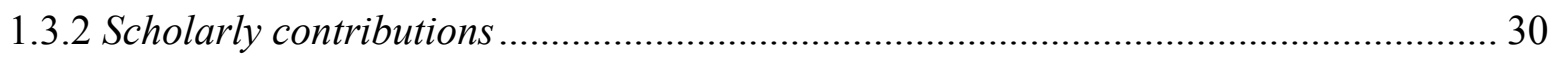

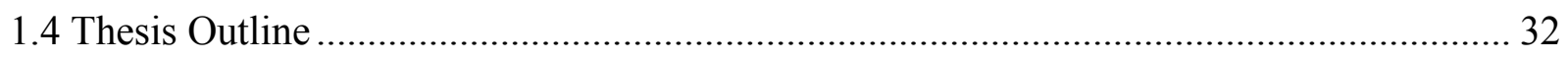

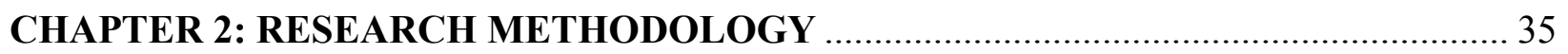

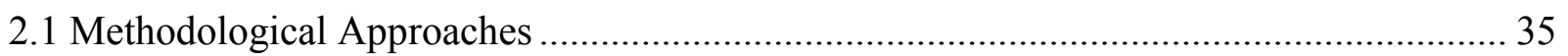

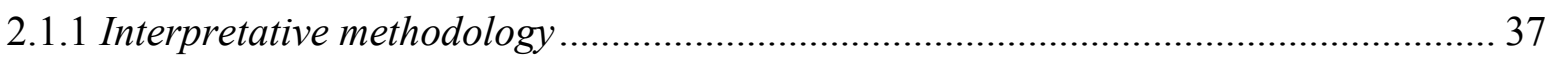

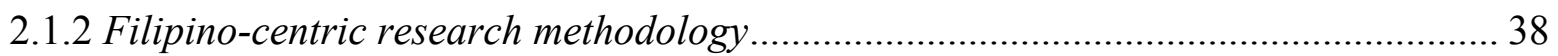

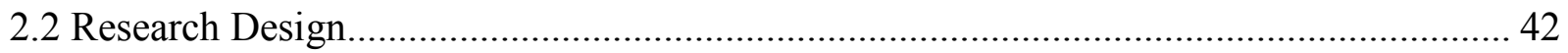

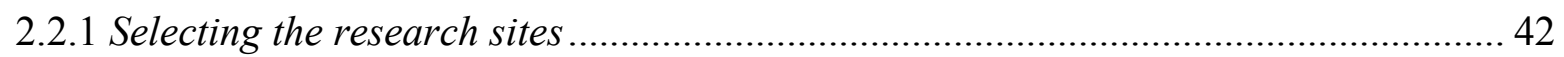

2.2.2 Recruitment strategies ............................................................................................ 44

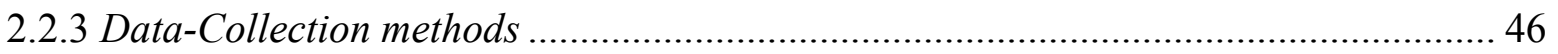

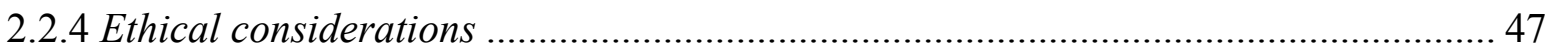

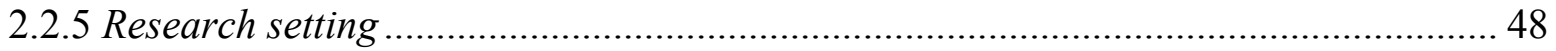

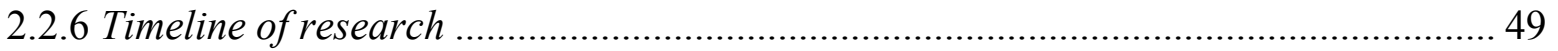

2.2.7 Recruiting research participants .............................................................................. 50

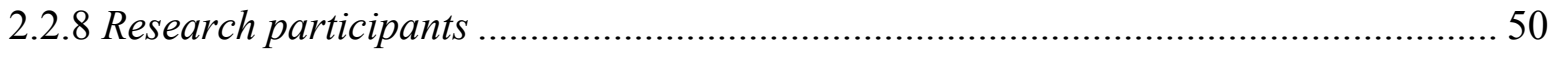

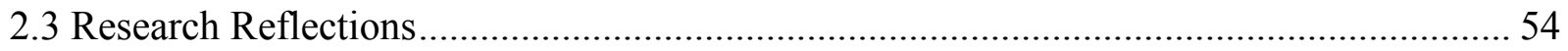

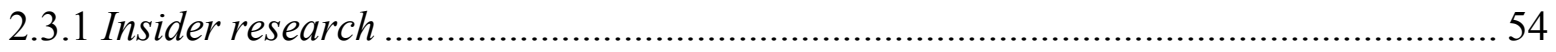

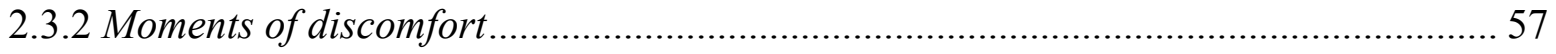

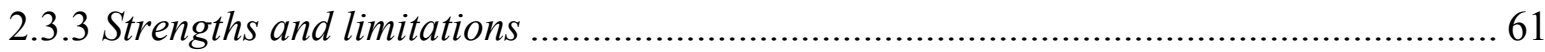

CHAPTER 3: SITUATING THE FILIPINO DIASPORA IN THE CANADIAN

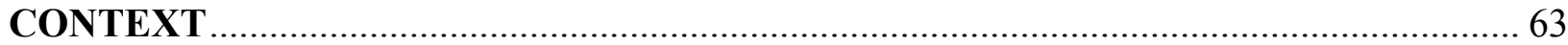




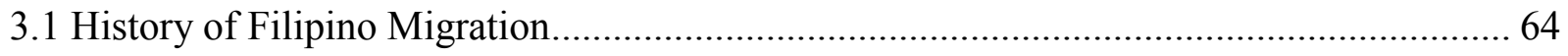

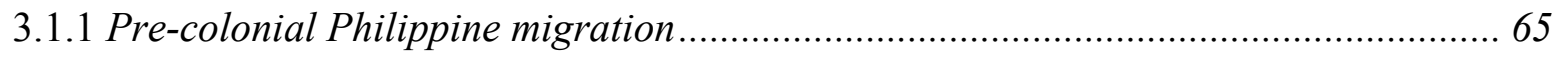

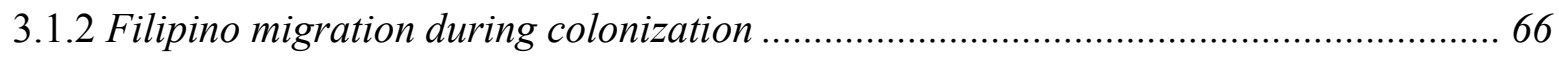

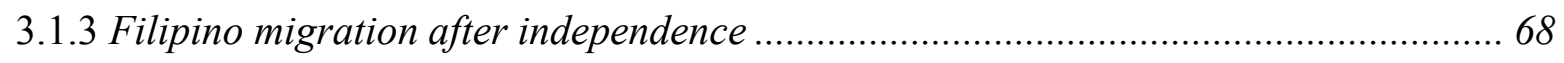

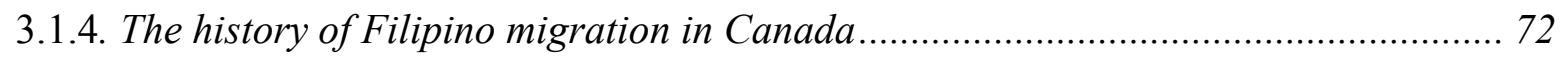

3.1.5 The Filipino diaspora in the Canadian present t.................................................... 75

3.2 The Filipino Community in Winnipeg and Ottawa ........................................................ 77

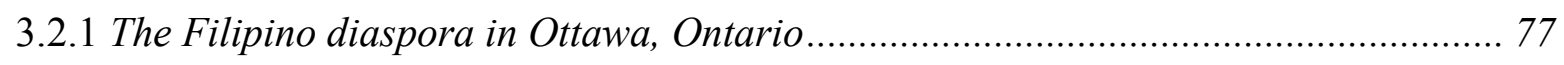

3.2.2 The Filipino diaspora in Winnipeg, Manitoba ................................................... 82

CHAPTER 4: FILIPINO CUISINE ESTABLISHMENTS IN CANADA ………................ 86

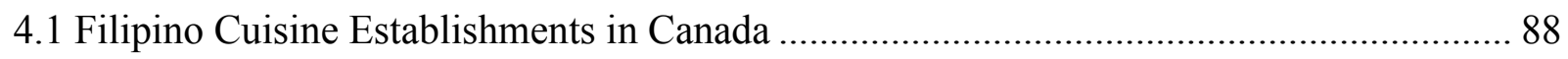

4.2 "Traditional” and "Modern” Filipino Cuisine Establishments ............................................. 98

4.2.1 Traditional Filipino cuisine establishments............................................................... 98

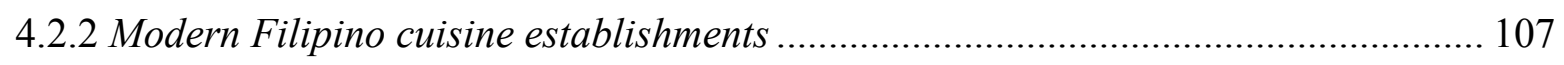

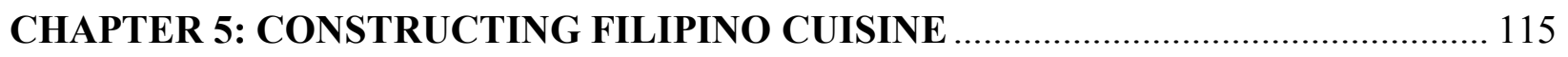

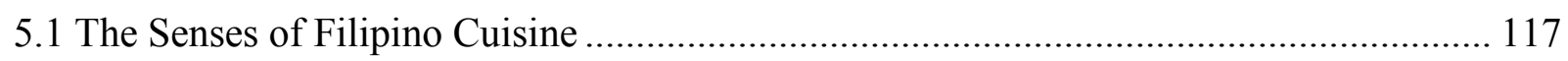

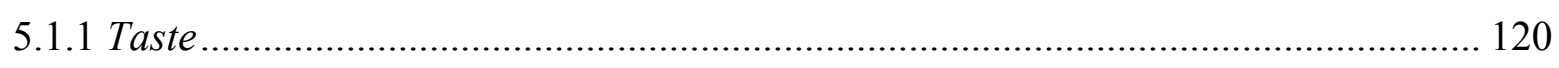

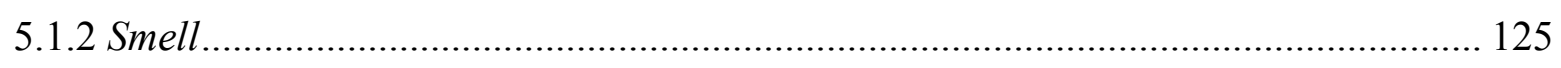

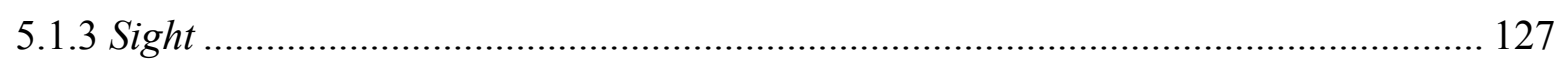

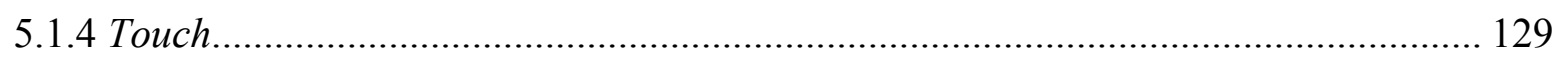

5.2 The Cultural and Regional Diversity of Filipino Cuisine ............................................... 132

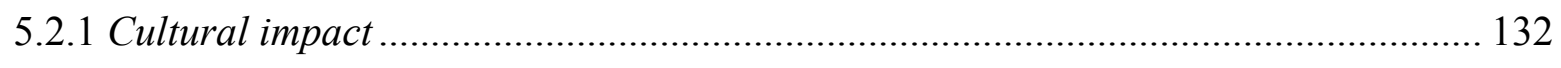

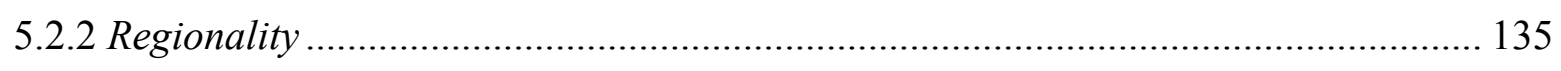

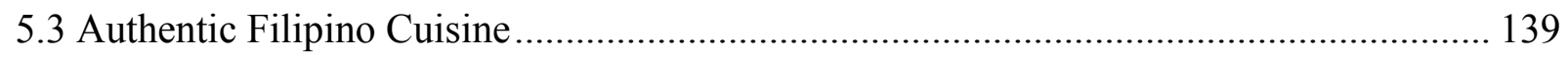

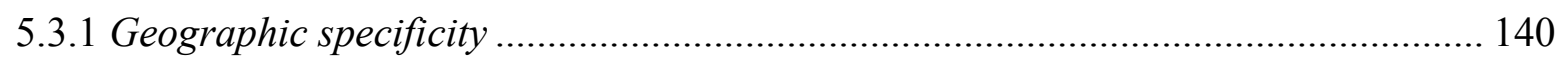

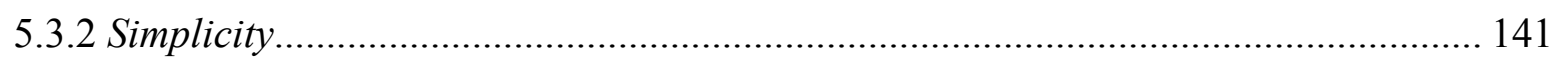

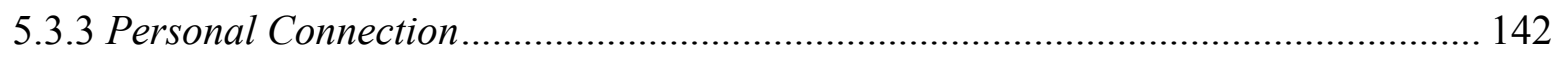

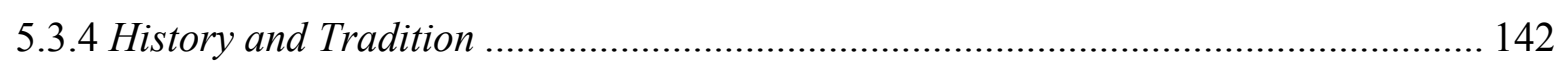

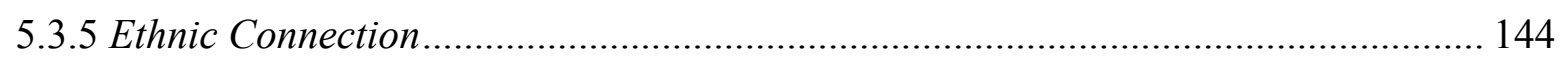

CHAPTER 6: THE STATUS OF FILIPINO CUISINE IN CANADA ……….................. 146

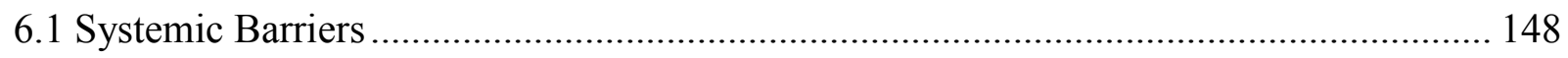

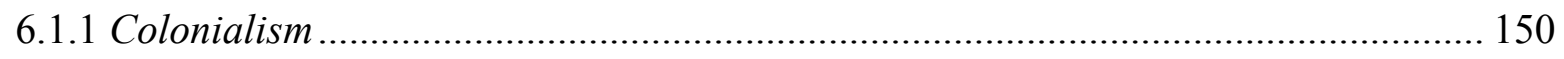

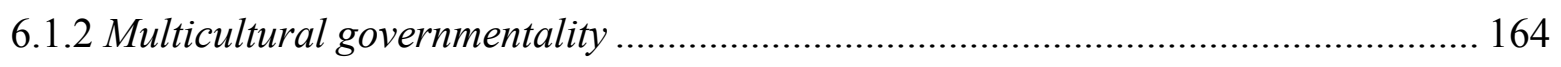




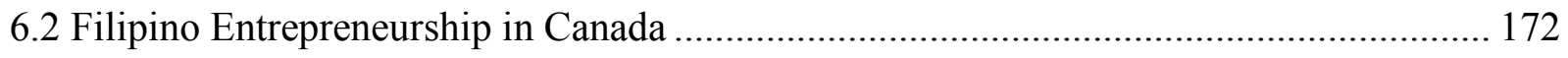

6.2.1 Theories of Filipino entrepreneurship .................................................................... 174

6.2.2 Filipino Pride and Culinary Entrepreneurship .................................................. 177

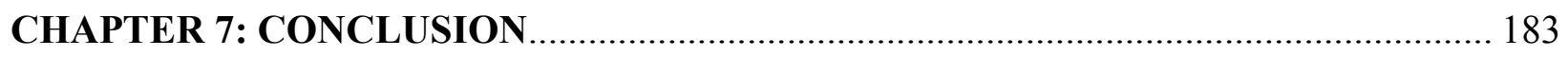

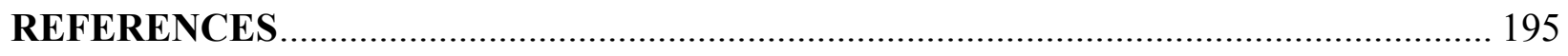

APPENDIX A: LIST OF TERMS AND TRANSLATIONS ….................................... 219

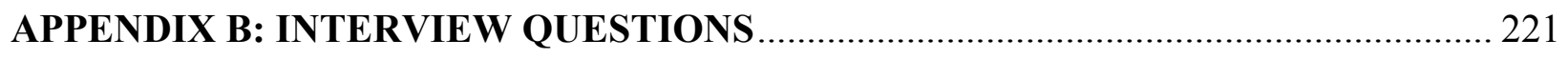

APPENDIX C: LETTER OF INVITATION ........................................................... 223

APPENDIX E: CUREB CERTIFICATE OF APPROVAL ........................................ 227 


\section{CHAPTER 1: INTRODUCTION}

I will admit that before moving to Ottawa for graduate school, I never really thought about Filipino ${ }^{1}$ cuisine. In Winnipeg, is no shortage of places where I could get Filipino food. If I had a craving, I knew I could go to one of the many turo-turo restaurants in Winnipeg; or if I wanted to make something at home, I could easily source ingredients from a local Filipino market. I could also count on my mother to make me anything I wanted. Although I must confess that over time I found it tiresome to be constantly surrounded by Filipino culture - the food, people, markets, and festivals. I am ashamed to admit it now, but there was a moment in time when I refused to eat Filipino food because I found it to be boring and not as exciting as other ethnic cuisines. In fact, if I were given the option to dine at Filipino restaurant or elsewhere, I often chose the latter. In retrospect, I was so foolish to ever think that Filipino cuisine was boring. It was during the course of this research that I embarked on a journey to (re)discovering that Filipino cuisine is multifaceted - like other cuisines, Filipino cuisine can be exciting too - it just depends on who is making it and in what contexts.

I do not believe that I would have come to this awareness had I not left my home in the prairies to move to the National Capital Region. It was when I moved to Ottawa/Gatineau that I realised I never knew what I had until it was gone. As the expression goes, "absence makes the heart grow fonder.” Being away from the Filipino community, including Filipino culture has

\footnotetext{
${ }^{1}$ The use of "Filipino" vs. "Pilipino" has been debated in the literature (Flores 1999; Nadal 2011). In Tagalog (the most widely spoken dialect in the Philippines), the correct spelling would be "Pilipino", as there is no "F" sound in the indigenous languages. Spelling "Filipino with the letter "F" was implemented by the Spanish and was later adapted by the Americans (Flores 1999). Some Filipinos use "Pilipino" as a political identifier to signify resistance to colonialism and imperialism, however, government publications and academic research have used "Filipino" because it is the most common spelling (Nadal 2011). I take a decolonization stance in this thesis, although I use "Filipino" because it is the most commonly used among various contexts, in an effort to make this research accessible to a wider audience.
} 
definitely made me appreciate it a lot more. Also, while I was always aware of my Filipino-ness in Winnipeg, it was not until I had been displaced from it I became really "conscious" of my Filipino identity in Ottawa/Gatineau. Before moving to the National Capital Region, I never felt like an "actual" visible minority because there were so many others like me in Winnipeg. Indeed, Winnipeg has a diverse visible minority population, accounting for $21.4 \%$ of the city's total population. Filipinos comprise $8.7 \%$ of the city's visible minority population (Statistics Canada 2013a). In comparison, while $23.7 \%$ of Ottawa's demographic are visible minorities, only $1.2 \%$ of them are Filipinos (Statistics Canada 2013b). There are even less Filipinos in Gatineau ${ }^{2}$, the other part of the National Capital Region connected to Ottawa by the Ottawa River. While there are Filipinos in Ottawa, there were not as many as I was used to. In Winnipeg I could find a large number of Filipinos in most public spaces. Tagalog, which is the dominant language in the Philippines, was the common background noise in Winnipeg's malls or even at a bus stop in many areas of the city. I find that there is something very comforting to be in the presence of people who look similar to me; and hearing Tagalog on a day-to-day basis.

My world changed when I moved to Ottawa/Gatineau. I began to gradually understand what it meant for Filipinos in Canada to feel simultaneously invisible and hypervisible (McElhinny et al. 2012; Coloma et al. 2012). In Ottawa/Gatineau, the background noise that I was so used to faded away and Tagalog was replaced by the sound of Canadian French. I no longer could find an abundance of Filipinos walking down the street at the same frequency I was used to. I now had to purposely seek them out at churches, festivals, or at small mom-and-pop

\footnotetext{
${ }^{2}$ Although I refer to the National Capital Region (which is comprised of Ottawa and Gatineau), this thesis will only focus on Ottawa. The reason being is that the primary topic of discussion pertains to Filipino cuisine establishments. To date, there are no Filipino cuisine establishments in Gatineau. The field work undertaken in the National Capital Region only took place in Ottawa. As such, Gatineau is only mentioned in this introductory chapter, which relates to my personal experiences rather than the research data itself.
} 
Filipino markets. If I had a craving for Filipino food, I could no longer just stop by my mom's house to get homemade foods, nor could I make a pit stop at the local tapsilogan ${ }^{3}$ to satisfy my tapsilog craving (there are restaurants that serve silog meals, but they are not an actual tapsilogan). Filipino restaurants in Ottawa are uncommon - and to this day, I can only count how many there are with one hand. If I wanted the Filipino comfort foods I grew up with I would have to make it myself - even with the help of cookbooks and internet food blogs, I can never fully replicate the flavours made by a seasoned Filipino cook. Now, whenever I go back to visit family in Winnipeg, I always make sure to stop by a Filipino restaurant and stock up on Filipino snack foods and ingredients that I cannot not easily find in Ottawa. When I leave for Ottawa, my mother always makes sure to stuff as much homemade food as possible in my luggage and carryons, so I can still get a taste of home from the depths of our deep freeze.

During my first year of graduate school I lived in Gatineau. In that year, I was hyperconscious of my Filipino identity because I was "othered" by merely existing and living my dayto-day life. Living in the predominantly white suburbs of Gatineau, I quickly became aware of how "different" I was—even something as mundane as grocery shopping made me selfconscious. I would find that people would stare at me or assume that I could not speak French based on how I looked. Even when my partner and I moved to Ottawa a year later, the microaggressions still persisted. For instance, I would often be mistaken as Vietnamese; and my name gets mispronounced with much more frequency than when I lived in Winnipeg. Here, people would often refer to me as "Manuel" rather than my first name - perhaps "Gazel" is too "unfamiliar". Yet in Winnipeg, I did not have this issue as my last name is a common Filipino

\footnotetext{
${ }^{3}$ A tapsilogan refers to an eatery that specializes in selling silog (a dish made of a meat, eggs, and garlic fried rice). Tapislog is an iteration of a silog that incorporates beef tapa, a type of soy-marinated cured beef (Fernandez 1994).
} 
last name. If anything was mispronounced, it would be my first name - and that has not changed since moving out east.

Being a Filipino in the National Capital Region is markedly different from being a Filipino in Winnipeg. As a graduate teaching assistant, I had the opportunity to have insightful discussions with my undergraduate students about the different lived experiences of Filipinos in Ottawa. I also learned about the Ottawa Filipino community through my involvement with organisations like Migrante Ottawa (an organisation that advocates for migrant Filipino worker's rights around the world). From these encounters, I learned that a sizeable number of Filipino women ${ }^{4}$ living in Ontario were working as nannies or live-in caregivers, often to rich white families (Atanackovic and Bourgeault 2014; see also Stasiulis and Bakan 2005). In fact, some students told me that they grew up with a Filipino nanny. In Winnipeg, the impetus of wide-scale Filipino migration can be traced back to the garment factories in the 1960s (Gonzalez 1998; Dalayoan et al. 2008; Vachon and Toews 2008; Marshall 2014), and later on, Filipino migrants working in those factories would bring their families to Canada through family reunification programs, like my family did. Filipino migrants were also brought over through the Manitoba Nominee Program, and more recently, Temporary Foreign Worker Programs to work in manufacturing and service sectors (Vineberg 2010; Marshall 2014; Bonifacio 2013; McElhinny et al. 2012). Given these migration patterns, Filipino live-in caregivers are uncommon in Manitoba than they are in Ontario.

\footnotetext{
${ }^{4}$ This thesis will use the term "Filipino" rather than differentiating between "Filipino/Filipina/Filipinx". It has been argued that "Filipino" is a gender-neutral term, as indigenous languages such as Tagalog do not make use of gendered pronouns. The gendering of "Filipino" into "Filipina", along with other terminology was implemented during Spanish colonization (Domingpe and Domingo 2012; Reid 2005).
} 
Unfortunately I could not find much information on Ottawa's Filipino migration history as there are very few works published, which corresponds to the demographic reality of Filipinos in Ottawa. Meanwhile, there has been a steady growth in the number of works published on Filipinos in Winnipeg (see Vachon and Toews 2008; Buduhan 1972; Manzanilla 2009; Bautista and Udarbe 2001; Allard 2013; Bonifacio 2013; Marshall 2014, 2015), even though the size of Winnipeg's Filipino population pales in comparison to major metropolitan areas such as Toronto and Vancouver which have larger Filipino demographics. There were also gaps in the literature pertaining to Filipino entrepreneurship, especially restaurant ownership (see Andrei 2010 and Barker 2014). Scholarly works pertaining to Filipino cuisine have been written extensively by Philippine culinary historians (see Cordero-Fernando 1976; Fernandez 1988, 1994, 1993, 2002; and Fernandez and Alegre 1990), and there is a steady growth in literature pertaining to Filipino cuisine in transnational contexts (see Zappia 2015; Mabalon 2013; Orquiza 2013; Manalansan 2013; Bullinger, Seitz, and Volz 2012).

Again, the Filipino experience in Ottawa differs from those in Winnipeg - this thought can also be extended to Filipino cuisine. How does the cultural politics of Filipino cuisine differ in Ottawa and Winnipeg? Through my lived experience as a Filipino living in both cities, and through the findings in this research project, it is evident that Ottawa and Winnipeg represent two different worlds for Filipinos; in part because both cities are distinct in terms of their migration histories. Unlike Winnipeg, Ottawa is not a city that historically receives Filipino immigrants on a large scale (Carriere 2016; Vineberg 2010). Correspondingly, the amount of Filipino cuisine establishments in Ottawa is much smaller in comparison, as one participant remarks: 
First of all we're not centralized anywhere in Ottawa. We can't say "oh this is Filipino town", and this street is Filipino street. We're not like that. We're scattered all over the city.

Ottawa's Filipino population is not enough to have an ethnic enclave, nor is the Filipino community large enough to solely sustain Filipino restaurants on its own. In such circumstances, Filipino cuisine entrepreneurs need to revise their business strategies in order to entice a nonFilipino market. In comparison, Winnipeg has enough Filipinos to be able to sustain some Filipino cuisine establishments. However, as I will later explore in this thesis, relying on the Filipino community itself is not enough to break Filipino cuisine into the mainstream. Some Filipino cuisine entrepreneurs have to negotiate maintaining "authenticity" and "tradition" to satisfy their Filipino demographic and at the same time, they also have to make sure their establishments are "modern" and "fresh" in order to draw in a non-Filipino, or "white" audience, as one participant confesses:

Our target market is Caucasians. You know what I mean? That's what we want. We want those people to try our food...

The participant's statement is not unique to only Filipino cuisine entrepreneurs. This line of thinking is very common among ethnic minority restaurateurs, especially among the younger generation who hope to bring their ethnic cuisine into the culinary mainstream (Janer 2007; Mannur 2005ab). In this study, restaurants that seek to cater to a white mainstream audience are comprised of the modern "Pan Asian" fusion restaurants; and even if Filipino cuisine entrepreneurs do not classify their restaurants as "fusion", they still employ "modern" techniques which, in the realm of haute cuisine, are derived from the French tradition (Janer 2007). Whereas other participants, mainly those of the older generation, remain ambivalent about catering to a non-Filipino audience. These participants operate their establishments without the agenda of 
"modernizing" and "mainstreaming" Filipino cuisine; and instead choose to only focus on the needs of their community. As such, the business strategies among Filipino cuisine entrepreneurs will vary. How they $d o$ Filipino food differs.

This thesis focuses on the unique experiences of Filipino cuisine entrepreneurs in Winnipeg and Ottawa. I chose to study culinary entrepreneurship because food is something that is often taken for granted as it is integral in our-day-to-day lives. At the very basic level, all people need to eat food in order to survive; and it is precisely the banality of food that makes it ideal to study identity work and cultural politics (Johnston and Baumann 2010; LeBesco and Naccarato 2012). Ethnic foods in particular are useful to study topics pertaining to identity politics in liberal multicultural societies (Mannur 2005b; Janer 2007; LeBesco and Naccarato 2008).

The inspiration for choosing my thesis topic came from one of my Filipino-Canadian professors who suggested that I should consider writing about Filipino cuisine. At first, I was not sold on the idea. Filipino cuisine? Really? At the time, the prospect of writing about Filipino cuisine was not enticing. Yet he managed to convince me that it would be an interesting project because first, it would be interesting to find out why Filipino cuisine is not mainstream; second, scholarship on Filipinos - much less Filipino cuisine - is lacking; and third, as a Filipino it may be methodologically advantageous for me to do "insider research" on the Filipino community. After this encounter, it was the first time I ever thought the status of Filipino cuisine not only in Canada, but in the Western context in general. I started to think about the possible reasons as to why Filipino cuisine is not mainstream. The fact it remains underrepresented is puzzling - even though many Filipinos live in the United States and Canada, why is it that Filipino cuisine has not yet "made it" to the public consciousness? Will there be a time when Filipino cuisine has 
reached the mainstream? These questions, I would later find out, were also something that was on the minds of many of the research participants.

Recently, the idea that Filipino cuisine is on the cusp of a breakthrough has been suggested in various media outlets (Clapson 2016). Even the acclaimed food authority, Anthony Bourdain, has made comments about Filipino cuisine being the "next big thing" (Kludt 2017), as if it were a fashion trend. Ironically enough, Vogue magazine recently published an article stating that Filipino cuisine becoming an ethnic restaurant staple in the United States (McNeilly 2017). The media hype corresponds with the opening of several Jollibee ${ }^{5}$ restaurants across Canada, with the first to open in Winnipeg. A sizeable number of Filipino restaurants have opened up across Canada, with more to come. There is also a steady growth of Filipino chefs that have been featured in shows like Top Chef and Chopped, and more recently, two Filipino-Canadian chefs were finalists in Masterchef Canada (Corydon Times n.d.). The second best restaurant in the United States according to Bon Appetit magazine in 2016 is a Filipino restaurant called "Bad Saint" in Washington, D.C. (Knowlton 2016). Indeed, with all of these factors considered, writing this thesis could not have been written at a more a propos time.

\subsection{Empirical Literature on Filipino Cuisine in Diaspora}

Since 2015, there are approximately 2.4 million Filipinos abroad, working as Overseas Filipino Workers (OFWs) (Philippines Statistics Authority 2016). In the 2009 US census, there are an estimated 3.7 million Filipinos reported to be living in the United States (McNamara and Batalova 2015). According to the Canadian 2011 National Household Survey, Filipinos comprise

\footnotetext{
${ }^{5}$ Jollibee is the biggest fast food chain in the Philippines surpassing even McDonalds (Bullinger, Seitz, and Volz 2012). It holds a special place for many diasporic Filipinos across the world as it symbolizes nostalgia and represents the Philippine homeland (Gehman 2012).
} 
of the fourth largest visible minority population, with an estimated 662,600 Filipinos residing in Canada (Statistics Canada 2013c). As these statistics show, there is a large number of diasporic Filipinos across the world. Despite this growing demographic, it is only recently that Filipino cuisine is becoming recognized by the mainstream (Clapson 2016; Knowlton 2016; McNeilly 2017). The status of Filipino cuisine can be described by the adage, "always the bridesmaid, but never the bride" (Palanca 2016). Relative to other minority ethnic cuisines such as Chinese (Lu and Fine 1995; Mannur 2005a; Cho 2010), Thai (Molz 2004, 2007), Vietnamese (Huynh 2012), and Japanese (Tanaka 2008), Filipino cuisine remains largely unnoticed and has yet to capture the attention of the mainstream.

The factors that contribute to the "invisibility" of Filipino cuisine has been of interest for some researchers (Andrei 2010; Barker 2014), however the exact cause of why Filipino cuisine is underrepresented in the culinary world has yet to be thoroughly investigated on a scholarly level. Barker's (2014) research investigates the invisibility of Filipino cuisine in the United States by identifying "crab mentality" as a cause for the underrepresentation of Filipino cuisine in the culinary mainstream. Crab mentality or utak-talangka is a metaphor used by Filipinos to describe the behaviour of crabs in a boiling pot-in order to survive, each would climb over and push others out of the way (Aguila 2014: 84). In the interviews and literature, Filipinos commonly understand crab mentality as a cultural phenomenon unique Filipinos. Filipinos who manifest crab mentality are said to have a psychological defect and character flaw characterized by hypercompetitiveness, where people would rather "pull each other down" than supporting one another (Vergara 2009; Bonifacio 2013). Similarly, Andrei (2010) also mentions that her research participants attributed Filipino crab mentality as a possible reason why there is a "perceived lack of Filipino restaurants" in the United States. 
Like Andrei (2010) and Barker (2014), I also found that crab mentality was a recurring theme identified among my research participants to explain why Filipino cuisine has not yet "made it" in the mainstream culture. However, their analyses do not probe further to examine the causes of crab mentality and why it appears to be a phenomenon prevalent among the Filipino communities across the United States. It would be misinforming to conclude that crab mentality is an inherent characteristic of the Filipino personality—-to do so would perpetuate essentialist assumptions of the existence of a singular Filipino identity and generalized Filipino experience. To assume that crab mentality as an innate part of the Filipino psyche fails to consider that Filipino identities are constructed through social, political, historical, and cultural processes. Like other scholars, I posit that it would be analytically productive to analyse crab mentality as "colonial mentality", which is a perspective that avoids making essentialist claims about Filipino behaviour. Drawing from Frantz Fanon's $(2005,2008)$ works on the psychological impact of colonialism, Filipino-American psychologists have argued that the history of colonization in the Philippines has impacted Filipinos on a psychic level (David 2013; David and Nadal 2013; Nadal 2011; Decena 2014).

Colonial mentality is a phenomenon that is found among subaltern groups. At the very basic level it is defined as the perception of ethnic and cultural inferiority and a manifestation of internalized racial oppression (Decena 2014). Colonial mentality stems from the violent legacy of colonization and imperialism in the Philippines. Consequently, Filipinos have been left with psychological scars, which is expressed as an inferiority complex and identity crisis (David 2013; Nadal 2011; David and Nadal 2013). Studies have suggested that colonial mentality is a significant problem affecting the Filipino diaspora in the United States (David 2013; David and 
Nadal 2013; Nadal 2011; David, Petalio and Sharma 2017; Decena 2014), as well as in the Canadian context (Bonifacio 2013; Aguila 2014).

Sociological studies on food and cuisine reveal that ethnic restaurants are sites where identity work takes place. Within the confines of the ethnic restaurant, identity is being (re)constructed and (re)negotiated for both the consumer and the producer (Heldke 2005; Johnston and Baumann 2010; Long 2004; Molz 2004, 2007). Wiley's (2016) research demonstrates how food plays a major part in the identity construction and the politics of recognition among second generation Filipino-Americans. Food preparation and consumption has played a large symbolic role in Filipino culture (Fernandez 1994), and is recognized as a dominant form of "non-verbal cultural transmission", especially among Filipinos who cannot speak Filipino languages (Wiley 2016: 72). Through food consumption and preparation, second generation Filipinos are able to express their Filipino-ness and experience their Filipino identity (Wiley 2016; Andrei 2010; Zappia 2015). The notion that Filipino cuisine is not represented on a grand scale also speaks to the politics of recognition of Filipino-Americans in the United States. I also think this is true in the Canadian context. In later chapters of this thesis, I elaborate how my second generation Filipino-Canadian participants endeavour to shift how Filipino cuisine perceived in Canada through partaking in acts of resistance that challenge Filipino cuisine's invisibility and hypervisibility (i.e., racism and stereotypes) through their entrepreneurial practices. Ultimately, their goal is to make Filipino cuisine recognised by the dominant culturethe Canadian mainstream—on their own terms.

Andrei (2010) suggests that the invisibility of Filipino cuisine can be attributed to "the conflicted nature of Filipino identity in the United States" (Andrei 2010: 27), which speaks to wider discussions pertaining to American imperialism's legacy in the Philippines. In postcolonial 
Filipino-American scholarship, the "conflicted nature of Filipino identity" has been connected to issues regarding the racial and ethnic classification of Filipinos in the United States census. Filipino-Americans are the only ethnic group to be classified into several categories at once either as "Asian American" or "Pacific Islander" (Nadal 2004; Nadal and Mozones 2011). At one point in history, Filipino-Americans were also classified as "Hispanic" due to the legacy of Spanish colonization in the Philippines. Filipino-Americans have also been commonly mistaken as members of different racial/ethnic groups, such as Latino, Pacific Islander, Chinese, multiracial, and Arab among others (Nadal and Mozones 2011). The ambiguity of these categorizations has left Filipinos feeling "invisible", yet at the same time, "hypervisible" (Wiley 2016). The Canadian context of Filipino identity politics has not been explored at the same depth as the American context, as Filipinos have a shorter migration history in Canada compared to the United States (Marshall 2014, 2015). In spite of this, there have been some works that refer to a Filipino-Canadian “fragmented identity" (Mendoza 2012; Pratt 2006; Manzanilla 2009). Like Filipinos in the United States, Filipinos in Canada were also subject to being inconsistently classified in the census. In Canada, Filipinos were historically classified as "Other" and later on, “Asian" (Manzanilla 2009; Pratt et al. 2017).

The "invisibility" and "hypervisibility" of Filipinos in Canada is also a topic of interest among Filipino-Canadian scholars (Coloma et al. 2012; McElhinny et al. 2012). According to McElhinny et al. (2012), Filipino communities are in a paradoxical position of being simultaneously invisible and hypervisible (McElhinny et al. 2012: 5). On one hand, Filipinos are hypervisible in the sense that "only the stereotypes are deemed relevant and significant for public circulation" (ibid.). Filipinos are considered to be "model immigrants" because they are able to easily assimilate into Canadian society, which has led to generalizations regarding their 
character. For instance, it is a common misconception that Filipinos are inherently agreeable, submissive, loyal, and labourious (Bonifacio 2013; Vachon and Toews 2008). While this idea seems to be a positive appraisal of Filipinos, it fails to acknowledge the problems facing the Filipino diaspora. In this way, Filipinos are invisible in a sense that "numerous people, problems, and achievements are ignored" (McElhinny et al. 2012: 5). Moreover, these character traits are not because they are a natural trait that Filipinos possess, rather, the apparent propensity for Filipinos to be "loyal and hardworking" can be linked to the realities of many Overseas Filipino Workers - who, in order to survive and provide for their families in the Philippines, they often have to endure precarious and abhorrent working conditions (Guevarra 2010; Stasiulis and Bakan 2005).

\subsection{Theoretical Framework}

This thesis' theoretical framework derives from three bodies of literature: critical multiculturalism studies, postcolonial theory, and Bourdieusian theory in order to analyse the complexities surrounding the cultural politics of Filipino cuisine in liberal multicultural societies such as Canada. I use these theories as conceptual lenses to understand, as well as articulate, the lived experiences of Filipino culinary entrepreneurs and how the production of Filipino cuisine shaped by complex range of social, historical, and political processes.

\subsubsection{Critical multiculturalism studies}

I draw from critical multiculturalism studies to provide some insight as to how Filipino cuisine entrepreneur's decisions regarding their food establishments are tempered by liberal multiculturalism. A prime example is how the mass media constructs Filipino cuisine through an Orientalist lens (Said [1978]2000), as demonstrated through culinary tourism programs, which 
are informed by liberal multicultural discourse. These programs are intended to educate a Western audience (Kelly 2014). Yet, under the guise of education and entertainment, consequently construct Filipino culture and cuisine as "bizarre", "scary", and "exotic". I contend that such portrayals of Filipino cuisine can be understood as essentialist and racist, and may contribute to negative perceptions of Filipino culture and cuisine. I draw upon two main concepts from critical multiculturalism studies to frame my arguments. First is the concept of neoliberal racism (e.g., colourblind racism) and multicultural governmentality.

\section{Neoliberal Racism}

Neoliberal racism is a term used to describe the contemporary manifestation of racism (Frankenberg 1993; Goldberg 2008). To understand the implications of colourblind racism it is crucial to take into account how conceptualizations of race have shifted throughout history. Early conceptualizations of race were based upon biological characteristics (such as skin colour, body structure, and skull size), to classify different groups of people. These classifications were used to make assumptions of people regarding their morals, character, values, and behaviour (Balibar 1991; Winant 2006). These race classifications were used to justify colonial projects embarked by the Europeans and were also used to argue the superiority of whites over persons of colour (Duster 2005).

Over time, there was a paradigm shift with regards to how race was understood. Academics have destabilized the concept of race as a legitimate scientific category, and as such, the biological construct of race became recognized as a social construction (Winant 2006; Goldberg 2008; Hall 1992). This paradigm shift did not result in the eradication of racism, rather, another form of racism began to emerge in its place: "cultural racism", or "neo-racist ideology" 
(Balibar 1991: 21). Under a neo-racist ideology, rather than conceptualizing race as a biologically determined fact, race is imagined under new categorizations, such as ethnicity, nation, and culture (Hall 1997; Balibar 1991). Cultural racism is what fuels the contemporary form of racism-“colourblind racism" (Frankenberg 1993).

It is important to consider the role of neoliberalism, specifically neoliberal ideology, in understanding the contemporary form of cultural racism. Scholars have argued that neoliberalism can be defined as an ideology, political philosophy, or economic theory (Harvey 2005; Dean 2014). Others have read neoliberalism as a governmentality, which has contributed to the prevalence of colourblind racism in liberal multicultural societies (Ong 2006; Melamed 2006; Goldberg 2008; Cotoi 2011). Governmentality is a term coined by poststructural theorist Michel Foucault (1991: 102), who describes it as:

The ensemble formed by institutions, procedures, analyses and reflections, calculations, and tactics that allow the exercise of this very specific power that has the population as its target, political economy as its major form of knowledge, and apparatuses of security as its essential instrument.

Foucault also explains that governmentality consists of the "knowledge of the state, knowledge it comes to acquire, diffuse, and circulate as necessary for governing" (Foucault 1991: 102). The knowledge Foucault refers to in this passage is the knowledge of "the state's reality" and "the population deemed necessary to govern" (Goldberg 2008: 328). These knowledge claims and associated strategies - understood as governing arrangements-have come to form, fashion, and make up heterogeneous populations, not only demographically but through "conditions of being and distribution, as well as social and natural ecology" (ibid.).

One key logic of neoliberal governmentality is the assumption that people are assumed to be self-entrepreneurs who are solely responsible for their own destinies with little to no 
intervention by the state. What this means for contemporary race and ethnic relations is that race has become a privatized matter (Goldberg 2008: 330). The burden is on the individual to "overcome" racism (Chen forthcoming in 2018). This narrative of "overcoming racism" is evident in the ideal of meritocracy, which propagates the idea that through hard work, individuals can tackle all obstacles, including institutionalized forms of oppression such as racism, sexism, ableism, and poverty (Goldberg 2008). Claims to structural racism may be dismissed altogether, thereby overlooking how institutional racism affects the life chances of racialized populations, which poses implications for labour market representation, education, and job prospects.

\section{Multicultural Governmentality}

Like neoliberalism, there are variations as to how multiculturalism is defined. At the empirical level, multiculturalism can refer to the demographics of a population (Stasiulis 1980; Fleras and Eliott 1996), denoting the population's "diverse cultural origins and practices" (Chen forthcoming 2018: 2). Examples of these include religious beliefs, worldviews, festivals, languages, texts, art forms, foods (Chen 2015, forthcoming 2018). The latter example is most pertinent in my analysis, as in Canadian food culture, multiculturalism is often tied with multicultural eating practices (Flowers and Swan 2012), such as food adventuring and culinary tourism, which are consumption practices that seeks to learn about and engage with ethnic and cultural “Others” (Heldke 2003; Long 2004; Kelly 2014).

Multiculturalism as a discourse is most commonly framed as an initiative of inclusion, one that is emblematic of social and political justice (Chen forthcoming 2018; Henry and Tator 1999). It can be understood as a normative philosophy that advocates for "an inclusive vision of 
humanity that encourages and entertains different forms of cultural diversity" (Mahtani 2002:

86). Multiculturalism is also understood as a strategy to foster tolerance and respect to people of different cultures (Chen forthcoming 2018). The discourse of tolerance is noted to be premised on the notion that the dominant culture (that is, mainstream Canadian white culture) is the normative standard (Brown 2006; Janer 2007; Xu 2008; Mannur 2005ab), while other cultures are merely peripheral (Chen 2015, forthcoming 2018; Janer 2007). Understood in this way, tolerance does not necessary denote acceptance, but for some it implies extending respect to cultures different from one's own (Brown 2006).

Multiculturalism can also be understood in its political form as state policy. This is also known as "official multiculturalism" (Chen forthcoming 2018: 4). In Canadian society, multiculturalism is legally defined as a national value, and there are programs for enacting multicultural values into policy frameworks. Multiculturalism, like neoliberalism, can be understood as a governmentality (Foucault 1991; Ong 1996; Shome 2012; Chen forthcoming 2018), a way in which the state exercises control over the body of its population (Ang 2010: 3). Drawing from the Foucauldian concept of governmentality, Xiaobei Chen (forthcoming 2018: 4), defines multicultural governmentality as:

... the considered, rational activities that seek to shape mental, emotional, social and even political conduct of racialized multicultural others - officially known as "visible minorities" in Canada - as well as the conduct of unmarked, apparently culture-less dominant groups. As a governmentality, multiculturalism is analyzed for its mobilization of a range of knowledges, axioms, strategies, and techniques to achieve particular nationbuilding ends.

Chen relates multicultural governmentality to the concept "cultural identity imperative", which she explains as the "hegemonic, depoliticized preoccupation with essentialized cultural identities for the racialized non-white population, in other words, the making of ethnicized 
citizens in the existing hierarchy of belonging" (Chen 2015: 626). Some have argued that in liberal multicultural societies, there is a hegemonic and depoliticized preoccupation of ascribing ethnicity to racialized groups. Ethnicity is foregrounded as the "primary identification" (Chen 2015: 628; Shome 2012; Mahtani 2002).

\subsubsection{Postcolonial studies}

I use three concepts from postcolonial studies literature to situate broader discussions on identity. Specifically, I draw concepts from postcolonial discourse such as identification, hybridity, and Orientalism. I also draw concepts from the field Sikolohiyang Pilipino (Filipino Psychology) (SP), a postcolonial psychological perspective (Enriquez 1975).

\section{Identification}

Ethnicity can be extended beyond individual persons or groups of people and can be ascribed to objects such as food, music, and clothing (Pitcher 2014). Food practices, such as food production and food consumption, are forms of identity work (Fine 1992; Lu and Fine 1995; Johnston and Baumann 2010). Food production can be used to express one's ethnic identification (Molz 2004). Food consumption on the other hand can be used as a means used to fashion one's identity (Heldke 2003; Long 2004).

To make sense of identification, I draw from Stuart Hall's work on ethnic and cultural identity. In the era of postmodernity, the process of identity formation is complex because identity is becoming fragmented (Hall 1990: 222). Hall argues that there is no singular essential identity, rather, the subject is made up of "several, sometimes contradictory or unresolved identities" (Hall 1992: 277). These identities are formed through the process of identification, 
which he describes as the formation of identity that is "formed through unconscious processes over time, rather than being innate at consciousness at birth" (ibid: 287).

Identity formation must therefore be understood as a process that is situated within a complex web of social, historical, and political processes (Hall 1991). Hall proposes that we think about identifications (e.g., cultural and national identity) as a process of "being" and "becoming" (Hall 1991) rather than as something that is "literally imprinted in our genes" and as part of people’s “essential natures” (Hall 1992: 291). Using Hall’s theory of identification, I inquire how Filipino cuisine entrepreneur's identifications can be represented through their food production practices. Through these practices, how is "Filipino-ness" being articulated? In what ways do these representations of Filipino identification differ?

\section{Hybridization}

Hybridization can be understood as the process of mixing of different cultures, people, and ideas (Bhabha 1994; Gilroy 1993; Ang 2003). Hybridity can also be understood as the interlocking of histories and cultures (Hall 1990: 310). Like the process of identification, the process of hybridization is also complex and entangled in a web of power dynamics. On one hand, hybridization can be harmonious and produce positive outcomes, however, hybridization can be enforced through violence, such as colonialism and imperialism (Ang 2003; Bhaba 1994). It has been suggested that hybridity is a strategy that can be used by colonized groups to articulate difference, but at the same time, "subvert and reappropriate dominant discourses" of Otherness (Kraidy 2002: 3). Such strategies demonstrate that hybridity can be thought of as an ongoing negotiation, as Bhabha (1994: 2) writes: 
The social articulation of difference, from the minority perspective, is a complex, ongoing negotiation that seeks to authorize cultural hybridities that emerge in moments of historical transformation.

Bhabha coins the term "third space" to denote how hybridity is situated in a liminal and in-between space that allows for productivity and new possibilities (Bhabha 1996). The third space is at once "interruptive, interrogative, and enunciative" (Bhabha 1994: 103), and an "ambivalent site where cultural meaning and representation have no primordial unity or fixity" (Meredith 1998: 2). The third space, therefore, disrupts the "realm of colonial binary thinking and oppositional positioning" (ibid.), and "initiates new signs of identity, and innovative sites of collaboration and contestation" (Bhabha 1994: 1). In this thesis, I use the concept of hybridity to think about how restaurants can be conceived of as a "third space", through which Filipino cuisine entrepreneurs can simultaneously subvert and reappropriate dominant discourses of Filipino culture and cuisine.

\section{Orientalism}

Orientalism is a theory coined by postcolonial scholar Edward Said used to refer to a system of ideas and beliefs that assumes the existence of fundamental and oppositional differences between the West (Occident), and the East (Orient) (Said 1993, [1978]2000). Said's seminal work, Orientalism, interrogates the ways in which Orientalist discourse constructs the West, specifically Europe, as superior; meanwhile, the East is marked as inferior (Said [1978]2000: 87). Orientalism can be conceived of a style of thought based upon epistemological and ontological distinctions between the West and the East (Hirose and Pih 2011). Orientalist discourse has been used by colonizers to justify their colonial projects, which relies on the subjugation of colonized subjects (Said 1993). 
The inferiority of the East in Orientalist discourse is articulated through racial and cultural terms. Orientalist narratives portray the East as primitive and "exotic", while the West is portrayed as "rational" and an exemplar of social progress (Said [1978]2000). Orientalism is the West's "way of coming to terms with the Orient that is based on the Orient's special place in the European Western experience" (ibid: 68). Through this binary opposition, Orientalist narratives of the East has helped to define the West as a contrasting, superior image, idea, personality and experience (ibid.). Like identity, the categorizations produced by Orientalist discourse are social constructions, as they are ideas that are "made up of human effort, affirmation, and identification of the other" (Hirose and Pih 2011: 1487).

In this thesis, Said's critique of Orientalism is used to analyse the cultural politics of ethnic food consumption and production in the Canadian context. As several food scholars have argued, Western foodie culture is entangled with Orientalist discourse (Heldke 2001, 2003; Molz 2004, 2007; Chez 2011; Hirose and Pih 2011), through framing ethnic foods as "exotic", "bizarre" and "scary" (Johnston and Baumann 2010; Kelly 2014). As the interview data suggests, some participants are aware of the ways in which Filipino cuisine is portrayed through an Orientalist lens, citing culinary tourism media as a key source of these portrayals (Kelly 2014; Molz 2004; Heldke 2003). I suggest that decisions made by some Filipino cuisine entrepreneurs take into consideration the Orientalist depictions of Filipino cuisine through strategies of "staged authenticity" (Huynh 2012; MacCannell 1976; Liu 2016) in which they engage in "selfOrientalism" by exaggerating their ethnic "Otherness" through creating an "exotic" experience that conveys ethnic authenticity in their restaurants (Molz 2004, 2007). Such strategies, I argue, are ways for Filipino cuisine entrepreneurs to subvert racism by profiting off their racialization- 
however it is also important to recognise that at the same time, employing these strategies can also problematically perpetuate racial stereotypes.

\section{Sikolohiyang Pilipino (Filipino Psychology)}

Sikolohiyang Pilipino (Filipino Psychology) (SP) is a postcolonial psychological movement that was spearheaded by the late Virgilio Enriquez (1975). SP is distinct from Western psychology as it emphasizes the importance of using indigenous knowledges to study Filipino identity, thought, behaviour, and experience, rather than using Western paradigms that dominate the field of psychology (Pe-Pua 2006; Enriquez 1975). Although SP is rooted in psychological discourse, sociologists and anthropologists have found it useful to study the Filipino diaspora (Aguila 2014, 2015; Mendoza 2002). I want to emphasize by using SP in this thesis, I am not presuming the existence of an essential Filipino identity. I assert that identity is socially, historically, and politically constituted, and is continually constructed through the process of identification (Hall 1990, 1992). Nonetheless, it is still possible, and analytically and politically productive, to draw on SP insights. This caveat comes with the understanding that SP has been critiqued for using essentialist language to describe Filipino identities, as Mendoza (2002: 167) points out in her conversation with a colleague:

... Thinking about and against categories means having to speak their names and sometimes inhabit those problematic identities (which identities are NOT "problematic?"), sometimes with a touch of irony, but always with a sense of the contingent nature that politics demands.

My engagement with SP takes an evaluative and critical stance. SP is a useful analytical lens to studying how colonialism has impacted Filipino subjectivity. In order to understand colonialism's impact, I use the concept of kapwa (collective identity), which is explained as the heart of the structure of Filipino social interactions and values (Enriquez 1978). At the root of 
Filipino social interaction, which is understood as members of the Filipino community interacting with any individual person, regardless of their positionality (i.e., age, race, ethnicity, class, nationality, gender, etc.) is the notion of pakikipagkapwa, which means "treating the other person as a kapwa or fellow human being" (Pe-Pua and Protacio-Marcelino 2000: 56). It is important to note that kapwa is an idea that predates colonialism in the Philippines (Enriquez 1978; Pe-Pua and Protacio-Marcelino 2000; David 2013), yet despite colonialism, kapwa manages to persist as a core value of social interactions among Filipinos in the Philippines and in the transnational context (David, Petalio and Sharma 2017).

By using kapwa in this thesis, I reject the idea that there is an essential Filipino identity and social interactions (Mendoza 2002; Mendoza and Perkinson 2003). Although I also acknowledge that kapwa is theoretically and methodologically useful to help contextualize my interactions with my Filipino participants. It is also useful in making sense of phenomenon such as "crab mentality" or "colonial mentality" (David 2013). Indeed, the link between kapwa and colonialism has been discussed by Filipino-American scholars to describe "colonial mentality" (David 2013; David, Petalio and Sharma 2017; Nadal 2011; David and Nadal 2013). The existence of colonial mentality has been repeatedly mentioned by research participants in this research, albeit under a different name, known as utak-talangka (crab mentality). By using the theory of "colonial mentality" I will showcase how for some participants, they believe "crab mentality" is the primary reason why Filipino cuisine is "invisible" in the culinary mainstream. This idea is not unique to my own research, and has been mentioned in similar studies examining the status Filipino cuisine in the Western context (see Andrei 2010 and Barker 2014). 


\subsubsection{Bourdieusian theory}

The theories of French sociologist Pierre Bourdieu has been used in food studies to study how practices of food consumption and production can articulate a particular social position and status distinction (Johnston and Baumann 2010; Naccarato and LeBesco 2012). In this thesis, I use Bourdieu's concepts of habitus, taste, and capital to analyse how practices of food consumption and food production can be linked to a larger process of identity work.

\section{Habitus}

Habitus is useful in thinking about how outside structures can shape people's dispositions, tastes, and habits. According to Bourdieu, habitus can be understood as a "system of dispositions" (Bourdieu 1984: xxix), classifications, judgments, and practices that are embedded within the individual's consciousness (Wacquant 2007). Habitus is a "structuring structure" which organizes "practices and the perception of practices" (Bourdieu 1984: xxix), it is the embodied representation of external structures that exist outside of the individual (Wacquant 2007). Things that are taken for granted, such as taste, etiquette, way of speaking, body language, and ritualized practices are dependent on a person's “class condition” (Bourdieu 1984: 95). Therefore, habitus can be understood as "the internalized form of class condition and of the conditionings it entails" (ibid.).

\section{Taste}

Bourdieu connects status distinction with a person's taste and their habitus. According to Bourdieu, taste functions as a marker of an individual's social class (Bourdieu 1984: xxv). It is through taste that social subjects come to distinguish themselves from one another. Understood in this way, taste classifies, and at the same time it also classifies the classifier (ibid: xxix). To 
articulate these distinctions, Bourdieu uses food consumption practices as a metaphor to denote the differences in taste between people of different classes, notably, those who have high status distinction possess "good" taste in comparison to those who have low status distinction and possess “poor" taste (Bourdieu 1984: 172):

Even the field of primary tastes is organized according to the fundamental opposition, with the antithesis between quantity and quality, belly and palate, matter and manners, substance and form.

In this passage, Bourdieu is inferring that fundamental oppositions to taste can be attributed to a person's capital composition (Kamphuis et al. 2015). With this in mind, one should not erroneously make the assumption that culinary dispositions are only directly correlated to economic status. One's taste is also implicated by a multitude of different dimensions, such as race, ethnicity, gender, sexuality, nationality, immigration status and religion (Johnston and Baumann 2010; Naccarato and LeBesco 2012).

\section{Capital}

Habitus, as well as taste, is associated with the type of capital a person possesses, and by how much. In Bourdieusian terms, capital does not only refer to one's socioeconomic status, rather, it encompasses several dimensions, which are: economic capital (money and financial resources), cultural capital (social assets), social capital (social networks), and symbolic capital (recognition, honour, and prestige) (Bourdieu 1984: 114). Food scholars have paid special attention to cultural capital in analyses of food consumption, highlighting the ways in which the consumption of certain foods bestows people with cultural capital (Johnston and Baumann 2010; Naccarato and LeBesco 2012). In this way, the acquisition of cultural capital can be seen as a “self-improvement project" (Naccarato and LeBesco 2012: 10). Analyses which centralize on 
food and cuisine, and social and cultural practices associated with gastronomy, have led to the conceptualization of new terms such as "culinary cultural capital" (Bell 2002) and "culinary capital" (Naccarato and LeBesco 2012). Cultural capital is used to the advantage of those involved in food production practices (Fine 1992), and according to Bell (2002), culinary cultural capital refers to the acquisition of culinary expertise that bestows an individual with status distinction, which is an indicator of someone possessing good taste. I consider that for Filipino cuisine entrepreneurs, culinary cultural capital may factor in the management of the

physical and symbolic spaces of their food establishments. As Fine (1992) argues, food production can be an indicator of the cultural capital of the cook, as well, it also indicates the cook's habitus.

\subsection{Filipino Culinary Art of Resistance}

\subsubsection{Research objectives and research question}

This thesis is informed by postcolonial transnational Filipino scholarship (see Mendoza 2002; Ignacio 2005; Coloma et al. 2012; David 2013; Aguila 2014, 2015) and builds upon existing academic research on Filipino culinary entrepreneurship (see Andrei 2010; Barker 2014). Unlike Andrei (2010) and Barker (2014), both of whom briefly discuss the invisibility of Filipino cuisine by attributing crab mentality (as an essential negative personality trait that supposedly exists among Filipinos) to explain why Filipino cuisine lacks presence in the culinary mainstream; this thesis is distinct from these works in that I reject the notion that all Filipinos inherently possess crab mentality. I contend that such explanations are problematic because they make essentialist claims about Filipino people and Filipino culture. 
Drawing from postcolonial Filipino perspectives, I posit that interrogating structural aspects, such as colonialism and liberal multicultural governmentality, play a role in the underrepresentation of Filipino cuisine in Canada. Scholars have argued that crab mentality can be better understood as "colonial mentality" (Nadal 2011; David and Nadal 2011; David 2013; Okazaki, David and Abelmann 2008), a psychological phenomenon that exists among subaltern groups (see also Fanon 2005, 2008). Existing works in ethnic and immigrant entrepreneurship literature have not made clear connections to how structural and psychological aspects, and their interactions can help explain why certain ethnic and immigrant groups choose to pursue selfemployment. Hence, I argue that it may be useful to factor in how social processes such as colonialism and structural racism may contribute to the patterns of entrepreneurship among certain ethnic groups in the transnational context. This thesis seeks to explore these connections by focusing on the experiences of Filipino culinary entrepreneurs in Canada.

This thesis has two primary objectives. The first is to examine what constitutes the "boundaries of ethnicity" in liberal multicultural societies. In other words, what is considered "too ethnic" and "not ethnic enough" in Canadian society? It has been suggested that there exists a spectrum in which expressions of ethnic diversity can be considered by the dominant groups to be too much or too little, and what is considered to be appropriate and inappropriate (Chen 2015; Shome 2012). Some chefs have had to strategically make use of culinary fusion (Mannur 2005b; Xu 2008; Janer 2007), staged authenticity (MacCannell 1976), and self-Orientalism (Hirose and Pih 2011) in order to keep their businesses afloat and stay competitive in local markets (Mannur 2005b; Xu 2008; Janer 2007). In particular, scholars have argued that fusion cooking has been used by Asian chefs in the Western context as a strategy to "quietly and subtly" assimilate into the Western culinary landscape (Mannur 2005b: 85). Moreover, as Xu (2008) points out, the 
culinary fusion of the East with West serves as an emblem of Western liberal multiculturalism, whose success "chiefly rests upon quiet and subtle coercion of multiethnic cultures into a highly commodified and self-exhibitionist performance" (Xu 2008: 9). In later sections of this thesis, I discuss how some Filipino cuisine entrepreneurs have found success in introducing Filipino cuisine to a non-Filipino (primarily Caucasian) audience by adapting strategies that incorporate "fusing" indigenous Filipino recipes with other culture's cuisines. In analysing the politics of fusion cuisine by using Filipino cuisine entrepreneurship as a case study, this thesis can gauge the boundaries of ethnicity in liberal multicultural societies.

Second, this thesis explores the question of power and agency in ethnic entrepreneurship. There have been multiple works written about the power relations that manifest within the confines of the ethnic restaurant (see Huynh 2012; Molz 2004; Long 2004; Lu and Fine 1995; Hirose and Pih 2011). Some authors have implied that ethnic restaurateurs are at the losing end of the power relationship between producer and consumer, because they have to cater to the whims of the white mainstream by engaging in "assimilationist politics" (Mannur 2005ab; Xu 2008), rather than having complete freedom over their businesses (Janer 2007). Meanwhile other scholars note that there is no power imbalance in play ( $\mathrm{Lu}$ and Fine 1995; Molz 2004; Long 2004; Huynh 2012; Liu 2016), although structural barriers such as racism and classism may pose difficulties in the conduct of ethnic restaurateurs' business practices. Despite these challenges, it does always not mean that ethnic restaurateurs are automatically rendered powerless without agency. Rather, it is worth considering how both the consumer and restaurateur are in an ongoing dialectical negotiation. In examining the business decisions made by the Filipino cuisine entrepreneurs, this study can also contribute to the larger discussion of power and agency in the culinary industry at large. 
In this thesis, I consider how Filipino cuisine entrepreneurs ${ }^{6}$ in Canada engage in a form of identity work that is implicated in a broader politics of resistance against "invisibility" and “hypervisibility" (McElhinny et al. 2012; Wiley 2016). Therefore, the main research question asks: how do Filipino cuisine entrepreneurs, through their practices, engage in a politics of resistance in liberal multicultural societies? And in what ways do Filipino cuisine entrepreneurs disrupt and resist the "invisibility" and "hypervisibility" of Filipino-Canadians, as well as Filipino cuisine, through their food establishments? To fully understand this politics of resistance, the social context of colonialism, racism, migration, and liberal multiculturalism must be taken into consideration.

In addition, I pose two sub-questions: how do Filipino cuisine entrepreneurs negotiate their identities through their establishments? And how do they work with and contest notions of "Filipino", "Asian", and "immigrant”? Following these questions, this thesis also considers the relevance of social locations and identifications (Hall 1990) as a key aspect in the politics of resistance among Filipino cuisine entrepreneurs. Indeed, how Filipino cuisine entrepreneurs undergo these processes of negotiation can vary depending on their multiply constituted identities such as age, gender, class, place of birth, immigration path and status, and place of settlement. It is important to consider how the Filipino cuisine entrepreneur's approaches to Filipino foods, as well as the ways in which they manage their businesses are not only influenced by the dominant culture's conception of ethnic "Otherness" (e.g., hypervisibility) - they are also shaped by their social locations.

\footnotetext{
${ }^{6}$ I use the term "Filipino cuisine entrepreneur" as opposed to "Filipino entrepreneur" to denote that not all participants involved in this study identify as an ethnic Filipino. The participants of this study are diverse, having identified as Filipino, Laotian, Vietnamese, South African, Chinese, and/or Caucasian. The term "Filipino cuisine entrepreneur" is used to describe persons who produce and sell Filipino cuisine in their restaurants rather than an ethnic identification.
} 
As I demonstrate in subsequent chapters, the "invisibility" of the Filipino community and the invisibility of Filipino cuisine are connected. I argue that Filipino cuisine, at large, is invisible; and the achievements of enterprising Filipino chefs and restaurateurs are left unnoticed due to larger historical and societal factors. Through their culinary and entrepreneurial practices, Filipino cuisine entrepreneurs in Canada challenge the effects of colonialism and structural racism. For some Filipino cuisine entrepreneurs, their engagement in the politics of resistance is implicated in the struggle against cultural assimilation. For instance, in response to some apartment regulations, which prohibit the preparation of "smelly" Filipino dishes such as tuyo (dried fermented fish), there are some Filipino cuisine entrepreneurs who sell tuyo so that Filipinos affected by these strict apartment regulations are able to access these dishes. For others, their entrepreneurial practices is an act of cultural pride which is also implicated in a politics of representation - one that seeks to disrupt the invisibility and hypervisibility of FilipinoCanadians and Filipino cuisine, through efforts of "mainstreaming" Filipino cuisine. As such, the aspect of cultural pride as a motivator of ethnic and immigrant entrepreneurship will also be discussed in this thesis.

\subsubsection{Scholarly contributions}

This thesis examines the cultural politics of ethnic food in Canada through the lens of Filipino entrepreneurship and contributes to four bodies of literature: critical multiculturalism studies, Filipino-Canadian studies, critical food studies, and ethnic/immigrant entrepreneurship studies. The findings of this research indicate that the "invisibility" of Filipino cuisine can be attributed to structural barriers, specifically colonialism and multicultural governmentality; and the low patterns of Filipino entrepreneurship in Canada. 
First, this research contributes to critical multicultural studies by connecting identity politics with food production via entrepreneurial ventures in multicultural societies (i.e., Canada). However, nuanced discussions connected to identity, multiculturalism and entrepreneurship must also take into consideration how neoliberalism (as an economic ideology and a form of governmentality) plays a role with regards to how people "make" themselves, their identities. Drawing from critical multiculturalism perspectives, this thesis considers the marginal position of ethnic minority entrepreneurs in liberal multicultural societies. Ethnic minority entrepreneurs often have to negotiate their ethnic identity in order to navigate structural barriers (i.e., institutional racism), by conforming to the cultural standards of the dominant culture (Ang 2010; Janer 2007; Huynh 2012; Mannur 2005ab; Xu 2008) - failure to do so can result in negative outcomes for their business. Under a neoliberal logic, it is assumed that failures are due to individual action rather than by structural and systemic causes such as racism (Goldberg 2008; Shome 2012). The results of this study suggest that the logics of liberal multicultural governmentality have, in part, contributed to the "invisibility" and "hypervisibility" of FilipinoCanadians and Filipino cuisine - and to counter this, Filipino cuisine entrepreneurs engage in a politics of resistance through the cultural production of Filipino cuisine.

Second, this thesis contributes to the growing field of Filipino-Canadian studies. Unsurprisingly, most scholarly works on the Filipino diaspora are situated in the American context, which is an effect of the colonial history and existing political relationship between the United States and the Philippines. Canadian scholarship on the Filipino diaspora is lacking in comparison, although there has been some steady growth in recent years. This study contributes to the gaps in Filipino-Canadian studies by focusing on the Filipino-Canadian experience in midsized Canadian cities. Currently, there are few works that focus on the experiences of Filipinos in 
mid-sized cities (Lusis 2005), especially when compared to larger cities such as Toronto and Vancouver. The findings of this study contribute to the growing body of works pertaining to the Filipino diaspora situated in mid-sized Canadian cities, notably the Winnipeg context and the Ottawa context (see Vachon and Toews 2008; Buduhan 1972; Manzanilla 2009; Bautista and Udarbe 2001; Allard 2013; Bonifacio 2013; Marshall 2014, 2015).

The present scope of studies on small Canadian businesses (e.g., restaurants) is limited. Like Filipino-Canadian studies, most of the existing research has been conducted in larger Canadian cities such as Toronto (Tanaka 2008; Huynh 2012) or in small cities and rural towns (Cho 2010). There are few works on ethnic entrepreneurship situated in mid-sized Canadian cities. Moreover, existing scholarly works pertaining to Filipino entrepreneurship in the transnational context is limited. Compared to other ethnic minority groups, Filipinos are grossly unrepresented in immigrant and ethnic entrepreneurship literature. The majority of these studies are situated either in the American context (Fawcett and Gardner 1994; Johnson, Munoz and Alon 2007) or in the European context (Maas 2005; Fresnoza-Flot and Picoud 2007). This study addresses these gaps in the literature by focusing on Filipino culinary entrepreneurship in the Canadian context, specifically in mid-sized Canadian cities.

\subsection{Thesis Outline}

This thesis is comprised of seven chapters. The first chapter is the introductory chapter which provides a detailed explanation of what research project entails and includes the following: the empirical literature on Filipino cuisine in diaspora, theoretical framework, information about the study (i.e., the research question, objectives, and scholarly contributions), and the thesis outline. 
The second chapter describes the research methodology of this study. It begins by detailing the methodological approaches that forms the basis of this thesis' methodological framework. I employ an interpretive approach (Schwartz-Shea and Yanow 2012; Hesse-Biber 2013), that takes special considerations with respect to race and ethnicity (Gunaratnam 2003), and Filipino-centric research methodologies (Narag and Maxwell 2014; Pe-Pua and ProtacioMarcelino 2000; Pe-Pua 2006). What follows is a detailed explanation of the research design and research process. Lastly, I provide my reflexive accounts as they pertain to the dilemmas, limitations, and other observations made during the course of the research.

The third chapter is a literature review which provides the background and context of the Filipino diaspora. I draw from historical and archival data to outline Filipino migration history from the pre-colonial era in the Philippines until the contemporary era in the American and Canadian context; although this chapter will primarily focus on the Canadian context. Covering these aspects, this chapter serves as the contextual backdrop for this thesis. Since the subjects of study are Filipino cuisine entrepreneurs (most of whom are Filipino-identified), it is important to incorporate a chapter that focuses on the political and historical context of the Filipino diaspora in Canada. In doing so, it also helps to understand the contemporary landscape of Filipino cuisine in Canada and the different cultural influences that has shaped Filipino cuisine.

The fourth chapter is the first of the three data analysis chapters. It provides a descriptive summary of the different types of Filipino cuisine establishments encountered during the course of this study. I briefly discuss the differences and similarities of restaurant culture in the Philippines and Canada, as how Filipino cuisine entrepreneurs understand restaurant culture is informed by their habitus (Bourdieu 1984; Fine 1992). What follows is an analysis of Filipino cuisine establishments, where I note the distinction between the "traditional" and "modern" 
Filipino cuisine establishments. Upon closer examination, the dichotomy of "traditional" and "modern" Filipino cuisine establishments reveals a larger discussion pertaining to class differences and generational distinctions among the Filipino cuisine entrepreneurs and their establishments.

The fifth chapter is the second of the three data analysis chapters. It discusses how participants discursively construct Filipino cuisine. I argue that by understanding how participants define Filipino cuisine, it can also reveal how their definitions of Filipino cuisine also inform their entrepreneurial practices and business decisions (e.g., menu planning). I analyse the participant's discursive constructions of Filipino cuisine through three aspects: the senses (taste, smell, sight, and touch), cultural and regional diversity, and the idea there exists an "authentic" Filipino cuisine.

The sixth chapter is the last of the data analysis chapters. It focuses on the status of Filipino cuisine in the Canadian context. The consensus among the research participants is that Filipino cuisine is not mainstream. I interrogate possible reasons as to why it remains a cuisine with a subaltern status. First, I discuss the various explanations provided by the participants as to why they think Filipino cuisine has not reached mainstream popularity. I divide their responses into two themes that deal with structural barriers: colonialism and multicultural governmentality. Second, I examine the connections between the underrepresentation of Filipino cuisine to the low patterns of Filipino entrepreneurship in Canada.

The seventh and final chapter is the conclusion of this thesis. I summarize the main findings of this thesis and key takeaways from this research. I reflect upon this thesis' contributions to the scholarly community. I end the thesis with some discussions about the study's limitations and recommendations for future research. 


\section{CHAPTER 2: RESEARCH METHODOLOGY}

This chapter discusses this study's research methodology. First, this chapter begins with an overview of the methodological approaches that inform my research, which are interpretive methodology and Filipino-centric research methodology. Second, I discuss the research design of this study which includes discussions pertaining to the process of selecting the research sites, recruitment strategies, eligibility criteria, methods used, and ethical considerations. The third section of this chapter provides reflexive accounts of the research process, which features reflections regarding my positionality, the insider/outsider research dynamic, moments of discomfort, and strengths and limitations of the research methodology.

\subsection{Methodological Approaches}

This study adopts an interpretive methodological framework. At the outset of the research process, I had only intended to use an interpretive methodology. As I began to conduct the field work in Winnipeg, I quickly realised that I had to approach doing my research in a manner that is culturally appropriate, and complies with the cultural and social norms of Filipino cultureespecially when it came to the older generation of Filipino cuisine entrepreneurs. My interactions with participants, forays in the literature, and reflecting on my own life experience enabled me to become gradually aware of the importance of employing a methodology that centres on a Filipino perspective. Being mindful of the cultural norms of research participants is an important aspect of feminist research methods (Hesse-Biber 2013), and interpretative research methods (Yanow and Schwartz-Shea 2009; Schwartz-Shea and Yanow 2012). One of my research participants, who is a second generation Filipino-Canadian participant who is actively involved in Winnipeg's Filipino community, had warned me about potential challenges when it came to 
forming connections with older first generation Filipinos. He cautioned that the older generation is not as trusting or willing to collaborate with younger Filipinos such as ourselves. It was then I understood that I could not solely rely on my "insider" status as a member of the Winnipeg Filipino community to gain the trust of potential participants. I was an outsider by virtue of my generational status, age, class (my education), and my "Canadian" accent.

Difficulty in accessing participants and gaining their trust was a challenge that was similarly encountered in Andrei's (2010) research on Filipino restaurants in the United States. In order to gain the trust of older Filipino participants, Andrei had to perform "Filipino-ness", which entailed speaking Tagalog and eating Filipino foods that are considered to be "too bizarre" for non-Filipinos (i.e., foods with pungent smells and aesthetically unpleasant foods), and using honourifics (i.e.: $t i t a$ and $t_{i t o}{ }^{7}$ ) when speaking to older Filipinos. Performing "Filipino-ness" was a necessary strategy for Andrei as her positionality as a young mixed Filipino-American (Filipino and Romanian specifically), called into question her "insider" status as a "legitimate" and "authentic" Filipino, and her trustworthiness (Andrei 2010: 44). Like Andrei, I also found that my positionality as a young 1.5 generation Filipino immigrant made it difficult to connect with older Filipinos. Similarly, I also had to "perform Filipino-ness” by speaking Tagalog, using honourifics to address older Filipinos, and speaking in a formal manner when I interacted with older generation Filipinos. In order to overcome potential barriers to establishing trust during the research process, I had to strategically "perform Filipino-ness", which meant that I had to be aware of cultural norms and if need be, conduct myself in a manner that is culturally appropriate.

\footnotetext{
${ }^{7}$ In Tagalog, Tita means "aunt" while Tito means "uncle". Younger Filipinos are expected to use these terms when speaking with older Filipinos (regardless of familial relation) as a sign of respect and endearment (Nadal 2011).
} 


\subsubsection{Interpretative methodology}

This study uses an interpretive methodology. It is ontologically rooted in constructivism, which assumes that the knowledge of our reality and how we understand and participate in our social worlds is socially constructed by humans (Yanow and Schwartz-Shea 2009). A key attribute of an interpretive methodology is the research focus on "meaning-making" (SchwartzShea and Yanow 2012). By understanding the significance of meaning-making, it acknowledges that contextuality is critical when studying human beings and the social worlds they inhabit. Being flexible and open to changes is also an essential characteristic of an interpretative methodology - the researcher is encouraged to make note of the changes and "puzzles" that emerge in the research process and in doing so, the researcher is simultaneously collecting and analysing data (Schwartz-Shea and Yanow 2012; Yanow and Schwartz-Shea 2009).

Interpretivist approaches critically scrutinize the idea that true "objectivity" in the positivist sense can be achieved during the research process. Positivist approaches emphasize that researchers detach themselves from the research process by remaining "objective", in order to prevent contaminating the data with biases (Hesse-Biber 2013; Schwartz-Shea and Yanow 2012). However, interpretivist researchers argue that it is nearly impossible for research to be detached from bias and achieve value-neutrality (Schwartz-Shea and Yanow 2012; Gunaratnam 2003), and therefore avoiding "contaminants" is seen as a fruitless task. It is also problematic to

adhere to the positivist conception of objectivity, as it can lead to losses of critical information of the experience and perspectives of individuals (the researcher and the researched) themselves (Merry and Coutin 2014). Instead, it has been suggested that researchers should be aware of their biases and assumptions by engaging in reflexivity, which is the process in which the researcher engages in critical self-reflection and self-evaluation of their positionality (Berger 
2015; Schwartz-Shea and Yanow 2012). Feminist researchers like Hesse-Biber (2013) use the concept of "situated knowledges" (Haraway 1988) as a guide to enacting reflexivity.

Acknowledging situated knowledges recognizes that "knowledge and truth are partial, situated, subjective, power imbued, and relational” (Hesse-Biber, Leavy and Haiser 2004: 13). By viewing knowledge in this way, perceived impediments to reliability, such as biases, are not considered inherently negative or detrimental; rather, it is encouraged that researchers be made aware of and account for their biases and assumptions (Crang and Cook 2007; Yanow and Schwartz-Shea 2009; Schwartz-Shea and Yanow 2012). Although it is not enough that the researcher recognizes their positionality—researchers also have to acknowledge how their positionality may affect the entirety of the research process (Berger 2015). Thus, by practicing reflexivity one can see how “experience is shaped by one's particular context, by specific circumstances, conditions, values, and relations of power" (Hesse-Biber 2013: 9). Reflexivity also challenges how knowledge production is independent of the researcher producing it, and problematizes the notion that knowledge is objective (Berger 2015).

\subsubsection{Filipino-centric research methodology}

Since this project is primarily concerned with studying the Filipino community, it is important to use a research methodology that is culturally appropriate to the experiences and perspectives of Filipinos. Existing textbook protocols on conducting qualitative research have been largely developed in Western settings which are based off of Western assumptions and knowledges (Narag and Maxwell 2014). Filipino scholars in particular have made note of the problems associated with colonialism's impact in conducting research on Filipinos, especially with regards to the dominance of Western concepts and frameworks that are used to interpret the 
social worlds and social dynamics of Filipinos (Enriquez 1975; Pe-Pua and Protacio-Marcelino 2000; Pe-Pua 2006; Clemente 2011; David 2013). Drawing from Virgilio Enriquez' works on Sikolohiyang Pilipino (SP), scholars developed Filipino indigenous research methods to accurately capture the experiences and perspectives of Filipinos in the Philippines (Pe-Pua and Protacio-Marcelino 2000; Enriquez 1975). SP stresses upon the importance of understanding Filipino thought, behavior, and experience from a distinctly Filipino perspective and orientation (Pe-Pua 2006; Enriquez 1975).

The key concepts that I find methodologically useful from SP are "kapwa" (shared identity) and "pakikiramdam" (shared inner perception) (Enriquez 1975). According to SP scholars, at the root of Filipino social interaction, people are concerned with being pakikipagkapwa, which means "treating the other person as a kapwa or fellow human being" (Pe-Pua and Protacio-Marcelino 2000: 56). In SP theory, in Filipino social interactions, people are placed into two distinct categories: ibang-tao (outsider), and hindi-ibang-tao (one-of-us). The social dynamics and social interactions can differ depending on which category one is placed (Pe-Pua 2006; Pe-Pua and Protacio-Marcelino 2000; Aguila 2014; Clemente et al. 2008). Pe-Pua and Protacio-Marcelino (2000: 56) explain the logistics of the categorizations:

For example, if one is regarded as ibang-tao, the interaction can range from pakikitungo (transaction/civility with), to pakikisalamuha (interaction with), to pakikilahok (joining/participating), to pakikibagay (in-conformity with/in accord with), and to pakikisama (being along with). If one is categorized as hindi-ibang-tao, then you can expect pakikipagpalagayang-loob (being in-rapport/understanding/acceptance with), or pakikisangkot (getting involved), or the highest level of pakikiisa (being one with).

It is important to take note of where one is positioned in these social interactions, as it can determine the access to prospective research participants and the quality of data that is acquired during the interview process. It is especially pertinent to practice pakikiramdam as a form of self- 
reflexive exercise that also considers the emotional and affective aspects of the research. The pakiramdam approach is not unique to Filipino-centric research methodologies. It is worth noting the similarities of the pakikiramdam approach with interpretive approaches, such as the "production of psycho-social space" (Gunaratnam 2003: 158). The production of psycho-social space takes into consideration four aspects that emerge in the research process: first are the subjective processes (situated thoughts and feelings that include inter-subjective relations between the researcher and participant); second are the embodied activities (overt forms of embodied interaction such as verbal expression, non-verbal cues (silence, touch, movement, body language); third considers the social context of research interaction; and lastly, the physical research environment. The theory of the production of the psycho-social space therefore considers the emotional and affective aspects of the research process and has been found to be useful when discussing "threatening" or "uncomfortable" topics (ibid: 176)

Like the production of psycho-social spaces (Gunaratnam 2003), being attuned to pakikiramdam means "being sensitive to non-verbal cues, having concern for the feelings of others, being truthful but not at the expense of hurting other's feelings" (Pe-Pua and Marcelino 2000; Pe-Pua 2006). What makes pakikiramdam specific to the Filipino experience is that the researcher has been socialized to understand Filipino social interactions at an intuitive level, meaning the researcher is able to "read between the lines" by being aware of subtle nuances in body language and tone of their voice (Narag and Maxwell 2014; Pe-Pua and Marcelino 2000). According to Pe-Pua and Marcelino (2000), having pakikiramdam is something that Filipinos take for granted because this is what they are born into and grow up with - it is only when these behaviours come into conflict with Western social interactions that it becomes apparent. 
Another key principle of the Filipino indigenous research methodological approach is the expectation that people behave in a manner that is in accordance to the following Filipino values and norms: deference for authority, modesty/humility, and concern for others (Pe-Pua and Protacio-Marcelino 2000: 56). The first value, which is "deference for authority", was something I especially had to take into consideration as a Filipino youth, especially in circumstances where I need to establish rapport and trust with older Filipino cuisine entrepreneurs. With these factors considered, a Filipino-centric research approach may be used as a guide in conducting research on Filipinos, done from a perspective of a Filipino-identified researcher, making it a distinct approach of conducting insider research.

In adopting a Filipino-centric research methodology, I acknowledge that some assumptions of the methodology (such as SP theories regarding Filipino behavior and social interaction) may not completely align with the lived experiences of transnational Filipinos. The original Filipino-centric research methodology, that is, Filipino indigenous research methodology, was initially designed to conduct research on Filipinos living in the Philippines (Pe-Pua 2000). It must be taken into consideration that there are vast differences in the political, historical, and social contexts among Filipinos living in the Philippines and Filipinos living in transnational contexts. One must recognize these differences because as Gunaratnam (2003) cautions, failing to recognize the "contingency and the ambivalent complexity of lived experience maintains an essentialist view of 'race' and ethnicity", consequently construes experience as “unchanging 'essences' cordoned off from social, material, and emotional relations" (Gunaratnam 2003: 6). Going forward, when I refer to "Filipino social relations" and "Filipino cultural norms", I am referring to the specific context of my research, which focuses on the Filipino-Canadian experience. I only use SP and Filipino Indigenous research methodology 
as a loose guide as other Filipino scholars have done to better understand and discuss the experiences of transnational Filipinos (see David 2013; Nadal 2011; David, Protacio, and Sharma 2017; Aguila 2014).

\subsection{Research Design}

This section will first describe the research design component of this project. I will then discuss the strategies used to recruit participants, methods used for data collection, and data analysis; taking note of their appropriateness and limitations.

\subsubsection{Selecting the research sites}

When choosing the research sites for this study I took into consideration that Filipino cuisine is not mainstream in Canada, which means there are not as many restaurants I could access. The lack of Filipino restaurants would pose challenges in terms of finding research participants to interview and research sites in which I can conduct participant observation. To address these potential issues, I expanded the criterion to go beyond Filipino restaurants and included specialty food establishments that served Filipino food or Filipino-inspired food. This would include bakeries, take-out, and catering businesses.

The definitive factor in selecting the research sites for this study was the size of the Filipino population of the city as it would determine the number of Filipino cuisine establishments where I could conduct participant observations. The secondary factor was chosen by convenience, which would determine the feasibility of completing the field work over the course of one month. In theory, Ottawa would be the most convenient location because it is my current city of residence, however the Filipino population in the National Capital region is not large enough to acquire a satisfactory sample size. According to the results of the 2011 National 
Household Survey, there are only 11,445 Filipinos residing in the National Capital region, making up approximately $0.7 \%$ of Ottawa's total population (Statistics Canada 2013b).

With such grim prospects I had to turn to other Canadian cities. Three other cities were considered as potential sites of research due to the large Filipino population: Toronto, Vancouver, and Winnipeg. The Greater Toronto Area has the highest number of Filipinos in Canada, accounting for approximately 246,345 Filipinos (Statistics Canada 2013d). The Metro Vancouver area has approximately 120,645 Filipinos (Statistics Canada 2013e). Lastly, Winnipeg is home to 56,400 Filipinos (Statistics Canada 2013a), and is noted to be the city with the highest concentration of Filipinos in Canada relative to its population size (Marshall 2014; Vachon and Toews 2008). Vancouver was not a realistic option due to its geographical distance from Ottawa, making it inconvenient to conduct research in a timely manner. While Toronto would be ideal due to the sheer number of Filipinos residing in the metropolitan area, I do not have any connections in Toronto, which would pose problems in terms of accessing participants, time, and budgeting.

Winnipeg was chosen as the primary city to conduct the research for this study as it has a relatively large Filipino population. Additionally, as someone who grew up in Winnipeg, my existing ties to Winnipeg and my local knowledge of the city was something that I could use to my advantage. With Winnipeg as the primary city, I also included Ottawa as a site to discern if there would be any differences between the two cities in terms of how Filipinos engage in the cultural politics of entrepreneurship in their food establishments. Both Ottawa and Winnipeg are demographically distinct in terms of the population size of the Filipino community. 


\subsubsection{Recruitment strategies}

Participants were selected by using two non-probability sampling approaches: the purposeful sampling approach and the snowball sampling approach (Berg 2009). The purposeful sampling approach is also known as the judgment sampling approach (Tongco 2007; Berg 2009). The purposeful sampling approach involves identifying and selecting individuals who are knowledgeable about or experienced with the phenomenon of interest, and are willing to participate in the research study (Tongco 2007; Berg 2009). I selected people who are involved with the Filipino cuisine establishments but are also involved with the production and selling of Filipino foods. For the purposes of this research, the persons of interest were either employees or owners of Filipino cuisine establishments in Winnipeg or Ottawa.

The snowball sampling approach involves identifying several people with relevant characteristics and having them participate in the study, either through interviews or a questionnaire. Afterwards, research participants are asked to provide referrals of other people in their social network who possess the same attributes (Berg 2009). Snowball sampling can be the best way to locate subjects with a particular set of attributes or characteristics needed in a study. Snowball sampling is also popular among researchers interested in studying sensitive topics or difficult to reach populations (Atkinson and Flint 2001). Compared to purposeful sampling, I did not rely as much on snowball sampling. There was only one instance where I used snowball sampling, and that was with one participant who is very prominent in the Filipino culinary scene across Canada - he was very willing to provide potential leads and connect me with others in his networks. With his assistance I was able to access four additional participants to interview and visit five Filipino cuisine establishments that I would have otherwise not known about. 
The pitfalls of both approaches is that research data can be skewed to represent only a small segment of a population. This has the potential of sampling bias and calls into question the validity and generalizability of the data (Berg 2009; Mayan 2016). In Winnipeg and Ottawa's cases, since Filipino cuisine is such a niche market, there is a possibility that research participants know each other, or are aware of others in their networks involved in the study. I also observed that participants who were willing to be interviewed tended to be younger in age, second generation, and/or could speak English fluently. In contrast, I noted that older Filipino cuisine entrepreneurs who primarily spoke Tagalog (despite being able to speak Tagalog myself), were untrusting of me, and did not show initial interest in participating in this study.

The eligibility criterion for this study is that participants must be employed at a food establishment serving Filipino food or Filipino-inspired food. Priority was given to the people who were involved with decision-making or had intimate knowledge regarding the business which is why most of the participants were either owners, managers, or executive chefs. Every single one of my participants had either worked or owned a registered business. I cannot discount the possibility that I could have accessed even more participants had I considered reaching out to those who were involved in the "informal economy" (Knezevic 2016), such as owners of Filipino catering "side-businesses". However, these businesses also tend to operate under-thetable which opens the potential for legal ramifications and delays in the ethics review process.

Another important criterion was language. To be eligible for this study, participants must be able to speak Tagalog or English. I informed participants they can choose between the two, letting them know that I am comfortable in either language, and there was no pressure for them to communicate in English. Despite my efforts, the majority of research participants, with the exception of one, chose to speak English during the interviews. Lastly, despite this study's focus 
on Filipino cuisine entrepreneurs, I was flexible with the participant's ethnic background as the main qualifier for this study is that the participants be employed at a food establishment serving Filipino food or Filipino-inspired food. While most participants identified as Filipino, there were a small number of participants who identified as non-Filipino.

\subsubsection{Data-Collection methods}

This study employs the use of two qualitative methods: participant observation and semistructured interviews. Participant observation is also known as ethnography, which Berg (2009: 318) simply describes as "any research conducted in the field". Ethnography has been used by scholars to investigate sensitive issues because it can provide rich, detailed descriptions about the unknown or under-researched ( $\mathrm{Li} 2008)$. Ethnography is especially popular among researchers of small communities (Guevarra 2006; Bonifacio 2013; Aguila 2014; Nagar and Maxwell 2014). As Li (2008: 100) notes, the strength of ethnography is that it "allows researchers to observe what people do in 'real life' contexts, not what they say they do". The strength of ethnographic participant observation is that it can supply "detailed, authentic information unattainable by any other research method" (ibid.). In this study, I use participant observation to take notes of the physical and symbolic spaces of the restaurant and food establishments, as details that are taken

for granted such as menu items, atmosphere, décor, and even the people present (i.e., employees and customers) can reveal a lot about the restaurant.

The semi-structured interviewing method involves asking participants a predetermined set of questions, while still allowing for flexibility and spontaneity during the interview process (Berg 2001, 2009). Participants were informed and given the option to proceed with the interview in either English or Tagalog, and most participants had opted to do the interview in 
English, except for one, who had chosen to do the interview in Tagalog due to her limited English. Using my pakikiramdam (shared inner-perception), I would assess if the participant indicated through non-verbal cues was comfortable in answering certain questions, despite having verbalized otherwise.

\subsubsection{Ethical considerations}

This research was approved by the Carleton University Research Ethics Board (CUREB) and has been classified as low-risk. To ensure confidentiality, the participants were given pseudonyms by default unless the participants expressed their willingness to be identified by name. As an added measure to protect the identity of research participants, I did not take photographs of human subjects. Pictures that were taken during the course of the field work was of the physical spaces of the restaurant or food establishment.

There were no issues accessing the field sites for this research. Restaurants and retail stores (i.e., bakeries or groceries) are legally considered to be public spaces because the public is invited to the establishment (Sprang 2000). Under this definition there were no ethical issues involved in conducting participant observations at restaurants or specialty food establishments. I was able to conduct participant observation as a customer. I would take field notes and take photographs of the establishments' décor, food, and so on. Given the prominence of social media in contemporary foodie culture, it is not at all unusual for customers to take pictures in restaurants (Lok 2011; Wessel 2012; Johnston and Baumann 2010). Photographs featured in this thesis were either taken by me, with the establishment's permission; or were taken from the restaurants' public social media page. 
Participants who were interviewed for this study were informed about the aims of the study, measures to protect their confidentiality, and were given consent forms prior to the interview. I assured participants that if they were not comfortable disclosing information during the interview, they were not required to respond, nor was there any obligation for them to continue the interview if they felt any discomfort. Using my knowledge of the indirect communication style of Filipinos (Pe-Pua 2006; Pe-Pua and Protacio Marcelino 2000), I relied on pakiramdam (shared inner perception) to make note of any non-verbal cues (such as tone of voice, facial expressions, etc.) that indicate the participant's discomfort regarding questions or themes being addressed during the interview.

\subsubsection{Research setting}

Research took place at Filipino cuisine establishments. There was some flexibility in terms of defining what would constitute as a "Filipino cuisine establishment", due to the original assumption that there may not be as many establishments if the criterion was narrowed down to only Filipino a-la-carte restaurants. In an effort to broaden the sample size I included turo-turo (which are similar to take-out establishments), bakeries, and specialty food vendors as acceptable spaces in which to conduct participant observation for this project. I also included establishments that advertise Filipino dishes on their menu but do not specifically advertise their restaurants as Filipino or Filipino-owned. Rather, several of these restaurants are self-defined and advertised as either "fusion" or "Pan Asian", or alternatively, they do not advertise any allegiance to a particular ethnic cuisine. 


\subsubsection{Timeline of research}

This study took place in two mid-sized Canadian cities: Winnipeg and Ottawa. Field work was conducted over the course of five weeks from late October 2016 until the first week of December 2016. Three weeks were spent in Winnipeg from late October 2016 to mid-November 2016. I spent two weeks in Ottawa, from mid-November 2016 to the first week of December 2016. During the holiday season, I was able to visit two additional establishments in Winnipeg. In addition, I also was able to visit two additional restaurants in Ottawa in April and May 2017 because they had just newly opened.

I conducted the research in Filipino cuisine establishments, both the interviews and participant observations. The specific types of Filipino cuisine establishments encountered during the research process are as follows: a-la-carte restaurants, buffets, carinderia (cafeteriastyle), turo-turo (take-out style), bakery, sari-sari (variety) store, and food truck. In a later chapter, I will discuss in greater detail the specific characteristics of each establishment.

Table 1. Chart of Filipino Cuisine Establishments Visited

\begin{tabular}{|c|c|c|c|c|c|c|c|}
\hline & $\begin{array}{l}\text { A-La- } \\
\text { Carte }\end{array}$ & Buffet & Carinderia & $\begin{array}{c}\text { Turo-Turo } \\
\text { (Standalone) }\end{array}$ & $\begin{array}{c}\text { Bakery } \\
\text { (Standalone) }\end{array}$ & $\begin{array}{l}\text { Sari-Sari } \\
\text { Store }\end{array}$ & $\begin{array}{l}\text { Food } \\
\text { Truck }\end{array}$ \\
\hline $\begin{array}{l}\text { Winnipeg } \\
(n=35)\end{array}$ & 15 & 2 & 3 & 5 & 5 & 3 & 2 \\
\hline $\begin{array}{l}\text { Ottawa } \\
(n=6)\end{array}$ & 2 & 0 & 0 & 0 & 0 & 3 & 1 \\
\hline \multicolumn{8}{|c|}{$\begin{array}{c}\text { TOTAL } \\
(\mathrm{N}=41)\end{array}$} \\
\hline
\end{tabular}

Participant observation was conducted at 41 sites between Winnipeg and Ottawa that sold Filipino food or Filipino-inspired (fusion) food. I visited 35 establishments in Winnipeg, and of these, 15 were a-la-carte restaurants, 2 buffet restaurants, 3 carinderias, 5 standalone turo-turos, 
5 standalone bakeries, 3 sari-sari stores, and 2 food trucks. In Ottawa, I visited 6 establishments, and of these, 3 were sari-sari stores with a turo-turo attached, 2 a-la-carte restaurants, and 1 food truck.

\subsubsection{Recruiting research participants}

Research participants were contacted through either of the following: telephone, social media, or in-person. Cold-calling and in-person visits were the most effective recruitment methods among older participants aged 40 and over. For younger participants, social media and e-mail was the most effective form of communication and recruitment, followed by cold-calling. Contact information was mostly obtained through the internet, the majority of which came from restaurant review websites, which readily list the contact information of businesses. Phone numbers and social media handles were also obtained through snowball sampling (Berg 2009). Furthermore, I also relied on word-of-mouth from family and friends for connections and leads to restaurants. Snowball sampling and getting information from my immediate social networks proved to be useful as some businesses were not listed on these restaurant review websites. There were some establishments, which, despite serving Filipino food (distinct from Filipino-inspired fusion) on their menus, did not publically advertise themselves as Filipino. I also observed that some establishments had distinctly Western-sounding names which, interestingly, were owned by Filipinos and served Filipino dishes on their menu.

\subsubsection{Research participants}

The research participants in this study consist of 25 individuals which are mostly Filipino cuisine entrepreneurs (owners), with the exception of two who are employees. One participant is a cook and the other is the store manager of a sari-sari store. Of the 25 participants, 22 were 
from Winnipeg and 3 were from Ottawa. This section provides some details about the participants such as ethnic identity, generational status, occupation, and gender. It is worth disclosing that I did not include any specific questions regarding ethnicity, generational status, or gender in the interview script - these details were shared with me during the interview or during conversations prior to or after interviews.

\section{Ethnicity}

Out of the 25 participants, 19 participants self-identified as Filipino and 7 self-identified as non-Filipino. Three participants from Ottawa self-identified as Filipino. The remaining 7 participants who did not self-identify as Filipino were from Winnipeg. To break it down further, 5 of the non-Filipino participants identified as Asian: one participant identified as Chinese, one identified as Vietnamese and three identified as Laotian. None of these participants had claimed any ties or ancestry to the Philippines. The remaining two participants identified as "Caucasian" which was later clarified as "Canadian"; and the other identified as South-African.

\section{Generational Status}

There were noticeable differences in immigrant generational status among the research participants. By generational status, I am referring to the categorizations of first generation immigrant, 1.5 generation immigrant, and second generation immigrant. Before discussing the generational differences of the research participants, it is important to clarify and define these three categorizations. (1), first generation immigrant refers to people who were born outside of Canada - this encompasses people who are currently, or have ever been, landed immigrants in Canada. First generation in the Canadian context may perhaps be more accurately described as people who were born outside of Canada, and have migrated to Canada in adulthood (Statistics 
Canada 2013f); (2), 1.5 generation immigrant refers to those born outside of Canada yet grew up in Canada for the majority of their childhood and adolescent years (Tatsoglou 2008). 1.5generation immigrant is not formally listed category in the Canadian census. Nevertheless, it is recognized by scholars and policy analysts that it is distinct from first generation immigrant and second generation immigrant (Kobayashi 2008); and (3), second generation immigrant refers to individuals who were born in Canada and had at least one parent born outside of Canada (Statistics Canada 2013f). Although some scholars consider people who immigrated to Canada as children (also referred to as the 1.5-generation) as part of the second generation (Kobayashi 2008; Tatsoglou 2008). Like the 1.5-generation, "members of the second generation see themselves and are seen as others as a cultural bridge between their parents' ways of living and a new way of living that is thought of as Canadian" (Kobayashi 2008: 3).

For the purposes of this study, I group 1.5 generation and second generation together because I did not ask for further clarification as to whether or not participants were 1.5 generation. Most had described themselves as first or second generation immigrants. Out of the 25 research participants, 11 are first generation, 13 are 1.5 generation/second generation, and 1 as non-immigrant, referring to themselves as "Canadian." The majority of participants who identified as first generation and as non-immigrant are in the age range of 40 to 65 years old. The 1.5 generation/second generation are in the age range of 40 years of age and younger, with the majority of them in their late 20 's to early 30 's.

\section{Occupation}

In terms of occupational profile, most research participants are either the owners of their businesses or are in a managerial position. Only one participant is in a non-managerial position 
and is an employee in the kitchen. Another participant holds a unique position of not being a restaurant owner, rather, he is an active member of the Filipino Food Movement and facilitator of a pop-up dinner series in Winnipeg called Baon Manila Nights.

\section{Gender}

The majority of the participants interviewed are male. Of the 25 participants, 16 are male and 8 are female. Some participants had indicated that they do not have single ownership of their businesses, rather, they co-own their businesses with a partner. A number of male participants had indicated during the interviews that they co-own the business with their female spouse. According to a 2017 budgetary report published by the Government of Canada's Treasury Board, women and visible minorities are underrepresented in entrepreneurship and have been identified as a "priority group" for business ownership (Treasury Board Secretariat 2017). Given this, I stipulate that there are less women participating in this study because visible minority women are less likely to own businesses. The gender discrepancy came as no surprise and was something I had anticipated. It is worth noting that most of the second generation participants were male, yet because we had a shared understanding of being children of Asian immigrants in Canada, it was very easy to establish rapport with them. The majority of female participants in this study were found among the first generation demographic, accounting for six, and two are from the second generation group. I did notice that older Filipino women were far more likely to refuse recruitment attempts in comparison to males. In terms of my positionality as a woman, there were moments of discomfort during the research process that I could attribute to being a fat ${ }^{8}$

\footnotetext{
${ }^{8}$ In using the term "fat" I use it as a neutral descriptor of my body, rather than a negative attribute. In feminist writings, "fat" is considered as a political identifier (Rothblum and Solovay 2009; Braziel and LeBesco 2001).
} 
female Filipino researcher. I expand upon this in a later section of this chapter which discusses the researcher's reflexive accounts.

\subsection{Research Reflections}

\subsubsection{Insider research}

In migration research, an "insider" researcher is understood to be a member of the migrant group or ethnic group they are studying. In contrast, an "outsider" researcher is a cultural outsider, which typically describes someone who is a member of the majority population in the country of settlement (Carling, Erdal, and Ezzati 2014). Since I am a Filipino who is studying Filipinos, under this definition I would be considered an insider researcher. A benefit to being an insider researcher is being able to access information with more ease, because in comparison to outsider researchers, there is a shared understanding between the insider researcher and participants (Padgett 2008; Kacen and Chaitin 2006). In some cases, I found this to be true, especially with my interactions with the younger second generation Filipino participants, and a select few from the first generation Filipino demographic. However, it was difficult to establish rapport with older first generation Filipino participants as they were not initially trusting of me. For these participants, I was not an insider at all - my age, lack of accent, and generational status demarcated me as an outsider. As such, it is misleading to assume that insider or indigenous researchers who are privy to insider knowledge will automatically be granted group membership (Guevarra 2006; Gunaratnam 2003).

It is also naïve to assume that having shared ethnic identity with my participants would automatically mark me as an insider. A number of other factors, such as age, class, immigration status, education, gender, geographical location, and language can change the "insider" dynamic 
(Colic-Peisker 2004; Guevarra 2006; Gunaratnam 2003; Bonifacio 2013). Like Guevarra (2006), a Filipino-American researcher conducting research on migrant Filipino workers, I found that while I shared the same ethnicity as my research participants, there were aspects such as my education, political beliefs as a leftist-feminist, and (my lack of) religious beliefs that marked me as an outsider to certain members of the Filipino community. As a result, I had to downplay these parts of myself to prevent jeopardizing my rapport with my participants.

In circumstances where the participant was not Filipino-identified, the outsider research dynamic was particularly pronounced. Some interview questions were framed under the assumption that participants had visited the Philippines and had also presumed that the participant had an extensive knowledge of the various kinds of Filipino cuisine. Most of the nonFilipino second generation participants were unable to answer these questions, and therefore the interviews took less time to complete. I was an "outsider" to these participants by virtue of my ethnicity. It was beneficial being an "outsider" among these participants because I was not expected to behave in a "culturally appropriate" manner (i.e., using polite language and honourifics) and conform in accordance to Filipino social norms. At the same time, we shared commonalities such as our similarities in age and life experience growing up as a 1.5/second generation immigrant in Canada, which marked me as an "insider" among these participants. Similarly, with the older white male participant, I observed that because he is not Filipino, I did not feel the pressure to behave in a "culturally appropriate" manner, however our differences in age, ethnicity and immigration status also demarcate me as an "outsider".

Thus, rather than viewing researcher-and-researched relationships as a fixed binary between "insider and outsider", these relationships should be viewed as multiple and fluid (Nicholls 2009; Sultana 2007; Gunaratnam 2003). To this end, researchers must acknowledge 
one can never be fully an insider among their research participants due to the power dynamics between the researcher and researched (Aguilar 1981; Guevarra 2006; Berger 2015; Gunaratnam 2003). Further, as Guevarra (2006) points out, a researcher's academic training and professional commitments shapes their analytical lens as a researcher and distinguishes them from their participants.

Being Filipino certainly helped me gain some access to information, although it was not enough to gain everybody's trust. My age, gender, immigration status/citizenship, education, hometown, and even family membership all contributed to the varied process of accessing participants and gaining their trust. These were all determining factors as to whether or not I was ibang-tao (outsider) or hindi-ibang-tao (one-of-us) among members of the Filipino community (Pe-Pua and Protacio-Marcelino 2000). This was further complicated when communication was done over the phone or through social media. During the first round of cold-calling, I noticed that people were unwilling to speak with me by listening to the tone of their voice, which was marked with a tinge of annoyance. Like Andrei (2010) found in her research, perhaps it was my unaccented English or my "Canadian" accent that marked me as an untrustworthy. After several refusals, I opted to change my strategy by altering the way I speak-I started speaking Tagalog or using Taglish (Tagalog and English hybrid), and began using polite language (i.e., using -po at the end of a sentence or question). I observed that with these changes, the tone of the conversation changed and people were more open to speaking with me. During the interviews, language definitely helped solidify my insider status among Filipinos both young and old and across generations. Although I am Filipino in my appearance, among older Filipinos my Canadian accent may have "othered" me as a Filipino-Canadian youth who lost touch with her heritage (David, Sharma and Petalio 2017). Once I started using Filipino terms and expressions, 
and incorporated Tagalog into our conversations, any sense of distrust seemed to have dissipated. Older Filipinos were the most receptive when I spoke Tagalog or used Filipino terms, and some had remarked that that despite living in Canada for so long, it was nice that I did not lose my fluency in the language. Even among 1.5 generation and second generation Filipinos, knowing Tagalog was useful because there are some words and expressions that could not be seamlessly translated into English.

\subsubsection{Moments of discomfort}

First, age called into question my insider status among the older first generation Filipino participants. The issues relating to my age presented challenges during the research process, and destabilized the power dynamics between researcher and participant. As a cultural insider, I had intimate knowledge of Filipino norms and social interactions because of my socialization. Like other Asian cultures, among Filipinos, filial piety - respect for one's elders and deference to authority—is a core social value (Torres 1985; Pe-Pua and Marcelino 2000; David, Sharma and Petalio 2017). One way to show respect to elders is to use polite language, such as "-po" at the end of a sentence or question and to use honourifics such as tita (aunt) and tito (uncle) (Andrei 2010; Nadal 2011). At times, I felt infantilized by some of my older research participants. In an interview, I was referred to as anak (child) by one participant, despite being in my mid-twenties. In these interactions, I was no longer just a researcher-I was a Filipino youth who had to defer to Filipino elders-I had to be hyper-conscious of the way I conducted myself, so I did not

offend my older research participants. It is worth considering as to whether or not a non-Filipino researcher would have had to adhere to such rigid social norms and conform to these cultural expectations. In my case, because I am a Filipino, the assumption is that I am privy to Filipino 
social norms and as such, it is expected of me by the older generation to behave in accordance to these norms. For instance, there were also moments where older Filipino participants would assume that I was takot sa diyos (god fearing), because most Filipinos, whether in the Philippine context or transnational context, tend to be religious (Marshall 2014, 2015). Normally I would disclose that I do not ascribe to a particular faith, but in these circumstances I did not make a point to state purposely that I am not religious. The reason why I chose not to disclose my (lack of) religious beliefs is because among Filipino communities, being non-religious (such as Atheism and Agnosticism) is seen as taboo (Nadal 2011). I have experienced first-hand how identifying as non-religious among some Filipinos can lead to marginalization, this was especially true amongst my religious family members. Therefore, hiding that aspect of myself from my participants, I feel, is the "rational" and "safe" choice—although at the time, choosing between my principles or my research made me feel very uncomfortable. In the end I decided conform to the expectations placed upon me in these interactions to prevent offending my participants. And perhaps it may be considered as a form of deception to radically change one's behavior in order to appease and gain access to participants - however, I see it as a form of face work and strategically adapting to one's environment as one would normally do in day-to-day interactions.

Second, my positionality as a fat female Filipino contributed to additional moments of discomfort. Filipino culture, like other Asian cultures, has problems with fatphobia, meaning that fat-bodied individuals are marginalized based on their size. Scholars from the Western context have written about how fatness is attributed to "poor character" and "bad morals" (Braziel and LeBesco 2001). Drawing from my own experience as well as other fat Filipinos experiences, I believe that the same thought can be applied to non-Western contexts. Filipinos from the 
Philippine context and transnational context have written about how Philippine culture has an issue with fatphobia, especially among women (see Lichauco 2016; Waters 2017; Agner 2017). Making comments about a person's body and weight, or "body shaming" is perceived as normal and "part of Filipino culture" (Lichauco 2016; Waters 2017), especially among the older generation of Filipinos. Those who take issue with body shaming are seen as "overly-sensitive" and are regarded negatively because they are not acting in accordance to being hindi-ibang-tao (one of us), which emphasizes collectivity through pakikibagay (in-conformity with/in accord with) and pakikisama (being along with) (Enriquez 1975; Pe-Pua and Protacio-Marcelino 2000). In other words, one must prioritize maintaining the collective social order (through pakikibagay and pakikisama), even if it is at the expense of one's individual needs (i.e., mental health). The fatphobic culture has played a significant role in my upbringing and has been mentally and emotionally detrimental to my well-being. Consequently, I am very sensitive and paranoid regarding how other Filipinos interact with me because in the past, I have been mistreated by (mostly older) Filipinos due to my size. I find that in these instances, people have already judged my character due to my appearance, so I tend to over-compensate for my size by acting as wellmannered as possible. Moreover, because I am a woman, there is a higher expectation of subservience and politeness (Espiritu 2001). With the older Filipino participants, I felt that by virtue of my body size, Filipino-ness, and womanhood, I had to radically change the way I conducted myself so I could be taken seriously. To my pleasant surprise, not one participant made any comments regarding my appearance — in fact, I was treated with warmth and respectalthough I cannot discount the possibility that perhaps my status as a graduate student researcher may have tempered how participants perceive me. 
Lastly, another moment of discomfort was when the older research participants bestowed me with gifts and meals. Each time this has happened I offered to compensate them but was met with refusal. It was even more uncomfortable when some participants gave me bags literally bursting at the seams full of food to take home because the value of those gifts, given the sheer quantity, is quite high. I did not want to take advantage of their hard work and generosity. I felt that by already agreeing to participate in an interview they are giving a lot already. In short, as a researcher, receiving gifts from participants felt exploitative — participants were already giving their knowledge, time, and energy to participate in this study. At the same time I also understood that if I did not accept these gifts, it would be perceived as offensive. Using the kapwa (shared identity) concept, this can be interpreted as the participants were acting hospitable and bestowed me with gifts and meals because they perceived me as hindi-ibang-tao (one-of-us) (Pe-Pua 2006).

With these reflections of my discomfort and vulnerability, it is important to consider how power in fieldwork relations does not reside primarily with the researcher. Participants also have an upper-hand in terms of granting the researcher access to information (Ong 1995). Like Guevarra (2006), I had to overcome these conflicting feelings and make compromises in order to access participants for this study. Doing this research made me reflect upon my own positionality, which sometimes can be emotionally taxing for the researcher. However, it is necessary to engage in this "difficult and messy work" in order to recognize how race, ethnicity, and other social differences "are produced and have effects" in research (Gunaratnam 2003: 104). 


\subsubsection{Strengths and limitations}

The large sample size in this study is a double-edged sword. I had reached the point of saturation with 25 interviews and 41 participant observations. On one hand, having an abundance of data in some cases is better than having no data at all, which is what I had feared initially. In social science research, it is important to consider why saturation took place. According to Bowen (2008), qualitative researchers often mention saturation in their research reports and journal articles yet do not specify what it means in the context of their studies. In this research, the reason for such a large sample size can be attributed to the initial anxieties of not being able to gather enough data for this study, because at the time I had made the assumption that there were not many Filipino cuisine establishments from which to choose - which is why I considered sari-sari stores and bakeries, as well as Pan Asian fusion restaurants (which do not specifically identify themselves as Filipino, but sell some Filipino fusion dishes) as Filipino cuisine establishments. If I had excluded these establishments my sample size would be substantially smaller than it is now. The most glaring limitation of having a large sample size is that the process of coding and data analysis is time-consuming. On the upside, the data collected is rich and diverse because I was flexible with the concept of "Filipino cuisine establishment". I was able to interview people who do not identify as Filipino and get their outsider opinions about Filipino cuisine.

I believe using a Filipino-centric approach in my research methodology was useful for this project overall. Using a pakikiramdam (shared inner perception) approach and paying close attention to verbal and non-verbal cues is not at all "objective" in the positivist sense and requires a lot of interpretation on the part of the researcher (Pe-Pua 2006; Pe-Pua and ProtacioMarcelino 2000). Hence I do not think I would have generated the same quality of data had I 
tried to make my research "objective" in the positivist sense. Furthermore, by engaging in antiracism and decolonization research I am in effect aligning myself to a particular social justice agenda, and as such I cannot make claims to political neutrality (Gunaratnam 2003). As interpretive and feminist methodologies assert, it is not possible to remain objective in research because of pre-existing biases and assumptions (Hesse-Biber 2013; Schwartz-Shea and Yanow 2012). Rather than trying to fruitlessly avoid bias and assumptions in research, it is important to be critically aware of these biases and assumptions by engaging in reflexivity (Hesse-Biber 2013; Schwartz-Shea and Yanow 2012; Gunaratnam 2003).

In retrospect there are a few aspects of my research design that I would have liked to change. For instance, I noticed after coding and analysing the data, I found that the interview questions could have had more nuance or could have probed for further information. At the time, I did not consider to ask the participants about their other social positionings such as generational status and socioeconomic class. I could have captured this information had I asked about their migration history. I also did not make clear distinctions between ethnicity and nationality, and consequently, this was not formally touched upon in the interviews. For instance, because there is a long history of Chinese migration in the Philippines, it is not at all uncommon to have a person could identify as ethnically Chinese but consider their nationality as Filipino (Pacho 1986). I also did not think to formally ask the Filipino-identified participants about their regional affiliation, which could have enriched the data in terms of discussing cultural influences in terms of how they prepare Filipino dishes in their Filipino cuisine establishments. To take note of these aspects is important, especially in doing "race" and ethnicity research (Gunaratnam 2003) in order to highlight that there is no singular and essential "Filipino" identification. 


\section{CHAPTER 3: SITUATING THE FILIPINO DIASPORA IN THE CANADIAN CONTEXT}

In studying ethnic minority foodways, it must be taken into consideration that political and historical processes have shaped food practices as they relate to the processes of production and consumption (Mannur 2005ab; Fernandez 1994). To examine the cultural politics of Filipino cuisine and Filipino-Canadian foodways, the history of the Filipino diaspora in Canada must be taken into account. According to Aguila (2015: 63), when studying the Filipino diaspora, it is important to view the "linkages of our colonized past to our diasporic present, and to our uncertain future as a (geographically) fragmented community." In other words, in studying the Filipino diaspora, history should not be analysed as archival and disconnected from the present. Rather, history is the past and the present, and it has shaped, and continues to shape the material realities of the diaspora.

A historical overview of the Philippines is incomplete without a critical discussion of colonialism and imperialism, and how their legacies have shaped the Philippines politically, economically, socially, and culturally (Said 1993; David 2013; San Juan 2002). I will begin this historical overview by first discussing the history of Filipino migration, beginning with the precolonial era in Philippines up to the contemporary era in transnational contexts. As a caveat, a number of the texts referenced in this section are situated in the American context, given the history between the United States and the Philippines. Since thesis is concerned with the Filipino diaspora in Canada there will be a section that solely focuses on the Canadian context, notably, I review the history of the Filipino diaspora in Ottawa, Ontario, and Winnipeg, Manitoba; as these two cities are the research sites from which I draw my data for this study. 


\subsection{History of Filipino Migration}

Currently, there is little information or historical works pertaining to the pre-colonial Philippines as they are said to have been destroyed by Spanish colonizers ${ }^{9}$ (Aguila 2015). Scholars have attempted to fill in the gaps by writing about pre-colonial Philippines (Agoncillo 1974; Scott; Hung et al. 2011; Bellwood and Dizon 2005; David 2013), however much of these works tend to document the lives of Indigenous tribes residing in the Philippines rather than a detailed account of early Philippine migration (Agoncillo 1974; David 2013). The majority of works pertaining to migration history in this time period detail the immigration of settlers entering the Philippines, rather than emigration from the Philippines. The distinction between immigration and emigration patterns is especially noticeable when comparing the migration history of the Philippines pre-colonialism with the Philippines during Spanish occupation and American occupation - emigration appears to have been more widely documented post-Spanish occupation.

There could be a number of reasons accounting for this discrepancy, and perhaps there may have been historical works detailing pre-colonial migration patterns. Unfortunately, there is a possibility that this historical knowledge has been destroyed by Spanish colonizers - I can only refer to the existing works that are available - as such, it must not be taken for granted that existing Philippine historical knowledge is biased towards the perspectives of the colonizers (Spanish and Americans). Thus, it is critical to understand that the history of the Philippines cannot be disconnected from colonialism and imperialism.

\footnotetext{
${ }^{9}$ According to Aguila (2015: 72), Spanish colonizers were tasked with destroying documents and written works that they deemed as "pagan culture", thus leaving a large gap of knowledge surrounding the precolonial Philippines.
} 
So far I have argued that history is essential in studying the modern-day Filipino diaspora. I must emphasize that the purpose of this section is not to provide a detailed and full historical account of the Philippines. Rather, I turn to history in order to provide some background pertaining to the target population of this study: Filipino culinary entrepreneurs in Winnipeg and Ottawa, Canada. I also want to consider how Philippine history shaped the lived experiences of diasporic Filipinos, in terms of social processes such as immigration, as well as facets of Filipino culture, specifically Philippine culinary culture. This historical overview will serve as a backdrop to later chapters of this thesis, which details how colonialism and imperialism has shaped Filipino cultural production, such as food and cuisine.

\subsubsection{Pre-colonial Philippine migration}

There is evidence that suggests migration had taken place prior to Spanish contact (Aguila 2015; Marshall 2014; David 2013). Several Indigenous tribes from the Philippines are said to have descended from Austronesian migrants, whose roots can be traced from Taiwan and other neighbouring countries situated on the Southern Pacific coast (Bellwood and Dizon 2005; Hung et al. 2011). It is worth noting that the accuracy of the Austronesian migrant theory has been a contested topic of debate among scholars, however, engaging in such discussions go beyond the scope of this thesis. Nevertheless, pre-colonial societies were described as fragmented. The Indigenous tribes, also referred to in the literature as "Tao" (which roughly translates to "person" in Tagalog), were scattered throughout the Philippines and they tended to live in isolation. It is likely that migration actively took place as the Tao were no strangers to navigating the sea, and it is said that they possessed acute navigation skills, and travelled on 
vessels used for a variety of purposes such as travel, war, or trading (David 2013; Agoncillo 1974).

Historians suggest that the first wave of migration took place in the early $1400 \mathrm{~s}$ (Agoncillo 1974; Pacho 1986; Scott 1989; Dagdag 2009; Ang 2016). This period took place prior to Spanish contact. Rather than Christianity, Islam was recognized as the dominant organized religion in the Philippines, especially in major settlements such as Manila (David 2013; Ang 2016). During this time, migration took place in the Sulu region of the Philippines, which located in the south. Migrants came from neighbouring Islamic countries, which are now known as Malaysia and Indonesia in present times (Jocano 1967; Curaming 2011). In 1417, it is said that Sultan Paduka Batara had initiated a tributary mission to in an attempt to improve trade relations with the Chinese emperor Yung Lo (Scott 1989). Due to existing trade routes between the Philippines and China, there were a number of Chinese migrants that ended up permanently settling in the Philippines (Bullinger, Seitz and Volz 2012), concentrated in the Visayas region and Luzon region of the Philippines (Pacho 1986). However, Scott (1989) provides an alternative perspective, suggesting that Filipinos had migrated to China centuries prior to this established trade route, as early as the Tang Dynasty from 618-906 AD.

\subsubsection{Filipino migration during colonization}

The year 1521 marks beginning of the Spanish occupation in the Philippines, when the Portuguese explorer, Ferdinand Magellan claimed the land for the Spanish (Agoncillo 1974; David 2013). With Spain having established a colony in the Philippines, there was of course an increase of Spanish migrants settling in the archipelago. Many of these settlements were located in the Central region of the Philippines, with the first Spanish settlement being established in 
Cebu (Agoncillo 1974). From the late 1500s to early 1800s, Filipinos "worked" as seamen on Spanish galleon ships, although it has been argued that the Filipino seamen were not compensated for their labour and were actually working on these ships as slaves (Nadal 2011). The Spanish established a trading network across the Pacific, spanning from Manila to Acapulco in Mexico (Borah 2004; Bonifacio 2013; Marshall 2014). With Mexico being in close proximity to the United States, it is a possibility that Filipino slaves working on the Spanish galleon ships would later escape to the United States (Borah 2004; Mercene 2007), later settling in states such as California (Borah 1996), Louisiana (Espina 1988), Alaska (Buchholdt 1996), and Texas (Brady 2004). These accounts suggest the likelihood of Filipinos have migrated and settled to the United States long before the American occupation.

In 1898, the end of the Spanish-American war would also signify the end of the Spanish colonial rule in the Philippines, although it did not signify the end of colonial occupation in the Philippines - the United States would later take Spain's place as the colonial power. The American occupation would last for several decades, posing several implications in the realm of Filipino migration. Significant shifts in migration, such as large-scale emigration during the early to mid-twentieth century took place during the era of the American occupation (Tyner and Kuhlke 2000; Asis 2006). Notable changes took place after the Philippine-American war, a period of time in which Filipinos were granted the status of US Nationals (Tyner and Kuhlke 2000). Being granted this status meant that Filipinos were not subject to the draconian 1924 Immigration Act, which prevented foreigners from entering the United States (Roces 2014). This would later pose ramifications for Philippine immigration in subsequent years, especially after gaining independence from the United States. 
Extensive migration took place in the early twentieth century. Filipino workers, mostly comprised of poor single men, migrated to the United States as a means of supporting their families in the Philippines. Some workers were deployed to the territory of Hawai'i to work on the sugarcane and pineapple plantations (Tyner and Kulhke 2000; Asis 2006). Others were sent to work in agriculture on the American West Coast, in the states of California, Washington, and Oregon (Asis 2006), or in the American South, shrimping in the marshes of Louisiana and Mississippi (Espina 1988; Westbrook 2008), or in fisheries and canneries on the coast of Alaska (Asis 2006). The United States Navy also recruited Filipinos into the military, many of whom would later be granted US citizenship (Tyner and Kulhke 2000; Roces 2014). Male scholars, known as "pensionados" (Roces 2014; Asis 2006), were also recruited from the Philippines and were granted scholarships from the American government to study in the United States. Critics have argued that the pensionados program was ultimately a tool to further the colonial agendathrough education, the hope was that the pensionados would gain a comprehensive knowledge of Western civilization, as well as gain an understanding of the U.S. government system. The hope was that after their studies, and upon their return to the Philippines, pensionados would be able to govern in the same fashion (Teodoro 1999). While the majority of Filipino migrant workers during this period were mostly comprised of men, women were not necessarily excluded from the opportunity of working in the United States. Filipina women were mainly recruited as nurses during this time (Asis 2006).

\subsubsection{Filipino migration after independence}

After decades of struggling with the American occupation, the Philippines was granted independence from the United States in 1946 (Tyner and Kulhke 2000; Roces 2014; Asis 2006; 
Aguila 2014). This period is marked by political instability, contributing to significant changes Filipino immigration patterns, such as the start of the Filipino Overseas Workers program during the Marcos dictatorship in the 1970s (Pido 1986; Tyner and Kuhlke 2000), which still continues onward into the contemporary era. The historical events that took place during this time are especially relevant when looking at the present conditions of the modern-day Filipino diaspora.

The Philippines' newfound independence would pose dire implications for PhilippineAmerican immigration. As a consequence of Philippine independence, Filipinos no longer had the status of US nationals which meant that they were no longer exempt from the United States' strict immigration policies. Subsequently, this meant that Filipinos were subject to immigration quota restrictions, resulting in less Filipinos entering the United States (Tyner and Kulhke 2000). However, this would later change after World War II, when the United States implemented more liberal immigration policies, allowing for more Filipinos to immigrate to the United States (Tyner and Kulhke 2000; Roces 2014).

The first wave of Filipino migration to the United States after Philippine independence begins in 1965. In response to the shortage of working professionals in medicine and education, the United States government recruited doctors, nurses, and teachers from the Philippines (Roces 2014). Canada also had a similar problem with the shortage of professionals employed in medicine and education during the 1950s and 1960s. To tackle this issue, the Canadian government recruited workers from the Philippines to address the shortages (Tyner and Kuhlke 2000; Damasco 2012; Chen 1990). Yet, the widespread migration of working professionals was not without consequence. With many skilled workers and professionals leaving, the Philippines underwent "brain drain", which would later have repercussions for the Philippine economy (Gonzalez 1992; Tyner and Kuhlke 2000). 
The Marcos dictatorship in the 1970s is recognised by scholars as a pivotal moment in Filipino migration history (Tyner and Kulhke 2000; Aguila 2014; Marshall 2014; Allard 2015). The events that transpired during the Marcos regime would serve as a catalyst for the existing trends in Filipino migration, such as the rise of Filipino overseas workers in recent years. Indeed, Ferdinand Marcos is recognized as the "instigator of Filipino Overseas Employment" (Aguila 2015: 65) through the implementation of the Balikbayan ${ }^{10}$ program. The Balikbayan program was spearheaded by the Marcos regime as response to the harsh economic conditions in the Philippines, such the unemployment crisis and the brain drain (Pido 1986; Gonzalez 1992; Tyner and Kuhlke 2000; Aguila 2015). To rectify these issues, Filipinos were encouraged to seek work abroad and send remittances as a way to stimulate the Philippine economy. The most popular destinations for work were in Saudi Arabia, the United States, Canada, and Australia (Tyner and Kulhke 2000; Aguila 2014). In addition, Marcos offered overseas Filipinos incentives for continued connections to the Philippines- these connections constitute as remittances, regular visits, and/or investments (Rodriguez 2010). To entice overseas Filipinos to pay regular visits to the Philippines, they were offered discounts on hotels, shops, food, and travel (Pido 1986).

During this period, in addition to the poor economic conditions, the Philippines was also plagued with civil unrest. Despite gaining independence from the United States, the Philippines still maintained ties to the American government. The Marcos dictatorship had made no attempts to sever these relations and were still actively working under the influence of the United States. In 1972, Marcos implemented martial law in an attempt to maintain political power with the

\footnotetext{
${ }^{10}$ I turn to Guevarra (2006: 529), who provides an explanation of the term balikbayan: "Balikbayan is a cultural label for Filipinos who have settled elsewhere and returned to the Philippines temporarily for a visit or vacation". Balikbayan is an amalgam of the Tagalog words "balik", meaning "return", and "bayan" meaning "town or nation".
} 
backing of the American government (Bello 1991; Aguila 2015). Martial law was used to justify the threat of communist violence in the Philippines, which in actuality was a means to quell any signs of rebellion. Under martial law, Marcos ordered the arrests of students, activists, and journalists (many of which were staunch critics of the regime) and the closure of media outlets and organizations (San Juan 2001; Marshall 2014; Aguila 2015). Marcos also enforced strict curfews through increased military presence by implementing military checkpoints and enforced heavy restrictions on foreign travel (Aguila 2015). What caused many members of the Philippine middle class to leave was during the assassination of Marcos' political rival - Benigno Aquino Jr. (Dresang 1985; Aguila 2015), with some never to return. The political instability during this time would motivate Filipinos look settle elsewhere, beyond the Philippine borders. As such, the Marcos dictatorship is regarded as the starting point of contemporary Filipino migration because of the legacy of the Balikbayan program. While the program helped stimulate the Philippine economy through remittances sent by overseas Filipino workers, the Philippine government has continued to rely on remittances and has failed to tackle the country's economic problems or government corruption (San Juan 2001; Aguila 2014).

Today a large percentage of Filipinos live overseas and continue to send remittances to the Philippines (Allard 2015; Aguila 2015). Over 8 million Filipinos live outside the Philippines (Bonifacio 2013; Tyner and Kuhlke 2000), residing in over 160 countries and territories. According to a report published by the World Bank (2011), 1 out of 10 Filipinos live abroad, with $40 \%$ being overseas Filipino Workers. Unsurprisingly, taking into account the history and relationship between the United States and the Philippines, the majority of the overseas Filipino population resides in United States (McNamara and Batalova 2015). The number of Filipinos migrating overseas continues to rise each year. McElhinny et al. (2012: 9) list three key 
explanations that contribute to the increase of Filipino overseas migration. First, current immigration regulations in many countries which stress "educational qualifications and skills as the main conditions of admission regardless of country of origin"; second, Filipinos migrate in order to leave the conditions of underdevelopment, poverty, and low standards of living in the Philippines; and third, the legacy of United States imperialism has played a role in shaping North America as "an attractive destination goal" for Filipinos.

\subsubsection{The history of Filipino migration in Canada}

Historical works tracing Filipino migration in Canada prior to 1921 is limited. It has been suggested that Filipinos have settled in Canada as early as the 1890s. In Irene Howard's (1973) book, Bowen Island 1872-1972, there is reference to the Flores family, a family of fishermen and beachcombers from the Philippines residing in Bowen Island, British Columbia. The Flores family has been documented through a series of anecdotes and photographs (Lopez 2016; Malek 2016). However, archival evidence that pertains to the Filipino diaspora in Canada, such as Howard's book, is a rarity. According to Alison Marshall (2014: 12), it is "nearly impossible" to document Filipino migration prior to 1921 because the Canadian census lacked a Filipino category. Filipinos who may have migrated to Canada prior to 1921 would have been recorded under the heading of "various" (Marshall 2015). These changes can be attributed to revisions made to Canada's immigration policy during the early twentieth century.

Prior to the 1960s, the Canadian Immigration Act barred immigrants from entering Canada on the basis of race, nationality, and religion. Whites were the preferred race, especially if they were English or French nationals. Other groups, such as the Italians and Greeks, were considered undesirable as they were coded as "ethnic" rather than "white", unlike the English 
and French (Kelley and Trebilcock 2010). Other Europeans were discriminated on the basis of religion, such as Eastern Europeans who were part of Anabaptist sects like Hutterites and Mennonites (Knowles 2016). Asians were especially discriminated against on the basis of their race, nationality, and culture. As a group, they did not meet the criteria that corresponded with Canada's nation-building aims at the time which largely prioritized white British and French nationals (Backhouse 2007; Knowles 2016).

In the mid-1960s, significant changes were made to the Canadian Immigration Act. The Canadian immigration policy could no longer discriminate on the basis of race, religion, and nationality. Instead, a points-based system was implemented in 1967. Under the points system, immigrants were selected based on skill level. Recruiting skilled immigrants was a strategy employed by the Canadian government as a means of stimulating the Canadian economy and encourage population growth (Stasiulis and Bakan 2005; Winter 2007; Marshall 2014). FilipinoCanadian historians have noted that the Canadian immigration policy in the 1960s coincides with the addition of "Filipinos" as a listed category in Canadian immigration statistics (Lacquian 1973; Marshall 2014).

The consensus among scholars is that Filipino migration to Canada is marked by three distinct periods in Canadian history (also referred to as "waves"), typified by a noticeable influx of Filipinos entering Canada (Chen 1990; Kelly 2006; Marshall 2014; Vachon and Toews 2008; McElhinny et al. 2012). The first wave begins in the 1950s and early 1960s. Filipinos who migrated to Canada during this time period were mostly professionals working in biomedical fields as nurses, doctors, and laboratory technicians (Chen 1990; McElhinny et al. 2012; Damasco 2012; Marshall 2014). According to McElhinny et al. (2012: 13), these workers entered Canada as landed immigrants and skilled workers, which coincides with the change to a points- 
based system in Canada's immigration policy in 1967 (Chen 1980, 1990). The vast majority of these Filipino migrants were young women ages 20-30, who had just finished nursing school (Vachon and Toews 2008; Chen 1998; Bonifacio 2013). A number of these health care workers had originally worked in the United States. However, because their two-year visas had expired (McElhinny et al. 2012; Chen 1990; Marshall 2014), they migrated northwards to Canada as an alternative entering as skilled workers, as during this time Canada was experiencing a shortage of nurses in the health care sector (Ronquillo et al. 2011). These nurses would eventually settle in the larger cities of Toronto and Vancouver (Damasco 2012; Chen 1990).

The second wave begins in the late 1960s to the late 1970s. As a consequence of the changes in the 1967 Canadian Immigration Act, a number of Filipinos that had migrated during the late 60s were highly skilled and educated (Allard 2015; McElhinny et al. 2012), and as a result of these changes, it was easier for Filipinos to migrate to Canada. By the 1970s, there were noticeable shifts in the age, gender, and occupational profile of Filipino migrants (McElHinny et al. 2012; Vachon and Toews 2008). The number of professionals declined, while the demand for clerical, construction, service, and manufacturing jobs increased (Laquian 1973; Chen 1990). Further revisions were made in the late 1970s, with the Canadian government introducing family reunification as an immigration category in 1978 (McElhinny et al. 2012; Vachon and Toews 2008). Family members of the first wave of immigrants were sponsored, dramatically increasing the number of Filipino senior citizens (McElHinny et al. 2012; Chen 1998). Around the same time, the Philippine government under the Marcos regime had introduced the labour export policy (Tyner and Kuhlke 2000; Aguila 2015), leading the Canadian government to recruit Filipinos to work in Canada through various migrant worker programs, among them include the 
Foreign Domestic Workers Program, the Live-In Caregiver Program, and the Temporary Foreign Worker Program (McElhinny et al. 2012: 10; Stasiulis and Bakan 2005).

The third wave begins in the 1980s to today. Like the first wave, a number of these Filipino migrants were women. These women were mostly working in non-professional fields such as domestic work having entered Canada through the Foreign Domestic Movement (FDM) program (Chen 1984; 1990). Under the FDM program, domestic workers were eligible for applying for landed immigrant status after doing two years of live-in service with their employer (McElhinny et al. 2012). The FDM program would later be replaced by the Live-in Caregiver Program, which had a more restrictive eligibility criterion than its previous iteration. At the present, many Filipino women migrate to Canada through the Live-In Caregiver Program (McElhinny et al. 2012), provincial nominee programs (Allard 2015), chain migration to family or through marriage as pen pal/mail order brides (Marshall 2014).

These migration periods have led to distinctions within the Filipino community, which noticeably manifests as socio-economic class distinctions (McElhinny et al. 2012; Aguila 2015). A proportion of Filipino immigrants that came through the first wave possess more social and economic capital than the immigrants that came through subsequent waves. Therefore, when analysing Filipinos in Canada, it is critical to take into consideration that the Filipino diaspora cannot be understood as one general entity, nor can Filipino migration in Canada be understood as a singular phenomenon.

\subsubsection{The Filipino diaspora in the Canadian present}

Compared to other Asian immigrant groups, such as the Vietnamese (Pfeifer 1999;

Huynh 2012) and South Koreans (Noh, Kim and Noh 2012), scholars have argued that Filipinos 
are most adaptable in terms of integrating into Canadian society. Vachon and Toews (2008: 124) suggest this is due to the cultural commonalities Filipinos share with the majority in Canadian society, such as language and religion. They note three cultural similarities between the Philippines and Canada: first is adherence to Catholicism, second is their familiarity with the English language, and third is their labour involvement. Bonifacio (2013:2) shares similar findings, adding "practice of liberal-democratic politics" as another factor. These factors combined shape Filipinos into an ideal "immigrant" subject as well as "citizens of the world" in Western societies (Aguilar 2002). Canadian census data supports this claim. Compared to other immigrants or even the average Canadian, Filipinos have a historically lower unemployment rate and Filipinos are more likely than the average immigrant to possess a university degree (Vachon and Toews 2008).

Despite their noted successes in adapting to Canadian society, Filipinos are still a racialized population, and like other racialized populations they experience marginalization through discrimination and exploitation. In Bonifacio's (2013) study of migrant Filipino women in the Canadian prairies, she found that her respondents experienced varying degrees of racism including subtle forms of "public racism" (Bonifacio 2013: 83), like having one's accent being the subject of mockery; or more covert forms of racism, such as institutionalized forms of racism. Filipinos overseas workers are also faced with negotiating their precarious working conditions since their families often rely on them financially by having money sent through remissions, and some may find themselves having to endure exploitation and abuse at the hands of their employers (Davidson 2012; Walia 2010; Marshall 2014; Stasiulis and Bakan 2005). Studies on second generation Filipinos in Canada have also brought to light factors such as the fragmentation of the family unit and systemic barriers (Kelly 2014), which have contributed to 
problems facing Filipino-Canadian youth, such as involvement in "deviant" activities (Catungal 2012), or poor academic performance (Pratt 2006; Farrales and Pratt 2012; Pratt et al. 2017).

\subsection{The Filipino Community in Winnipeg and Ottawa}

This section focuses on the Filipino diaspora in Winnipeg, Manitoba, and Ottawa, Ontario, as this thesis is concerned with the experiences of Filipino cuisine entrepreneurs in Winnipeg and Ottawa. This section is divided into two subsections: first, the Filipino diaspora in Ottawa and second, the Filipino diaspora in Winnipeg. Both sections will provide a historical overview of Filipino migration in the two cities. As a caveat, there are no published works on Filipino migration history in Ottawa, so I will instead provide a general migration history of Ottawa. In contrast, the second part of this section, which discusses the Filipino diaspora in Winnipeg, will only focus on the Filipino migration history in Winnipeg, as opposed to a general overview of Winnipeg's migration history. For this reason, the section on Ottawa will be noticeably lengthier than Winnipeg's section. The purpose of outlining Ottawa's migration history (as opposed to Ottawa's Filipino migration history, which is not available in the literature) is to provide some context and to help conceptualize possible reasons as to why the Filipino community in Ottawa is smaller than other mid-sized Canadian cities.

\subsubsection{The Filipino diaspora in Ottawa, Ontario}

The majority of published works on the Filipino migration history in Ontario mostly centralizes on Filipinos in Toronto (Lusis 2005), given that the majority of Filipino immigrants in Canada have settled in the Greater Toronto Area (Lindsay 2007). The Greater Toronto Area has the highest population of Filipinos in Canada, accounting for 246,345 Filipinos (Statistics Canada 2013d). The history of Filipino migration in Ontario is therefore directly intertwined 
with the history of Filipino migration in Toronto. Filipinos historically settled in Toronto because of the opportunities for work available, especially during the 1960s when changes were being made to the Canadian immigration policy, which sought to recruit skilled immigrants to address the shortage of healthcare professionals (Tyner and Kuhlke 2000; Vineberg 2010). There is a shortages of information available on Filipinos in Ottawa (Lusis 2005), subsequently I am unable to reference documents provide a comprehensive overview of Filipino migrantion history in Ottawa. Given this limitation, when I discuss the Filipino diaspora in Ottawa, I can only refer to anecdotal evidence, as well as statistical data on immigration trends in the National Capital Region (Vineberg 2010).

In the early twentieth century, the majority of immigrants that had settled in Ottawa were originally from Europe, tracing their origins in Great Britain, Scotland, Ireland, France, Belgium, Switzerland, Germany, Italy, and Poland or were French-Canadians from Quebec (Canadian Heritage River 2005). Later on, the Scots, Irish, Italians, and Poles were among the immigrant groups that entered Ottawa through refugee policy. Other refugees, such as African-American slaves from the United States and Jews from Europe also sought sanctuary in Ottawa in the early to mid-twentieth century (Carriere 2016). In the late 1950s, Ottawa saw an increase of refugees from former Yugoslavia, countries in Africa, the Middle East, South Asia, and parts of South America, such as Peru (Vineberg 2010; Carriere 2016).

While Ottawa's population has been diversified by the influx of refugees in the early to mid-twentieth century (Carriere 2016), Ottawa did not have many immigrants entering the city through skilled labour programs (Vineberg 2010). When changes were being made to the Canadian immigration policy in the mid-1960s, Ottawa was especially lagging behind in comparison to other cities, such as Toronto, Montreal, Vancouver, Calgary and Winnipeg 
(Vineberg 2010). Visible minority immigrants were attracted to these cities because they were presented with an array of accessible job opportunities—especially in the bigger cities of Toronto and Vancouver, where health care workers were in demand due to shortages in the health care industry (Tyner and Kuhlke 2000; McElhinny et al. 2012); and in the Western prairie cities, where there was a boom in manufacturing jobs (Marshall 2014; Vachon and Toews 2008). Furthermore, these cities had established and growing visible minority communities, making these cities culturally diverse, which was also a factor in attracting visible minority immigrants (Vineberg 2010).

The primary labour sector in Ottawa is the public service sector, with many of these being public service workers employed by the Canadian federal government (Vineberg 2010; City of Ottawa n.d.). Historically, those employed with the federal government were predominantly British and French nationals (Keshen and St-Onge 1999), which can be attributed to the language requirements enforced by the federal government as public service employees were required to have proficiency in either English or French, as well as institutional racism in general. When Pierre Elliot Trudeau implemented the Official Languages Act in 1969, English and French were formally recognized as the official languages of Canada. Subsequently, government workers were required to be proficient in one of the two official languages, and ideally, workers were to be bilingual and have working proficiency in both languages (Vineberg 2010). These language restrictions discouraged people who were not bilingual or neither proficient in either of the official languages from working in the federal government. Indeed, this language barrier may account for one of the reasons as to why Ottawa's immigration is lacking in comparison to the other Canadian cities at the time. 
Ottawa's demographic landscape began to change rapidly in the 1970s (Vineberg 2010; City of Ottawa n.d.), with the implementation of the Project 4000 program, which sought to provide refuge to 4000 refugees. During this time an influx of Indochinese refugees from Laos, Vietnam, and Cambodia were brought into Ottawa, having been displaced by the ravages brought upon the Vietnam war in the 1970s (Carierre 2016; Vineberg 2010). Their settlement was not without difficulty—-the Indochinese refugees often worked in low-paying marginal jobs due to issues related to language barriers and racism (Neuwirth and Clark 1981). It was challenging for these refugees seek education or upgrade their skills, as their working hours were prohibitive (ibid.). As an alternative, some pursued self-employment through small business ownership, such as restaurants (Huynh 2012), which can explain Ottawa's large number of Vietnamese restaurants.

From the late 1970s until today, Ottawa has seen a rapid increase of immigrants compared to prior decades (Vineberg 2010; City of Ottawa, n.d.). Compared to years past, Ottawa's demography has changed dramatically. According to a 2001 report from Statistics Canada, the most common country of birth among immigrants in Ottawa is China. Other top source countries include Middle Eastern countries such as Iran, Lebanon, and Pakistan (Vineberg 2010; Carriere 2016; Statistics Canada 2005; City of Ottawa n.d.). Ottawa has also seen an influx of immigrants whose previous country of origin was from the United States from the Skilled Immigrant Program, which may be attributed to the growing technology sector (i.e., IT, communications, programming, etc.) in Ottawa (City of Ottawa n.d.). Like previous years, Ottawa's public service sector remains at the centre of Ottawa's labour economy (Vineberg 2010; City of Ottawa n.d.), which attracts interprovincial migrants from across Canada. 
It is evident from the lack of literature and data available that Filipinos are not as prominent as other visible minority immigrant groups in Ottawa's migration history. As of 2011, there are 11,445 Filipinos living in Ottawa (Statistics Canada 2013b). In comparison, this number is significantly smaller than cities with traditionally larger Filipino communities such as Toronto and Vancouver. When compared to the mid-sized cities in the West, such as Winnipeg and Calgary, Ottawa boasts a larger population overall (Vineberg 2010; City of Ottawa n.d.), however, Ottawa has significantly less Filipinos. This can be attributed to Alberta and Manitoba's provincial governments proactive immigration policies and their use of Provincial Nominee Programs (Vineberg 2010; Marshall 2014; Bonifacio 2013). Nevertheless, there is still a small but growing number of Filipinos in Ottawa.

As a consequence of having a relatively small Filipino population, there are few research publications on the Filipino community in Ottawa (Obokata 2014). Further, there are no comprehensive texts that outline the history of Filipino migration in Ottawa. It has been suggested that Filipinos moved to Ottawa in the mid-1960s, around the time when changes were made to the Canadian Immigration Act in 1967, which shifted from a system that discriminated on the basis of race, religion, and nationality to a points-based system (Marshall 2014; Vineberg 2010). With this in mind, it can be assumed that Filipinos who settled in Ottawa during this time entered through skilled labour programs, working in the service and office sectors or in manufacturing (Vachon and Toews 2008; Marshall 2004). It is unlikely that many Filipinos were employed in the federal government due to the desired bilingualism qualification. It can be stipulated that the majority of recent immigrants from the Philippines were able to enter Ottawa through the Live-In Caregiver program. According to McElhinny et al. (2012), an overwhelming number of recent Filipino immigrants entered Canada (with the exception of Manitoba) as 
domestic workers. Additionally, Salami's (2014) study points out that Philippine nurses that migrate to Ontario do so through the Live-In Caregiver program.

Anecdotally, through my conversations with some friends and acquaintances who grew up with a Filipino nanny in Ottawa, and Filipinos I had encountered in public spaces such as ethnic grocery stores - the Live-In Caregiver explanation may be plausible. I can also recall about a year ago there used to be a Filipino grocery store with a turo-turo (take out) restaurant located near the affluent neighbourhood of Rockliffe Park in East Ottawa. I discussed this with one of my professors, who suggested that the existence of this establishment may be because it caters to the needs of Filipino domestic workers employed by wealthy families living in Rockliffe Park. My professor's suggestion seems to correspond with the findings in FresnozaFlot and Pecoud's (2007) study of Filipino entrepreneurs in Paris, France. They noticed that Filipino niche businesses such as restaurants, grocery stores, and other services seemed to be concentrated in higher numbers nearby wealthy neighbourhoods, since it is wealthy families from these areas of Paris that mostly employ Filipino domestic workers.

Unfortunately I cannot explore this subject further because it falls beyond the purview of this thesis. The lack of information available of Filipinos in Ottawa is representative of its relatively small population. As it relates to my research, the small Filipino population can also account for the meagre number of participant observations and interviews conducted during my field work in Ottawa.

\subsubsection{The Filipino diaspora in Winnipeg, Manitoba}

Filipino migration patterns in Manitoba closely mirrors the national Filipino migration patterns (Bautista and Udarbe 2001; Vachon and Toews 2008). As noted previously, there are 
three distinct periods of Filipino migration in Canada. The first wave spans from the 1950s to 1960s, the second wave from the late 1960s to late 1970s, and lastly, the third wave began in the 1980 to the present day (Laquian 1973; Chen 1990; Marshall 2014; Vachon and Toews 2008; McElhinny et al. 2012). During the first wave of Filipino migration in Canada, Filipinos migrated to British Columbia and Ontario, originally working in the medical sector as nurses or doctors (Chen 1990; Damasco 2012). Like the two larger provinces, Manitoba also imported nurses from the Philippines, albeit on a smaller scale (Bautista and Udarbe 2001; Vachon and Toews 2008; Marshall 2014; Bonifacio 2013).

The primary industry that brought Filipinos to Manitoba is the garment industry (Bautista and Udarbe 2001; Vachon and Toews 2008; Marshall 2014). It has been well-documented that a number of Filipinos had entered Canada as domestic workers (McElhinny et al. 2012), although this is not necessarily the case in Manitoba. Compared to Ontario and British Columbia, the number of Filipino migrants in Manitoba employed in domestic work (such as nannies and caregivers), is quite smaller in number (Vachon and Toews 2008; Marshall 2014). Compared to the rest of Canada, Manitoba makes use of the Provincial Nominee Program to recruit skilled immigrants from the Philippines (Allard 2015; Vineberg 2010; Marshall 2014), rather than recruitment via the Live-In Caregiver program (Marshall 2014; Vachon and Toews 2008; Bonifacio 2013).

The first wave of Filipino migration in Manitoba begins in the 1950s (Marshall 2014). The majority of Filipino immigrants coming in during this time were young bachelorettes ages 20 to 30 (Vachon and Toews 2008; Chen 1998), working in the medical field as nurses. Others worked as teachers, doctors, or domestic workers (Marshall 2014). A segment of these migrants came from the United States, from the northern states of North Dakota and Minnesota, given that 
both states are in close proximity to Manitoba. Nurses were specifically recruited from Minneapolis to work at Winnipeg’s Misericordia General Hospital (ibid.).

The second wave of Filipino migration in Manitoba begins in the late 1960s to the 1970s. In 1967, changes were made to Canada's immigration policy, which moved towards a pointsbased system, focusing on skills and education rather than a system based on race and ethnicity (Chen 1990; Marshall 2014). In the same year, 300 nurses were recruited directly from the Philippines to work in hospitals in Winnipeg (Vachon and Toews 2008). This period brought in Filipino migrants working in a variety of occupations, such as teaching, nursing, and manufacturing (Marshall 2014). However, the primary industry that brought Filipino migrants to Winnipeg was the garment and textile manufacturing industry. In the late 1960s to early 1970s, the garment and textile industry in Winnipeg was booming. ${ }^{11}$ Workers were recruited directly from the Philippines and the Netherlands to work in Winnipeg's garment factories ${ }^{12}$ (Vachon and Toews 2008; Camia 2012), leading to an influx of unmarried women migrating to Manitoba. Later on, they would sponsor their siblings, cousins, and spouses, allowing their networks to follow them to Canada (Vachon and Toews 2008). In the latter part of the second wave, spanning from 1974 to the early 1980s, Manitoba would see a decline in Filipino immigration arriving through labour programs, but would also see an increase in student immigration and family reunification immigration (ibid: 14). This can be explained by changes made to the point system as a method of dealing with the effects of the economic recession during this time.

\footnotetext{
${ }^{11}$ Winnipeg's garment and textile industry was primarily responsible for supplying clothing to the Prairie Provinces (Vachon and Toews 2008).

12 The Netherlands was home to many Filipino migrants working contracts in garment factories. In the 1960s, garment factories were shut down (Gonzalez 1998; Dalayoan et al. 2008).
} 
The third wave begins from 1985 and continues to the present day (Vachon and Toews 2008; Marshall 2014). This period is "characterized by higher number of professionals and a higher number of non-workers" (Vachon and Toews 2008:111). Compared to the previous waves, there were many Filipino immigrants employed in natural sciences, engineering, or managerial positions (ibid.). Since the 1990s, there has been a noticeable increase of Filipino immigrants arriving to Winnipeg through the Manitoba Nominee Program, which recruits skilled Filipinos to come to Canada as permanent residents. (Allard 2015; Marshall 2014). Furthermore, thousands of male and female Filipino temporary workers come to Manitoba, working in "meat processing plants, restaurants, resorts, inns, construction, gas stations, health care, and domestic work" (Marshall 2014: 14).

A large proportion of the Filipino population in Winnipeg can be traced back to the first wave of garment workers in the 1960s (Marshall 2014), who have since brought over family members to Canada. Other Filipinos have been recruited through programs such as the Manitoba Nominee Program (Allard 2015; Marshall 2014), Live-In Caregiver programs (Bonifacio 2013), or through reunification (Vachon and Toews 2008). Currently the Province of Manitoba is a key destination for Filipino migrants in Canada, accounting for the third largest Filipino population in the country (Vachon and Toews 2008; Marshall 2014). The majority of the Filipino population in Manitoba resides in Winnipeg, which boasts the largest number of Filipinos in relation to its total population (Vachon and Toews 2008). Filipinos make up the largest visible minority population in Winnipeg, comprising of $36.1 \%$ of the visible minority population (Government of Manitoba n.d.). Tagalog is the number one spoken foreign language in Winnipeg (Statistics Canada 2012). 


\section{CHAPTER 4: FILIPINO CUISINE ESTABLISHMENTS IN CANADA}

In order to analyse the cultural politics of Filipino cuisine in Canada, it is important establish what Filipino cuisine establishment is. Before describing the establishments, I will provide some background and context on Philippine restaurant culture in order to better understand the current context of Filipino Cuisine establishments in Canada. As I will later demonstrate, what constitutes as a restaurant in the Philippines may not necessarily be the case in Canada. I suggest that this inconsistency in recognising what constitutes as a "proper" restaurant in Canada may be a contributing factor as to why there is a widespread perception that there are no Filipino restaurants in Canada.

First, to understand Philippine restaurant culture it is necessary to be aware of how meals are structured in the Philippines. The Philippine conception of the meal differs from Canada's. The latter emphasizes the traditional three meal structure, which is composed of a breakfast, lunch, and dinner, with some (or no) small snacks eaten in between (Levesque 2017; Agriculture and Agri-Foods Canada 2005). While meals in the Philippines constitute of smaller meals: an umagahan (breakfast or morning meal), merienda (mid-morning snack), tanghalian (lunch), another merienda (mid-afternoon snack), and hapunan (dinner) (Cordero-Fernando 1976; Fernandez 1994). In the Philippines, snacks are considered by many as meals in themselves rather than something separate from a meal (Fernandez 1994). There are no strict guidelines as to what types of foods are assigned to each meal. Meals are therefore understood in the Philippines as "moveable in time, as flexible feasts that make their own spaces and shape their own meanings" (ibid: 13). This understanding also extends to where foods are eaten. Foods are enjoyed anywhere, "out in the open, in the market or street field" and is not perceived as unusual or strange, nor is it at odds with meals indoors or at home (ibid.). 
The flexibility of the Philippine meal is noted to be a consequence of modernization. In an era where most people do not have the luxury of cooking their own meals, due to longer working hours, it is convenient to be able to eat anywhere and at any time (Fernandez 1994). This is also true in Canada - due to the demands of the capitalist system, being able to adhere to the traditional three meal structure is becoming a rarity (Levesque 2017; Agriculture and AgriFoods Canada 2005). Yet, despite these changes, Canada's social norms surrounding the mealtimes and eating practices remain firmly intact and like most of Western culinary culture, still adheres to French culinary standards, as French cuisine is argued to occupy the hegemonic position in contemporary culinary practices across the globe (Janer 2007).

Despite the flexibility of the Philippine meal, the widespread practice of "eating out" at ala-carte restaurants is a relatively modern phenomenon that began in the latter part of the twentieth century (Cordero-Fernando 1976: 69). Among Filipinos, Chinese restaurants were popular choices to dine out, as it differed from Filipino food - with the latter perceived as lowbrow home cooking (Cordero-Fernando 1976; Fernandez 1988, 1994). Moreover, the appeal of Chinese restaurants is because Chinese foods cannot be easily replicated at home. Secondly, it is often served family-style, which corresponds with the collective eating practices of Filipinos (Cordero-Fernando 1976). For Filipinos, the restaurant is seen as an extension of the home, and so meals are commonly served family-style meant to be shared with others (Cordero-Fernando 1976; Fernandez 1994).

In contrast, writing from a Western perspective, Simmel ([1910]1997) observes that the sociological structure of the meal reveals a particular individualistic social structure. The individualistic quality of the Western meal is associated with regards to how meals are regulated, such as times when certain meals are eaten (which is why some restaurants have separate menus 
for breakfast, lunch and dinner) and how meals are eaten (individual portions as opposed to family style, or eaten with certain utensils) (Symons 1994; Simmel [1910]1997). This type of meal structure that Simmel describes corresponds with the norms of Canadian restaurant culture, as meals are structured according to the Western standards of a meal (Janer 2007), wherein diners are expected to eat at certain times and eat individual portions as opposed to shared family-style portions.

In the Philippines, the preference for Chinese cuisine and eating meals family-style does not mean that is representative of all Filipinos practices, nor does it infer that Filipinos are not open to trying other cuisines or eating styles. The preference for family-style meals has an economical explanation, as they are cheaper than eating individual portions at a-la-carte restaurants. Many Filipinos also patronized Western-style establishments, as individual-sized portions were suitable for merienda (Cordero-Fernando 1976: 73). For those who wanted to dine at a-la-carte Filipino restaurants, the selection for fine dining contemporary Filipino establishments was scarce, and only few could afford the luxury to eat at such establishments (Fernandez 1994). If Filipinos wanted to eat indigenous Philippine cuisine in the Philippines, it was mostly served outside the confines of a-la-carte style restaurants and could be found at turoturos and carinderias, with the latter being commonly patronized by members of working class because they could get lutong-bahay (home cooking) at low prices, without spending long hours cooking (Cordero-Fernando 1976; Fernandez 1994).

\subsection{Filipino Cuisine Establishments in Canada}

Using a combination of my field notes, as well as observations from other scholars (Andrei 2010; Fernandez 1994; Cordero-Fernando 1976; Sprang 2000), I conceptualize the 
following terms to describe Filipino cuisine establishments I had encountered during my field work:

A-la-carte: A-la-carte refers to establishments in which patrons can sit down, order dishes from a menu, and receive table service (Sprang 2000).

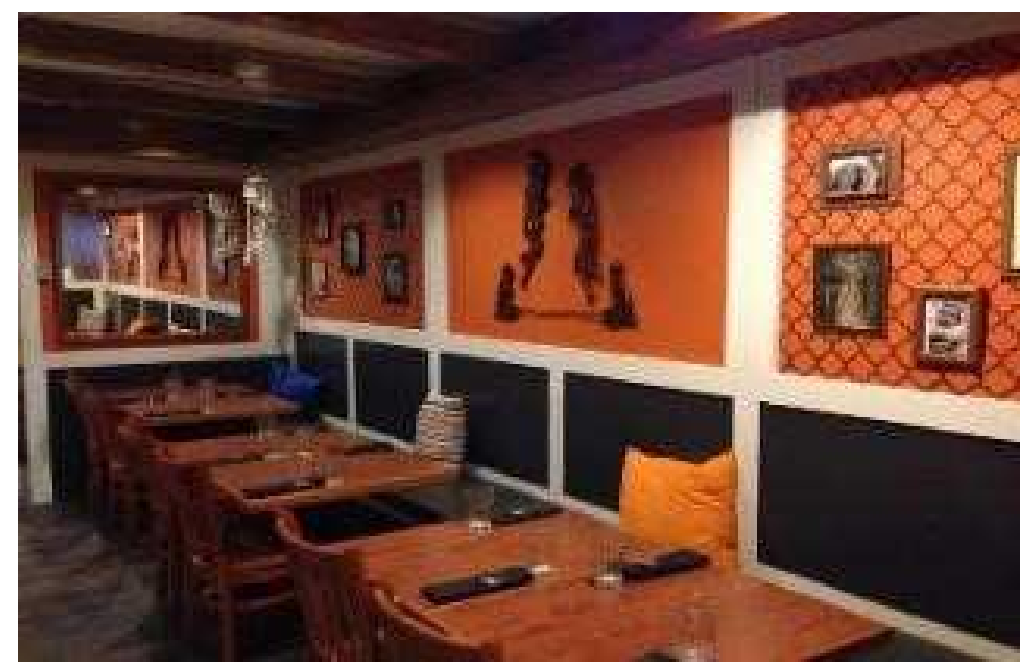

Figure 4.0: An example of an a-la-carte style Filipino restaurant. Patrons are seated at tables, order dishes from a set menu, and receive table service (Sprang 2000).

Buffet: A buffet refers to an establishment that has a set-up of food where customers can independently fill their plate with dishes that has been set up on a buffet line or a designated area. Like a-la-carte establishments, customers are able sit down and enjoy their meals and receive table service. 


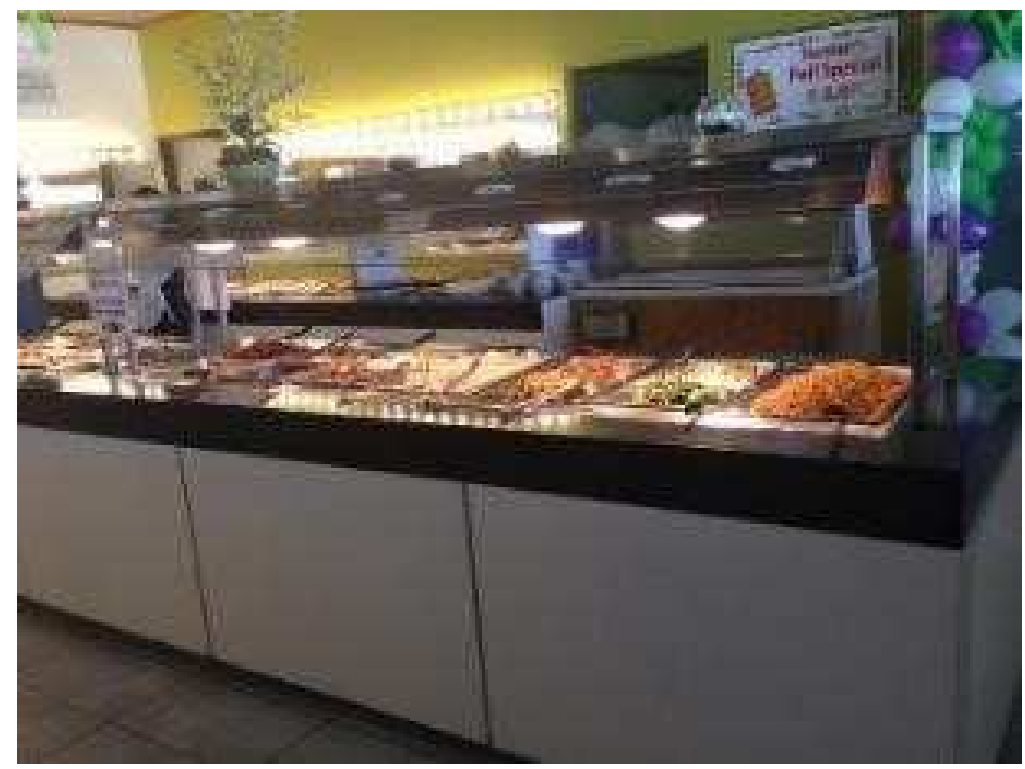

Figure 4.1: An example of a self-serve buffet restaurant. Several dishes are presented on a buffet line from which patrons can choose and portion their meals according to their preferences. Like a-la-carte restaurants, buffet restaurants offer table service [source: field research].

Pop-up-dinner: A pop-up-dinner does not constitute of a permanent space, nor is it a formally recognized establishment. Rather, pop-up-dinners can be understood as a series of events are set up by local organizations or chefs, which take place at various venues in a geographical area. Not all pop-up-dinners are structured in the same manner and can vary depending on the parties hosting the event. The pop-up-dinners featured in this research are events that take place in different venues, serving multiple course meals conjured by different chefs done a-la-carte style (Larsen 2016). 


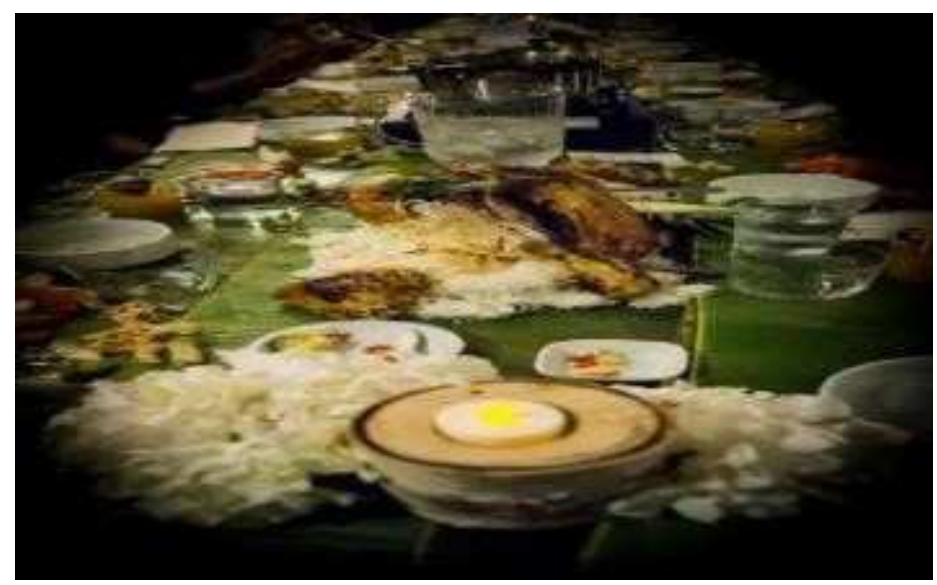

Figure 4.2: This is a picture taken from the Baon Manila Nights public social media page, which features one of their pop-up dinners (Larsen 2016). This is an example of a "Boodle Fight" ${ }^{13}$ dinner, which is marketed as a "kamayan" dinner (Macaalay 2015). Kamayan is an indigenous style of serving and eating meals in the Philippines. Various dishes are prepared, served on a long table adorned with banana leaves. Diners eat the foods family-style, allowing for flexibility in terms of portion size. Meals are eaten with hands, rather than with utensils (Cordero-Fernando 1976; Fernandez 1994).

Carinderia: A carinderia is a restaurant concept that originates from the Philippines. They are also known as "mini-restaurants" in the Philippines (Cordero-Fernando 1976; Andrei 2010). Unlike a-la-carte establishments, carinderias do not have table service and have fairly casual settings. A carinderia is comparable to the concept of a cafeteria, where the customer can order food at a counter by choosing from items on a buffet line. Alternatively, customers can also order dishes from a menu. Menu items are usually fixed, while items on the buffet line change daily. After ordering, customers pay for their food at the counter before the meal. Another distinctive characteristic of a carinderia is the quality of the foods served, carinderia foods are often described as lutong bahay or "home cooking" produced in bulk (Fernandez 1994). This idea is also reproduced in

\footnotetext{
13 According to Macaalay (2015), a "Boodle Fight" is a "Filipino tradition of eating that originated from the Philippine military. where a big pile of food [is] served in the middle of a really long table in a mess hall where every hungry soldier eats with their hands symbolizing of camaraderie, brotherhood and equality in the military. The "fight" in the name refers to the act of grabbing and eating as much as the soldier can before others grab them or runs out, remember this is served to very hungry men so if you're slow you will definitely run out of food".
} 
Western context, where carinderias are also known for their home-style cooking (Andrei 2010).

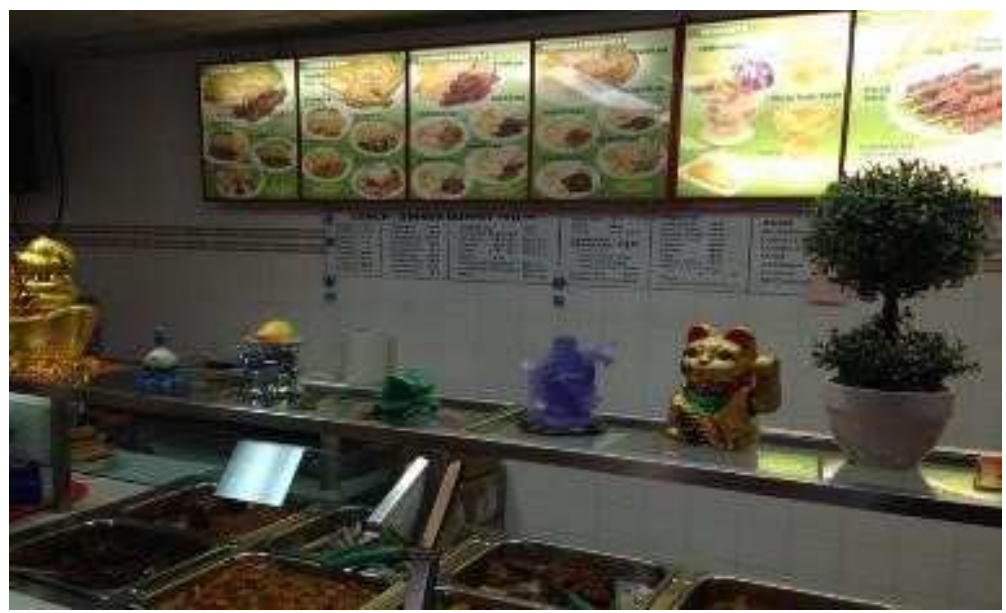

Figure 4.3: An example of a carinderia. Note the menu on the wall, from which customers can get made to order dishes; and the buffet line, featuring foods that are already prepared. In this restaurant, at the end of this counter is where the customer pays for their meal (Andrei 2010).

Turo-turo: Turo-turo is a literal translation of the Tagalog word for "point" or "pointing". Thus, turo-turo literally means to "point-point" with reference to a finger when customers are ordering their meals (Cordero-Fernando 1976; Zappia 2015). Turoturo establishments can be best described as a type of take-out establishment or as a counter-service type of restaurant that sells pre-prepared foods (De Leon 2016; Oldham 2015; Zappia 2015). In the Philippines, foods sold at turo-turos are mainly produced in bulk quantities and are stored in aluminum trays or pots (Cordero-Fernando 1976). In the Western context, turo-turo establishments have their foods displayed on stainless steel trays or warmed buffet lines. Sometimes cold foods and desserts are found in refrigerated displays (Andrei 2010). At the establishments I visited, the customer can order at the buffet line and can either verbally indicate, or nonverbally indicate with one's finger, which foods they want to order - the server will then scoop these foods and put them in 
take-out containers. Menus rotate daily at turo-turos, although there are consistent staple dishes offered every day. Pricing depends on the establishment—-some dishes are priced individually or are priced according to container sizes. Furthermore, turo-turo establishments can exist as an entity in themselves, such as a space in a strip mall or can be attached to Filipino grocery stores or Filipino sari-sari (variety) stores. Like carinderias, dishes sold at turo-turos are recognised as "home cooked" foods (Fernandez 1994; Oldham 2015).

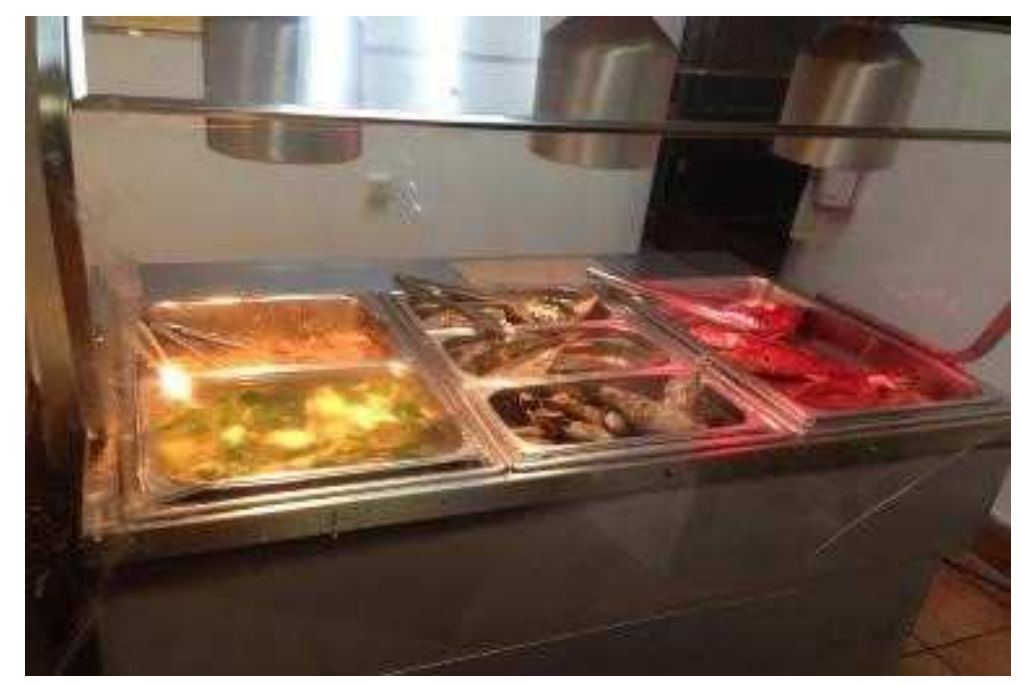

Figure 4.4: An example of a turo-turo. Pre-prepared foods are laid on a buffet line warmed in stainless steel trays, and customers are able to point to the dishes that they want to order (Andrei 2010; Oldham 2015; Zappia 2015). The selection of items are always rotating at a turo-turo, with some fixed menu staples.

Sari-sari store: In the transnational context, the sari-sari store is also known as a "variety store" selling Filipino goods (De Leon 2016: 52). These stores are bigger than convenience stores, but are not as large as a standard grocery store. Sari-sari stores have an assortment of Filipino imported goods, such as cosmetics and toiletries, canned goods, frozen foods, produce, and snack foods. Some sari-sari stores serve fresh-made food and may have a combination of a bakery, carinderia, or turo-turo inside the store. In the 
Philippines, sari-sari stores are smaller, with an average size of two by four metres, as they are commonly operated from a portion of the owner's house (Chen 1997: 88). They sell a small assortment of goods, mostly dried goods such as snack foods, candy, uncooked rice, canned or bottled drinks, and on occasion, some home cooked street foods. For this reason sari-sari stores are associated with the urban poor population in the Philippines, as they are not regulated, fully-fledged retail stores (Chen 1997).

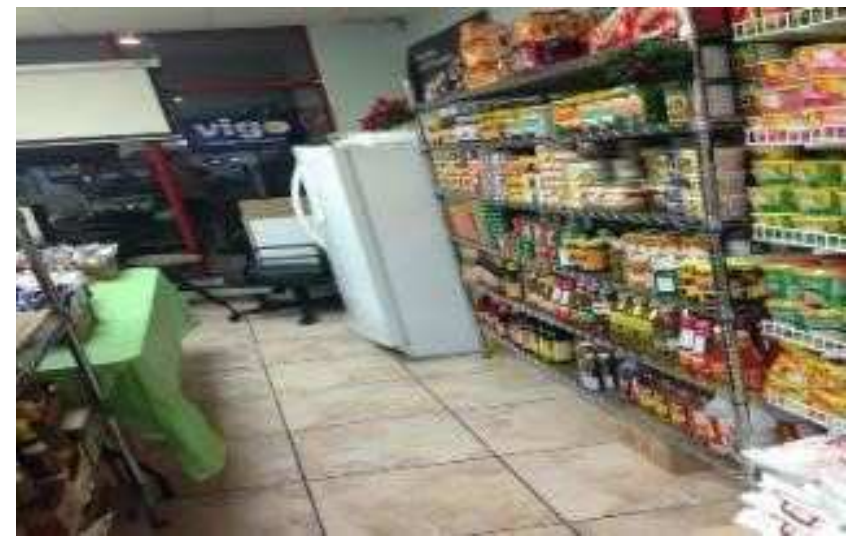

Figure 4.5: An example of a sari-sari store - this specific establishment has a bakery and a turo-turo as part of the sarisari store. Sari-sari stores typically sell Filipino imported goods and may offer additional services, such as remittance services (De Leon 2016).

Bakery: Filipino bakeries are establishments that are either standalone or can be found in conjunction with a Filipino grocery store or sari-sari store. Filipino bakeries often sell baked specialties such as breads, cakes, or pastries, or non-baked specialties such as frozen desserts, custards, or puddings. Some Filipino bakeries will also offer savoury foods in addition to baked goods and frozen desserts. However, these savoury foods are either refrigerated or frozen. 


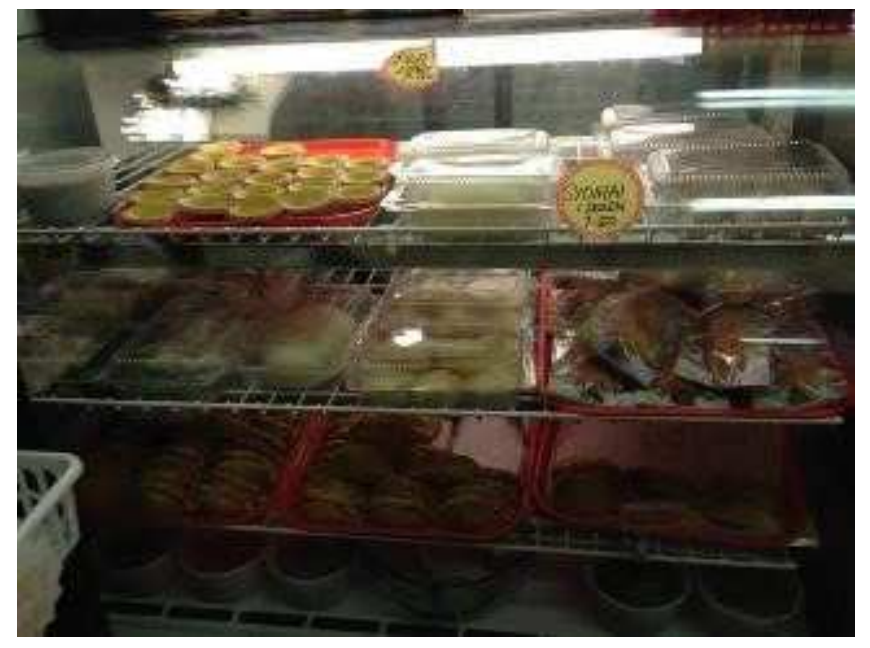

Figure 4.6: This is a refrigerated display at a Filipino bakery. As shown in this photograph, there is a combination of sweet baked goods as well as savoury foods, such as "siomai", which is a Filipino version of the Chinese "shumai", which has been adapted and "indigenized" to suit the Filipino palate (Fernandez 1988, 1994).

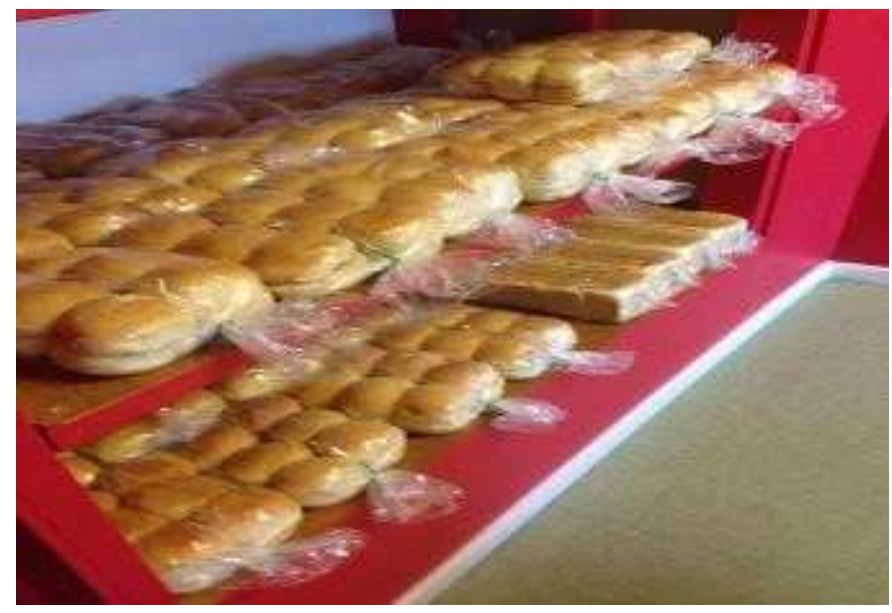

Figure 4.7: Breads are laid out and displayed on shelves in Filipino bakeries. On this shelf are "pan de sal", a sweet bread roll that is commonly enjoyed during breakfast among Filipinos (Fernandez 1994).

Food Truck: In contemporary times, food trucks are akin to mobile restaurants (Caldwell 2012; Wessel 2012). Like restaurants, modern food trucks have a concept and a set menu from which patrons can order. Customers pay for the food before receiving it. Some food trucks may have designated spaces for customers to eat (Siu 2011), however they are mostly take-out style. 


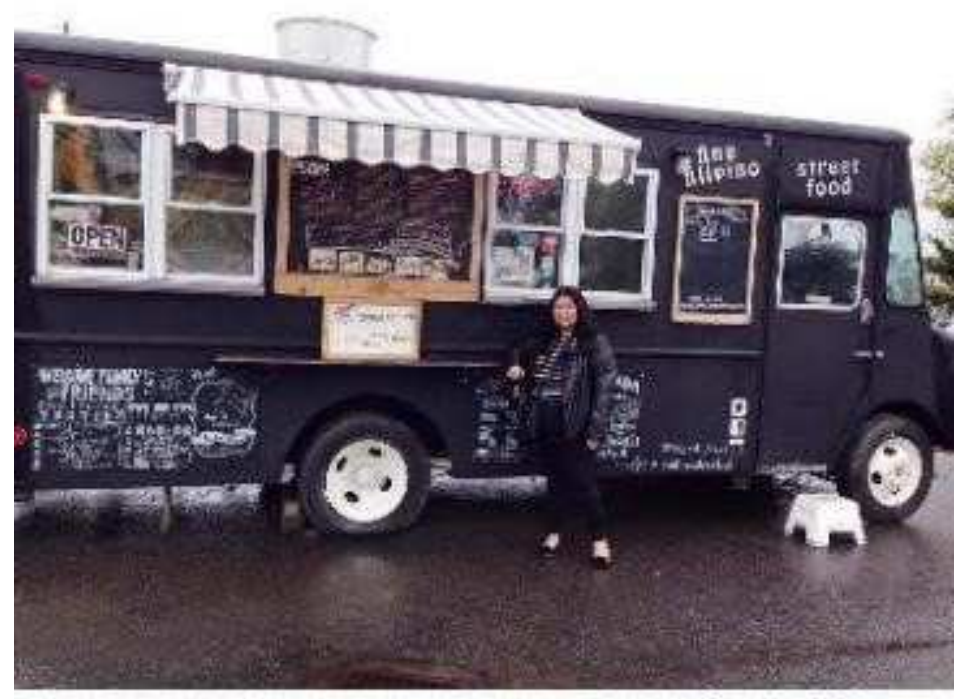

Figure 4.8: This photograph features me posing beside a Filipino food truck. Some food trucks are decorated according to the preference of the owner. Food trucks usually have small menus and serve foods take-out style (Siu 2011). Some food trucks have areas designated for dinign. This particular food truck has picnic tables nearby where customers can enjoy their meals.

In the Philippines, the establishments listed above are all considered to be fully-fledged restaurants with the exception of bakeries and sari-sari stores (Cordero-Fernando 1976; Fernandez 1994). Although a-la-carte restaurants and buffet restaurants tend to feature cuisines from other cultures rather than indigenous Filipino cuisine (Cordero-Fernando 1976; Fernandez 1986, 1994). More recently food trucks are steadily becoming popular in large urban areas such as Manila. Like the a-la-carte and buffet restaurants in the Philippines, these food trucks tend to serve other culture's cuisines rather than indigenous Filipino cuisine (Uy 2012). In Canada, restaurants are largely imagined as the a-la-carte type, and what comes to mind is that there is an expectation that restaurants are spaces where customers can sit down, order from a set menu, and receive table service (Sprang 2000; Douglas 1999; Simmel [1910]1997). These culinary 
standards are noted to be based on the French structure and logic of meals (Janer 2007). Scholars have pointed out that the French conception of what constitutes as a "proper" restaurant is the normative standard from which other restaurants are evaluated. Subsequently, restaurants that fail to satisfy these standards are evaluated negatively. This evaluation system is argued to be representative of the hegemony of French cuisine in culinary discourse, which is not only unique to Western countries, rather, it operates on a global scale. It signifies the superiority of French cuisine as "the culinary expression of European modernity-rationality" (Janer 2007: 391).

Keeping in mind the distinction between Philippine restaurant culture and Canadian restaurant culture, I posit that it is critical to be aware of how some Filipino cuisine entrepreneurs, most notably the first generation Filipino immigrants, import their indigenous knowledge of food and eating practices into the Canadian context and apply these knowledges to their food establishments. Upon migration they also bring with them their habitus - their "system of dispositions" and embodied representations of external structures, manifested as bodily practices, cultural beliefs, rituals, tastes, and habits (Bourdieu 1984; Wacquant 2007). In analysing the cultural politics of Filipino cuisine entrepreneurs, their habitus and social context plays a role in informing their business decisions. For some, their indigenous knowledges are at odds with contemporary culinary knowledges, (Janer 2007: 391). In the analysis that follows, I detail how these conflicting knowledges takes on a particular class dynamic which can be observed through the classification of "traditional" and "modern" Filipino cuisine establishments. 


\section{2 "Traditional" and "Modern" Filipino Cuisine Establishments}

Participants were asked to define their restaurants given the following categories: "traditional", "modern", or if inapplicable, as "something else". I chose these specific categories because in the literature, ethnic restaurants are often described as either traditional (authentic) or modern (Stierand and Lynch 2008; Guerrero 2009; Huynh 2012). I included the third category, "something else" because I wanted to provide participants the opportunity to define their establishments as they see fit without any constraints. Yet, despite these efforts, most participants had chosen either "traditional" or "modern" to describe their establishments. There were others who would describe theirs as a mixture of both.

\subsubsection{Traditional Filipino cuisine establishments}

In cultural studies, tradition can be understood as a representation of a group belonging to a defined space, and "is part of a culture that implies the cooperation of the individuals operating in that territory" (Guerrero 2009: 345). Tradition is a system of values and knowledge which are rooted in a distant past (Stierand and Lynch 2008), and according to Hall (1992: 277), traditions

are honoured and valued because "they contain and perpetuate the experience of generations." In culinary discourse, tradition is often conflated with the concept of authenticity, which is understood as a state of being "that which is believed or accepted to be genuine or real" (Lu and Fine 1995: 539).

Among culinary tourists, the quality of the ethnic restaurants are measured based on whether the restaurant delivers an authentic dining experience (Huynh 2012; Heldke 2005; Johnston and Baumann 2010). The implications of "seeking authenticity" will differ depending on the social positioning of the diner. For instance, a white diner who engages in culinary 
tourism (a cosmopolitan practice that is predicated upon knowing, engaging with, or experiencing another culture), seeks authenticity for reasons relating to cultivating cultural capital to fashion a cosmopolitan identity or to incite a sense of adventure (Heldke 2005; Molz 2007; Chez 2011). On the other hand, a Filipino migrant worker living in Canada may yearn for authentic Filipino foods because of reasons related to nostalgia and memory (Mannur 2007, 2009; Andrei 2010).

For culinary tourists, authenticity is evaluated based on whether the dining experience is culturally distant from daily life (Bessier and Tibere 2013; Molz 2004; Long 2004; Johnston and Baumann 2010). For instance, Ellie, a first generation Filipino owner of a trendy Filipino restaurant in Ottawa describes her restaurant as traditional because of the restaurant's cultural distance from Canadian culture:

The dominant food here is pizza, hamburgers, pho... and people are looking for different variations. And now we have customers saying, "We never tasted Filipino food before!" and they'd say it's good, they don't know what pandan is...So yeah, I think people are coming because it's something new and authentic...

Ellie explains that the selling point her restaurant is that it is new and novel (Johnston and Baumann 2010), and disrupts the culinary landscape of Ottawa which is presently dominated by pizza, hamburgers, and pho. Vietnamese restaurants selling pho is particularly common in Ottawa because of the Project 4000 program that brought in refugees from the Vietnam War in the 1970's (Carriere 2016; Vineberg 2010). Some have asserted that pho's widespread presence has made it "Canadian" and "familiar" rather than norm-breaking (Huynh 2012). Pho, like many ethnic foods in liberal multicultural societies are considered "norm-breaking" when foods are newly introduced (Johnston and Baumann 2010), yet over time, as these foods become more prominent among members of the dominant culture, they are no longer considered "norm- 
breaking", rather, they become integrated into the society's culinary culture. Like ethnic identity, the nature of ethnic foods and ethnic restaurants change over time (Gvion and Trostler 2008). Filipino cuisine has yet to shed its norm-breaking status, as evidenced in Ellie's account, because it is uncommon among members of the dominant culture-making it culturally distant from Canadian culture.

Culinary tourism has been criticized for producing a colonial logic and its implicitness in reproducing the normativity of whiteness (Heldke 2005; Hirose and Pih 2011; Janer 2007). The white diner's quest for an authentic dining experience is based upon an Orientalized search for racialized "Otherness" in their ethnic food encounters. Their search for authenticity is only confirmed when they are reminded of the distinctive "exoticness of the other" and "the neutral and unmarked quality of themselves" (Hirose and Pih 2011: 1495). Nonetheless, ethnic restaurateurs are aware of the demand for traditional and authentic dining experiences especially since the ascendency of liberal multiculturalism, and strategically use this knowledge to their advantage (Hirose and Pih 2011; Lu and Fine 1995). Some ethnic restaurant owners use the strategy of "staged authenticity" (Huynh 2012; MacCannell 1976) to create an authentic dining experience made to create an "authentic" encounter with the exotic other (Hirose and Pih 2011; Huynh 2012; Lu and Fine 1995). Staged authenticity refers to the ways in which "owners of experiential places, such as restaurants, make everyday activities, such as eating, into something more" (Huynh 2012: 89). Staging is accomplished through the physical and symbolic manipulation of the restaurant space, which entails curating menus, décor, and atmosphere (Huynh 2012; Hirose and Pih 2011; Brayton and Millington 2011). In some cases, the overt manipulation of ethnic restaurants with the purpose of evoking "exoticness" and "otherness" can 
be a form of self-Orientalism (Said [1978]2000; Hirose and Pih 2011) from which ethnic restaurateurs can profit off their racialization.

Under this definition, a Filipino cuisine establishment is a site where Filipino-ness can be staged. For instance, Roddy, a second generation Filipino and owner of two successful Filipino restaurants in Winnipeg, describes how Filipino-ness is consciously staged through his food truck restaurant:

I think the majority of the truck... its colours are straight from the colours of the flag from the Philippines. You will see throughout the truck if you take notice and take a minute to look... there's iconic Filipino symbolism. Like tinikling which is like a native dance to us. A pair of roosters with boxing gloves, just not to offend the animal people out there - I love animals, but it's part of our culture in that there's cock fighting. I wanted to represent it but not the way it is originally. To get the point across I put boxing gloves and they're cock fighting...

Roddy explains that his food truck was intended to draw a non-Filipino audience to Filipino cuisine. At the time his food truck first opened, Filipino cuisine was considered to be an anomaly in Winnipeg's culinary scene. To capture the attention of non-Filipino clientele, Roddy felt that his truck had to be recognizable not only from a marketing standpoint, but he also wanted people to begin to recognize the presence of Filipino cuisine. He stages Filipino-ness by making references to the Philippine flag from the colour scheme (blue, red, white, and yellow) to the symbolism (sun and stars). Additionally, there are images of straw huts, palm leaves, cock fighting, a banana, and a Filipino person. On the very front end of the truck says the Tagalog expression "Mabuhay!", which is loosely translated to English as "welcome". 


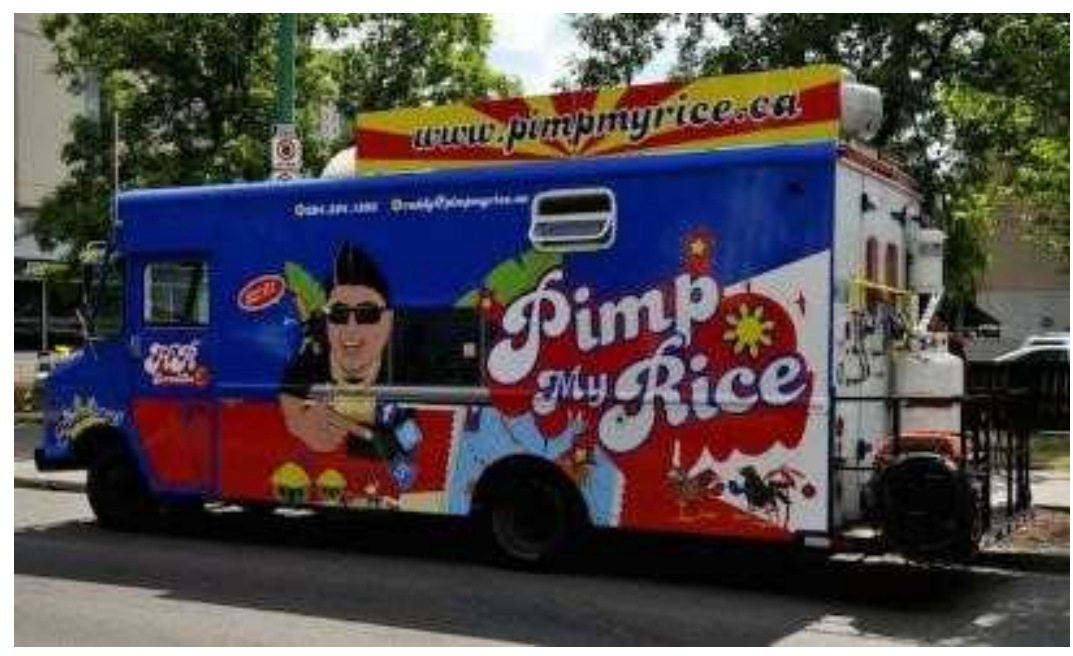

Figure 4.9. The picture is taken from a Food Network article (Furdyk 2015) which features Roddy's food truck. His food truck is a pop culture reference of the MTV reality show, "Pimp My Ride" (2004-2007).

As Roddy's example shows, some ethnic entrepreneurs employ staged authenticity when the intended audience is outside of their ethnic community. Andrei's (2010) research on Filipino restaurants in the United States showcases how some Filipino restaurateurs decorate their restaurant spaces with overt symbols of Filipino culture, such as banana leaves, palm trees, and photographs of different landmarks in the Philippines. In Huynh's (2012) research on Vietnamese restaurants in Toronto, she found that Vietnamese restaurants that were obviously intended for a non-Vietnamese clientele relied on stereotypical symbols of Asian-ness as décor, such as bamboo panelling or Buddha statues. Similarly, Pan Asian fusion restaurants in Winnipeg and Ottawa also relied on Orientalist, stereotypical symbols of Asian-ness to signify the Asian-ness of the restaurant. For instance, Charlie, a second generation Filipino and owner of Charlee's Restaurant and Lounge Winnipeg, explains that the aesthetic choices of his restaurant space was intended to evoke an "Asian-ness":

Everything to me, in my restaurant, just my general outlook on life has to make sense and has to have a reason for something. Even the way these dividers right here are opened in the middle so I can see through them as far as patrons if they need something. You can 
see through them, instead of them being closed off. So now the bamboos, because of the Asian feel for the bamboo.

If I had not asked Charlie to explain the rationale behind the décor, I would have never made the connection with the Asian-ness of Charlie's restaurant. Charlie's restaurant space is bright and contemporary looking with stylized photographs adorned on the walls. Unlike Roddy, Charlie employs a subtle approach rather than overt references to Asian-ness. There is no indication besides the bamboo that Charlee's is Asian-owned. Charlie had also clarified that the spelling of his name as "Charlee" as the restaurant's name is supposed to reflect an "Asian feel" because of the "Lee" at the end. Further, he also explains that the Filipino items on his menu are written in English and were purposely given English names (such as the tocino burger, which is called the caramelized pork burger on the menu), because the clientele of his restaurant are mostly non-Filipino working class white people.

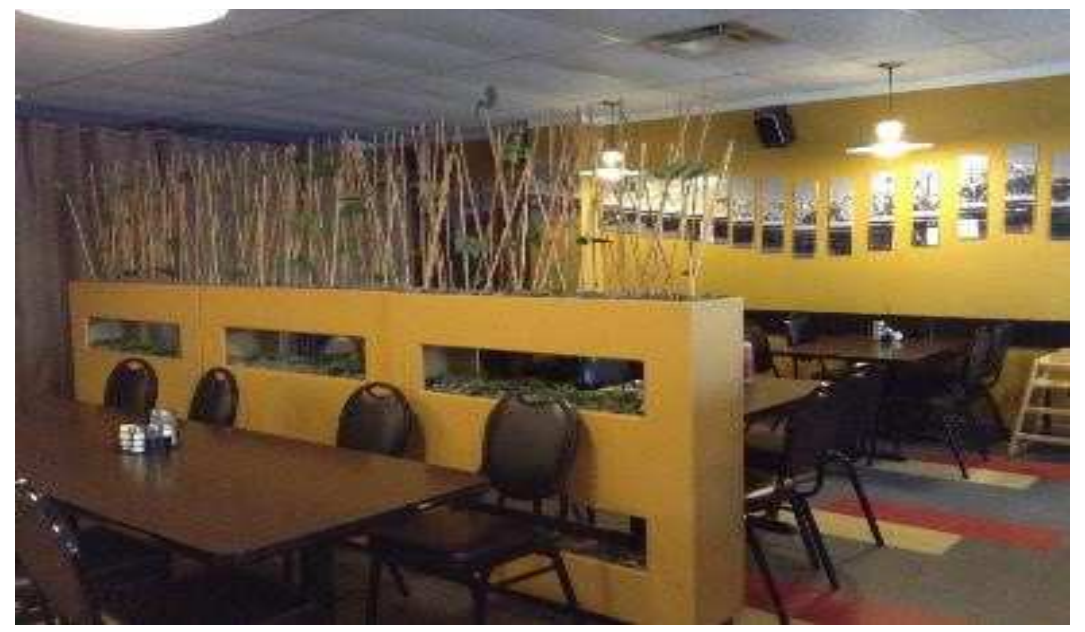

Figure 4.10: The inside of Charlee's Restaurant and Lounge. The owner says that the dividers in the middle have bamboo in order to convery an Asian atmsophere.

For the most part, the participants were ambivalent about incorporating overt references to Filipino culture in their restaurant spaces. Most restaurants owned by older first generation Filipinos were not elaborately decorated to purposely evoke imagery of Filipino culture. For a 
lack of a better word, the atmosphere and décor of such spaces were kitschy with mismatched furniture and out-of-place artwork and decorative items to boot. Yet at the same time, there was a distinct Filipino quality to these spaces that felt so familiar. The kitschy decorations, such as the ceramic bonsai trees, porcelain elephants, and jade ornaments reminded me of moments as a child when I had visited countless Filipino tita's (aunt) and lola's (grandmother) houses with my mom. These spaces felt authentic to me because I could link them to my nostalgic encounters (Mannur 2007, 2009).
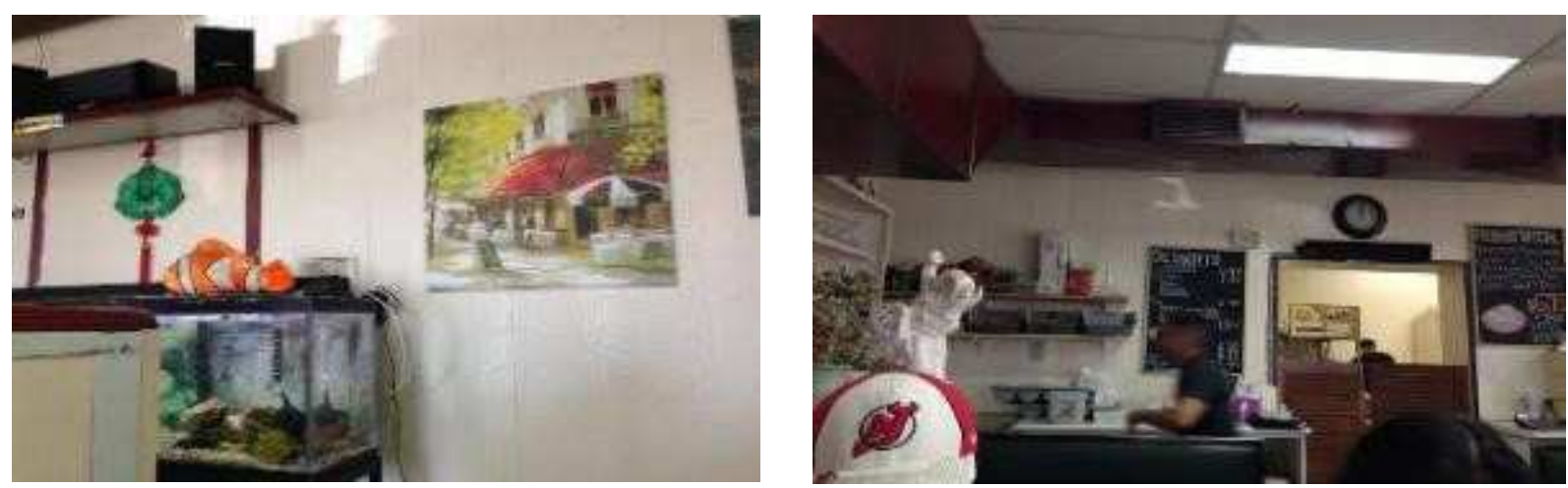

Figure 4.11: The pictures above were taken in a Filipino restaurant located in a rural municipality 30 minutes outside of Winnipeg. The décor is "kitsch", complete with porcelain elephants, aquariums, and a ceramic bonsai tree. These decorations are commonly found in Filipino homes I visited growing up.

The preference for 1970s kitschy décor among older Filipinos does not appear to be exclusive to my own experience. In Ignacio's (2005: 129) research on online communities among transnational Filipinos, she noted that several participants had made reference to the kitschy decorative style that seems to be a trend among the Filipino community, conveyed in the form of jokes:

Many of the jokes that participants listed contained references to 1970s cultural artifacts and/or kitschy things and behaviors that people of various races and ethnicities in the United States own or do: "You own a 'barrel man' (you pull up the barrel and you see something that looks familiar)." "You own one of those fiber optic flower lamps." "You own a lamp with the oil that drips down the strings." "You have plastic runners to cover the carpets in your house"... 
Even in such establishments, Filipino-ness is staged — although not for the sake of deliberately inciting "exoticness" and making overt references to Filipino culture. When I had asked some owners to explain the kitschy décor of their restaurant, they said that there was not a lot of thought put into the décor and atmosphere. Rather, they chose the decorations as they simply liked the way it looked and not because they were trying to convey a specific message. Despite this, I contend that these spaces do articulate a particular Filipino-ness, one that evokes memory and nostalgia among transnational Filipinos such as myself (Mannur 2009). For others, the kitsch-factor may not be significant or obvious because Filipinos do not have sole ownership of these cultural artifacts - they are present in several other ethnic communities as well (Ignacio 2005: 128).

Interestingly, Roddy's a-la-restaurant, Bisita, is stylized as kitsch. It is the only Filipino restaurant that is decorated with kitsch décor that is owned by a second generation Filipino. Roddy explains that the décor was a deliberate choice to make Filipinos feel welcome:

The overall response to our dining room and the restaurant as a whole is that they feel like they're at their grandma's house which means they feel comfortable...

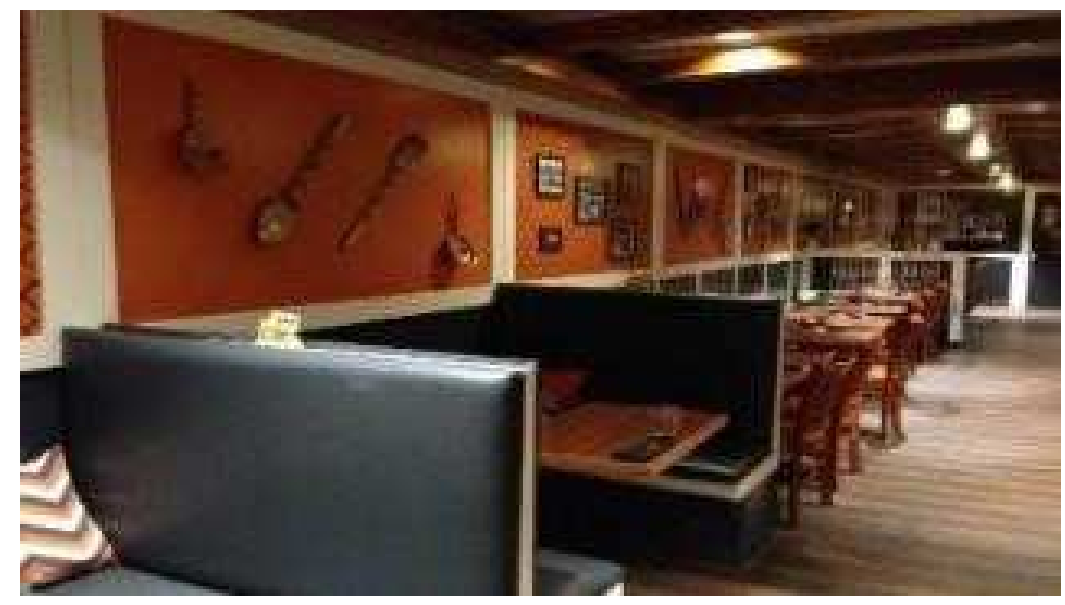



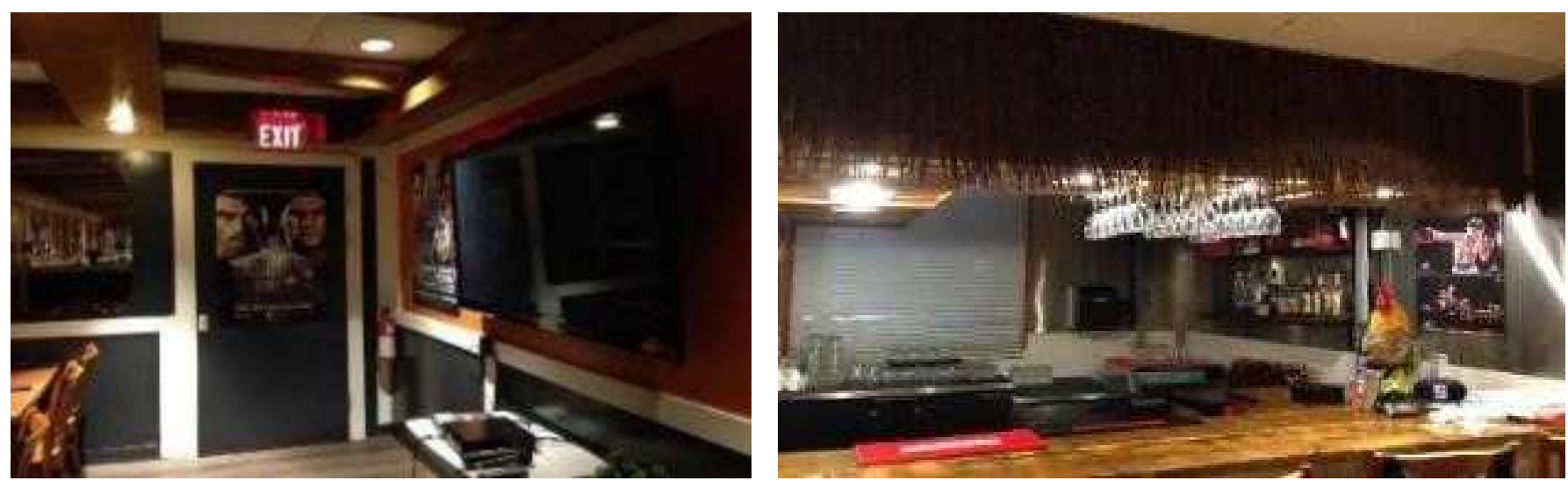

Figure 4.12abc: Bisita Restaurant's interior.

Unlike the food truck, which is intended to captivate the attention of non-Filipino consumers, Bisita restaurant is meant to capture all audiences-Filipinos and non-Filipinos alike. Still, while Bisita is meant to be decorated like a Filipino grandmother's house, it is evident that most wall décor are showcased as artifacts of Filipino culture, rather than simply liking the decorations because they "looked nice". Drawing from my own experience, I am unsure if Filipino grandmothers would be hanging Manny Pacquiao posters all over their walls or have straw hanging from their ceiling to look like a straw hut. However, I have seen the puka shell ceiling decorations and the giant wooden forks and spoons on plenty of walls.

Besides décor there are other aspects that contribute to the perceived "authentic" atmosphere of a restaurant. In the case of Filipino restaurants, things like sound (languages being spoken), bodies (other Filipino people), and menu items can construct a restaurant space as traditional and authentic (Hirose and Pih 2011; Huynh 2012). At one restaurant, even though there were no overt symbols relating to the Philippines (i.e., the name of the restaurant, which 
was simply named after the street it's on), Filipino-ness was still apparent in other ways. For instance, everyone, including the servers, spoke Tagalog. The Filipino Channel was playing on a nearby television. Most people visibly appeared to be Filipino. The pungent smell of tuyo, daing, and bangus (types of fried fermented dried fish) permeated the air.

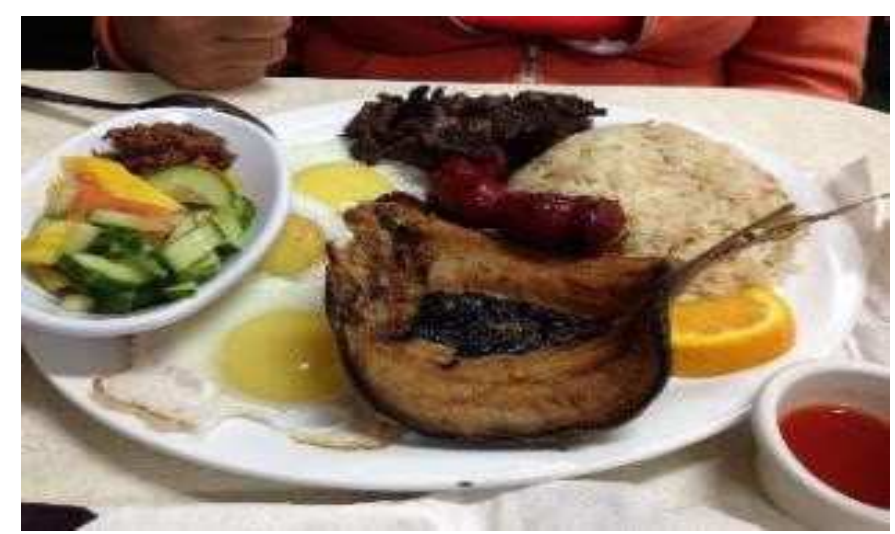

Figure 4.13: This picture is from the restaurant referred to above. Plates of tuyo, daing, and bangus were commonly found on other tables.

As these examples show, what makes a Filipino cuisine establishment "traditional" is dependent on the intended audience (consumers) and the social context of the owner. The target market of Roddy's restaurants are primarily non-Filipino consumers. To evoke authenticity in his restaurants, he used staged authenticity strategies, such as décor, to create a traditional dining experience. Meanwhile, establishments owned by first generation Filipinos do not rely on staged authenticity, however, the atmosphere contributed to an authentic and traditional dining experience such as sound, menu items, and smell.

\subsubsection{Modern Filipino cuisine establishments}

While tradition is often associated with a state that is "static" and "backwards", modernity is associated with social progress (Janzer 2007; Said [1978]2000; Bullinger, Seitz, and Volz 2012). The idea of progress is exemplified in modern cuisine as culinary innovation 
(Guerrero et al. 2009; Stierand and Lynch 2008), which is defined as "the addition of new or unusual ingredients, new combinations of product", expressed as foods from different cultural origins or traditional foods that have been presented and "re-imagined" in novel and exciting ways (Guerrero et al. 2009: 349). Innovation is linked to culinary creativity, which is described as combination of "personal identity, motivation, mood, professional knowledge, and experience" (Agogue and Hatchuel 2016: 174). Experience is understood as an awareness of other cultures that can be cultivated through books, films, or travelling abroad (Horng and $\mathrm{Hu}$ 2008: 223). This implies that in order to have a successful "modern" restaurant, the parties involved in the operation of the restaurant needs to possess social, economic, and cultural capital (Bourdieu 1984), as the latter are deemed necessary to have an understanding of contemporary culinary trends.

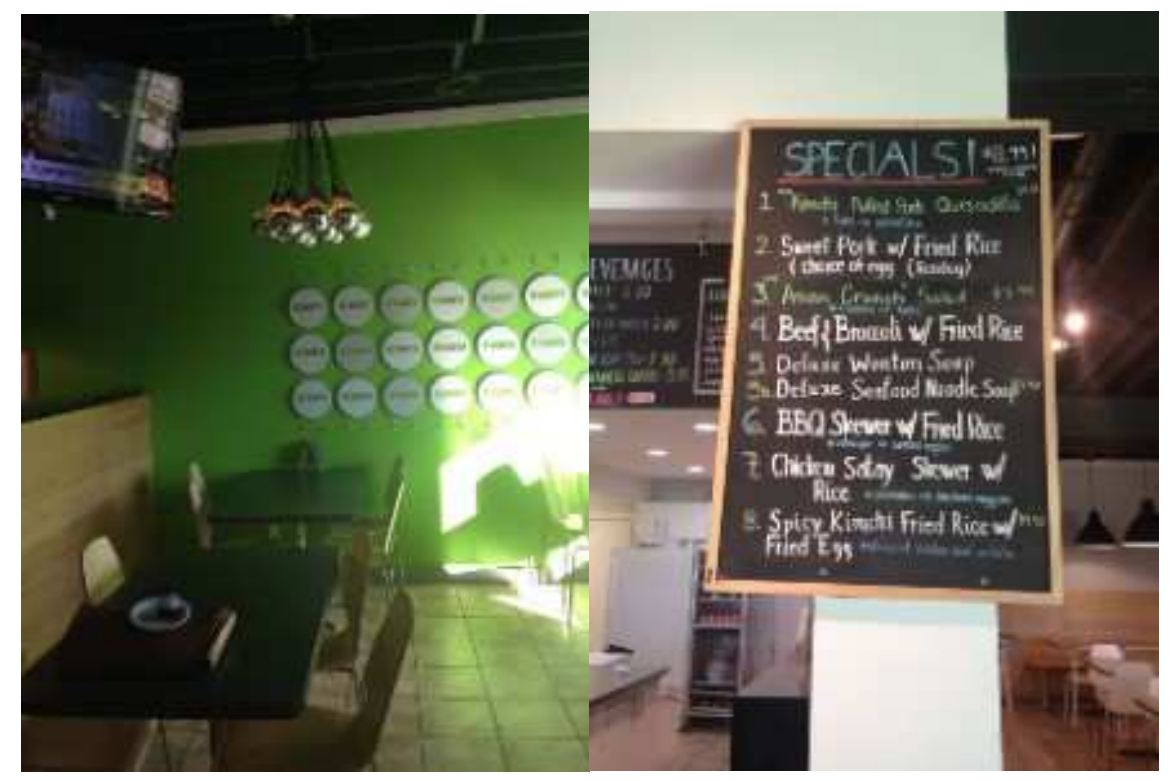

Figure 4.14: A contemporary Pan Asian fusion restaurant. Note the trendy interior and the fusion-inspired menu items.

A common example of a modern restaurant featured in this study are the fusion restaurants. At the most basic definition, fusion cuisine can be simply defined the as reinvention 
and reinterpretation of classic dishes, recombining existing elements or implementing new technologies and inventions in the culinary process (Agogue and Hatchuel 2016; Janzer 2007; Stierand and Lynch 2008; Guerrero et al. 2009). This definition does not necessarily indicate that there is any semblance of cultural fusion. Nevertheless, fusion restaurants are widely understood in the Canadian culinary foodscape ${ }^{14}$ as the mixing of different cultural cuisines, usually ethnic foods combined with French techniques and modes of preparation (Janer 2007).

Culinary fusion is the main concept at the Baon Manila Nights pop-up dinners in Winnipeg, where Filipino cuisine becomes re-interpreted by fusing it with other ethnic cuisines, as Vincent, a second generation Filipino chef and participating chef of Baon Manila Nights describes:

Manila Nights dinners really mix tradition with modern flavours. When me and my partner made kare-kare... it's not your typical rice with kare-kare on top with eggplants and such. We added rice cakes... and we got a lot of compliments because kare-kare does have a unique flavour, right? But adding Thai flavours and with chiles and whatnot... it opened people's eyes and they say they've never experienced it. You can tell it's kare-kare but... it's not your typical home cooking... when we do Baon Manila Nights dinners... it's not just cafeteria food with rice piled on top, with sauce. I want people to know that food can be whatever you want it to be. If you want it to look different, you can make it look different. If you want it to taste the same, you can make it taste the same. If it's visual for some people you can change it. As a cook we will try to fix things. Food is always changing, techniques are always changing.

Vincent's account describes two things. First, he describes a class distinction between modern establishments and traditional establishments that serve "home cooking". In particular, modern Filipino food served at the Baon Manila Nights pop-up dinners are definitely not the type of Filipino food you would find at a "cafeteria" (referring to turo-turo and carinderia) type of establishment. Second, his account illustrates how fusion cuisine is indicative of the

\footnotetext{
${ }^{14}$ I draw from Johnston and Baumann (2010:3) to define term "foodscape", which refers to "the cultural spaces of gourmet food", it is a "dynamic social construction that relates food to specific places, people, and meanings."
} 
conditions of modernity in contemporary society. The conditions of modernity are described as a time of "constant and rapid change" (Hall 1992: 278), where experiences and identities have become fragmented and unstable, resulting in new forms of subjectivity (Reisenleitner 2001; Hall 1992; Howard 2011). Scholars have attributed these changes to globalization, which is described as the process of transforming local phenomena (such as economic, technological, social, and/or cultural phenomena) into global ones (Howard 2011: 14). This transformation occurs because of deterritorialization, wherein borders are considered to be eroded, facilitating the exchange and movement of people, markets, ideas, and cultures around the world (Reisenleitner 2001; Howard 2011).

Globalization has been associated with the popularization of fusion cuisine in contemporary times (Johnston and Baumann 2010). Fusion cuisine has been lauded as an example of multiculturalism and is an example of how cultures can co-exist and intermingle in harmony. Alternatively, fusion cuisine has been criticized as "cultural homogenization", however, such critiques reinforce an essentialist understanding of ethnic identity (Janer 2007; Ku 2015; Kim 2015). Fusion cuisine does not necessarily demonstrate assimilation. It points to a larger process of indigenization and cultural hybridity (Bhabha 1994; Fernandez 1988). For members of the subaltern class, hybridity can be deployed as a strategy to articulate difference while simultaneously subverting and re-appropriating dominant discourses of Otherness (Kraidy 2002; Bhabha 1994).

On the other hand, writing from an American perspective, Janer (2007) provides a postcolonial critique of fusion cuisine in the West, arguing that fusion is a reproduction of the asymmetrical power dynamics between the colonizer and subaltern groups. She contends that fusion cuisine in contemporary times is often framed as the amalgamation of French cuisine with 
cuisines of the ethnic and racialized "Other". Even if ethnic cuisines are not literally fused with French cuisine - techniques, plating styles, and even menu structures (i.e, appetiser, breakfast, lunch, dinner, etc.) are based off of the French tradition. Thus, how fusion cuisine is framed in contemporary culinary culture is representative of the hegemony of French cuisine-French culinary knowledge is considered to be superior while cuisines of the racialized "Other" occupies an inferior position; one that is merely complementary to French cuisine (Said [1978]2000). Only when cuisine of the racialized "Other" is combined with French cuisine (via techniques, ingredients, or presentation), it becomes a "proper modern restaurant" (Janer 2007: 395).

In the interviews, I had asked participants to describe what makes Filipino restaurants "modern". A handful of participants alluded to "improving" and "elevating" Filipino cuisine in their explanations, as Phillip, a second generation co-owner of a modern Filipino restaurant in Ottawa does here:

In a way we put a twist on that, touch on that, turn [langonisa] (sweet cured sausage) into a burger instead of a sausage. I don't think we're blaspheming the food, but we're enhancing it and making it appealing. Now I'm not saying it wasn't appealing before, but we're interpreting it so that other folks who are not Filipino can see it a bit better, in a better light.

As Phillip's account illustrates, his restaurant aims to make Filipino cuisine appealing to the broader masses. This is accomplished by reinterpreting the foods to become "modernized" through preparation and presentation. In Phillip's case the décor of their restaurant also evokes modernity, describing it as "minimalistic and contemporary". Similarly, Allan describes the Baon Manila Nights pop-up dinners, which specialize in modern Filipino cuisine, as "elevated Filipino food":

We're trying to make it better. It's good as it is, but you know... I'm like, trying to get people to like it, and you can't get people to like it who don't know about it if it's not presented well or make it visually appealing. So we make it look nice. We make it - it's, 
people - I'm not gonna say safe, but if they see something at the dinners, that kind of... say gnocchi for example. A lot of foreigners know what gnocchi is. But if we make $u b e$ (purple yam) gnocchi or taro gnocchi, that's still Filipino food.

Like Phillip, Allan emphasizes that in order to make Filipino cuisine "modern", it has to be appealing to the masses and it also has to be familiar to non-Filipino customers. This can be accomplished through stylizing Filipino foods through plating and presentation.

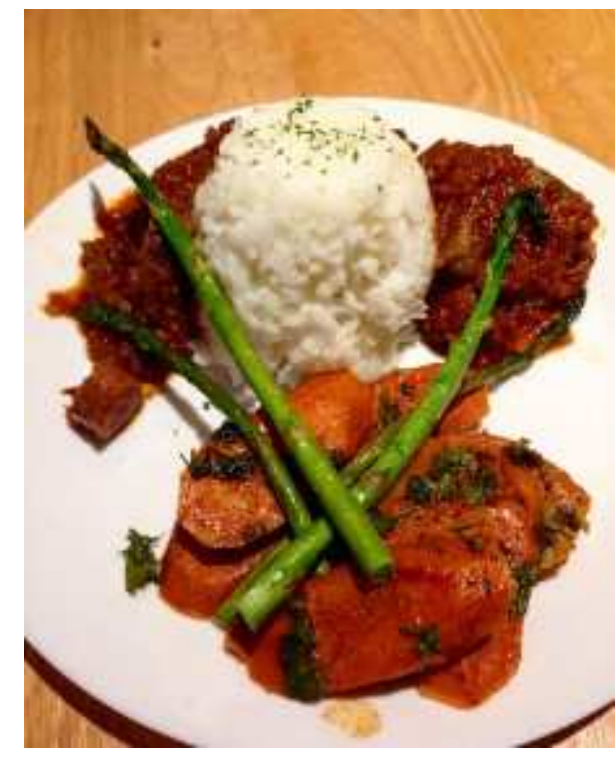

Figure 4.15: A meal I ate at a "modern" Filipino cuisine establishment. This is mechado, which is a beef dish simmered in tomatoes and spices. Here it is served with carrots and asparagus. The owner explained their mechado is an example of a modernized take of Filipino cuisine due to the plating style - the asaparagus was included to provide aesthetic visuals to the dish and to make it more appealing to non-Filipino diners.

Another characteristic of modern cuisine is that meals go beyond feeding the mouth - it should also feed the eyes - special attention is placed on aesthetic judgments (taste). According to Bourdieu, upper middle-class taste is contingent on the antithesis of "quantity and quality, substance and form" (Bourdieu 1984: 172), which corresponds with the opposition between necessity (i.e., value for money and filling foods) and luxury, which focuses on "stylized forms" (Pujol 2009: 450). The dichotomy between substance and form has been referenced by some participants who consider their restaurants as "modern" cuisine. Here, Elsa, a first generation Filipino owner of a Filipino bakery chain in Winnipeg describes the importance of visual aesthetics: 
So it's just a matter of presenting the product to them, because once they see it - because before if they see it served at a buffet and it's been sitting there a while, you see the oils are floating and some kind... we love most meats, you know Filipinos, we love most meats, and they say they see lots of fats there. So it's a matter of presentation and how you introduce food to a different kinds of people.

What this suggests is that some participants perceive that Filipino cuisine is not aesthetically pleasant in itself to be able to appeal to members of the dominant culture. As such, Filipino cuisine entrepreneurs have to use modernizing strategies such as hybridization (i.e., fusion cuisine). Even older generation Filipinos like Matthew, a co-owner of a turo-turo restaurant in Winnipeg, who deems modernized approaches as "blasphemous" and attributes fusion cuisine and technologies as "shortcuts", employs hybridization as a strategy without even knowing it:

We cook something a bit different, say sausage with potato. We try to introduce to the Filipino clientele which is incorporated with Canadian, because Canadians like sausage.

It should be noted that the narratives above are not negative commentaries of Filipino cuisine itself, rather, they speak of a wider issue. Their accounts indicate that ethnic and immigrant cuisines, such as Filipino cuisine, are devalued in mainstream culinary culture. In order to level the playing field, Filipino cuisine entrepreneurs must employ "modernizing" strategies to make Filipino food appealing to non-Filipinos. Adopting these strategies showcases how some Filipino cuisine entrepreneurs have to navigate the "boundaries of ethnicity", making sure that their establishments are "ethnic", but "not ethnic enough" (Chen 2015). Indeed, these responses correspond with Janer's (2007) argument regarding the relationship of culinary fusion with the hegemony of French cuisine: in order to "modernize" a cuisine, it must be prepared in a way that conforms to French standards of preparation. Moreover, restaurants should also be upto-date on trends in gastronomy as well as in interior design (Gvion and Trostler 2008; Brayton 
and Millington 2011). Should the restaurant meet these standards, the probability of being "recognized" by the culinary mainstream increases - especially if the restaurants are recognized by authorities in the culinary field. For instance, Chez (2011) notes that these ethnic food guides act as authoritative mediators between members of the dominant cultural group and members of ethnic minority groups. These authorities possess significant power, and by deeming restaurants as "noteworthy" it may provide restaurants with exposure, which in the culinary industry is instrumental to success. Given these factors, it is unsurprising that participants have the goal of mainstreaming Filipino cuisine and gaining recognition. 


\section{CHAPTER 5: CONSTRUCTING FILIPINO CUISINE}

In spite of his daily participation in its preparation and consumption, the Filipino is often hard put to say just what Philippine food is. [The] reason for the confusion is that Philippine cuisine, as dynamic as any phase of culture that is alive and growing, has changed through history, absorbing influences, indigenizing, adjusting to new technology and tastes, and thus evolving...

(Fernandez 1988: 219)

This chapter examines how Filipino cuisine entrepreneurs present and construct Filipino cuisine in their establishments. I contend that their presentation of Filipino cuisine depends on their subjective definition of Filipino cuisine - as it is their personal knowledge and understanding of Filipino cuisine that informs their business decisions (i.e., menu planning). However, it must be understood that Filipino cuisine, like other national cuisines, are discursive constructs much like ethnicity and nationality (Appadurai 1988). Understanding how Filipino cuisine entrepreneurs discursively construct Filipino cuisine must also take into account various social, historical, and political dimensions.

To my surprise, an interview question that seemed to elude several participants was, "how do you define Filipino cuisine?" I had assumed that this question was simple enough, and I had anticipated responses that identified flavour profiles and ingredients that are commonly associated with Filipino cuisine. I had also expected responses that pinpoint how Filipino cuisine draws influences from a variety of cuisines from countries such as Spain, Malaysia, China, and the United States (Cordero-Fernando 1976; Fernandez 1994; Barretto et al. 2013). Yet, I had overlooked that there is a subjective component to defining Filipino cuisine - it was during my initial conversation with John and Roland that I began to realise that there was a subjective component to understanding and defining Filipino cuisine:

John: My question to you now is, what is Filipino food? Do you know what Filipino food is? 
Gazel: It's subjective and varies.

John: Yeah, and it's because of our culture. And not only that, we have different kinds of people living - like [Roland] said, there's Pampanga, there's Pampanga cooking, there's Visayas cooking, Cavite cooking, Mindoro cooking... it all depends on the cooking, it's what Filipino food is to you... but seriously, what is Filipino food? Can you name one?

Gazel: What do you mean?

John: Can you name one Filipino food?

Roland: Authentic Filipino food?

Gazel: Adobo (soy sauce and vinegar-based dish)?

John: Adobo? But that's Spanish ... can you say pancit (stirfried noodles)? It's Chinese, we got it from [the] Chinese. What is Filipino food? And people who cook adobo, sometimes it's sweet, it's salty.

Roland: [And] sour.

John: Sometimes it's tasteless, sometimes it's really sour, sometimes it's not sour enough...

Gazel: Sometimes there's no sabaw (broth)...

John: That's right. It's wet, it's dry. It depends.

Roland: It depends what region from the Philippines you are.

John: Like I said ... I ask you, what Filipino food? What is Chinese food?

Gazel: That's a good question. I don't know.

As this excerpt demonstrates, being able to provide a seamless definition of Filipino cuisine is a complicated and personal endeavour. Conceptualizing Filipino cuisine goes beyond merely describing how it tastes, looks, or smells and knowing what sorts of ingredients there are in each dish. It must not be taken for granted that the process of defining a national cuisine is challenging task mired in identity politics (Appadurai 1988), and the concept of "nation" itself is socially constructed, imagined, negotiated, and politicized (Ignacio 2005; Anderson 1983).

Much like John, Roland, and myself have struggled with defining Filipino cuisine above, Phillip also finds it challenging to articulate a definition of Filipino cuisine:

I would have a hard time describing that, because I'm me. Somebody else might have a different way to explain it. For me? I have so much things to say about it! I don't know where to start...

Phillip's account suggests that in order to define Filipino cuisine, one must take into account how Filipino cuisine is imagined among individuals, and that it will vary depending on 
the social context. As such, memories and lived experiences is an important aspect of this analysis (Mannur 2009), as they factor into how people subjectively construct their own definitions of Filipino cuisine. With this in mind, I turn to the late Doreen G. Fernandez, who reminds us in her writing that Filipino cuisine cannot be articulated through "exact description, but through memory" (Fernandez 1994: xii). I argue that how Filipino cuisine is understood is shaped by the individual's social contexts and life history, which differs depending on the varying aspects of their identification, such as regional affiliation, nationality, their ethnicity, current place of residence, class status, and so on.

To better understand how Filipino cuisine entrepreneurs discursively construct Filipino cuisine, I draw from literature on Philippine culinary culture (see Cordero-Fernando 1976; Fernandez 1994, 2003; Fernandez and Alegre 1988; Fernandez and Best 2000) to help contextualize the research participant's responses by providing some background information. The data showcases that the participant's descriptions of Filipino cuisine signify three distinctive themes: first, sensations (taste, smell, sight, and touch); second, ethnic, cultural, and regional diversity; and third, authenticity.

\subsection{The Senses of Filipino Cuisine}

Participants described Filipino cuisine according to sensations such as taste, sight, smell, and touch. As an insider researcher who is familiar with Filipino cuisine, I did not feel the need to probe further for detailed explanations in their descriptions. In retrospect, perhaps probing for more details could have led to richer data. Some participants provided examples to clarify their explanations by referencing their existing menu items, while others connected their explanations to past experiences. According to Fernandez (1994: xi), it is important to consider how sensory 
experiences are interconnected with memory and nostalgia, and how that contributes to variances in descriptions of Filipino cuisine:

... food is not a matter of dipping into the thesaurus to discover the many ways to say 'tasty'. Instead it means digging deep into the human experience, because tasting, eating, and savouring are very intimate ventures. They are not external activities like shopping or travelling; they are - literally and metaphorically - gut experiences. They occur within the person, involving memory, sensation, pleasure. When one describes food, one does not use words alone... remembering as well - of past pleasures, savoured sensations... alluding to food tasted as children, drawing on their reservoirs of pleasure. In effect, one draws on all the culture that shaped oneself...

The majority of the second generation participants made references to their childhood or adolescence in their narratives. Through their accounts, they described Filipino foods as "comfort foods". Comfort foods are foods "associated with childhood or with home cooking" and are "prepared in a traditional style having a usually nostalgic or sentimental appeal" (Locher et al. 2005: 274). A nostalgic description of Filipino food is exemplified by Andrew, a second generation Laotian owner of a trendy Pan Asian fusion restaurant in Winnipeg who describes his connections with Filipino cuisine:

[Filipino cuisine is] comfort food. It just brings back so many memories and so it's very comforting. It can be very fatty, a lot of things are, I guess... a lot of greasy Filipino food... I think... yeah. Filipino food is something that can just... it just brings back so many memories and there's something so very comforting about it.

Andrew explains that although he is not Filipino, his positive interactions with others in the Filipino community have led him to associate Filipino foods as "comfort foods". In an informal conversation, Andrew reveals that the Winnipeg Filipino community plays a big role in his life: he has many Filipino friends, went to a predominantly Filipino high school, and later on, he started a family with a Filipino woman. Eating Filipino food evokes fond memories for Andrew, whose restaurant concept is Asian comfort food composed of dishes he enjoyed 
growing up. Indeed, Andrew's restaurant is a manifestation of his pleasant memories - it is a reflection of his life, his identity.

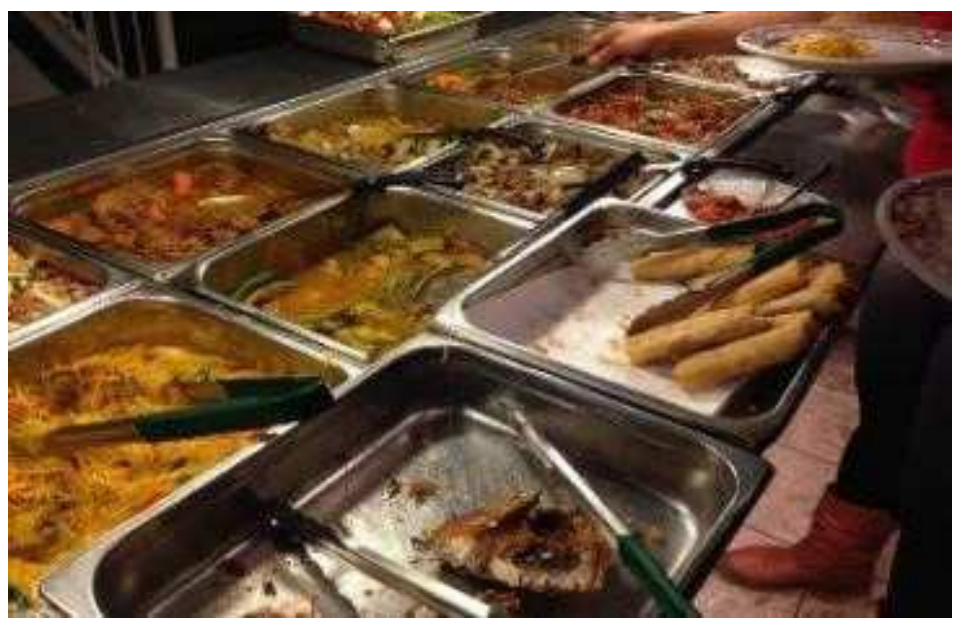

Figure 5.0: A selection of Filipino comfort foods served at a buffet restaurant. Many items on the buffet line are deep fried or have rich sauces.

Similarly, Melissa, a second generation Filipino and manager of her family's Filipino restaurant, also ascribes Filipino food with sentimentality by associating Filipino food with her parents:

... good soul Filipino food [is] usually cooked by your parents because it's cooked food. There's nothing else in it, they'll cook it, it's real Filipino food, that's what you know... I would say it's good soul food. It's very filling, yummy, saucy dishes... it's just good comfort food. Every time I don't eat it for a long time, I almost say I need it - I don't need Filipino food, but I tell myself I need it to feel whole, to feel me again. It's because I learned to love Filipino culture, and Filipino food...

The foods served at Melissa's restaurant are what she describes as cheap and filling comfort foods. Some comfort foods are also known for being foods that are rich in taste, fatty, and unhealthy (Locher et al. 2015). For Melissa, Filipino cuisine is comfort food - it is the sinful quality that makes it titillating. To remove MSG and fat from Filipino foods would be unfathomable, as Melissa believes those qualities make it quintessentially Filipino: 
Some restaurants try to make [Filipino food] healthy, but then they're taking everything away from it. Then it's not Filipino food anymore. Filipino food is greasy and they put the things that lots of people don't like, like MSG... but that's what makes it so delicious! If you take it all away, it's just bland and healthy, it's not Filipino food anymore. I don't feel like eating this.

\subsubsection{Taste}

It was challenging for participants to pinpoint the exact flavour profiles that make up Filipino cuisine - the ingredients used and how dishes are prepared can vary depending on the region in the Philippines. According to Fernandez (1994: 62), the four dominant flavours of the Philippine palate and food repertoire are "alat (salty), asim (sour), tamis (sweet), and anghang (spicy)". Filipino cuisine is also known for its contrasting flavours, as Chorillo (2014: 31) describes, "one of the distinct characteristics of Filipino cuisine is "counterpoint", which means pairing something sweet with something salty, and it results in surprisingly pleasing combinations".

The majority of participants had identified sourness as a dominant flavour profile of Filipino cuisine. The sourness that dominates Filipino cuisine is due to the widespread use of vinegar as a flavouring agent (Fernandez 1994: 64). The prominence of vinegar in Filipino cuisine is noted by second generation Chinese and Vietnamese business partners Ronnie and Devon, who are co-owners and chefs of three successful Pan Asian fusion establishments in Winnipeg:

...a lot of dishes are around vinegar or is based around vinegar and is included in a lot of dishes where I've eaten similar dishes to Filipino cuisine... The big difference is that [Filipinos] add vinegar to their dishes that another culture would not add to. So a big thing I think would be vinegar that would make Filipino cuisine stand apart from others...

A large repertoire of Filipino dishes incorporate vinegar as a primary ingredient, such as 
adobo (soy sauce and vinegar-based dish), beef tapa (jerky), kinilaw (ceviche), atchara (pickles), and various sawsawans (dipping sauces) ${ }^{15}$ (Cordero-Fernando 1976; Fernandez 1991, 1994; Barreto et al. 2013). However, vinegar is not the sole source of sourness. Tropical fruits like calamansi (calamondin), kamias (bilimbi) and sampaloc (tamarind), are abundant in the Philippines and are used as souring agents in several dishes (Fernandez 1994, 2002). The fruity sourness is most notably distinctive in the comfort food classic, sinigang, which is a soup that is usually soured by tamarind and includes indigenous vegetables and a source of protein, such as meat, poultry, and seafood (Fernandez 2002).

Sweetness was the second most cited flavour. Interestingly, when sweetness was mentioned participants had associated the flavour to meat dishes. The flavour of sweetness was mainly associated with the flavour of cured meats found in silog breakfasts. Silog breakfasts ${ }^{16}$ are commonly referred to by Winnipeg locals as the quintessential Filipino breakfast, despite the vast array of Filipino dishes that are also eaten for breakfast such as lugaw (savoury rice porridge), champorado (sweet chocolate rice porridge), and a cornucopia of sweet breads such as pan de sal (sweet bread roll), pan de coco (coconut bread roll), and ensaymada (brioche) (Cordero-Fernando 1976; Fernandez 1994). Most restaurants that I visited had an iteration of a silog on their menu. Silog appears to be especially popular among a younger demographic, as indicated by the non-Filipino participants, such as Reggie, a second generation South African manager of a popular Pan Asian fusion small business restaurant chain in Winnipeg, who describes Filipino cuisine, specifically Filipino breakfasts as sweet:

\footnotetext{
${ }^{15}$ For detailed explanations of these dishes please refer to Appendix A for a list of terms and translations.

${ }^{16}$ The etymology of a silog breakfast is derived from the name of the meat, then itlog (egg), and lastly sinangag (garlic fried rice). A beef tapa silog breakfast would be named "tapsilog", which are an amalgamation of all three components of the dish. In the same manner, a pork tocino (sweet cured meat) silog breakfast would be would be called "tocilog".
} 
All I know is "mix-mix", tapsilog... I really like it. One of my favourites is "mix-mix" I guess because it's a bunch of everything in there, it's like longanisa, tocino, egg, some vegetables and stuff... it's sweet. You know like "mix-mix", it's got the pork in there, it's sweet cured pork. It adds a lot of sweetness. Then some vinegar on top, so some tartiness...

Reggie's restaurant serves a dish inspired by silog breakfasts, which is a bowl of rice topped with sweet cured meats with vegetables and a fried egg. According to Reggie, it is the sweetness of the meats that gives the dish its distinctive Filipino taste. Reggie's restaurant is not the only one to incorporate a rice bowl inspired by silog breakfasts. Other Pan Asian restaurants in Winnipeg also serve similar dishes.

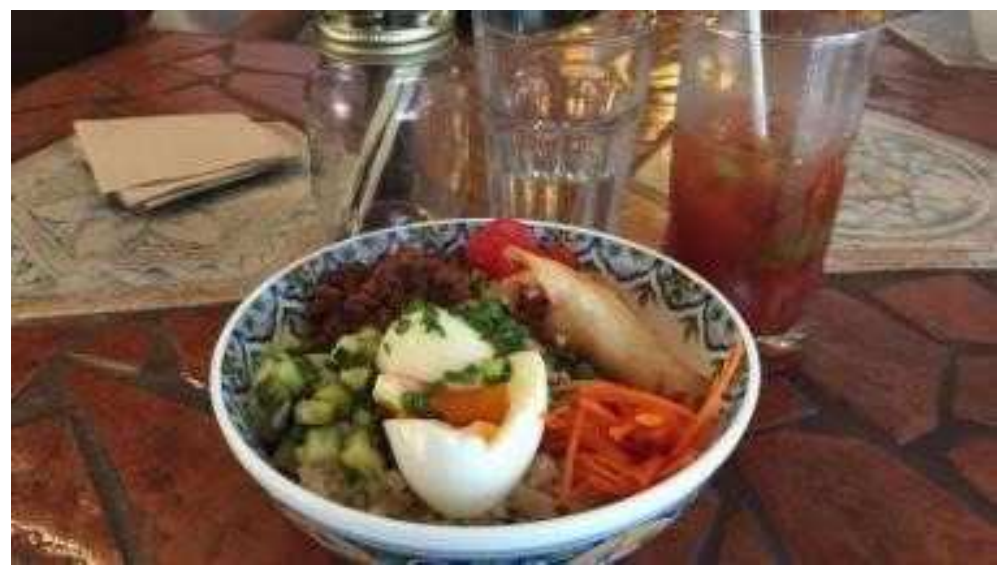

Figure 5.1: A photograph obtained from a Winnipeg Pan Asian restaurant's social media page featuring a rice bowl inspired by Filipino silog breakfasts. This version has longanisa, a Filipino sweet cured sausage, vegetables, a softboiled egg, and an egg roll.

The popularity of silogs in Winnipeg may indicate that silogs are "gateway foods" that introduce non-Filipinos to Filipino cuisine. During my visit to the most renowned "traditional" tapsilogan in Winnipeg's West End, there were many non-Filipinos eating a silog meal, including a white police officer who was noted to be a regular customer. Meanwhile, in Ottawa,

\footnotetext{
17 "Mix-mix" is not a recognized Filipino dish. It is a menu item that is specific to one Filipino eatery in Winnipeg that specializes in Filipino silog breakfasts. It is made up of all the cured meats commonly found in Filipino -silog breakfasts such as tocino, longanisa, and tapa.
} 
only three restaurants in the entire city served silog. Even though it is the same dish, Ottawa silog differs significantly from Winnipeg's. For instance, in Ottawa silogs were prepared with more expensive cuts of meat; while in Winnipeg the average silog costs $\$ 5$ to $\$ 10$ at most Filipino restaurants, and in trendier Pan Asian restaurants, they can cost upwards to $\$ 15$. In Ottawa, silogs were only sold at the "modern" Filipino restaurants and were similarly priced to those served in Pan Asian restaurants in Winnipeg. Perhaps the price is the reason why silogs are not as widely recognized in Ottawa as in Winnipeg - as popular ethnic foods, such as pho, doner kebabs, samosas, and Chinese takeaway plates tend to be cheaper in price and which make them accessible to lower-income people (Warde 2000).
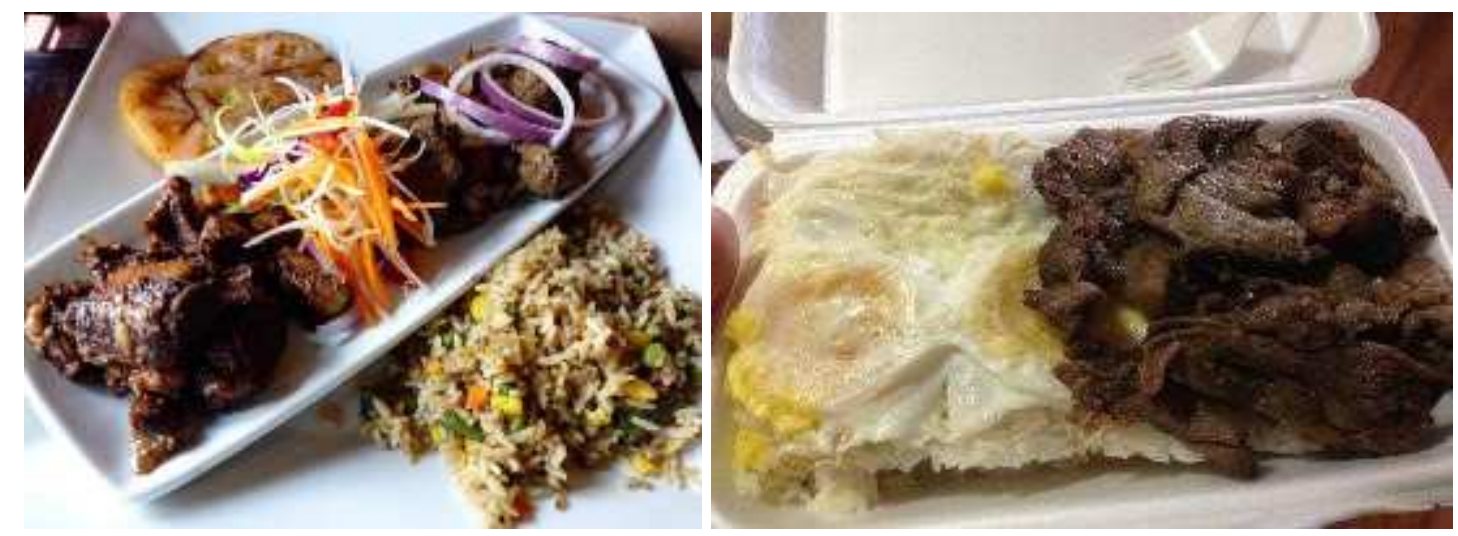

Figure 5.2 (a)(b): Examples of silog breakfasts. (Figure 5.2a, Ottawa; Figure 5.2b, Winnipeg)

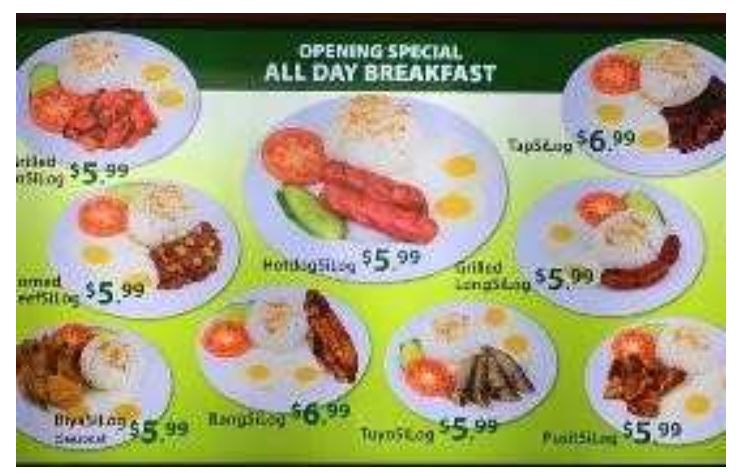

Figure 5.3: A silog breakfast selection on a menu at a carinderia. 
It is striking that desserts were not mentioned in the interviews even though sweets were readily found at every single Filipino cuisine establishment encountered. What's more, Filipino cuisine entrepreneurs who owned bakeries did not even mention sweetness with relation to desserts. It would be understandable if Filipino cuisine was lacking in sweets, but on the contrary, Filipino cuisine has plethora of desserts due to the abundance of sugar canes in the Philippines (Fernandez 1994: 70). During the Spanish occupation more sweets were introduced such as breads, milk-based desserts such as leche flan (similar to the French crème caramel), candies, and pastries (Cordero-Fernando 1976; Fernandez 1993, 1994). I postulate that this gap is perhaps because sweets are not understood as foods or dishes in the same manner that other foods are. While sweets are prominent in Western culinary culture, sweetness is "charged with ambivalence" (Beardsworth and Keil 2002: 253). Sweetness is most commonly associated with desserts, which in the Western meal structure, is not the main event and is eaten at the very end of the meal (Douglas 2000; Beardsworth and Keil 2002). In the Philippines, most indigenous desserts are regarded as ceremonial foods reserved for special occasions (Cordero-Fernando 1976; Fernandez 1993, 1994).

Saltiness was the third flavour participants associated with Filipino cuisine. The widespread use of salt in Filipino dishes is noted as a survival strategy (Fernandez and Alegre 1990; Fernandez 1994). In the Philippines, salt was used to preserve foods as they were prone to spoiling due to the harsh tropic climate. The majority of these preserved foods were acquired from the sea, such as fish, shrimp, and squid (Fernandez 1994). These preserved foods were either eaten themselves along with rice, turned into fermented foods such as burro (fermented rice with fish) or various types of dried and salted seafood such as tuyo, daing, bangus and pusit 
(squid) or were made into condiments such as bagoong (fermented shrimp paste) and patis (fish sauce) (Fernandez 1994; Barreto et al. 2013). Patis in particular holds a special significance for Filipinos, who use patis as a way of taming the flavours of foreign dishes through "indigenizing", a process that makes the unfamiliar taste familiar (Fernandez 1994: 63). In some Filipino cuisine establishments, most notably the turo-turos and carinderias, a bottle of patis is found on every table alongside salt, pepper, and hot sauce.

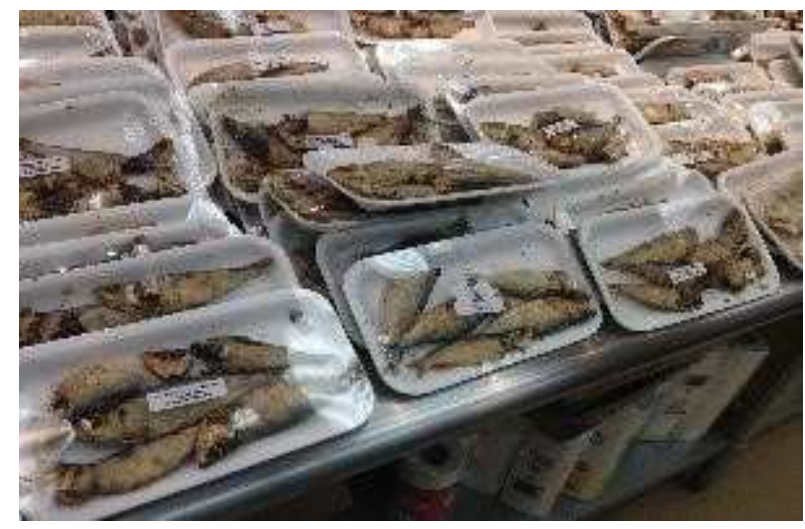

Figure 5.4: A selection of salt-preserved fish at a Filipino sari-sari store and turo-turo hybrid.

\subsubsection{Smell}

Participants have suggested that Filipino cuisine has a distinctive aroma. Vincent, a second generation Filipino chef and a participant of Baon Manila Nights, makes connections to scent as he describes the first time he participated in a Baon Manila Nights pop-up dinner. He recalls that the venue smelled like Filipino food, which he thought contributed to the Filipinothemed atmosphere the pop-up dinners were trying to accomplish:

... and all the chefs were Filipino, you could just smell the Filipino food. When I walked in, I was like, "I guess this could work too!" I mean we don't try to push it too much because people will know it's gonna be Filipino food. But we do try to as best as we can give the atmosphere but not pushing that it's Filipino food in your face. 
In Vincent's account, the presence of other Filipino chefs and the lingering smell of Filipino foods was enough to convey Filipino-ness in the pop-up dinners. However, what exactly is Vincent referring to, when he refers to a "Filipino smell?" Perhaps it is the acidic aroma of some Filipino dishes, which use abundant quantities of vinegars and tropical fruits. For Phillip, when he thinks of scents, he imagines adobo, a dish that uses soy sauce, vinegar, garlic, and bay leaves as its primary ingredients:

A typical [dish] is adobo, it's something that permeates in the house if it's been simmering for a while. Soy sauce, vinegar... then it's aromatic because of the garlic and the bay leaves.

Like adobo, there are Filipino dishes known for having garlic as an aromatic. The silogs are known for the garlic scent, as garlic is the primary ingredient in the sinangag (garlic fried rice) (Fernandez 1994: 19). Moreover, garlic is also used in other popular Filipino dishes such as pancit, lugaw, and atchara, and in many sawsawans (Cordero-Fernando 1976).

There was one dish was not particularly favourable among participants due to its smell, which is tuyo (dried fermented fish). Tuyo is commonly eaten for breakfast and is especially popular among first generation Filipinos (Mabalon 2013). This was evident when I visited some turo-turos and carinderias, where the faint odour of tuyo lingered in the air. I noticed that many older Filipinos were eating it with gusto. Elsa, a first generation Filipino and co-owner of a Filipino bakery in Winnipeg, recalls a time when her a-la-carte restaurant was still in business, she would often encounter comments being made by non-Filipinos, "the tuyo, they say... why do you eat stinky food?" Despite the criticism, they continued to serve tuyo anyway, because it is a key staple for many Filipinos during breakfast time. Dishes like tuyo mark Filipino cuisine as "exotic" which indicates that Filipino foods are socially distant from Canadian culture (Johnston and Baumann 2010: 107). By calling to Filipino foods as smelly, it requires "some reference to a 
norm that it is not" (Oum 2005: 110). A deeper examination reveals an Orientalist logic, with the implication that Canadians are "clean, pleasant, civilized, hygienic, good, and normal", signifying that Canadian identity is the normative culture (ibid.).

\subsubsection{Sight}

When participants described the visual appearance of Filipino cuisine, it is rather telling that not one person referred to Filipino foods as aesthetically pleasing. An overwhelming number of participants had described Filipino cuisine as ugly and visually unappealing. The more "traditional" dishes tend to use ingredients that are uncommon to the Canadian culinary repertoire. For instance, dishes made with organs are not visually pleasing, and they do not conform to the norms of Canadian culinary culture (Zappia 2015). Melissa insists that dishes like dinuguan (a stew made of pork blood and internal organs), does not entice people to want to try it because of its outward appearance:

... It's just sometimes when you look at it - like if you look at dinuguan, it doesn't look appealing at all. You're more like, "ugh". The way it looks, I don't know. It's made of blood. It's probably one of the most unattractive thing to hear, so they don't like it, and a lot of people won't try it... It's not something that most people will eat. It's not. Fifty percent - a lot of people won't touch that unless they tried it somewhere else, then they'll be open to trying it. But if... it's just, it's not appealing. It depends on the looks.

Since the main patrons of Melissa's restaurant are older generation Filipinos who prioritize substance over form, the aesthetic component is not too important in her case. In Bourdieusian terms, the preference for "substance over form" points to a class distinction, signifying lower-class tastes (Bourdieu 1984). It has been suggested that the propensity for "quantity over quality" among older generation Filipinos is because many Filipinos in the Philippines live in poverty (Fernandez 1994; Chen 1997), and therefore food consumption is understood as means for survival rather than a leisure activity or an aesthetic or sensual 
experience. As such, this demographic tends to patronize restaurants which offer good value for money - much like Melissa's buffet. Moreover, the rampant poverty in the Philippines is also the reason why many indigenous Philippine dishes tend to incorporate organ meats - every part of the animal is used rather than discarded (Cordero-Fernando 1976; Fernandez 1994). As Charlie elucidates, poverty in the Philippines has led to a culture of resourcefulness which has profoundly influenced Filipino cuisine:

[Filipino food] is good because they utilize... it revolves around local products like rice, fish and local vegetation in the Philippines... [the Philippines] is not a rich country so people learn how to utilize different parts of plants or the animal... we use the tongue, eyeball, or lungs. So many different things that people would normally discard. People normally use banana leaves to wrap like suman (sweet glutinous rice dumpling). Or banana leaves to lay for kamayans. We do things to utilize every part of everything. That's what I love about Filipino food.

In Melissa's case, even though she does not like dinuguan, it is still served at her buffet restaurant because it is a popular dish among older generation Filipinos. Like Melissa, Ellie does not have a favourable opinion towards dinuguan, and identifies it as a dish that would not make a first good impression because of its colour scheme:

...when you present a food it has to... the first thing you should do is feed the eyes. You know what I mean? Then you see the dinuguan, which is black.

Participants have pointed out that a number of Filipino dishes have one-note colour schemes, with brown and beige being the dominant colours. The lack of vibrant and diverse colours puts Filipino cuisine at odds with norms of the Canadian "gourmet foodscape" (Johnston and Baumann 2010), which emphasizes aesthetics as an important component in a dining experience. 


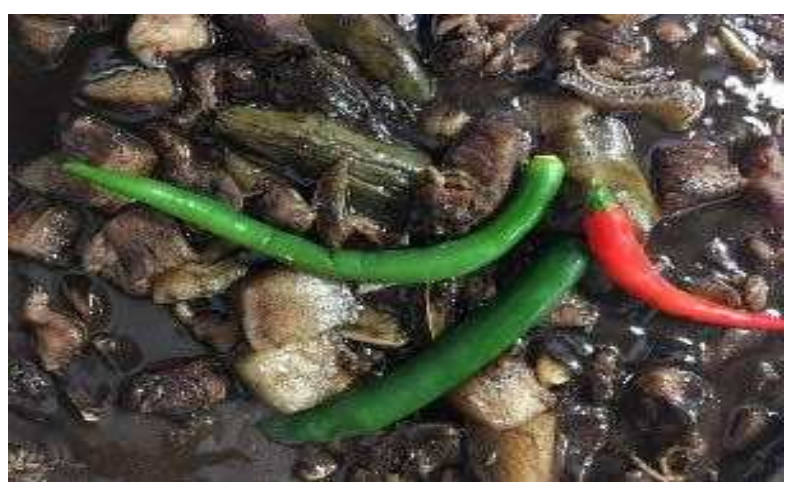

Figure 5.5: Dinuguan in a warming tray at a turo-turo restaurant.

The lack of bright colours from vegetables can be attributed to many prominent Filipino dishes as predominantly meat-based, as Roddy suggests:

Filipino cuisine as a whole... I truly believe there isn't a lot of options for vegetarian pure vegetarian dishes, [and] pure vegan dishes? I would say pretty close to impossible..."

At several Filipino cuisine establishments, many dishes found on menus were made with meat as the main component with hardly any vegetarian options. If there were vegetables, it was either a side-dish, garnish, or was prepared alongside meat rendering it unsuitable for vegetarian eaters. Interestingly, the dominance of meat does not seem to be a typical characteristic of indigenous Philippine cuisine according to Philippine culinary historians, rather, many indigenous dishes draw heavily from local vegetation (Cordero-Fernando 1976; Fernandez and Alegre 1990; Fernandez 1988, 1994). The widespread consumption of meat is said to have been encouraged by the Spanish and American colonizers (Fernandez 1994).

\subsubsection{Touch}

The aspect of touch was not directly referred to in the interviews and its significance was only implied by some participants. The novelty of eating foods with one's hands is relatively popular in Charlie's kamayan dinners: 
Now to introduce [kamayan] to Canadians, right? What a kamayan is, just to say it properly, right? It's a form of dining where you eat with your hands, right? [They say], "So now, what is that, it's cool! Wow!"

Kamayan refers to a traditional eating practice in the Philippines, an act in which people eat their meals family-style on a banana leaf by using their hands as a utensil (Cordero-Fernando 1976). Filipino restaurants in the West often serve kamayan meals with a lavish amount of food sprawled on a long table adorned with banana leaves. Although kamayan is socially distant from Canadian culinary norms, it is regarded positively because it is a new and fun way to eat foods. It provides diners with a novel cultural dining experience, bestowing eaters with satisfaction of curiosity and even cultural capital (Johnston and Baumann 2010). Recent media coverage which features Filipino cuisine has mostly featured kamayan dinners, which tend to include vibrant pictures of elaborate spreads of food (Cabral 2016; Larsen 2016). I stipulate that kamayan dinners are relatively popular in contemporary times because of its visual aesthetics - the latter is considered to be desirable in an era where it is commonplace to take stylized photographs of food and posted on social media.

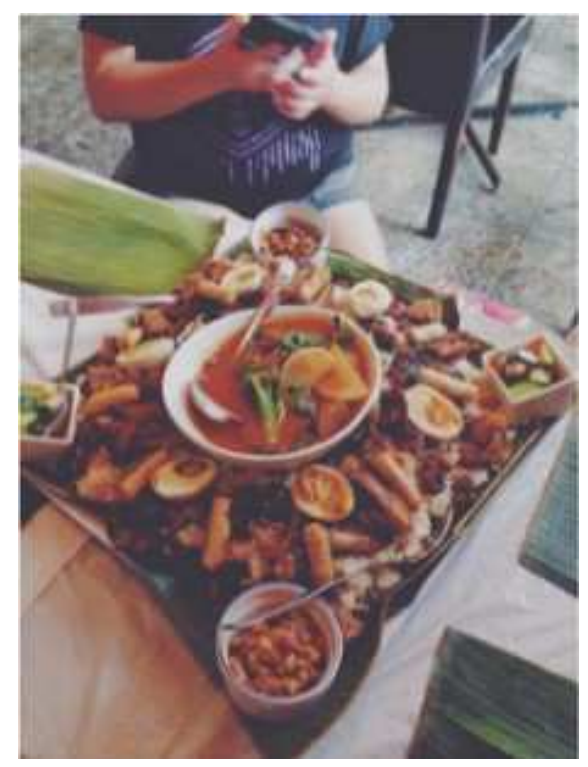

Figure 5.6. A small kamayan shared with my family. Note the abundance of food, banana leaves, lack of utensils, and a person taking a photograph of the spread for social media. 
Touch is also articulated as mouth-feel. As Vincent mentions, the aspect of mouth-feel is an important factor to one's dining experience. He describes Filipino cuisine as having a lot of "unappetizing textures", which he attributes to Filipino cuisine's widespread use of organ meats, many of which are rubbery and slimy in texture (Zappia 2015). These textures may be offputting to those who are not used to it, as Ellie recalls when she used to incorporate tripe in karekare, a peanut-based stew traditionally made with oxtail and honeycomb beef tripe:

The tripe in the kare-kare... here, I can see the tripe coming back! So they're not into that yet, so I removed the tripe... I think they don't like the texture.

Ellie noticed that her customers (Filipinos and non-Filipinos) removed the tripe from the kare-kare because they find the textures unappetizing. To hear that Filipinos removed the tripe from the dish was something that surprised me, as in Winnipeg, I did not hear such comments. In fact, some Winnipeg participants had identified kare-kare as a popular dish across the board. For instance, Elsa noted that at her previous restaurant, the white clientele loved kare-kare which she prepared with beef tripe and ox-tail because it resembled beef stew.

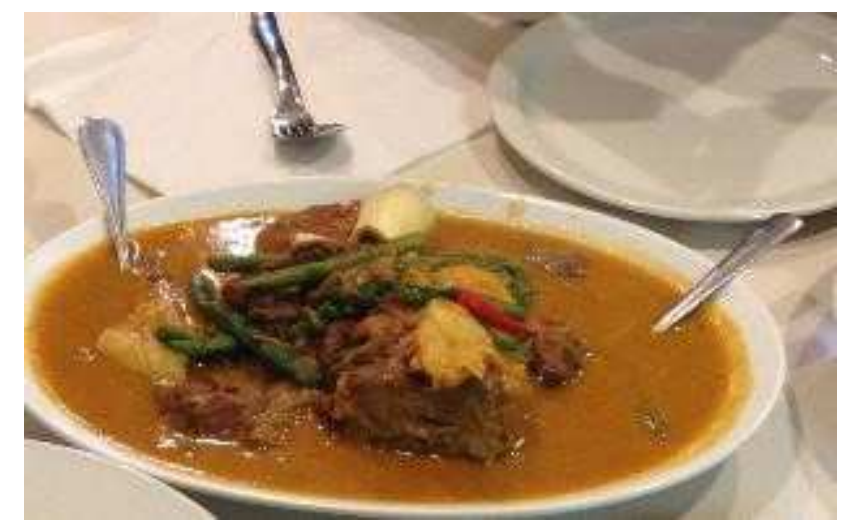

Figure 5.7: Kare-kare served at a Filipino a-la-carte restaurant. This version has oxtail and honeycomb tripe.

Most restaurants in Winnipeg served kare-kare either as made-to-order or was offered as a regular item for take-out. In contrast, the Ottawa establishments (with the exception of Ellie's 
restaurant), did not offer kare-kare as a staple menu item - it was only served on the weekends, which may indicate that it is not popular enough to be offered every single day. Thus, the difference between Winnipeg and Ottawa's accounts is a reminder to take into consideration how the participant's geographical and social context factors in their descriptions of Filipino cuisine.

\subsection{The Cultural and Regional Diversity of Filipino Cuisine}

Participants generally framed Filipino cuisine as a diverse cuisine, which is expressed not only through its many cultural influences, but also through the array of regional differences in cooking styles and dishes across the Philippines.

\subsubsection{Cultural impact}

According to Fernandez (1988: 219), the key to understanding Philippine food is through examining how the process of indigenization has "brought in, adapted, and then subsumed foreign influences into the culture." A recurring idea that emerged in the interviews is the notion that Filipino cuisine is a conglomeration of different culture's cuisines, making Filipino cuisine a type of fusion cuisine:

I'd describe it as a mixture of different cultures. In a way, we are fusion food. Like our food is a fusion food from Chinese, Spanish, Malay... first of all, as the basis. (Vincent)

[Filipino cuisine] is a melee of Japanese, Spanish, Chinese of course, and surrounding kind of Asian countries. As you know a lot of everything to do with Filipino is Spanishinspired, so a lot of cuisine is also Spanish-inspired. But like I said there's hints of different kinds of cultures... (Roddy)

Both the interviews and the literature describe Philippine cuisine as having derived influence from a number of different countries such as Spain, the United States, and Japan (through colonial occupation); Malaysia, Indonesia, China, and India (through trade routes); and 
more recently, the rest of the world, especially in countries where Filipinos work abroad, such as countries in the Middle East, Singapore, and Canada (globalization) (Fernandez 1988: 219).

The history of colonization in the Philippines was referenced the most in terms of the cultural diversity in Filipino cuisine. Participants were able to associate colonization's impact in terms of ingredients, such as tomatoes brought to the Philippines by the Spanish:

As you know, the Philippines has been under the Spanish rule for 300 years. Our food has been influenced by them. That's why we have a lot of tomato sauce in our menus, tomato sauce base - afritada, menudo, mechado... it's all tomato based recipes which has been influenced by the Spaniards. (Ellie)

On the other end, the history of trade routes between the Philippines and neighbouring countries was not directly identified and only alluded to in the interviews by description or by briefly describing Filipino cuisine as a mixture of Malaysian and Chinese due to the geographical proximity of Malaysia and China's to the Philippines.

Lastly, the effects of globalization was implied in two aspects: the first refers to the contemporary labour processes among Filipinos, specifically, the ways in which Filipino migrants are able to adapt to their new country of residence, as John mentions:

...we have the Middle East... oh... we have everything in there. Then they open up a business, and then the Filipino food is influenced by other cultures.

John's account refers to several processes that influence Filipino cuisine. First, the historical process, referring to the history of trading between the Middle East and the Philippines. Prior to the arrival of the Spanish, the dominant organized religion was Islam (David 2013; Ang 2016). The Islamic and Middle Eastern influence is noticeable in Southern Philippine cuisine in the Sulu region in the province of Mindanao. Second, he refers to the political and economic processes that influence Filipino cuisine. The Middle East is one of the top regions that employ Filipino migrant workers. This can be linked to the legacy of American imperialism in the 1970s 
during the Marcos regime, which gave rise to the labour export policy. Due to the corruption and political instability of the Philippine government, Filipinos search for labour prospects abroad because they cannot find work in their own country (San Juan 2002; Aguila 2014). The effects of globalization and transnationalism has given rise to hybridized Filipino cuisine that goes beyond the standard canon of Chinese, Malay, American, and Spanish influences.

Hybridization is the process of mixing different cultures, people, and ideas (Bhaba 1994), and is a key characteristic that makes Filipino cuisine "unique". Participants like Joseph, a first generation Filipino and owner of several businesses, imagines Filipino cuisine as a hybrid cuisine rather than something that is narrowly defined. Here, he describes Filipino cuisine as neither "Filipino" nor "Asian", rather, it is "international":

...Filipino cuisine is quite different since we have so many influences inspired by different cultures and different types of cuisines from West to East. So I would say Filipino cuisine is more of an international taste rather than a particular taste or a Filipino taste, or an Asian taste. It's more international than being Asian or being a Filipino.

Joseph's explication of Filipino cuisine is markedly different from other's descriptions. At first his definition was puzzling because he described Filipino cuisine as neither Asian nor Filipino. A closer analysis of his description signifies that his understanding of Filipino cuisine speaks to how globalization has changed Filipino cuisine in contemporary times. Filipino cuisine cannot be conceived of as only strictly being "from the Philippines"-it is transnational. Through migration, Filipino cuisine is in constant flux, making it international. Joseph has situated Filipino cuisine in the "third space" (Bhaba 1994, 1996) by disrupting colonial binary thinking and oppositional position of Filipino cuisine and bringing it into a realm of new possibilities. 


\subsubsection{Regionality}

The peculiarities of regional Filipino cuisine cannot be understood without taking history and geography into consideration. In some areas of the Philippines the cultural influence of some countries may be more prominent in one region than in another. In coastal regions, the Chinese influence in foods is more evident because of the long history of trading in China and the Philippines (Bullinger, Seitz and Volz 2012; Fernandez 1994). Foods like siopao (meat bun), siomai (pork dumpling), pancit (stirfried noodles), and lugaw (congee, rice porridge) are examples of Chinese foods that have become adapted and indigenized to become uniquely Filipino foods (De Leon 2016; Cordero-Fernando 1976; Fernandez 1988, 1994). In the Southern province of Mindanao, where there is a higher Muslim population, pork is not as ubiquitous as in the North. Foods in the South are also seasoned and spiced differently with more emphasis on heat. This has been attributed to the religious influence as well as the South's geographic proximity to neighbouring Islamic countries such as Malaysia and Indonesia (Bullinger, Seitz and Volz 2012; Cordero-Fernando 1976; Fernandez 1994; Barretto et al. 2013).

In addition to cultural differences, the variety of different foods and cooking styles can also be attributed to the differences in ingredients found across the archipelago. Participants like Matthew are aware of these differences. He explains that Filipino foods are going to look and taste different depending on the region:

It depends on what kind of province you're talking about. If you're talking about cuisine from the North areas, it's going to be more spices (herbal). If you go on the Central area, it's going to be more coconut. And if you go to Mindanao area, which is far far belowbecause it's near Indonesia and Malaysia, so it's more spicy. If you're familiar with jalapeno peppers, that is nothing for the Mindanao people. 
The regional differences in Filipino cuisine is what makes it unique, according to John, which is why identifying a specific flavour profile that represents the tastes of Filipinos is difficult:

Filipino cuisine is one of the best. The reason why I say that is because we're influenced by different cultures in the Philippines. Because we're like - we're like a euphoria of different flavours and Filipinos have very very strong flavours. Because we have [flavours] in different regions - we have Pampanga, sweet. Bicol, spicy.

It is interesting to consider the earlier comments of Filipino cuisine tasting "sweet" while at the same time there is little reference to spiciness unless it's referring to a regional particularity. The sweet flavour profile is characteristic of the Tagalog region which is located in Southern Luzon - where the majority of Metro Manila is situated (Fernandez 1994). Those who identified Filipino cuisine as "sweet" were mostly from the Winnipeg demographic. Perhaps one could speculate that portion of the Filipino diaspora in Winnipeg is from the North, specifically the Metro Manila region because of the responses in the interview data, but also because there were many sweet dishes (not desserts) in several menus in Filipino cuisine establishments although there is no evidence to support this.

In contrast, participants in Ottawa did not readily identify sweetness as a characteristic flavour profile of Filipino cuisine. When I asked Ilan, a first generation Filipino and manager of a Filipino bakery and sari-sari store in Ottawa, to describe which dishes sold out the most in his store, he refers to the Ilocano dish papaitan:

... that's Ilocano, yes. Because the owner [of the store] is Ilocano and they taught our cooks to cook some Filipino Ilocano dishes, like the papaitan.

At the time, Ilan's response caught me off guard - it surprised me to hear that people in Ottawa actually enjoyed papaitan, a soup made of offal (traditionally made with goat, but more commonly with beef), which is seasoned with onions, garlic, ginger, and lastly, the core 
ingredient, goat bile, which is the source of the characteristic pait (bitterness) of the dish (Fernandez 1994; Barretto et al. 2013). Especially after hearing participants in Winnipeg previously describing it as unpalatable surprised me. Upon closer reflection I realised that it made sense, as Ilan had anecdotally divulged through an informal conversation that Ottawa has a large population of Ilocano people. I also noticed that Filipino cuisine establishments in Ottawa tend to serve Ilocano dishes on their menus such as goat caldareta or papaitan (Fernandez 1994). I had hoped to corroborate Ilan's account with Canadian census data. Unfortunately due to limitations in the existing data it is unknown as to how many ethnic Ilocano there are in Ottawa, as there is no category for "Ilocano" in terms of ethnicity. In the Canadian census, Filipinosregardless of their regional allegiances, are all grouped under the same categorization. While there is an "Ilocano" category under "languages spoken at home" (Statistics Canada 2013b) that refers to the "mother tongue" only. This categorization does not take into account that even ethnic Ilocanos more likely to speak Tagalog than Ilocano, because Tagalog is recognized as the dominant language in the Philippines. Tagalog is also widely spoken in major metropolitan areas as fluency in Tagalog is necessary in order to be competitive in the Philippine labour market (Llamzon 1968).

In Winnipeg, the Filipino-identified participants cited papaitan as an unpopular dish and added that most people would not want to eat because of the bitterness and what it is made of. That is not to say that Winnipeg does not cater to Ilocano tastes as there is at least one restaurant that solely specializes in Ilocano cuisine. It is rather telling that compared to the interviews in Ottawa, which seemed to suggest that papaitan was relatively popular among members of the Filipino community, in Winnipeg papaitan was an "unpopular Filipino food". Allan also 
speculates that Ilocano dishes like papaitan are not so common in Winnipeg's restaurant scene because:

...there's not enough demand for Ilocano - or maybe there is, I don't know. Will an Ilocano restaurant solely survive off of Ilocano people? Probably not - until [Filipino cuisine] gets to the mainstream, probably not.

Allan's observation suggests that the geographical context must be taken into consideration when analysing the cultural politics of Filipino cuisine. As implied in Ilan's account, Ottawa's Filipino population appears to have a penchant for Ilocano foods, which may be connected to the number of Ilocano people in the city. Another indicator that seems to suggest the prominence of Ilocanos in Ottawa is the recent opening of a Filipino fusion restaurant in Ottawa's Barrhaven neighbourhood (which appears to cater to a non-Filipino demographic). The restaurant advertises itself as a melange of Filipino, European, and Canadian tastes. There are few non-fused Filipino dishes listed on the menu—-though those that are listed are clearly Ilocano foods, such as dinakdakan - a dish made of pork belly and pork ears in a creamy sauce made of ginger and pig's brains. It bears some resemblance to sisig with common ingredients (i.e., pork belly and pork ears), yet the flavour profiles are so distinct that it can only be considered a distant relative at best. To my knowledge, there is no dish exactly like dinakdakan in other regions of the Philippines (Rogando 2015). Unfortunately, I was not able to interview the owner of this establishment to ask him more about why he included dinakdakan as a menu item, nor could I ask him if he is of Ilocano descent. I speculate that the inclusion of such an uncommon dish seems to indicate that there is an Ilocano population in Ottawa that creates a demand for Ilocano delicacies. In Winnipeg, with the exception of the one Ilocano restaurant, I have not seen this dish offered in standard menus - they were however offered at some restaurants that had specialty catering menus. 


\subsection{Authentic Filipino Cuisine}

Lastly, participants had expressed the concept of an "authentic" Filipino cuisine, which is explained as distinct from "modern" and "fusion" Filipino cuisine. Authentic Filipino foods are often framed as "traditional foods". According to Guerrero et al. (2009), a traditional food can be defined as a food "frequently consumed or associated with specific celebrations and/or seasons, normally transmitted from one generation to another, made accurately in a specific way according to the gastronomic heritage, with little or no process/manipulation, distinguished and known because of its sensory properties and associated with a certain local area, region or country" (Guerrero 2009: 348). To ascribe authenticity to foods has been deemed to be problematic (Gvion and Trostler 2008; Janer 2007; Appadurai 1988), and scholars have disputed the validity of ascribing authenticity to food and cuisine (Fernandez 1988; Lu and Fine 1995; Ku 2014; Kim 2015), when considering that all foods and cuisines have, at some point in history, always been a product of fusion and hybridization.

To avoid making essentialist claims about a true and "authentic" ethnic cuisine, perhaps it is not useful to think about authenticity in terms of ethnicity and culture (Heldke 2005; Kim 2015; Ku 2014; Lu and Fine 1995). Instead it may be worthwhile to think about authenticity in terms of other dimensions. Drawing from Johnston and Baumann's (2010) framework of culinary authenticity, which identifies other dimensions to authenticity such as geographic specificity, simplicity, personal connection, history and tradition, and ethnic connection (Johnston and Baumann 2010: 74-92), I explain how participants ascribe authenticity to Filipino cuisine. 


\subsubsection{Geographic specificity}

Geographic specificity refers how authentic foods are associated with geographic location (Johnston and Baumann 2010: 74). It can be imagined as "the geographic scale of continents" (i.e., Asian cuisine) or in terms of a national cuisine (i.e.: Philippine cuisine), or in terms of regionality (i.e., Mindanao cuisine). For some, the aspect of geographic specificity is what makes a food "authentic". For instance, John and Roland insist that "authentic" Filipino foods do not exist in Canada because:

John: You don't have authentic ingredients. If you say you're authentic, I won't believe you. But say you have the stuff, it's from the Philippines and you grew it in your back yard... then... but here? No. That's why I don't put authentic or "real" or anything like that. Because you're in Canada, how could you be authentic in Canada and serve Asian food?

Roland: ....and, when you say authentic, there's certain stuff with how it's made back home, and you can't get those ingredients here. How could you say authentic when you don't have the ingredients?

For John and Roland, the notion that there is such a thing as authentic Filipino cuisine in Canada is inconceivable. For them it is the ingredients, many of which can only be found in the Philippines, is what makes Filipino foods authentic. A simple solution to this dilemma would be to import these ingredients to Canada, however it is not as straightforward it seems, as Matthew explains:

It's different when you get products from the Philippines itself, so now we try to see the similarities, but in the end it's a different quality, so it's a totally different product. I can give you an example, you can ask your mom, if she tried the liver spread [brand] in the Philippines, Reno... it is used in caldareta, just for the sauce, or in mechado. But if you buy it here, and it's from the Philippines, [even] if it says export quality or import quality, it's still gonna be different.

Even though ingredients can be imported directly from the Philippines, it does not necessarily mean that the taste or quality is going to be the same. 


\subsubsection{Simplicity}

The second dimension of authenticity is simplicity, which conveys notions of "honesty and effortlessness", a trait that is associated with "individual sincerity" (Johnston and Baumann 2010: 76) and remaining "true to oneself" (Lu and Fine 1995: 539). Authentic foods that are premised on simplicity are detached from the conditions of modernity and industrial capitalism. Examples of simple foods by this definition are farmer's markets, fresh and unprocessed foods, and handmade, artisanal goods (Johnston and Baumann 2010: 76). According to Matthew, an essential characteristic of authentic Filipino food is that it must be detached as much as possible from industrial mass production. He explains that simplicity is the selling point of their turo-turo restaurant:

... ours is mostly cooking in the house... the way how we do it here is no shortcuts. You start from scratch. Like we always say in our advertisement, lutong bahay (home cooking)... we don't want to twist or do fusion or whatever... No shortcuts. Being traditional [is important] because lots of restaurants here in Winnipeg, they're trying to do all these ways to try and save money. But for us, it's the customer first. If the customer says the food is yucky, then we'll accept it in order for us to improve. But in reality, we like to eat too, so we know the difference [in quality].

Matthew's insights speak to the neoliberal capitalist system which he perceives as detrimental to the production of quality Filipino cuisine. The desire to accumulate profit and prevent losses may entice other Filipino cuisine entrepreneurs to take shortcuts in their food production. Traditional Filipino recipes are notorious for being time consuming, so people who are pressed for time may defer to using prepackaged seasonings or sauces rather than simmering foods on a stove for hours (Fernandez 1994). 


\subsubsection{Personal Connection}

The third dimension of authenticity refers to personal connection, which according to Johnston and Baumann (2010: 85), speaks to the "connection between an identifiable producer and a cultural artifact as an essential part of cultural experiences". This connection can be expressed through nostalgia and memory, by relating food with one's life experiences, as John describes his approach of making "traditional" Filipino cuisine:

... I try to go as close as I can with what I've learned growing up, and what I remember what I smell, I taste... it kind of reminds me of my childhood. And that's what I try to show in our food.

The personal connection with food and childhood experiences is something that Ryan, a second generation Filipino and owner of a small take-out restaurant in Winnipeg's North End, attributes to why his business is successful among members of the Filipino community:

You know, because we've been here over a year, I'd say tradition [is important] because it's something that people will come back to. It's a staple where you... there's this girl who was just here, who linked the food back to her childhood, saying she remembered having something like it in the Philippines.

\subsubsection{History and Tradition}

The fourth dimension of authenticity is history and tradition. Tradition is often interconnected with imagery of the "homeland". The homeland is understood to be a representation of "where place and memory, location and history intersect and are inextricably intertwined" (Reisenleitner 2001). Foods that are framed as authentic and connected to a specific historical tradition are commonly but "exclusively linked to an ethno-cultural tradition" (Johnston and Baumann 2010: 88). An example of this would be preferring to make foods according to how it has been eaten or prepared traditionally in a specific cultural context. 
Participants like Matthew believe that foods can only be considered "authentically Filipino" if it is prepared the way it is traditionally - prepared "low and slow" rather than the Canadian way, which relies on "shortcuts":

I mean... I can consider Filipino way of cooking is like taking time more in the kitchen, okay? It's not the way Canadians or Americans do the cooking, because if you go with the Filipino food you don't use microwave or you don't use the oven.

Prior the American occupation in the Philippines, microwaves and ovens were not considered to be a kitchen staple (Cordero-Fernando 1976; Orquiza 2013; Bullinger, Seitz and Volz 2013). Indigenous cooking methods were done over an open flame either grilled or roasted, or were boiled in clay pots known as palayok (Cordero-Fernando 1976; Fernandez 1994;

Fernandez and Best 2000). During my visit at Matthew's turo-turo restaurant, I noticed that there were deep fryers and refrigeration units, both of which are not historically part of the indigenous Philippine kitchen. Interestingly, he does not associate those technologies with the supposed bastardization of Filipino cuisine, unlike microwaves and ovens.

Like Matthew, the process of cooking Filipino foods "low and slow" is also what Roddy associates with traditional Filipino cuisine:

They're there to cook something dishes, to cook a lot of it - a lot of it is cooked in mass quantities because essentially the tradition they have being like the stewed low and slow dishes were made because we wanted to stretch out the amount of days to have this dish. A lot of times when you're gonna make a batch of sinigang for example, that batch of sinigang at home will essentially be good for ulam $^{18}$ the next day as well.

By comparing Roddy and Matthew's insights on the preparation time of traditional

Filipino foods, an interesting distinction becomes apparent. While Matthew's account refers to tradition as a moment of time that is typified by "pre-modernity", an era where foods were made

\footnotetext{
18 "Ulam" is a term in Tagalog to describe foods that are eaten alongside or on top of rice (Fernandez 1994). In the Western sense, the concept of ulam is similar to what would be referred to as the main course.
} 
without the conveniences of modernity (Kim 2015; Fernandez 1994). While Roddy's account suggests that preparing traditional Filipino foods is time consuming due to the conditions brought upon by modernity. Under capitalism, some people may find it necessary to make large batches of food in advance to compensate for the lack of time needed to make meals for their families (Fernandez 1994). Matthew and Roddy's differing narratives indicate is that it is important to avoid thinking of authenticity as bound to history and tradition, as cuisines change in its "taste, ingredients, forms, and cooking process with time and place as all of these dimensions are constantly being reinvented and redefined" (Kim 2015: 3). Remaining true to tradition does not signify an aversion to change, as Fernandez (1994: 48) reminds us, "Food, like language, is living culture, and as such changes with the times. The old ways are tested and true, the new ways are not necessarily betrayals, if they are appropriate and result in good food."

\subsubsection{Ethnic Connection}

Lastly, authenticity can be framed in terms of ethnic connection, which I argue is the most problematic way of ascribing authenticity. Ethnic connection refers to how foods are associated with an essentialist understanding of ethnic identity (Johnston and Baumann 2010; Kim 2015). Under this logic, ethnic foods are understood as authentic if there is an "overt signal of the ethnicity of the food's producers and consumers" (Johnston and Baumann 2010: 91). The links made between authenticity and ethnicity was not as pronounced in the interviews compared to the previous dimensions discussed. Those who did make the connection, however, identified as non-Filipino. For instance, Andrew, a second generation Laotian owner of a Pan Asian fusion restaurant in Winnipeg insists that the food at his restaurant cannot be described as traditional because of who he is and what he is not: 
There is no way I can be traditional, because I was born here. There's no way I can do traditional because I'm not an old Asian woman, you know what I mean? So a lot of people are confused with that. Is it traditional? No. I can't. I grew up in Winnipeg, I grew up with Filipino friends. I have white friends. You know?

There are several aspects to unpack in Andrew's account. First, he recognizes tradition as an amalgam of several things: nationality, ethnicity, age, and generational status. The idea he can make authentic traditional foods is inconceivable to him because he cannot claim a "true" connection to the homeland, because he is a young second generation Laotian-Canadian who was raised in a multicultural environment. This is reflected in Andrew's menu, which is marketed as a Pan Asian fusion eatery, and serves an array of East Asian and Southeast Asian dishes. What Andrew's account indicates is that authenticity can be understood as a mixture of several dimensions at once: geographical specificity, history and tradition, and ethnic connection.

From these accounts, it suggests that participant's descriptions of Filipino cuisine can be confusing and contradictory. For some Filipino cuisine entrepreneurs, their restaurants are reflections of their own identity. In postmodernity, identity is never simple - it is made complicated by historical, political, and social processes. As I have argued, there is no singular Filipino identity. That is not to say that there are no commonalities among cultural identities. After all, these can be bound by a shared history, ancestry, or cultural codes (Hall 1990). The varying descriptions of Filipino cuisine indicates that is a larger story to be told, one that goes beyond the restaurant and beyond the dishes themselves. Filipino cuisine is complex and cannot be easily reduced to simple "textbook" definitions—it is subjective, and how one defines Filipino cuisine is contingent on their social context and life history. For Filipino cuisine entrepreneurs, how they imagine Filipino cuisine is reflected in their food establishments, both symbolically and physically. 


\section{CHAPTER 6: THE STATUS OF FILIPINO CUISINE IN CANADA}

With the opening of the first Jollibee in Canada on December 2016 in Winnipeg

(MacLeod 2016), some participants felt that this signified the beginning of Filipino cuisine's

journey to reaching the culinary mainstream in Canada:

Now we're getting a Jollibee, which is one of the biggest fast food restaurants in the Philippines. I think it's going to be more mainstream with more Filipinos who come here. There's probably people of different race are interested, wanting to learn about Filipino culture. (Melissa)

Yet others were not so optimistic about Jollibee's arrival being able to mainstream Filipino cuisine, as it is a fast food restaurant that does not sell traditional dishes:

Yeah I don't like that. The reason why, because ... Filipino is not Jollibee! If you wanna experience Filipino food, go to a family's home. Experience it there. Jollibee doesn't represent Filipino food. Trust me, it's not. (John)

Besides Jollibee, participants felt that Filipino cuisine had very little presence in

Canada's culinary foodscape. It was overshadowed by other Asian cuisines such as Chinese,

Vietnamese, or Japanese cuisine:

There are not so many Filipino restaurants in the city. It's more mainstream to see Chinese or Vietnamese cuisine. Filipinos, not much, because they only have a few Filipino restaurants in here, it's not mainstream. (Elsa)

It's not on billboards. It's not like Japanese food where it's like sushi or whatever - those are like really mainstream. It hasn't taken off like that. It hasn't taken off like how, you know... Korean barbeque or Korean... you know, those sauces. Or butter chicken for Indians, hasn't taken off where there's bottles of it in supermarket, you know? (Charlie)

Filipino cuisine is a niche market and has not yet entered the public's imagination as part of Canada's repertoire of ethnic cuisines, as Ellie suggests:

Is Filipino cuisine mainstream? Not yet. The only Canadians who know more or less about it are those who worked with Filipinos who have links to Filipino families. 
Like Ellie, other participants have described a "Canadian" national identity that conflates with whiteness. Studies have shown that in liberal multicultural societies, national identity is linked to whiteness by virtue of skin colour or cultural norms (Bulbeck 2004; Hage 2000). While Ellie herself is a Canadian citizen, her brown skin and ethnic identification as Filipino codes her as a racialized "Other". Ellie's account indicates that Filipino cuisine is not mainstream because it is not widely recognized by white Canadians except for a select few who have connections with members of the Filipino community. Indeed, the lack of Filipino restaurants in Canada is a point of frustration among some participants, such as Allan:

Filipino cuisine is not at all mainstream because it's not like you go out and call your buddies and say, "Let's go out for Filipino food!" ... I think it's the next big thing like everybody is kind of saying, but it's just gonna take a while. Like even in Canada, somebody approached me for an article and said, "I need help looking for Filipino restaurants in Canada." I'm trying to make a list myself, but it's like, here's the list I have and it's not even 10 restaurants of modern Filipino cuisine.

Ellie and Allan's accounts suggest that for an ethnic cuisine to be labelled as mainstream, it has to be popular among members of the dominant culture. What's more, the modernization of Filipino restaurants (through modernization strategies or commercialization) appears to be a prerequisite in order to be recognized as mainstream. Interestingly, Allan laments over the small number of modern Filipino restaurants, yet he neglects to include the several dozen Filipino restaurants in Winnipeg, such as carinderia and turo-turos. While they are not necessarily modern, they are nonetheless Filipino restaurants - they just do not conform to the Western conception of a restaurant (Janer 2007). If Allan had considered those types of restaurants in his list, the number would increase dramatically.

Hence, the participant's responses seem to overwhelmingly suggest that Filipino cuisine is not mainstream. With this in mind, I endeavor to analyse the possible reasons to Filipino 
cuisine's perceived “invisibility” and why Filipino cuisine remains unacknowledged, despite Filipinos making up the fourth largest visible minority group in Canada (Statistics Canada 2013c). Previous studies have attempted to discuss the underrepresentation of Filipino cuisine in the United States (Andrei 2010; Barker 2014) - although their analyses did not fully interrogate the possible reasons as to why it remains underrepresented. In this section, I endeavor to explore the structural aspects that render Filipino cuisine "invisible" in the Canadian context. I examine the structural aspect through two dimensions: systemic barriers (colonialism and multicultural governmentality) and the social characteristics of Filipino entrepreneurship in Canada.

\subsection{Systemic Barriers}

Systemic barriers, such as colonialism and multicultural governmentality, have contributed to the marginal position of Filipino cuisine in Canada. I explore this point by first discussing colonialism's impact. Participants in Winnipeg and Ottawa have attributed the negativity and pessimistic attitude, utak-talangka (crab mentality) of the Filipino community as the primary reason why Filipino cuisine has not been successful in Canada. Postcolonial Filipino psychologists have used Sikolohiyang Pilipino (Filipino Psychology) (SP) to explain that crab mentality is in actuality "colonial mentality", a form of internalised racism that manifests as an inferiority complex among subaltern groups (David 2013; Nadal 2011; David, Petalio, and Sharma 2017).

The second systemic barrier that contributes to the invisibility of Filipino cuisine is liberal multicultural governmentality. I discuss how liberal multicultural governmentality perpetuates a subtle form of racism known as neoliberal racism (Chen forthcoming 2018; Frankenberg 1993; Goldberg 2008), which centres around culture rather than biological 
characteristics such as skin colour (Balibar 1991). I discuss how evolving versions of racisms are implicit in the stigmatization of Filipino eating practices and Filipino cuisine since the era of American occupation in the early twentieth century. During the American occupation, the American government embarked on an imperialistic "civilizing mission" to shape Filipinos into ideal American subjects (Domosh 2003; San Juan 2002). In turn, Filipinos and Filipino culture was marked as "unhygienic" and "uncivilized" (Elias 2014). Moreover, the racist legacy of the Filipino exhibit at the 1904 St. Louis World Fair in the United States framed an Indigenous Filipino tribe, known as "Igorots" as "uncivilized savages" due to their cultural practices such as the consumption of dog meat (McFerson 2002). Scholars have argued that the impact of 1904 St. Louis World Fair still affects how Filipinos are perceived in contemporary times (Sit 2008).

These racist attitudes towards Filipinos are compounded by racist depictions in the media, such as television programs, which are intended to educate audiences about different cultures (Kelly 2014; Flowers and Swan 2012). I further argue that culinary tourism programs and competitive reality television shows such as Fear Factor as key players in the racialization of Filipino cuisine in the media. Lastly, I discuss how governmental strategies such as policy frameworks (i.e., health and safety regulations) and codes of conduct that prohibit the production and consumption of certain foods (i.e., immigrant codes of conduct, apartment codes of conduct) are indicative of multicultural governmentality's neoliberal and communitarian rationalities (Stasiulis 2013), which regulates Filipino culture as it incorporates (Brown 2006; Chen forthcoming 2018).

The commonalities among these responses allude to the historical and ideological processes that are embedded in larger structures of colonialism and neoliberal racism, with the latter attributed to the contemporary conditions of multicultural governmentality. 


\subsubsection{Colonialism}

Participants have provided their insights as to why they think Filipino cuisine is not mainstream in Canada. They noted factors such as utak-talangka (crab mentality) among the Filipino community, the lack of entrepreneurial drive among Filipinos, racial stereotyping, and lastly, some have expressed that relative to other cuisines, Filipino cuisine is not unique or special - which can be understood as an inferiority complex.

The impact of colonization in the Philippines has resulted in the formation of a particular colonial subjectivity which is made through "elaborate systems that measure, compare, and explain human differences" which are then used to justify the colonial projects subjected by the "socially progressive" and "superior" colonizers upon the "inferior" colonized people (Okazaki, David, and Abelmann 2008: 92). Colonial regimes are perpetuated through a wide range of areas such as medicine, city planning, exhibition, ethnography, science, history writing, and through institutions such as the education system and the military (Okazaki, David and Abelmann 2008; David 2013; Said [1978]2000; Said 1993; Fanon 2005, 2008). Through examining how colonial power worked in these domains, postcolonial scholars have argued that civilizing projects put forth by Spanish and American colonizers have aided in constructing the Filipino colonial subject (Okazaki, David and Abelmann 2008; David 2013; San Juan 2002; David and Nadal 2013).

According to postcolonial psychologists, colonial mentality is a psychological phenomenon specific to colonized groups and is typified by an inferiority complex, negative perceptions and rejection of one's ethnicity and culture (which includes people and cultural objects such as food) (Okazaki, David and Abelmann 2008; David 2013; David, Petalio and 
Sharma 2017). At the most basic level, colonial mentality can be understood as internalised racial oppression, with the subaltern possessing a sense of ethnic and cultural inferiority (Decena 2014; David 2013; Nadal 2011). It is important to understand that colonial mentality is not innate characteristic, that is to say, people are not born with colonial mentality. Rather, they are born into conditions that contribute to the formation of colonial mentality. In short, colonial mentality is a product of "social, psychological, and infrastructural work" (Okazaki, David, and Abelmann 2008: 96). According to David, Sharma, and Petalio (2017), Filipinos with colonial mentality have loss of kapwa (shared identity), meaning they are disconnected from other Filipinos, detaching themselves from Filipino culture, beliefs, and values altogether. In a sense, it is the loss of a shared identification, a shared history, and a shared culture - it is a rupturing and for some, a rejection of a shared Filipino cultural identity.

Research has also observed that Filipinos with colonial mentality are more likely to assimilate to the dominant culture, possess an inferiority complex, and critique other Filipinos and aspects of Filipino culture (David, Sharma and Petalio 2017; David 2013; Nadal 2011; David and Nadal 2013). It has been identified that the loss of kapwa is more common in transnational contexts. When Filipinos migrate to other countries, there is a tendency to want to assimilate to the dominant culture. The adaptability and tendency of transnational Filipinos to assimilate in other contexts has been discussed in other studies (see Vachon and Toews 2008; Marshall 2014, 2015; Ignacio 2005).

\section{Crab Mentality}

A prevailing theme in the interviews is participants felt that the Filipino community itself was to blame for the subaltern position of Filipino cuisine in the culinary mainstream. 
Participants had identified negative character traits such as jealousy, over-competition, selfishness, over-criticalness, and lack of teamwork to be prevalent among Filipinos. This phenomenon can be understood as utak-talangka, or "crab mentality", which is a metaphor used to describe the behaviour of crabs in a boiling pot. To survive, each would climb over the other and push others out of the way (Aguila 2014: 84). According to David (2013), the traits associated with crab mentality correspond with "within-group discrimination" and "cultural shame and embarrassment" which is the tendency to "feel ashamed and embarrassed toward the Filipino culture" (David 2013: 76). Several participants have identified crab mentality as a phenomenon that plagues the Filipino community, especially the first generation Filipino participants. Participants like Matthew point out that crab mentality is something that stems from the Philippines and should have been left there, rather than being transposed to Canada:

To tell you the truth, the number one problem is that no one wants to teach anybody. The struggle there is that... [they say] "Why should I teach you?" Right? So that's... could I say the word "utak talangka?" ... you can check with your mom or your auntie about what I am saying. You know, this crab mentality from the Philippines still goes into Winnipeg...

By urging that I ask my family members about crab mentality, Matthew is implying that it is a common, if not inherent trait of Filipinos. Matthew finds it upsetting that Filipinos do not want to help one another, a fact that he finds unfortunate as a solid foundation of community support is integral for success, especially in small business ownership. The lack of community support was also something that other participants identified with, such as Elsa, who suggests that Filipinos should follow by the example of other Asian groups who do support one another such as the Chinese. Elsa felt that their previous restaurant would flourish in Winnipeg because of the large Filipino community. Unfortunately, it was not at all like they had hoped, because there was a lack of community support: 
... we thought because we had so much Filipinos in the city, but then in the end you know... if you are just like the Chinese who are used to supporting each other, there is no Filipino business that will not become successful... it's sad sometimes to hear that the people who came from your own kind do not support you sometimes... I hope Filipinos, we're looking for a time that everybody can unite and support each other so that we can build more businesses ...

As is, the negativity does not foster a supportive and collaborative business environment.

The present climate of the Filipino business community is hostile and wrought with overcompetition:

In Winnipeg I think they battle too much to try to be the best instead of helping each other, so that's what I'm trying to change that with the younger guys, so now we work together - everybody has competing restaurants, competing things, competing pop-ups.... And then now we've been working together in dinners, and just collaborating and helping each other... It's crazy. I think if we did something like that there would be more Filipino places, more Filipino businesses. But until they can get over just battling each other it's not gonna happen. (Allan)

You know I can say - I can't say for other cities, but I can say from Ottawa, from my own observations is that Filipino restaurants or Filipino businesses have failed in a way. Because of mismanagement, and because we don't support each other that much. (Phillip)

Historical research has shown that the predominant social structure in pre-colonial Philippines was based on collectivity. The arrival of the Spanish disrupted the social structure through the implementation of racial and ethnic hierarchies, which resulted in class stratification (McFerson 2002; David 2013). This was identified as the beginning of the development of colonial mentality among Filipinos, which was further exacerbated with the occupation of the Americans (Nadal 2011; David 2013; David and Nadal 2013). The influence of American culture encouraged American value sets such as individualism and competition. Competition in the community can manifest through the following: vocational or educational attainment, socioeconomic status, property ownership, or prestige in leadership (Nadal 2011: 48). Studies have also shown that among transnational Filipinos, competition is a strong motivator for 
success, and the idea of achieving success, or "making it" (a-la American dream), is noted to spur competition among Filipinos - both in the American context and Canadian context (Bonifacio 2013; Nadal 2011).

While competition can be healthy for businesses, it can also be taken to extremes, creating circumstances where people would rather "pull each other down" and seeing "who is better than the other" (Vergara 2009: 77), by outdoing, outshining, or surpassing another at the other person's expense (Nadal 2009; Bonifacio 2013). Gossip, or tsismis, is an effect of overcompetition and colonial mentality. With the desire to "level off" or "be on equal footing" with others on a social and economic level (Bonifacio 2013: 109), people will put each other down. Tsismis is used as a way to belittle their peers, and is noted to be widespread among Filipino communities (in the Philippine context and transnational context), regardless of relationships - it transpires between family members, peers, and others within the larger community (Nadal 2011; David 2013; Bonifacio 2013). The origin of tsismis remains unclear, however it is a noticeable trend in contemporary Filipino communities, leading to "many divisions within Filipino society" in transnational Filipino communities (Nadal 2011: 51). In the Canadian context, Bonifacio (2013) identifies that competition-induced tsismis is widespread among Filipino communities in the prairie provinces, suggesting that successful people are especially susceptible to being targets of gossip, noting that "someone who is presently successful may be persecuted for previous life circumstances, such as coming from a poor background in the Philippines" (Bonifacio 2013: 109). Matthew and his wife, Nellie, explain that their business was the target of tsismis, which they speculate was motivated by "Filipino jealousy". They recount a previous situation when other Filipinos had reported their establishment to Winnipeg's health and safety department: 
Just to give you the best example we have... we were running our business already, we were legalized. Everything! Our house was designed for the kitchen. But suddenly, because of the Filipino jealousy, they're threatened by us as competitors. Then suddenly, the inspectors themselves, they were surprised! Saying that, who gave this authorization to you guys? I showed them the paper work... zoning, fire department... I have the permits. Licensing with public health? I have the permit.

Matthew and Nellie have made attempts to distance themselves from the negativity and gossip by not engaging in it directly. This has proven to be challenging as their customers would engage in tsismis by belittling other businesses in order to uplift theirs in a misguided act of support:

That's what they're saying... I keep on telling everyone, I don't care about [business redacted], which is near my place. They're not my enemy. I don't treat them as a hindrance to my success. Competition is the best in the business, everywhere! There will be no Burger King or McDonalds if there's no competition with each other. But with Filipinos, it's different.

There are circumstances where participants themselves are the target of direct tsismis.

Customers have made comments directly to their face, have expressed critical viewpoints, or made derogatory comments regarding their businesses within an earshot. This was particularly salient when customers were unhappy with the pricing of foods:

Ah, you know... Filipinos will be Filipinos... It's so hard to please everybody because everybody knows how to cook the same adobo or mechado, but in different ways. Sometimes you don't get support, 100\% from them... They say it's too expensive, or I cook better - stuff like that. (Ellie)

Filipinos are more concerned of the pricing. When they see our price is higher than the other stores then they usually tell us that our price is higher, they' $\mathrm{d}$ rather buy it somewhere else. (Ilan)

The complaints regarding pricing was something that puzzled and frustrated Roddy, who explains that the pricing scheme is not an attempt to gouge customers - it is priced fairly so it can sustainably support their livelihood. His Filipino customers fail to take into account that at the end of the day, it is a business: 
In terms of business, price-wise, we stay competitive to industry standards just to be fair. We are obviously in business for a reason, at the same time we're not out to gouge anyone, especially Filipino clientele because they know what it takes for this food to be made. What they don't know is the cost of operating business. Which is sometimes not thought about when you do have that comment, let's say not complaint, that "oh you know this is a little bit pricy for what it is" but it's kind of like, well, if you were to buy a steak and make it at home it's less than going to a steakhouse. It's just the cost of business.

To my surprise, non-Filipinos like Thomas had confided that Filipino cuisine establishments in Winnipeg are suffering because of the tsismis and overall negativity of the Filipino community. He acknowledges that as a white man, his experience differs because the criticism is never directly mentioned to him - which is unlike the experience of his wife and his Filipino employees, who tend to receive negative feedback directly:

The older Filipino people are very rude. They act different. They're different when they see a Filipino, but when they see a white guy up there?

However, it does not mean that his whiteness affords him the luxury of being free from criticism. Thomas is still subject to criticism, although how this criticism is deployed differs from his Filipino wife's experience. Unlike his wife, who tends to personally receive direct criticism from other Filipinos, the criticism directed towards Thomas is done passively through social media. Indeed, Thomas recounts previous experiences with his restaurant's former social media page to explain that his business is not safe from tsismis:

I'm gonna say this nicely because my wife is Filipino - I don't mind talking about Filipinos... (pause) they're negative. I find them very negative... we used to have Facebook - there was never a nice comment! But we were lined up at the door all summer... yeah, criticism... [Filipinos] won't come tell you to your face. Canadians and I'm saying Canadians, because that's me. They will come tell me! We took all our social media down.

Criticism has the potential to be constructive. If taken to the extreme the constant negativity and criticism can prove fatal to small businesses, especially in an era where social 
media marketing and internet platforms (i.e., restaurant review websites) play a pivotal role by influencing the daily operations of restaurants (Hirose and Pih 2011; Chez 2011). The restaurant's public image and reputation is crucial in the contemporary culinary foodscape. Restaurant reviews, both negative and positive, have a profound impact on the success of Filipino cuisine establishments (Heldke 2005). Over time, the saturation of negative critiques may deter curious diners, especially those who are not familiar with Filipino food. This especially applies to Western diners, who tend to use restaurant review websites, social media, and other forms of communications and media such as television and print as guides to aid them in making decisions such as choosing where to dine (Heldke 2005; Chez 2011; Johnston and Baumann 2010). Western diners have the most impact when it comes to "popularizing" restaurants and cuisines because they occupy the hegemonic position of being "authorities" of the culinary field (Janer 2007; Heldke 2005). Negative critiques, therefore, leave a bad lasting impression which has dire implications for businesses in the culinary industry.

While bad business was identified as a key effect of the negativity brought upon by "crab mentality", another effect is the mental health aspect of owning and operating a Filipino cuisine establishment. Participants have stated that owning a Filipino cuisine establishment is mentally taxing, especially when bombarded with constant critiques and negativity. Budding Filipino cuisine entrepreneurs may find the hostile business environment as a deterrent in starting a Filipino restaurant, which is why some have turned to Pan Asian cuisine rather than just specializing in Filipino cuisine. Those who have chosen to stay in the business have developed strategies to overcome the challenges arising from negativity and hyper-criticism, such as focusing on positive feedback, learning not to take critiques "personally", and/or ignoring the negativity altogether. Thus, opening a Filipino restaurant requires courage and thick skin: 
One of the reasons I'd say Filipinos would not wanna open a Filipino restaurant because of how we generally, you know... as the Filipino food culture, it's really... we're really hard to please, I don't know why. You have to be brave opening a Filipino restaurant knowing that a lot of Filipinos are called suplado (snobby) when it comes to food, either they just love it or hate it, no in between. When Filipinos don't like the food you expect nothing but hate, that's how it is. (Joseph)

To be brutally honest? It's the clientele - a lot of people don't wanna deal with Filipino customers. Even if they're one of your biggest supporters. Now if the food is good and affordable, they'll come, they'll 100\% come. But the expectations to dealing with Filipinos? Some of them are just rude, that's another reason why I kind of want to lure myself out of the restaurant business... (Melissa)

Filipino cuisine is one of the best cuisines in the world. Maybe people are afraid to try and open restaurants? They're afraid to try and fail. And earlier, I told you that Filipinos are very opinionated. They like to give feedback even though, whatever, even though the way you cook, the way you dress - everything. Every bleeping thing! Right? A lot of people don't like that criticism. (John and Roland)

When I asked participants who exactly was the source of the critiques - an overwhelming number of responses from both the second generation and first generation demographic identified that the older first generation Filipino demographic were the primary source of these critiques. Thomas claims that "crab mentality" is a phenomenon largely found among older Filipinos than the younger ones. He observes that older Filipinos tend to make comments that calls into question the quality of the foods served at his restaurant by comparing it to their own home cooking:

It's generational. They say I could do that, I could do that... well go home and do it! I think... it's just the Filipino nature of things. I'm sure you know all about it here. You're up here, and they wanna drag you. The crab mentality. It's... just... Filipino culture.

The connection with crab mentality and criticism among older generation Filipinos is because they are seeking a very particular iteration of Filipino food, one that they deem as "better" and closer to "traditional" tastes and modes of preparation. Foods that do not meet these expectations are judged harshly, as Phillip ruminates: 
I think because when they come to the [food] truck sometimes I have a sense maybe, I can see some of the Filipinos, the traditional ones at least, think that "oh I can do it myself" or "my mom can do it better". So they're judging, they're critical. Even before they started to try anything on the menu they've already decided they're not going to do it because they've already judged you.

Research probing the generational aspect of colonial mentality was conducted by several Filipino psychologists. Ferrera's (2016) research on Filipino-Americans found that the parenting styles of first generation Filipino parents supported colonial mentality (i.e., inferiority complex towards Filipinos and Filipino culture and propensity to encourage cultural assimilation within the dominant culture) which is then passed onto the second generation. This corresponds with David, Sharma, and Petalio's (2017) writings which points out that colonial mentality can be passed down from first generation Filipino-American parents to the second generation.

Scholars have also argued that second generation Filipinos are not passive recipients of colonial mentality - some have become conscious of colonial mentality and have actively tried to resist it by "decolonizing the mind", which entails being critical about how colonialism has impacted the Philippines and Filipinos in general. Decolonizing the mind also stresses that we, as individual people, may be implicit in perpetuating negative ideas (i.e., inferiority complex) about Filipinos and Filipino culture (Ignacio 2005; Ferrera 2016; Decena 2014). As such, in order to "decolonize the mind" it is crucial to engage in practices that support Filipino liberation and decolonization. In a later section, I will discuss how some second generation Filipino participants are actively resisting colonialism by being currently involved in initiatives that seek to empower the Filipino-Canadian community by supporting Filipino culture through culinary arts and entrepreneurship. 


\section{Inferiority Complex}

The other manifestation of colonial mentality in the Filipino community is the inferiority complex. The inferiority complex is typified by the "tendency to feel inferior" and being embarrassed "about one's Filipino ethnicity and culture" (David 2013: 76). Like crab mentality, the development of the inferiority complex began during the history of colonization in the Philippines, starting with the Spanish's incorporation of race and class based hierarchies which continued onwards to the era of American occupation. Participants have expressed an inferiority complex about Filipino cuisine by describing it as "boring" and not as unique as other Asian cuisines, making it difficult to market to the Canadian audience, as Ilan notes:

I think our food is similar to Chinese. When you talk about Chinese and Filipino food, people would always associate with the Chinese. Unlike... you have the Thai, Thai cuisine, they have a specific authentic taste that is specific to Thai. You have the Indian, you have the curry for the Indian. Then you have the soups for the Vietnamese. Filipinos don't seem to have it, it's a little mix of everything... hopefully. Even our food, it's a combination of different things, and like if you're talking about Canadians they wouldn't know. It's not identifiable like the Thai or the Vietnamese or the Chinese.

While Ilan is situated in the Ottawa context, which has a considerably lower Filipino population compared to the Chinese and Vietnamese, he is not the only one to make comparisons to other Asian cultures. Elsa had also previously mentioned that Winnipeg's Filipino community is not as unified as the Chinese, which is why she feels Filipino cuisine is not recognized on a national scale like Chinese cuisine. Others have attributed specific qualities, such as an unappetizing appearance, taste, and smell, as an inherent characteristic of Filipino cuisine, rendering it inaccessible or unappealing for non-Filipino consumers:

You will hear... especially when people are passing by here on Saturday... on Saturday, we have a thing here called "isaw-isaw" (grilled intestines). So here we have inihaw, or barbeque grills. People are questioning us saying, how could you serve that? (Matthew) 
I noticed with the Caucasians, depending on who they are, they are just skeptical - they won't try it unless you kind of persuade them to try it... if they have a lot of Filipino friends, they'll eat it. If they're kind of new, they'll try a little, they're skeptical about it. (Melissa)

Participants employed some strategies to make Filipino cuisine more "palatable" for the masses, by making it "user-friendly", such as making changes in décor and presentation, omitting or adding certain ingredients to dishes and carefully curating the restaurant menus. A common strategy was omitting the use of organ meats in some dishes through substitution. Here, John and Roland explain how their unique take on dinuguan can also be considered a business strategy:

And if you know, dinuguan ... people put... you know, insides... organs. [For us], it's pork butt and pork belly. And that's it. Some people put pork ears. Some people put innards, which, to me... only the hardcore people will eat that, you know? I would eat that, I'm not shutting it down, but... puti (white people), would they come here? Or some Filipinos, they don't eat that. They'll go "ugh, I don't want it." It's good business sense. You have to attract everyone, not just your culture. And not everyone eats innards.

Others have also mentioned incorporating chicken dishes to their menus, in an attempt to make Filipino cuisine accessible to white people, with the rationale that white people enjoy chicken more than other proteins, making it "safe", as Phillip explains:

Most of our customers are non-Filipino. So it's about $80 \%$, then $20 \%$ Filipinos... knowing that, non-Filipinos go for the inasal (grilled marinated chicken) - I think it's because it's a chicken dish. It's pretty neutral in terms of... when you're checking out a new ethnic food I think they will go to a neutral selection...

The notion that Filipino cuisine is "risky" is not a novel idea. Since the era of Spanish colonization, many ingredients indigenous to the Philippines, such as livestock and vegetation, were considered inedible by colonizers (Janer 2007). Ingredients that are now commonly found in many Filipino dishes such as pork and tomatoes are said to have been imported by the Spanish (Cordero-Fernando 1976; Fernandez 1994). Foods served on special occasions, such as fiesta 
foods, are heavily derived from Spanish influence. These foods are also regarded as "upperclass" foods, stemming from the class hierarchies imposed by the Spanish (Cordero-Fernando 1976; Fernandez 1993, 1994).

The pivotal moment for Philippine cuisine and the Philippine diet is said to have begun during the American occupation. It was during this time that the idea of Philippine cuisine as "risky" became pronounced. Radical changes began to take shape in the early twentieth century during the initial stages of American occupation in the Philippines (Cordero-Fernando 1976; Elias 2014; Orquiza 2013), when the configuration of Philippine kitchens began to shift. To address the specific needs of American military wives, American-style cooking ranges and refrigeration units were imported. Among local Filipinos, American-style kitchens were a luxury reserved only for the colonizers and the economic elite. While uncommon at home, these kitchens were commonly found in schools in domestic science classrooms. Prior to the American influence, Philippine school kitchens were outfitted with the components of the traditional Filipino kitchen. Filipino girls were taught to prepare American recipes in these kitchens, using equipment and ingredients that they most likely did not have at home. The revised curriculum stressed that the American way was "efficient" and "hygienic" making them more modern and progressive than "traditional" ways of cooking (Cordero-Fernando 1976; Orquiza 2013).

A connection can be made with the changing nature of Philippine kitchens to the widespread notion that the majority of Filipino cuisine is "home cooking" and is not worth paying for at a restaurant, as Ronnie and Devon suggest:

If the culture doesn't want to move forward, then it is hard for the food to move forward. It needs to go beyond home cooking... 
What their statement infers is that rather than the culinary mainstream being accepting of Filipino cuisine, the onus is on Filipino cuisine entrepreneurs to ensure that Filipino cuisine can adapt and modernize. These comments correspond with Cordero-Fernando's (1976) argument that the changing nature of the Philippine kitchen reinforced the idea of Western cuisine and cooking practices as superior and modern; unlike indigenous Philippine cuisine and cooking methods. Scholars have also connected the Filipino inferiority complex with the popularity of SPAM in the Philippines, noting that despite SPAM's terrible reputation in Western countries as questionable low-brow food, SPAM remains beloved in the Philippines and even transcends social and economic class distinctions because SPAM symbolizes for many Filipinos the American dream, which symbolically reinforces American superiority and modernization (Matejowsky 2007).

The inferiority complex does not only refer to feelings of inferiority towards Filipino cuisine. It also extends to Filipino people themselves - that idea being Filipino cuisine is not widespread because Filipinos in general are not entrepreneurial and are unwilling to take risks, which is a necessary trait for a successful entrepreneur:

Everyone has a talent, especially Filipino chefs. We are talented, but the question is who is willing to take the risk? Filipinos don't like to take a risk. (Matthew)

Even though they tell you - I don't think they have the guts to do it. Like, they don't have... how can I explain? ... they don't have lakas ng loob (self-confidence) (Elsa)

In sum, it is important to investigate how the legacy of colonialism may create conditions that serve as barriers to the mainstreaming of Filipino cuisine. While participants have readily identified Filipino people and Filipino culture itself as root causes, a closer investigation reveals that interpersonal conflicts stemming from negative personality traits such as "crab mentality" aka "colonial mentality" that manifests as jealousy, over-competition, and an inferiority complex 
can be traced back to colonial structures established by the Spanish, with the creation of race and class-based hierarchies; and later on, the Americans, through civilizing projects which were intended to construct Filipinos as "ideal American citizens" (McFerson 2002; San Juan 2002). As David (2013) argues, the crab mentality as a coherent phenomenon does not exist - in actuality, it is one of the many manifestations of colonial mentality, much like the inferiority complex. I posit that the real issue at hand is the insidious structure of colonialism itself, which evidently still haunts the Filipino community, be it in the transnational context or in the Philippine context. By stating this, I do not intend to dismiss the lived experiences of Filipinos that have encountered struggles due to inter-cultural conflict in the Filipino community - rather, I contend the conversation should shift towards the causes of conflict, which is the structure and context of colonialism (David and Nadal 2013: 298), rather than erroneously making the assumption that colonial mentality is an innate manifestation of the Filipino psyche.

\subsubsection{Multicultural governmentality}

Multiculturalism has shaped the present conditions of the Canadian foodscape in a variety of ways - whether through sheer demographic diversity or through liberal state policy that permits and even encourages respect of (acceptable) cultural diversity. Scholars have argued that in contemporary times, people are more likely to be "multicultural eaters" which in part is driven by the desire to be "cosmopolitan citizens" (Flowers and Swan 2012; Molz 2007; Cappeliez and Johnston 2013). In liberal multicultural societies being a good multicultural citizen can be enacted through adopting cosmopolitanism as social and cultural value. At the very basic level, cosmopolitanism can be defined as an openness to and willingness to engage with cultural "Others" (Johnston and Baumann 2010). With globalisation, cosmopolitan culture has become 
an integral part of the day-to-day experiences of Canadians, and its impact on Canadian culture is evident through the proliferation of ethnic restaurants in most cities and "globally diverse food items on restaurant menus" (Cappeliez and Johnston 2013: 433). While cosmopolitanism is a positive value in many ways, critics have also pointed to the limitations of the particular kind of superficial cosmopolitanism produced by state multiculturalism policy (Chen 2015, forthcoming 2018).

One of the most accessible ways to perform cosmopolitanism is through consumption practices which can consist of dining at ethnic restaurants or consuming media (i.e., television, print, music, art, etc.) to learn about different cultures (Flowers and Swan 2012; Johnston and Baumann 2010; Kelly 2014; Turgeon and Pastinelli 2002). Such practices, while seemingly harmless and respectable, cannot be left unscrutinised. Scholars like Xiaobei Chen (2015) have critiqued that under multicultural governmentality, these "celebrations" of cultural heritage are shallow, as acknowledging diversity through consumption does not encourage deeper discussions and critical engagements with the politics of race and ethnicity. Examining practices around celebrating Chinese culture, she writes:

Everyday practices of acknowledge and cultural heritage tend to take forms of consuming 'Chinese bites' (both figureatively and literally), collecting and displaying Chinese objects, and performing 'Chineseness' on specific occasions, while missing the stories they could tell about locality, migrancy, creativity, hybridity and survival. Chinese culture becomes objectified as a constant package of practices and meanings transportable across time, national borders, regional boundaries, detached from histories.

Under multicultural governmentality the practices of acknowledging and celebrating cultural differences lack any form of engagement beyond consumption. While food consumption is one of the most accessible ways of "learning about the Other" (Huynh 2012; Flowers and Swan 2012; Molz 2007; LeBesco and Naccarato 2008), it also has its limitations. 
By engaging in the consumption, as well as commodification of ethnicity, encounters with "ethnic Others" are dictated by the logic of the market and are conditioned by a considerable distance — detached from politics and history, overlooking the complex reality of being "ethnic" and "different" (Heldke 2001, 2005; Molz 2007; LeBesco and Naccarato 2008).

While participants did not outright state multiculturalism in the interviews, they did allude to a segment of consumers who engage in multicultural eating practices (Heldke 2005; Molz 2007), as Matthew notes in his observation of "Canadian" eating practices versus "Filipino" eating practices:

The Canadian way is different from Filipino way. The Filipino way is looking for the menu. The Canadian way is trying to explore, is trying to test, trying to get an example of it. Then after that, you make them convinced, then they will come back. So it's a different way of eating.

The Filipino way that Matthew describes refers to his observation that his Filipino customers tend to seek "authentic" foods that remind them of "home" in the Philippines (Manalansan 2013). Meanwhile, the Canadian way emphasizes "discovery" and "exploration", which are among the key tenets of culinary tourism and food adventuring (Heldke 2005). Culinary tourism is a type of multicultural eating practice that allows people to explore foods new to them as a way to encounter new cultures and ways of being (Molz 2007: 78), emphasizing the "experiencing of food in a mode that is out of the ordinary, that steps into the normal routine to notice difference and the power of food to represent and negotiate that difference" (Long 2004: 20). Under culinary tourism, food acts as "a transportable symbol of place, space, and cultural identity" as a moveable sign of Otherness (Molz 2007: 77).

In recent years, culinary tourism television programmes have become increasingly popular. They often involve a white host travelling to different countries and cities, doing some 
sightseeing, and of course, eating local foods. The appeal of these programmes is that it plays upon people's desires with engaging with the "Other", and these allow them to do so from a comfortable distance (LeBesco and Naccarato 2008; Kelly 2014). Culinary tourism progammes offer audiences a voyeuristic experience through which they can watch enthusiastic hosts eating the food of the Other (Kelly 2014), which is a sufficient substitute for an actual engagement with local people (Molz 2007: 86). Some people are motivated by the prospect of generating cultural knowledge and cultivating cultural capital, which confers them legitimacy and expertise (Johnston and Baumann 2010; Bourdieu 1984; Heldke 2001).

While culinary tourism programmes have the potential to educate the masses about different cultures they tend to portray exaggerated, stereotypical, and Orientalist (Said [1978]2000) depictions of different cultures under the guise of "celebrating diversity". The culinary tourism genre "manages racial and cultural differences that threaten white supremacy and white privilege in a globalized, postcolonial world" (Kelly 2014: 49). Cultural difference is the highlight, if not the focus of these programs (Kong 2011: 45), which is told from the perspective of a white Westerner. In some cases, these programmes serve as the only opportunity for some people to have an encounter with the culture of the "Other". As such, it is critical to consider that these programmes have the potential to shape how the masses think about some cultures and their cuisines.

The common association with balut, a snack comprised of fertilized duck embryo, with Philippine culture is a demonstration of the power of the media has in shaping the public perception. Balut is often featured in culinary tourism programmes like Bizarre Foods with Andrew Zimmern or in competitive reality television such as Fear Factor. Regardless of the genre of television, balut is almost always often framed as a "bizarre" and "risky" food 
(Matejowsky 2013). As Allan ruminates, these depictions are not at all favourable to Filipino cuisine's reputation in the West, which has dire implications for Filipino businesses:

Sometimes we have balut treats at the end, which is more for fun. And you'll get people who are like, "Oh that's gross... both, non-Filipinos say that... You only see stuff like that on Fear Factor, but that's like our food, right? ... They'll eat the balut, everybody has to eat the balut, I guess - we're not just balut you know what I mean?

To avoid or resist this stigma, some choose to not serve balut at their restaurants - or some may, but only on special occasions like Allan does at his pop-up dinners. There are also others who profit off the "fear" associated with balut as a way of subverting the racist stigma associated with the dish. At one restaurant, curious diners are encouraged to "conquer their fear" by participating in a contest to see who can eat balut the quickest without gagging. Those who succeed win a free meal at the restaurant. Such examples show that the consumption of balut is constructed as a rite-of-passage for non-Filipinos to prove their courage (Matejowsky 2013; Fernandez 2002). For Filipinos, eating balut is a way to prove their "Filipino-ness" (Zappia 2015).

Another common stereotype regarding Filipino cuisine is that all Filipinos eat household pets, as John explains, "they (non-Filipinos) associate Filipino food with the idea that we eat dogs." Historically speaking, it is true that dog meat along with other types of meats (i.e., cats, bats, iguanas, and other bush animals), were traditionally consumed in the Luzon province in the Northern Philippines (Fernandez 1994; Fernandez and Alegre 1988). However, with the American occupation, the consumption of dog meat became forbidden due to concerns over hygiene (Fernandez and Alegre 1988). Scholars have argued that the stereotype is the racist legacy of the 1904 St. Louis World's Fair, where the Igorot, an Indigenous tribe from the Philippines, was part of the main Philippine exhibit. The most controversial part of the exhibit 
was the Igorot's traditional customs of eating dog, which is said to have "sparked a frenzy among American newspapers reporting on the fair in St. Louis" (Heinrich 2017: 26). A hundred years later, the stereotype still persists and continues to follow Filipinos to this day. It has been suggested that the controversy over eating dogs is indicative of a larger issue pertaining to citizenship and nationalism. The practice of eating dog determines who is a "real" Canadian and who is not, and what cultural practice is "mainstream" and "exotic" $(\mathrm{Ku}$, Manalansan and Mannur 2013: 2).

The idea of Filipino cuisine as "unhygienic" and "risky" and the stereotype that Filipinos eat dogs is indicative of the larger system of racism found in multicultural societies. Neoliberal racism is a form of racism that is predicated upon cultural difference rather than biological characteristics (Frankenberg 1993; Goldberg 2008). It is insidious in character because it can be invisible and interwoven with larger systems such as policy and legislation. For instance, Stasiulis' (2013) study on the Gatineau immigrant code of conduct reveals the extent of multicultural governmentality's "neoliberal and communitarian rationalities" by limiting the “preparation of smelly foods and maintaining one's personal hygiene" (Stasiulis 2013: 198). The impact of such codes of conduct is illustrated in Matthew's account, who explains that tuyo (dried fermented fish) is a best-seller because his Filipino customers are prohibited from preparing and cooking dried fish in their apartment units:

In this area, for all the reasons with the condos and apartments, it's so hard for them to cook fish, because of the smell of the tuyo and everything. And now, we're giving [to] the people who are saying, "Hey, why not start cooking more fish?" ... It has become helpful for everyone because in [our] daily menu we can have eight different kind of fish... 
However, Matthew also points out that his business has also been scrutinized by health and safety officers, which dampers any plans for providing authentic, yet innovative menu items at their restaurant:

We [filed a request] to the city [so] we could do a "hang ten" (grilled chicken feet). The traditional way is that we grill it. We cannot sell it here because they don't allow it, even though Young's ${ }^{19}$ can sell chicken feet... with the Chinese, chicken feet dim sum is steamed. They said it has to do with the cooking process we do. It's called ihaw (grilling). Basically, it's the same issue with coagulated blood. We'd like to grill it but we cannot. We can only do the dugo (blood) in the dinuguan because we're boiling it. But why can steak be served rare or medium rare? In their logic, it makes sense because it's more bacteria in chicken than beef.

It seems that the issue at hand is that serving these grilled items are a public health concern, yet the comparisons Matthew makes with other foods produced with similar ingredients and mode of preparation leaves room for some critical interrogation of these health and safety standards. There are many foods that pose health risks - as a common example, the consumption of raw meats and fish (i.e., tartare, sashimi, oysters), yet they are still permitted to be prepared and sold. In another example, Matthew interrogates the logic of these health and safety standards regarding an issue that prevents them from being able to serve sorbetes (a frozen dessert akin to ice cream):

It's a public health issue because we cannot leave anything [out in the open]. In the Philippines, we put [food] out with all the flies and mosquitoes, and yet people are still buying it! So the sorbetes you cannot put it out here... but it's a nice concept! You can put out a tub and let people scoop it themselves... it is not allowed, but how come people can do it at a buffet?

What Matthew's insights seem to suggest is that perhaps his issues related to food health and safety standards is not necessarily only an issue of hygiene - it is also an issue relating to what foods are deemed "socially acceptable" for mass consumption. According to Knezevic

\footnotetext{
${ }^{19}$ Young's is a local ethnic grocery chain in Winnipeg.
} 
(2016: 411), regulatory instruments such as policy and food health and safety regulations are "shaped by institutional ideology and power relations that produce" (Hewitt 2009, cited by Knezevic 2016). These regulatory instruments can sometimes "clash with those of individuals or social groups" (Knezevic 2016: 411) because how health is perceived is diverse and varies across different geographical and social contexts. As indicated in Matthew's accounts, his understanding of "safe" foods are derived from the Philippine context which ultimately clashes with the Canadian food health and safety regulations.

Matthew's accounts also allows for further critical reflection regarding ideas surrounding creativity and innovation in the culinary industry. Matthew's examples show that he has creative and innovative ideas that could set his restaurant apart from others, and yet due to systemic limitations he cannot pursue these ideas. Similarly, Allan recalls his struggles as an aspiring Filipino chef a few years ago - his former restaurant had concepts that were innovative, however, at the time it was just too radically different from the standards of the culinary mainstream:

We were doing [Filipino] fusion back then - people didn't really understand it as YouTube wasn't huge yet, or Instagram and the Food Network wasn't big like it is now. Our restaurant had Korean tacos, Filipino bibimbap, gamjatang, and Filipino and Korean banh mi. And we did crazy specials like Korean and Filipino burritos and Korean silogs.

In another conversation, Allan also described a project involving a Filipino-fusion food truck. Due to financial reasons, the project was never able to fully come into fruition. He explained that Filipino cuisine back then was too unfamiliar for the mainstream. What Matthew and Allan's reflections suggest is that perhaps some people are rewarded for their creativity and innovation only when ideal conditions are met, such as gaining the acceptance of the dominant culture and the mainstream. Their observations also call into question the ideas that Filipino 
cuisine lacks uniqueness and excitement and that Filipino people lack the entrepreneurial drive to take risks. It is evident that many Filipino cuisine entrepreneurs possess the entrepreneurial propensity to innovate and take risks. Perhaps the entrepreneurial drive is simply not enough to "succeed" in the mainstream when systems like colonialism and structural racism remain firmly intact.

\subsection{Filipino Entrepreneurship in Canada}

The low incidence of Filipino entrepreneurship in Canada may account for why Filipino cuisine has not reached mainstream status. It is worth considering the role of systemic barriers such as colonialism and neoliberal racism regarding the low rates of Filipino entrepreneurship in Canada. Government publications have reported that only $4 \%$ of Filipinos were listed as selfemployed in the Canadian labour force (Lindsay 2007). Scholars have also reported low entrepreneurship rates among Filipinos living abroad, which indicates that this issue is not specific to the Canadian context (see Fresnoza-Fluot and Picoud 2007; Johnson, Munoz, and Alon 2007ab; Maas 2005).

The underrepresentation of Filipinos engaged in self-employment may contribute to the misconception that Filipinos as a group lack the entrepreneurial spirit to successfully own and operate a business. Compared to other Asian immigrant groups in Western contexts, Filipinos rank the lowest when it comes to entrepreneurship (Lindsay 2007), in comparison the Chinese (Zhou and Lin 2005), Koreans (Bonacich 1988; Fawcett and Gardner 1994; Oum 2005), and Vietnamese (Huynh 2012). This may also be the reason why Filipino cuisine is underrepresented in Canada. According to a 2007 Statistics Canada report, only 4\% of Filipinos were listed as selfemployed, compared with $12 \%$ of their counterparts in the Canadian labour force (Lindsay 
2007). In the United States, Filipinos have the lowest self-employment rate among other Asian groups (Posadas 1999; Johnson, Munoz, and Alon 2007; Allard 2011), with only 5.4\% of Filipinos reported as self-employed (Yu 2016). Given the low rates of Filipino entrepreneurship, it is not shocking that Filipinos are underrepresented in the ethnic and immigrant entrepreneurship literature.

Filipino entrepreneurship is a subset of ethnic and immigrant entrepreneurship. In the literature, the terms "ethnic" and "immigrant" as they relate to entrepreneurship are often used interchangeably even though they refer to two different things (Fregetto 2004). Ethnic entrepreneurship commonly refers to visible minorities engaged in entrepreneurial practices (Waldinger, Aldrich and Ward 1990) and is described as "a set of connections and regular patterns of interaction among people sharing common national background or migration experiences" (ibid: 3 ). These connections may also include a "shared history arising from the divergence of cultures, politics, and economics among groups in society" (Cohen 1997 cited in Waldinger, Aldrich and Ward 1990), and "commonality of culture and origin" (Yinger 1985 cited in Waldinger Aldrich and Ward 1990). Ethnic entrepreneurship is not defined by race or immigration status and is instead operationalized by shared connections such as culture, history, and nationality (Volery 2007; Johnson, Munoz, and Alon 2007ab). Immigrant entrepreneurship refers to people classified as first generation immigrants or recent immigrants (Butler and Greene 1997; Chaganti and Greene 2002; Fregetto 2004). The terms "ethnic" and "immigrant" entrepreneurship have been critiqued by the inconsistency of scholars in the field defining these concepts, as well, it does not take into account the nuances associated with the categorizations of "ethnic" and "immigrant" (Chaganti and Greene 2002). For instance, the dominant definition of 
immigrant entrepreneurship considers only first generation immigrants and recent immigrants, disregarding the experiences of second generation immigrants.

\subsubsection{Theories of Filipino entrepreneurship}

According to dominant theories of ethnic and immigrant entrepreneurship, immigrants and ethnic minorities are far more likely to engage in self-employment than members of the majority culture (Fregetto 2004; Chaganti and Greene 2002). Yet, as the statistics suggest, the low self-employment rate among Filipinos challenge this idea. Unlike other ethnic immigrant groups, Filipinos are noted to be more "adaptable" to assimilate into the dominant culture, which is why Filipinos have the reputation of being the "ideal immigrant" (Kelly 2006; Vachon and Toews 2008). Filipino immigrants also tend to be more educated having obtained post-secondary education and have a better grasp at English, granting them the advantage of being able to find work in the labour force, compared to other immigrant groups (Johnson, Munoz, and Alon 2007; Fresnoza-Flot and Pecoud 2007).

With these aspects considered, Filipinos are far more likely to engage in other occupations in other industries such as health care, administration, and customer service, which can be attributed to the migration history of Filipinos in Canada. Filipinos have historically entered Canada through skilled labour programs in the mid-twentieth century and in more recent years, through the Live-In-Caregiver Program and the Temporary Foreign Worker Program (McElhinny et al. 2012; Vachon and Toews 2008). Since Filipinos did not face the same kinds of exclusion from the labour market as some others, there was no need to pursue entrepreneurship, which is a high-risk occupation that does not yield immediate financial gains. Participants who 
liken themselves as experienced entrepreneurs have suggested that the high risk is why there are not as many Filipino restaurants in Canada:

I think that none of the Filipino chefs are not willing to take the risk and chance. A restaurant is very risky. I think they're just afraid to go into it. My personal opinion, it costs a lot of money to get into restaurants, it's a lot of work. (Thomas)

Others have also suggested lack of resources as a contributing factor as to why Filipinos are less likely to start a business. Money is necessary to even jumpstart a business. Filipinos as a group generally lack financial means to start a business due to a variety of reasons such as sending remittances (Polvorosa 2012). It is even more challenging for recent Filipino immigrants who tend to make less money yet are still expected to send remittances, while sustaining their own livelihood in Canada, as in Eleanor's case:

Siempre, sabi nila maraming pera kung gusto mo mag tayo. Kami, gusto namin mag tayo kaso malaking kailangan namin pera. Tatayo kami sariling namin pero kulang kami sa budget... (Of course, it's because you need a lot of money to start one. For us, we wanted to open a restaurant however you need a lot of money. We wanted to start our own restaurant but we lack the budget...)

Eleanor is a first generation recent immigrant working as a cook at a Filipino sari-sari store and turo-turo in Winnipeg's West End. She explains the reason why she is working in the restaurant industry is because it is her passion and something she enjoyed doing back in the Philippines. However, due to the lack of financial means, she cannot open a restaurant business even with the help of family members. Indeed, since entrepreneurship can be long process marked with risks and expenses, recent Filipino immigrants may instead opt to work in sectors that can provide financial stability, such as health care or in customer service (e.g., a cook or server in restaurants). These occupations are able to consistently provide small and immediate financial gains (Johnson Munoz and Alon 2007ab). 
Cultural values can also provide some insight as to why Filipinos as a group are less likely to engage in entrepreneurial practices. Sharing is considered to be a moral obligation among Filipinos, which is manifested through the Filipino social value utang-na-loob (debts of gratitude) (Enriquez 1975). In the entrepreneurial sense, these debts can be typified as borrowing money, asking for an advance, or favours (Polvorosa 2012). In the Philippines, it is not uncommon for owners of small eateries in poorer barangays (village/district), to have such a lending system in place - those who cannot afford to pay for meals at the very moment are given a tab, which they will be expected to pay off at a later time (Fernandez 1994). Such a system cannot be easily adapted in Western settler societies, where debts are discouraged and everything is expected to be paid for up front (Johnson, Munoz, and Alon 2007ab; Polvorosa 2012).

Others have attributed psychosocial explanations such as colonial mentality to the low patterns of Filipino entrepreneurship (Batalla 2010; Uy 2011). Batalla's (2010) study suggests that the low rates of Filipino entrepreneurship in Western countries are connected to colonial mentality among transnational Filipino communities. Colonialism has fostered certain economic attitudes that discouraged progress and industrialization because a particular image of the Philippines as an unmodern, agricultural society is being continually reinforced by the media, resulting in an inferiority complex that may deter Filipinos from pursuing entrepreneurship.

The prevailing explanation in the literature suggests that Filipino immigrants pursue entrepreneurship in order to serve the immediate needs of their community, whether it is to cater to the Filipino community at large, or to other ethnic minority communities in their geographical context (Johnson, Munoz, and Alon 2007ab; Fresnoza-Flot and Pecoud 2007; Maas 2008; Polvorosa 2012), acting as middlemen minority entrepreneurs. Addressing the immediate needs of their local communities may motivate Filipino entrepreneurs to pursue business ventures 
located within niche markets which include speciality stores selling Filipino cultural goods, remittance and Balikbayan businesses, or food establishments selling already-made foods turoturo style or specialize in catering services (Maas 2005; Fresnoza-Flot and Pecoud 2007; Maas 2008; Polvorosa 2012; Marshall 2014). Outside of these, research has shown that some Filipinos entrepreneurs are engaged in other ventures such as beauty and hairstyling (Fresnoza-Flot and Pecoud 2007), guest houses (Pijpers and Maas 2014), IT and technology (Polvorosa 2012), and full-service restaurants (Andrei 2010; Barker 2014).

\subsubsection{Filipino Pride and Culinary Entrepreneurship}

There was one motivator that stood out that was hardly ever mentioned in the ethnic and immigrant entrepreneurship literature which was the aspect of ethnic and cultural pride. Some have briefly alluded to the possibility that ethnic and cultural pride can serve as a motivator for ethnic minority groups to pursue entrepreneurship (Andrei 2010; Polvorosa 2012; Golob and Giles 2017). Others like Alexandre-Leclair (2014) have made connections between ethnic and cultural diversity as a motive for entrepreneurship, although no mention was made regarding the aspect of ethnic and cultural pride as a motivator for entrepreneurship. I did find that works in the Black entrepreneurship literature were able to provide the closest approximation of ethnic and cultural pride as a driver for entrepreneurship. Some have suggested that the existence of Black-owned businesses can foster racial pride and empowerment among Black communities. For instance, Anderson (1982) argues that Black entrepreneurship can contribute to cultural pride and self-determination of African Americans in the United States. Similarly, Green and Pryde (1997) note that Black entrepreneurship can contribute to the struggle against racial oppression by instilling a sense of cultural pride among the African American community. On the other side 
of business transactions, Butler (2005) suggests that Black pride is what motivates Black consumers to patronize Black businesses. However, these theories do not account for racial/ethnic/cultural pride as a precursor to starting a business, they only discuss pride as an after-effect.

A question that I had asked each participant was to explain why they had chosen the culinary industry as their line of work. What was striking was that none of the responses had made connections to necessity and survival, nor were there any mentions of being locked out of the Canadian labour market, as dominant ethnic and immigrant entrepreneurship theories would suggest. The answers varied among all interviewees such as: passion for cooking, a continuation of previous work from the Philippines, a family business, and interestingly, their pride for Filipino culture.

Indeed, passion for entrepreneurship or the restaurant industry, in addition to addressing the Filipino community's needs, was a common motivator among the first generation Filipino participants. Elsa explains that she and her husband started their bakery business:

So when the first time we came, we came as under the provincial nominee program. We roamed around the city and found out that there's so many Filipinos in Winnipeg. But then there's quite few bakeries in the city. When we went there and visited, there's only a few kinds of breads you can find in the bakery. So we thought maybe later on we can open a bakery. Also because that's our specialty...

The consensus among the research participants is that Filipino cuisine is not appreciated by the mainstream. I noticed that the older generation of Filipino cuisine entrepreneurs remained ambivalent about the status of Filipino cuisine while the younger generation of Filipino cuisine entrepreneurs, especially the Filipino-identified ones, had expressed the desire to have Filipino cuisine recognised. Pride in one's culture is what motivated Roddy to pursue culinary 
entrepreneurship, which he describes was a long, emotional, and tumultuous journey of finding pride in his Filipino identity in Canada:

I did this out of passion for sure... being a second generation Filipino-Canadian, it took me a long time to accept I was in fact a Filipino. I grew up in a predominantly nonFilipino neighbourhood in the city. My brothers and I, and another set of brothers, were the only Filipinos in the entire elementary school. Maybe through junior high. So we were quite a novelty, to put it nicely. Which meant growing up, we tried to adapt really hard to being Canadian - not necessarily being white - but being Canadian. We tried to learn the language, and I wanted to learn the language really well too.

[Later on], I became obsessed with being pro-Filipino. I started following from music to athletes to anything Filipino, I was by far, I thought, the proudest Filipino around. Everything else followed suit. I thought if I opened a restaurant it now has to be a Filipino restaurant because essentially this is what I wanted to do first, to open a restaurant.

As you know the cost of opening a business could be quite great so we took a direction of opening a smaller restaurant being our food truck and taking it from there. We've been since blessed to be able to get to where we are now, but now it's truly about Filipino pride and being able to share food through - or share culture through food is essentially what we're doing... if anyone was able to come into our restaurant they would know that it is proudly Filipino first then Canadian because I am in fact Filipino-Canadian. But Filipino first.

Roddy's story is unique, but his journey of self-identity which has resulted in him embracing his Filipino heritage is not unlike the experiences of other second generation Filipinos. Studies have shown that second generation Filipinos who were raised to "assimilate" into the dominant culture would later on attempt to reconnect with their Filipino heritage (Manalansan 2013; Ignacio 2005). Writing about transnational Filipino identities, Ignacio (2005: 6) explains that the postmodern "importance of identity" is desired not for assimilation, but for differentiation:

Many people wish to learn about their culture because they want to recapture the power to name themselves. That is, they need an identity, not only so that they know their own roots, but so others can learn of their roots as well. 
Opening a restaurant is one of the ways in which Filipino pride can be expressed, and is what motivates Phillip and his business partner to open their restaurant. He stresses that Filipino cuisine entrepreneurs should "show their pride their business, not just their food business, but any Filipino-related stuff." For some Filipino cuisine entrepreneurs, Filipino pride was not necessarily the initial motivator to entering the culinary industry. For Melissa, her journey to Filipino pride began only after she started working in her father's restaurant:

After working here I've learned to love the culture of the Philippines. I was born in the [South End of Winnipeg] with my siblings, which is why we don't speak Tagalog. You'd think we should've learned for being here for several years, but I had no desire for the longest time. Then I met a guy who taught me who spoke it so often, I thought it was a beautiful language. He taught me a lot and said to love where you're from. If you actually saw how beautiful the Philippines are, how beautiful the people are and the country is, I guarantee you, you will love it.

In addition, the existence of ethnic food cultural movements such as the Filipino Food Movement and the Philippine Culinary Heritage Movement seems to indicate that Filipino pride has become an important, if not core aspect of the cultural politics of Filipino cuisine. Indeed, the Filipino Food Movement was founded to mainstream Filipino cuisine through awareness, appreciation, and investment in Filipino Culinary Arts (Filipino Food Movement, n.d.). In short, the Filipino Food Movement is an expression of Filipino pride. It has gained momentum over the past several years with the assistance of social media marketing. According to Phillip, the reason Filipino cuisine is now gaining the mainstream's attention is due to the Filipino Food Movement:

One major one was on the newspaper where they described Filipino as up and coming... upcoming Filipino restaurants, in particular Lamesa and the other fantastic Toronto places there. They're describing how it's a new - we're introducing new flavours, new culture. A way from plain Chinese or just sushi or Vietnamese food. Now it's something new, something fresh, something interesting. The fact we're part of the movement, I'm really happy about that. 
Like Phillip, there were others who identified as being part of the Filipino Food Movement - mostly among those who owned modern Filipino restaurants. On the other hand, the Philippine Culinary Heritage Movement is not as well-known, in part because it is a relatively new social movement. The Philippine Culinary Heritage Movement is distinct from the Filipino Food Movement in that it seeks to promote and preserve the heritage of Philippine cuisine (Philippine Culinary Heritage Movement 2017). The idea that Filipino cuisine needs to be preserved because it is "dying" was noted by some participants:

With our younger clientele coming in it's because their parents are as busy as before and may not have as much time to cook traditional Filipino food as they used to... A lot of second and third generation Filipino-Canadians born and raised in Canada shockingly aren't familiar with Filipino food as they used to be, as the same way they begin to lose not their culture - but the ability to understand and speak Tagalog, our native tongue. Sad but it will come around for them... (Roddy)

Others have suggested that the lack of culinary knowledge among second generation

Filipinos may explain why Filipino cuisine is not widely recognised:

The reason because it's not as popular because no one has the knowledge to cook it anymore. And if they do... it's lost. It's lost along the way. Because those kinds of cooking, it's old school cooking. Like folk cooking. (John)

The anxieties regarding impending "death" of traditional Filipino cuisine is not solely a modern concern. Since the advent of globalisation and industrial capitalism, the increasingly busy lifestyle of Filipinos - in the Philippines and in transnational contexts - does not provide ample opportunities for Filipinos to spend time in their kitchens preparing food. Indeed, it is unfortunate that the younger generation of Filipinos are "losing touch", but on the other hand, it also provides restaurants business, as Allan points out:

We want people to try our food, that's the whole Filipino food movement, right? Even the younger people, you know the younger Canadians, the Filipino-Canadians, they don't know anything. If you ask a Filipino person to cook something they probably can't. And 
it's a shame, because honestly when everybody's parents are gone who's gonna make that food?

Social movements such as the Filipino Food Movement and the Philippine Culinary Heritage Movement are not only motivated by mainstream recognition or preservation of cultural heritage. They are also movements that attempt to subvert systems of oppression such as colonialism and institutional racism by fostering cultural pride among the Filipino community. As Phillip notes, "There should be a push being more visible, celebrating more Filipino food, sharing with other cultures. There should be more of that action." As the participant's accounts illustrate, it is worth considering that cultural pride can be a motivator for people to pursue restaurant entrepreneurship - especially since food is the most widely recognised form of communication between cultures. 


\section{CHAPTER 7: CONCLUSION}

This thesis studies the cultural politics of Filipino cuisine in liberal multicultural societies by focusing on the Canadian context. This thesis examines how Filipino cuisine entrepreneurs in Winnipeg and Ottawa "do" Filipino cuisine. The primary research question asks: how Filipino cuisine entrepreneurs engage in a politics of resistance through their culinary practices within the context of liberal multicultural societies? It explores the ways in which Filipino cuisine entrepreneurs disrupt and resist the "invisibility" and "hypervisibility" (McElhinny et al. 2012; Wiley 2016) of Filipino-Canadians and Filipino cuisine in Canada's culinary foodscape. The findings suggest that the cultural politics of Filipino cuisine in Canada is marked by a politics of resistance, which I contend is a form of cultural and identity work. Through comparing Winnipeg and Ottawa's contexts, it is evident that the cultural work involved in doing Filipino cuisine cannot be understood monolithically; how Filipino cuisine entrepreneurs engage in the cultural politics Filipino cuisine varies across different contexts.

The primary differences between Winnipeg and Ottawa had to do with their unique migration histories. Winnipeg is a city that has a long history of receiving Filipino migrants which is why there is a large concentration of Filipinos living in the city, which accounts for why there are so many Filipino cuisine establishments - far more than I had assumed initially situated across Winnipeg. Ottawa on the other hand is not a city that traditionally receives large numbers of Filipino migrants, which is aptly demonstrated with the lack of Filipino cuisine establishments across the National Capital Region. Due to these differences in demography, Filipino cuisine entrepreneurs in Ottawa were more likely to devise strategies to capture a wider non-Filipino audience, such as altering "traditional" recipes (i.e., adding more vegetables in a dish that otherwise would not have them), carefully curating menus to ensure there are "safe" 
dishes and the "scary" or "bizarre" dishes are omitted, focusing on visual aesthetics, and even changing the way Tagalog words are pronounced to sound more Anglicized such as one participant did with her restaurant ${ }^{20}$ which is named after a Tagalog word. Additionally, others have completely eschewed the "traditional" names of dishes and have opted to only use Anglicized names.

In Winnipeg, those who employed similar strategies were those who also owned modern Filipino restaurants or Pan Asian fusion restaurants - such establishments were mostly owned by second generation immigrants. Yet at the same time, Winnipeg's Filipino cuisine entrepreneurs were more likely to take risks with their interpretations of Filipino cuisine and were less likely to make major alterations, such as incorporating organ meats or other "bizarre" ingredients, referring to menu items or ingredients in their traditional (Tagalog) pronunciation, and so on. These strategies were employed not only from a business standpoint - these strategies were also employed in an effort to mainstream Filipino cuisine and make it accessible to the dominant culture.

It is to be expected, then, that these modern Filipino cuisine establishments in Winnipeg and Ottawa are involved in the Filipino Food Movement. It is worth noting that most establishments involved in the Filipino Food Movement are 1.5 generation immigrants or second generation immigrants. To my surprise, in Winnipeg, some non-Filipino identified participants (i.e., Laotian, South African, Chinese, Vietnamese, White) participated in activities related to the Filipino Food Movement, such as collaborating in the Baon Manila Nights pop-up dinner series. As some had explained, they are part of the movement because they were heavily connected with

${ }^{20}$ Due to reasons concerning confidentiality I could disclose the name of this restaurant. 
members of Winnipeg's Filipino community. Their connections are comprised of friend groups, spouses, or just simply growing up in Filipino-dense neighbourhoods across Winnipeg. Even though they are not ethnically Filipino, their connections with other Filipinos has shaped their personal identity. The findings of this research suggest that for many of the younger participants involved in the Filipino Food Movement, their restaurant is a way for them to express their ethnic and cultural identity. For many of the Filipino-identified participants, their restaurant was a way for them to assert their Filipino identity and engage in the politics of recognition. For the non-Filipino participants, their inclusion of Filipino cuisine in their Pan Asian restaurants signifies their unique identification growing up as a child of an immigrant in multicultural Canada.

Most of the younger second generation participants who owned modern Filipino cuisine establishments had incorporated fusion in some shape or form. Even though some had stressed they only use "traditional" Filipino recipes, they still employ European cooking techniques or arrange their plating in a way that adheres to the dominant standards of aesthetics. In contemporary times, Asian fusion cuisine has been critiqued as a form of cultural appropriation and a signifier of Eurocentric hegemony (Janer 2007). These critiques are completely valid as "modernity" in culinary discourse is often implicated in perpetuating Orientalist ideas of European superiority and rationality (Janer 2007; Said [1978]2000). The most common understanding of fusion cuisine is the intermixing of European techniques and traditions with the cuisine of an ethnic "Other" (Janer 2007). Cultural appropriation involves a party taking aspects of another culture in order to profit - there is no respect or consideration given to the culture that was appropriated, other than incorporating aspects of other cultures in order to seem "worldly" or "trendy" (Tam 2015). Under this definition it should be acknowledged that claims to cultural 
appropriation are often directed towards those who possess systemic privilege and power profiting off of marginalized populations. I contend that the entrepreneurial logics of fusion deployed by the younger second generation chefs in this study should not be painted as cultural appropriators. As their accounts demonstrate, their interpretation of Filipino fusion is form of hybridity situated in a liminal and in-between space that provides new possibilities - a "third space" (Bhabha 1996). The fusion foods they create are "assimilation foods" that takes into consideration their hybrid identities in multicultural contexts (Ho 2017), rather than a phenomenon that is predicated upon profiting off of another culture due to a trend.

Most participants - regardless of the city, ethnicity, and generational status—felt that Filipino cuisine was not mainstream in Canada or in most Western contexts. They provided a variety of reasons, such as Filipino "crab mentality", the supposed inferiority of Filipino cuisine compared to other Asian cuisines, Filipinos lacking an entrepreneurial drive to pursue restaurant ownership, and racism (through depictions in the media or stereotypes). The findings suggest that several of these reasons cited can be attributed to two overarching structures: colonialism and multicultural governmentality.

Crab mentality, in actuality, is colonial mentality. The inferiority complex is also associated with colonial mentality (David 2013). Even though colonization in the Philippines has "ended", the vestiges of Spanish colonialism and American imperialism continues to persist on many levels - at the psychic level, with "colonial mentality" (David 2013; David and Nadal 2013), at the gastronomic level, with Filipino cuisine having indigenized the cuisine of their colonizers (Fernandez 1994; Fernandez 1988; Matejowsky 2007), and at the political level, the longstanding legacy of the Marcos regime's Balikbayan program in the 1970's, which is understood to be the catalyst of the Overseas Filipino Employment schemes in contemporary 
times (Aguila 2015: 65). It is the latter reason why many Filipinos are not represented in entrepreneurship as they are in constant search of work that yields consistent pay and quick rewards in order to provide for their families in the Philippines, as opposed to choosing a risky and time-consuming occupation such as entrepreneurship. Multicultural governmentality, on the other hand, can account for the racist depictions of Filipino cuisine in the media. It can also account for the ways in which institutional frameworks such as health and safety standards and immigrant codes of conduct police ethnic minority and immigrant bodies, such as what kinds of foods they are allowed to eat and prepare (Stasiulis 2013; Knezevic 2016). In sum, structural barriers are implicated in the mainstreaming of Filipino cuisine.

For some, knowing that Filipino cuisine is not represented in the culinary mainstream is what motivates them to engage in culinary entrepreneurship. The findings also indicate that new modes of ethnic and immigrant entrepreneurship are also born out of the third space (Bhabha 1994, 1996) - a mode of entrepreneurship that is born out of pride of one's ethnicity and culture, even in a society that is wrought with institutional racism. Again, the second generation Filipino participants had expressed that they were motivated to enter the culinary industry and start their restaurant business because they felt immense pride for their culture. Perhaps unknowingly, these participants became engaged in a larger politics of recognition. Filipinos in Canada are simultaneously "invisible" and "hypervisible" (McElhinny et al. 2012). Their restaurants are a response to the invisibility of Filipino cuisine in the culinary mainstream, and at the same time, they are also responding to the hypervisibility of racist stereotypes regarding Filipino cuisine. They are motivated by the desire to change how Filipino culture is perceived on a global scale in a way, "bridging the gap" through food. 
In both cities, the older generation Filipino participants remain ambivalent in terms of making their foods more "appealing" to non-Filipinos. The establishments primarily owned by this demographic were the turo-turo, carinderia, sari-sari stores, and Filipino bakeries. These establishments focused on serving "traditional" foods that catered to the nostalgia of the Filipino diaspora, who were longing for foods similar to what they could find back in the Philippines. As such, they did not pay much attention to the aesthetics of the foods served - they prioritized taste over visual appearance or smell. An example can be seen with tuyo, a type of dried preserved fish that has a very strong and off-putting odour - it was found at nearly every establishment of the traditional kind. It is rather telling that I did not find tuyo at any "modern" Filipino restaurant, perhaps because the smell and sight of the dish is unpleasant and not good for first impressions. Another commonality with these establishments is that they emphasized value for money. Generally, the foods served at these establishments were inexpensive and very budget friendly. The cost is accessible to those who do not have a lot of disposable income, which is ideal for customers working multiple jobs or long hours and do not have time to cook for their families. It is unsurprising, then, that in this sample, most buffet restaurants were of the "traditional" kind. As Melissa observes with her first generation clientele:

Filipinos will go where food is good and price is cheap... they care about quantity, so it's more bang for your buck.

In other words, there seems to be a preference among first generation Filipinos to seek foods that have more substance than form (Bourdieu 1984). The predilection to cheap and filling foods can be traced back to the historical and political conditions of the Philippines (Fernandez 1994). It is well-known that the Philippines is not a rich country and many of its citizens are in perpetual poverty due to the legacy of American imperialism (San Juan 2002), which is why 
hundreds of thousands of Filipinos migrate elsewhere to earn a living. Even in transnational contexts, there are many Filipinos who do not have a lot of money, especially those who work as nannies and caregivers or as Temporary Foreign Workers (Guevarra 2010; Vineberg 2010; Marshall 2014; Bonifacio 2013; McElhinny et al. 2012). They endure precarious working conditions, often with little pay and long working hours. They not only have to account for their own living expenses abroad, but they also have to take into account sending remittances to their families in the Philippines.

What my findings demonstrate is that modes of doing Filipino cuisine is contextually dependent and is a product of global but also sometimes quite local social processes. While there are similarities across different locales, such as the collective opinion that Filipino cuisine is not mainstream, or the class and generational differences between the "traditional" Filipino cuisine establishments owned by older first generation Filipinos and the "modern" Filipino cuisine establishments owned by second generation Filipinos and non-Filipinos; there are notable differences between Winnipeg and Ottawa's contexts is because of the different historical, political, and social contexts in each city. They have different migration histories, different demographic makeup, and have different labour markets. The approaches to the production of Filipino cuisine, therefore, are going to differ because of these aspects.

Yet, despite the differences in the narratives, it is evident that among all participants the cultural politics of Filipino cuisine in Canada is marked by a politics of resistance. For some, producing Filipino cuisine is an empowering act of resistance in the face of cultural assimilation; as Matthew and Nellie had demonstrated by providing tuyo for Filipinos nearby who cannot make it themselves due to restrictive apartment regulations. Turo-turos and carinderias also disrupt what it means to be a "real" restaurant in Canada, and provides diners with an 
unadulterated "norm-breaking" experience of Filipino cuisine without having to place too much attention on the aesthetic components. The affordable prices of such "traditional" establishments provide support to some members of the Filipino community who work multiple jobs and cannot otherwise take the time to cook meals for their family. Furthermore, these establishments are often pillars to their local Filipino community by providing diasporic Filipinos a space to savour the tastes of their homeland, as well as being engaged in cultural events such as festivals and community-wide celebrations. As such, many "traditional" Filipino cuisine entrepreneurs do not feel the need to cater to the wider non-Filipino audience.

For others, producing Filipino cuisine is a radical act of resistance against the erasure of Filipino culture in Canadian society. Filipinos are simultaneously "invisible" and "hypervisible" in Canada (McElhinny et al. 2012), and a burgeoning class of young Filipino cuisine entrepreneurs are seeking to change these dynamics by using their establishments as part of a politics of recognition. Through their business activities, they seek to represent Filipino cuisine on their own terms and work towards defying the problematic stereotypes that currently place Filipino cuisine in a marginal position in the Western culinary foodscape. Their establishments are a "third space" (Bhabha 1994, 1996), a site of hybridity that breaks away from rigid conceptions of "traditional" and "authentic" Filipino cuisine. After all, for many of these entrepreneurs, these establishments are their own interpretation of an authentic Filipino cuisine based on their lived experiences as a second generation immigrant in multicultural Canada.

This thesis is sociologically and methodologically relevant. According to a consumer outlook report published by Agriculture and Agri-Food Canada (2005), Canadians are developing an appetite for ethnic foods and are increasingly becoming multicultural in their eating practices, which is in part due to the changing demographic landscape of Canada, with the 
increase of immigrant and ethnic minority populations. Studying foodways and entrepreneurship practices among ethnic minorities and immigrants reveals the complex stories pertaining to survival, struggle, migration, and identity work. Furthermore, this research is relevant as it pertains to the current status of Filipino cuisine in the West. My research participants have all expressed that Filipino cuisine is becoming "trendy" in the culinary mainstream. While there has been research done on the cultural politics of Filipino cuisine in Western contexts (Andrei 2010; Barker 2014), they were written at a time when Filipino cuisine was not recognized as the next "up-and-coming" ethnic cuisine. To my knowledge, this thesis is the only one of its kind that discusses the cultural politics of Filipino cuisine when it is now on the verge of a "breakthrough". My research is methodologically innovative as I have adapted a methodological approach that incorporates Filipino psychological scholarship with sociological interpretive methods (Pe-Pua and Protacio-Marcelino 2000; Schwartz-Shea and Yanow 2012), in order to develop a methodology that is culturally appropriate for the group being studied. There is also a need for more scholarship on the dynamics of being an insider-researcher from a FilipinoCanadian perspective. A large portion of methodological literature focusing on Filipinos are often from a Filipino-American perspective (Guevarra 2006; Carling, Erdal, and Ezzati 2014).

This thesis has three major limitations. The first pertains to the differences in sample size between Winnipeg and Ottawa. Winnipeg's sample size is disproportionately higher than Ottawa's due to differences in demography. As a result, the findings of this research are skewed towards the Winnipeg perspective. Since I only interviewed three people from Ottawa I cannot make generalized claims pertaining to the Filipino community in Ottawa. Furthermore, two of those people are owners of modern Filipino restaurants. Perhaps if I were able to interview the owners of the "traditional" establishments their contributions may have enriched the data 
generated from Ottawa. It would have been ideal to have an equal number of participants from both cities, although I recognize that is unfeasible due to their demographic differences. Second, this research could have benefitted from more empirical data or historical works pertaining to the Filipino community in Ottawa. Again, this is a limitation brought upon by the demographic reality of Ottawa. At the time of writing this thesis I could not find substantial works that detailed the history of Filipino migration in Ottawa. Most works that discussed Ontario focused on the Greater Toronto Area and less so in the National Capital Region (Lusis 2005). With the lack of data at hand, I could only rely on anecdotal evidence to make an educated assumption about the nature of Filipino migration in Ottawa. Going forward, it may be useful to do a comprehensive study on the history of Filipino migration in Ottawa to address these gaps in the literature. Third, in retrospect the data may have been more consistent had I stuck to a more rigid criterion rather than a flexible one. If I had limited the study to Filipino-identified participants, perhaps I may have been able to make solid claims pertaining to the Filipino diaspora. The inclusion of non-Filipinos in this sample was both a blessing and a curse. On one hand, it was great to see non-Filipino's perspectives pertaining to Filipino cuisine. On the other hand, their responses were not very useful or relevant to the larger discussions pertaining to the FilipinoCanadian experience related to migration, cultural politics, and identity work. There were times where I had to skip several questions in the interviews because it did not apply to their own experiences.

The main contribution of this thesis pertains to critical multiculturalism studies scholarship, specifically, practices of resistance in liberal multicultural societies. This thesis demonstrates that social activism and practices of resistance can be enacted through entrepreneurial practices, specifically the cultural production of ethnic food. Most studies that 
pertain to the politics of resistance and social activism in the context of food practices tend to centre upon alternative food movements such as veganism, the local food movement, and the slow food movement (see Johnston and Baumann 2010; Guthman 2011 ) - all of which focus on the ethical aspects of food production and consumption. Moreover, these movements have been critiqued for their overt whiteness (Guthman 2011) and exclusionary analyses, especially towards low-income populations and persons of colour. My research moves away from these exclusionary frameworks and instead examines food movements, such as the Filipino Food Movement, that takes into consideration the experiences of persons of colour. Indeed, the findings of this thesis suggest that there is potential in studying practices of resistance in culinary entrepreneurship through the dimensions of race, ethnicity, and culture.

Additionally, this thesis contributes to several other areas. First, my thesis contributes to the growing field of critical food studies. Many studies done on the cultural politics of ethnic food and identity work are mostly from the perspective of the consumer rather than producer. This project contributes to the growing body of food scholarship that addresses the producer's perspective. Second, this project contributes to the currently small but growing scholarship on Filipinos in Canada. There is a need for more works on Filipino-Canadians situated in mid-sized Canadian cities (Lusis 2005). This study contributes to this gap in the literature by providing research on Filipinos in the Winnipeg and Ottawa context, both of which are mid-sized Canadian cities. Lastly, I contribute to the ethnic and immigrant entrepreneurship literature by proposing a new framework in examining the entrepreneurial logics of immigrant and ethnic entrepreneurs in transnational contexts. As demonstrated in this study, there are a number of participants who were motivated by ethnic and cultural pride as a driver for entrepreneurship. To my knowledge, the aspect of ethnic and cultural pride has not been addressed or theorized in the literature. 
However, I do acknowledge that this may be more applicable in sectors that deal with cultural production such as food, clothing, or music; rather than manufacturing or the service industry. Furthermore, I also contribute to the ethnic and immigrant entrepreneurship literature by focusing on a segment that remains largely underrepresented, which are the second generation immigrant entrepreneurs. Currently, most discussions are centralized on the experience of first generation ethnic minority immigrant entrepreneurs.

Filipino-Canadians are underrepresented in academic research, which does not represent the demographic reality of Canada. Filipinos are the fourth largest visible minority group in Canada, yet they remain underrepresented in many areas of Canadian society (McElhinny et al. 2012). Moreover, scholarly research on Filipino entrepreneurship is lacking in general, even more so in Canadian context. Like other Filipino-Canadian scholars before me, I believe that more works on Filipino-Canadians need to be published. There is a need for more research that takes into consideration that Filipino-Canadians are too involved in the Canadian labour force, cultural production, and other facets of Canadian society. My hope is that this thesis will contribute to the much-needed academic scholarship on Filipino-Canadians. 


\section{REFERENCES}

Agner, Mara. 2017. "Is BodyShaming Part of Our Filipino Culture?" Candy Magazine. Retrieved on June 13, 2017. (http://www.candymag.com/features/let-s-talk-about-body-shaming-inthe-philippines-a1510-20170523)

Agogue, Marine and Armand Hatchuel. 2016. "Reinventing classics: the hidden design strategies of renowned chefs.” Research in Engineering Design 27(1): 165-177.

Agoncillo, Teodoro A. 1974. Introduction to Filipino history. Quezon City, Philippines: Garotech Publishing.

Agriculture and Agri-Foods Canada. 2005. "Canadian Food Trends to 2020: A Long Range Consumer Outlook." Agriculture and Agri-Foods Canada: Ottawa. Retrieved on November 10, 2016.

(http://stayactiveeathealthy.ca/sites/default/files/resources/Canadian_Food_Trends_2020. pdf)

Aguila, Almond N. 2014. "Social Media and the Renegotiation of Filipino Diasporic Identities." Doctoral Thesis. Department of Secondary Education and Faculty of Extension. Edmonton, AB: University of Alberta.

--- . 2015. "The Filipino, Diaspora and a Continuing Quest for Identity." Social Science Diliman 11(2): 56-89.

Aguilar, Filomino V. Jr. 2002. Filipinos in Global Migrations: At Home in the World? Manila, Philippines: Migration Research Network and Philippine Social Science Council.

Allard, Danielle. 2015. "Living "Here" and "There": Exploring the Transnational Information Practices of Newcomers from the Philippines to Winnipeg." Doctoral Thesis. Faculty of Information. Toronto, ON: University of Toronto.

Anderson, Benedict. 1983. Imagined Communities: Reflections on the Origin and Spread of Nationalism. London, UK: Verso.

Anderson, Talmadge. 1982. "Black Entrepreneurship and Cocnepts Toward Economic Coexistence." Western Journal of Black Studies 6(1): 80-88.

Andrei, Amanda L. Tira. 2010. "Nanay's Kusina or Carinderia? The Perceived Lack of Filipino Restaurants in American Dining." Undergraduate Honors Thesis, Department of Anthropology, College of William and Mary.

Ang, Ien. 2003. "Together-in-difference: Beyond Diaspora, into Hybridity." Asian Studies Review 27(2): 141-154. 
---. 2010. "Between Nationalism and Transnationalism: Multiculturalism in a Globalising World." ICS Occasional Paper Series 1(1): 1-14.

Ang, Josiah C. 2016. "Historical Timeline of the Royal Sultanate of Sulu Including Related Events of Neighboring Peoples." SEAsite: Center for Southeast Asian Studies. Northern Illinois University. Retrieved April 4, 2017. (http://www.seasite.niu.edu/tagalog/Modules/Modules/MuslimMindanao/historical_timel ine_of_the_royal.htm).

Aranas, Marcial Q. 1983. The dynamics of Filipino immigrants in Canada. Edmonton, AB: Coles.

Asis, Maruja M.B. 2006. “The Philippines' Culture of Migration.” Migration Information. Retrieved February 28, 2017. (http://www.migrationpolicy.org/article/philippinesculture-migration)

Atanakovic, Jelena and Ivy Lynn Bourgeault. 2014. "Economic and Social Integration of Immigrant Live-in Caregivers in Canada." IRPP Study 2014 46(1): 1-25. (http://oppenheimer.mcgill.ca/IMG/pdf/IRPP_Economic_and_Social_Integration_of_Im migrant_Live-in_Caregivers_in_Canada.pdf)

Atkinson, Rowland, and John Flint. 2001. "Accessing Hidden and Hard-to-Reach Populations: Snowball Research Strategies." Social Research Update 33(1).

Azanza, Ma. Patricia V., Corazon F. Gatchalian, and Melba P. Ortega. 2000. "Food safety knowledge and practices of streetfood vendors in a Philippines university campus." International Journal of Food Sciences and Nutrition 4(1): 235-246.

Backhouse, Constance. 2007. Colour-coded: A Legal History of Racism in Canada, 1900-1950. Toronto, ON: University of Toronto Press.

Bakan, Abigail and Daiva Stasiulis. 2005. Negotiating Citizenship: Migrant Women in Canada and the Global System. Toronto, ON: University of Toronto Press.

Balibar, Etienne. 1991. "Is There a Neo-Racism?" Pp. 17-28 in Race, Nation, Class: Ambiguous Identities, edited by E. Balibar and I. Wallerstein. London, UK: Verso.

Barker, Lexie. 2014. "The Invisible Cuisine: why Filipino food has gone unnoticed." MA Thesis, Department of Specialized Journalism, Annenberg School for Communication.

Barretto, Glenda R. et al. 2013. Kulinarya: A Guidebook to Philippine Cuisine. Quezon City, Philippines: Anvil Publishing.

Batalla, Eric Vincent. 2010. "Entrepreneurship and Philippine Development." Canadian Journal of Development Studies 31(3-4): 341-365. 
Bautista, Darlyene and Janice Udarbe. 2001. "From Manila to Manitoba: Family History and Filipino Migration to Winnipeg." Prairie Perspectives: Geographical Essays (4): 232-242.

Beardsworth, Alan and Teresa Keil. 2002. Sociology on the Menu: An Invitation to the Study of Food and Society. London, UK: Routledge.

Bell, David. 2002. "Fragments for a New Urban Culinary Geography." Journal for the Study of Food and Society 6(1): 10-21.

Bello, Walden. 1991. "Moment of Decision: The Philippines, the Pacific, and the US bases." Pp. 149-166 in The Sun Never Sets: Confronting the Network of Foreign US Military Bases, edited by Joseph Gerson and Bruce Birchard Philadelphia, PA: American Friends Service Committee.

Bellwood, Peter and Eusebio Dizon. 2005. "The Batanes Archaeological Project and the "Out of Taiwan" Hypothesis for Austronesian Dispersal." Journal of Austronesian Studies 1(1): $1-32$.

Berg, Bruce L. 2001. Qualitative Research Methods for the Social Sciences. Needham Heights, MA: Pearson.

----. 2009. Qualitative Research Methods for the Social Sciences (7th edition). Needham Heights, MA: Pearson.

Berger, Roni. 2015. 'Now I see it, now I don't: researcher's position and reflexivity in qualitative research.” Qualitative Research 15(2): 219-234.

Bessiere, Jacinthe and Laurence Tibere. 2013. "Traditional food and tourism: French tourist experience and food heritage in rural spaces." Journal of the Science of Food and Agriculture 93(14): 3420-3425.

Bhabha, Homi K. 1996. "Cultures in Between.” Pp. 53-60 in Questions of Cultural Identity edited by Stuart Hall and Paul Du Gay. London, UK: Sage Publications.

---. 1994. The Location of Culture. London, UK: Routledge.

Bonacich, Edna. 1988. "The social costs of immigrant entrepreneurship.” Amerasia 14(1): 119128.

Bonifacio, Glenda Tibe. 2013. Pinay on the Prairies: Filipino Women and Transnational Identities. Vancouver, Toronto: University of British Columbia Press.

Borah, Eloisa Gomez. 1996. "Filipinos in Unamuno's California Expedition of 1587." Amerasia Journal 21(3). 
---. 2004. "Chronology of Filipinos in America Pre-1898.” Los Angeles: University of California Los Angeles. (http://personal.anderson.ucla.edu/eloisa.borah/chronology.pdf) Bourdieu, Pierre. 1984. Distinction: A Social Critique of the Judgement of Taste. Oxon, UK: Routledge.

Bowen, Glenn A. 2008. "Naturalistic Inquiry and the Saturation Concept: A Research Note." Qualitative Research 8(1).

Brady, Marilyn Dell. 2004. The Asian Texans. Houston, TX: Texas A\&M University Press.

Brayton, Sean and Brad Millington. 2011. "Renovating ethnic identity on Restaurant Makeover." Social Identities 17(2): 185-200.

Braziel, Jana Evans and Kathleen LeBesco. 2001. "Editors' Introduction." Pp. 1-15 in Bodies Out of Bounds: Fatness and Transgression, edited by Jana Evans Braziel and Kathleen LeBesco. Oakland, CA: University of California Press.

Buchholdt, Thelma. 1996. Filipinos in Alaska: 1788-1958. Alaska: Aboriginal Press.

Buduhan, Cleto M. 1972. "An Urban Village: The Effect of Migration on the Filipino Garment Workers in a Canadian City." Unpublished MA Thesis, Department of Anthropology, University of Manitoba.

Bulbeck, Chilla. 2004. "The 'white worrier' in South Australia: Attitudes to multiculturalism, immigration and reconciliation." Journal of Sociology 40(4): 341-361.

Bullinger, Cathrin, Stefan Seitz and Andreas Volz. 2012. "Dad Jollibee-Phanomen: "Filipino in taste - making proudly Filipino." Aneignungsprozesse im philippinischen Konsumverhalten in Geschichte und Gegenwart." Internationales Asienforum 43(3-4): 301-323.

Butler, John Sibley. 2005. Entrepreneurship and Self-Help Among Black Americans: A Reconsideration of Race and Economics. New York, NY: SUNY Press.

Butler, John, and Greene Patricia G. 1997. "Ethnic Entrepreneurship: The continuous rebirth of American Enterprise.” Pp. 267-289 in Entrepreneurship 2000, edited by Donald L. Sexton, Raymond W. Smilor. Chicago, IL: Upstart.

Cabral, Javier. 2016. "You Can Only Eat with Your Hands at LA's Biggest Filipino Dinner." Vice Munchies, February 17. Retrieved on March 30, 2017. (https://munchies.vice.com/en_us/article/9a8vjy/you-can-only-eat-with-your-hands-atlas-biggest-filipino-dinner) 
Caldwell, Alison. 2012. "Will Tweet for Food: Microblogging Mobile Food Trucks - Online, Offline, and In Line." Pp. 306-321 in Taking Food Public: Redefining Foodways in a Changing World, edited by Psyche Williams-Forson and Carole Counihan. New York, NY: Routledge.

Camia, Shirley. 2012. "Stitching History: Filipina Garment Workers in Winnipeg." Master's Thesis. Department of Immigration and Settlement Studies. Toronto, ON: Ryerson University.

Canadian Heritage River. 2015. "A Background Study for Nomination of the Ottawa River Under the Canadian Heritage Rivers System." Ottawa River Heritage Designation Committee. Ottawa, ON: Quebec-Labrador Foundation. Retrieved on April 1, 2017. (http://www.ottawariver.org/pdf/0-ORHDC.pdf)

Cappeliez, Sarah and Josee Johnston. 2013. "From meat and potatoes to "real-deal" rotis: Exploring everyday culinary cosmopolitanism." Poetics 41(5): 433-455.

Carling, Jorgen, Marta Bivand Erdal, and Rojan Ezzati. 2014. "Beyond the Insider-Outsider Divide in Migration Research." Migration Studies 2(1): 36-54.

Carriere, April. 2016. "History and Legacy of Refugee Resettlement in Ottawa: A Primer." Ottawa Local Immigration Partnership (OLIP). Ottawa, ON. (http://cciottawa.ca/wpcontent/uploads/History-and-Legacy-of-Refugee-Resettlement-In-Ottawa_A-Primer.pdf)

Catungal, John Paul C. 2012. "Scales of Violence from the Body to the Globe: Slain Filipino Youth in Canadian Cities." Pp. 321-340 in Filipinos in Canada: Disturbing Invisibility, edited by Roland Sintos Coloma, Bonnie McElhinny, Ethel Tungohan, John Paul C. Catungal, and Lisa M. Davidson. Toronto, ON: University of Toronto Press.

Chen, Anita Beltran. 1980. "Filipinos in Canada: A socio-demographic profile." in Visible Minorities and Multiculturalism: Asians in Canada, edited by K. Victor Ujimoto and Gordon Hirabayashi. Toronto, ON: Butterworths.

---. 1990. "Studies on Filipinos in Canada: State of the Art." Canadian Ethnic Studies 22(1): 8395.

--- 1998. From Sunbelt to Snowbelt: Filipinos in Canada. Calgary, AB: Canadian Ethnic Studies, University of Calgary.

Chen, Kuang-Jung. 1997. "The sari-sari store: informal retailing in the Philippines.” Journal of Small Business Management 35(4): 88-91.

Chen, Xiaobei. 2014. "Not Ethnic Enough: The Cultural Identity Imperative in International 
Adoptions from China to Canada." Children and Society 29(6): 626-636.

---. Forthcoming 2018. "Governing Cultures, Making Multicultural Subjects.” In Re-Making Normal: Governing the Social in Neoliberal Times, edited by D. Brock. Vancouver, BC: University of British Columbia Press.

Chez, Keridiana. 2011. "Popular Ethnic Food Guides as Auto/Ethnographic Project: The Multicultural and Gender Politics of Urban Culinary Tourism." The Journal of American Culture 34(3): 234-246.

Cho, Lily. 2010. Eating Chinese: Culture on the Menu in Small Town Canada. Toronto, ON: University of Toronto Press.

Churillo, Thessa Obrero. 2014. "Filipino "Kulinarya" Cuisine and Chronic Kidney Disease." Journal of Renal Nutrition 24(4): 31-35

City of Ottawa. n.d. "Economy and Demographics." City of Ottawa Financial Documents. Retrieved March 30, 2017. (http://documents.ottawa.ca/sites/documents.ottawa.ca/files/documents/wc017976.pdf)

Clapson, Dan. 2016. "Globally influenced Filipino food is taking North America by storm." Globe and Mail, November 16. Retrieved on July 11, 2017. (https://www.theglobeandmail.com/life/food-and-wine/food-trends/globally-influencedfilipino-food-is-taking-north-america-bystorm/article32858349/)

Clemente, Jose Antonio. 2011. "An Empirical Analysis of Research Trends in the Philippine Journal of Psychology: Implications for Sikolohiyang Pilipino." Philippine Social Sciences Review 63(1): 1-33.

Cohen, Rina. 2000. "'Mom is a stranger': The negative impact of immigration policies on the family life of Filipina domestic workers." Canadian Ethnic Studies 32(3): 76-88.

Cohen, Robin. Global diasporas: An introduction. London, UK: UCL.

Colic-Peisker, Val. 2004. "Doing Ethnography in "One's Own Ethnic Community": The Experience of an Awkward Insider." Pp. 83-94 in Anthropologists in the Field: Cases in Participant Observation, edited by Lynne Hume and Jane Mulcock. New York, NY: Columbia University Press.

Coloma, Roland Sintos, Bonnie McElhinny, Ethel Tungohan, John Paul C. Catungal, and Lisa M. Davidson. 2012. Filipinos in Canada: Disturbing Invisibility. Toronto, ON: University of Toronto Press.

Cordero-Fernando, Gilda. 1976. The Culinary Culture of the Philippines. Manila, Philippines: 


\section{Bancom Audiovision Corporation.}

Corydon Times. n.d. "Winnipeg’s Own MasterChef.” Retrieved July 11, 2017.

(http://corydontimes.ca/winnipegs-own-masterchef/)

Cotoi, Calin. 2011. "Neoliberalism: A Foucauldian Perspective." International Review of Social Research 1(2): 109-124.

Crang, Mike, and Ian Cook. 2007. Doing Ethnographies. London, UK: Sage.

Curaming, Rommel A. 2011. "Filipinos as Malay: Historicizing as an Identity." Pp. 241-273 in Melayu, edited by Maznah Mohamad and Syed Muhd Khairudin Aljunied. Singapore: NUS Press Pte Ltd.

Dagdag, Edgardo E. 2009. "Philippine-China Connection from Pre-Colonial Period to Post-Cold War Era: An Assessment.” Pp. 31-61 in Connecting and Distancing: Southeast Asia and China, edited by Ho Khai Leong. Singapore: Institute of Southeast Asian Studies.

Dalayoan, Gemma, Leah Enverga-Magsino, and Leonnie Bailon. 2008. The First Filipino Immigrants in Manitoba (1959-1975). Winnipeg, MB: Manitoba Filipino Writers Guild.

Damasco, Valerie G. 2012. "The recruitment of of Filipino Healthcare Professionals to Canada in the 1960s.” Pp. 97-124 in Filipinos in Canada: Disturbing Invisibility, edited by Roland Sintos Coloma, Bonnie McElhinny, Ethel Tungohan, John Paul C. Catungal, and Lisa M. Davidson. Toronto, ON: University of Toronto Press.

David, E.J.R. 2013. Brown Skin, White Minds: Filipino -/American Postcolonial Psychology. North Carolina: Information Age Publishing.

David, E.J.R. and Kevin L. Nadal. 2013. "The Colonial Context of Filipino American Immigrants' Psychological Experiences." Cultural Diversity and Ethnic Minority Psychology 19(3): 298-309.

David, E.J.R., Kristine B. Dinghy Sharma, and Jessica Petalio. 2017. "Losing Kapwa: Colonial Legacies and the Filipino American Family." Asian American Journal of Psychology 8(1): 43-55.

Davidson, Lisa M. 2012. "(Res)sentiment and Practices of Hope: The Labours of Filipina LiveIn Caregivers in Filipino Canadian Families.” Pp. 142-160 in Filipinos in Canada: Disturbing Invisibility, edited by Roland Sintos Coloma, Bonnie McElhinny, Ethel Tungohan, John Paul C. Catungal, and Lisa M. Davidson. Toronto, ON: University of Toronto Press.

Decena, Ashley Mika. 2014. "Identity, Colonial Mentality, and Decolonizing the Mind: 
Exploring Narratives and Examining Mental Health Implications for Filipino Americans." MSW Thesis, Department of Social Work, Smith College School for Social Work.

De Leon, Adrian. 2016. "Siopao and Power: The Place of Pork Buns in Manila's Chinese History." Gastronomica: The Journal of Critical Food Studies 16(2): 45-54.

Domingpe, Jiedson and Nenita Domingo. 2012. Elementary Tagalog: Tara, mag-Tagalog Tayo! Come on, let's speak Tagalog! North Clarendon, VT: Turtle Publishing.

Domosh, Mona. 2003. "Pickles and purity: Discourses of food, empire and work in turn-of-thecentury USA." Social and Cultural Geography 4(1): 7-26.

Douglas, Mary. 1999. "Deciphering a Meal." Pp. 231-251 in Implicit Meanings: Selected Essays in Anthropology (2nd ed.), edited by Mary Douglas. London, UK: Routledge.

Dresang, Joel. 1985. "Authoritarian controls and news media in the Philippines." Contemporary Southeast Asia 7(1): 34-47.

Duster, Troy. 2005. "Race and Reification in Science." Science 307(5712).

Elias, Megan. 2014. "The Palate of Power: Americans, Food and the Philippines after the Spanish-American War." Material Culture 46(1): 44-57.

Espina, Marina E. 1988. Filipinos in Louisiana. New Orleans, LA: Laborde.

Espiritu, Yen Le. 2001. "We don't Sleep around like White Girls Do": Family, Culture, and Gender in Filipina American Lives." Signs: Journal of Women in Culture and Society 26(2): 415-440.

Enriquez, Virgilio G. 1975. "Mga batayan ng Sikolohiyang Pilipino sa kultura at kasaysayan (The bases of Filipino psychology in culture and history)." General Education Journal 29(1): 61-88.

---. 1978. "Kapwa: A core concept in Filipino social psychology." Philippine Social Sciences and Humanities Review 42(1): 1-4.

Fanon, Frantz. 2005. The Wretched of the Earth. New York, NY: Grove Press.

---. 2008. Black Skin, White Masks. New York, NY: Grove Press.

Farrales, May, and Geraldine Pratt. 2012. "Stalled Development of Immigrant Filipino Youths: 
Migration, Suspended Ambitions and the ESL Classroom.” Pp. 1-62, Metropolis Working Paper Series No. 12-10, edited by Linda Sheldon, Krishna Pendakur, and Daniel Hiebert. Vancouver, BC.

Fawcett, James T. and Gardner, Robert W. 1994. "Asian Immigrant Entrepreneurs and NonEntrepreneurs: A Comparative Study of Recent Korean and Filipino Immigrants." Population and Environment: A Journal of Interdisciplinary Studies 15(3): 211-238.

Filipino Food Movement. n.d. “About.” The Filipino Food Movement. Retrieved on July 11, 2017. (http://www.filipinofoodmovement.org/)

Fleras, Augie and Jean Leonard Elliot. 1996. Unequal Relations : An introduction to race, ethnic and Aboriginal Dynamics in Canada. Toronto, ON: Prentice Hall Canada.

Flores, Penelope V. 1999. "The Use of Pilipino/Filipino/Philippines: A Primer." Heritage 13(2).

Flowers, Rick and Elaine Swan. 2012. "Eating the Asian Other? Pedagogies of Food Multiculturalism in Australia." PORTAL Journal of Multidisciplinary International Studies 9(2): 1-30.

Fernandez, Doreen G. 1988. "Culture Ingested: Notes on the Indigenization of Philippine Food." Philippine Studies 36(2): 219-232.

---. 1993. “A Town Bejeweled: Philippine Food Art.” Pp. 74-79 in Look and Feel, Studies in Texture, Appearance and Incidental Characteristics of Food: Proceedings of the Oxford Symposium on Food and Cookery 1993, edited by Harlan Walker. Blackawton, UK: Prospect Books.

---. 1994. Tikim: Essays on Philippine Food and Culture. Quezon City, Philippines: Anvil Publishing.

---. 2002. “Balut to Barbecue: Philippine Streetfood.” Budhi 2(1): 329-340.

Fernandez, Doreen G., and Edilberto N. Alegre. 1990. Lasa: A Guide to Dining in the Provinces. Makati City, Philippines: Bookmark.

Ferrera, Maria J. 2016. "The Burden of Colonial Debt and Idebtedness in Second Generation Filipino American Families." Journal of Sociology and Social Welfare 43(3): 155-178.

Fine, Gary Alan. 1992. "The Culture of Production: Aesthetic Choices and Constraints in Culinary Work." American Journal of Sociology 97(5): 1268-1294.

Foucault, Michel. 1991. “Governmentality.” Pp. 87-104 in The Foucault Effect: Studies in Governmentality, edited by G. Burchell, C. Gordon and P. Miller. Chicago, IL: The University of Chicago Press. 
Frankenberg, Ruth. 1993. White Women, Race Matters: The Social Construction of Whiteness. Minneapolis, MN: University of Minnesota Press.

Fraser, Nancy. 2009. "Feminism, Capitalism, and the Cunning of History.” New Left Review 56(1): 97-117.

Fregetto, Eugene. 2004. "Immigrant and Ethnic Entrepreneurship." Pp. 240-253 in Entrepreneurship: The Way Ahead, edited by Harold P. Welsch. New York, NY: Routledge.

Fresnoza-Flot, Asuncion and Antoine Pecoud. 2007. "Emergence of Entrepreneurship Among Filipino Migrants in Paris.” Asian and Pacific Migration Journal 16(1): 1-28.

Gehman, Rebecca. 2012. "'Fast Food for the Filipino Soul:" Consuming Identity at Jollibee in Queens." Undergraduate Thesis, Department of American Studies, Fordham University.

Gilroy, Paul. 2012. “'My Britain is fuck all': Zombie multiculturalism and the race politics of citizenship.” Identities: Global Studies in Culture and Power 19(4): 380-397.

Goldberg, David Theo. 2008. “Buried, Alive.” Pp. 1-31 in The Threat of Race: Reflections on Racial Neoliberalism, edited by D.T. Goldberg. Oxford, UK: Wiley-Blackwell.

Golob, Matias I. and Audrey R. Giles. 2017. "Immigrant entrepreneurship in Canada: sites for cultural preservation, inclusion, and community development." Journal of Multicultural Discourses 1(1): 27-41.

Gonzalez, Andrew. 1992. "Higher education, brain drain and overseas employment in the Philippines: Towards a differentiated set of solutions.” Higher Education 23(1):21-31.

Gonzalez, Joaquin. 1998. Philippine Labour Migration: Critical Dimensions of Public Policy. Singapore: Institute of Southeast Asian Studies.

Government of Manitoba, n.d. "Population Groups and Ethnic Origins.” Pp. 1-62, Ethnicity Series: A demographic portrait of Manitoba, vol. 3. Winnipeg, MB. Retrieved March 1, 2017. (http://www.gov.mb.ca/chc/multiculturalism/pdf/manitoba-immigration-ethnicityseries-3.pdf)

Green, Shelley and Paul Pryde. 1997. Black Entrepreneurship in America. New Brunswick, NJ: Transaction Publishers.

Guerrero, Luis et al. 2009. "Consumer-driven definition of traditional food products and innovation in traditional foods. A qualitative cross-cultural study." Appetite 52(1): 345354. 
Guevarra, Anna Romina. 2006. "The Balikbayan Researcher: Negotiating vulnerability in fieldwork with Filipino labor brokers." Journal of Contemporary Ethnography 35(5): 526-551.

---. 2010. Marketing Dreams, Manufacturing Heroes: The Transnational Labor Brokering of Filipino Workers. New Brunswick, NJ: Rutgers University Press.

Gunaratnam, Yasmin. 2003. Researching "Race" and Ethnicity: Methods, Knowledge and Power. London, UK: Sage.

Guthman, Julie. 2011. "'If They Only Knew": The Unbearable Whiteness of Alternative Food." Pp. 263-282 in Cultivating Food Justice: Race, Class and Sustainability, edited by Alison Hope Alkon and Julian Agyeman. Cambridge, MA: The MIT Press.

Gvion, Liora and Naomi Trostler. 2008. "From Spaghetti and Meatballs through Hawaiian Pizza to Sushi: The Changing Nature of Ethnicity in American Restaurants." The Journal of Popular Culture 41(6): 950-974.

Hage, Ghassan. 1998. White Nation: Fantasies of White Supremacy in a Multicultural Society. Annandale, NSW: Pluto Press.

Hall, Stuart. 1990. "Cultural identity and diaspora." Pp. 222-237 in Identity, edited by Jonathan Rutherford. London, UK: Lawrence and Wishart.

---. 1991. "Old and New Identities, Old and New Ethnicities." Pp. 41-68 in Culture, Globalization, and the World-System: Contemporary Conditions for the Representation of Identity, edited by Anthony D. King. Minneapolis, MN: University of Minnesota Press.

---. 1992. "The Question of Cultural Identity.” Pp. 274-316 in Modernity and Its Futures, edited by Stuart Hall, David Held and Anthony McGrew. Cambridge, UK: Polity Press.

---. 2000. "Conclusion: the multicultural question." Pp. 209-241 in Un/settled Multiculturalisms: Diasporas, Transuptions, edited by Bamor Hesse. London, UK: Zed Books.

Haraway, Donna. 1988. "Situated Knowledges: The Science Question in Feminism and the Privilege of Partial Perspective." Feminist Studies 14(3): 575-599.

Harvey, David. 2005. A Brief History of Neoliberalism. Oxford, UK: Oxford University Press.

Heinrich, Samantha. 2017. "The 'Savage' Filipino Natives and Their Dog-Eating Habits." Western Illinois Historical Review 8(1): 25-41.

Heldke, Lisa. 2001. "Let's Eat Chinese! Reflections on Cultural Food Colonialism." 
Gastronomica 1(2).

---. 2003. Exotic Appetites: Ruminations of a Food Adventurer. New York, NY: Routledge.

---. 2005. "But Is It Authentic? Culinary Travel and the Search for the 'Genuine' Article." Pp. 385-394 in The Taste Culture Reader: Flavor, Food and Meaning, edited by Carolyn Korsmeyer. Oxford, UK: Berg.

Henry, Frances and Carol Tator. 1999. "State Policy and Practices as Racialized Discourse: Multiculturalism, the Charter, and Employment Equity." Pp. 88-115 in Race and Ethnic Relations in Canada, edited by Peter S. Li. Don Mills, ON: Oxford University Press.

Hesse-Biber, Sharlene Nagy. 2013. The Handbook of Feminist Research: Theory and Praxis. Thousand Oaks, CA: Sage.

Hirose, Akihiko and Kay Kei-Ho Pih. 2011. "'No Asians Working Here': Racialized "Other"ness and Authenticity in Gastronomical Orientalism." Ethnic and Racial Studies 34(9): 14821501.

Horng, Jeou-Shyan and Meng-Lei (Monica) Hu. 2008. "The Mystery in the Kitchen: Culinary Creativity.” Creativity Research Journal 20(2): 221-230.

Ho, Soleil. 2017. "Let's Call it Assimilation Cooking." Taste, June 26. Retrieved on July 2. (http://www.tastecooking.com/lets-call-assimilation-food/)

Howard, Irene. 1973. Bowen Island 1872-1972. Victoria, BC: Morriss Print Co.

Howard, Michael C. 2011. Transnationalism and Society: An Introduction. Jefferson, NC: McFarland and Company Inc.

Hung, Hsiao-chun, Mike T. Carson, Peter Bellwood, Fredeliza Z. Campos, Philip J. Piper and Eusebio Dizon. 2011. "The first settlement of remote Oceania: the Philippines to the Marianas." Antiquity 85(1).

Huynh, Nancy. 2012. "Eating Versus Selling Authenticity: Negotiating Toronto's Vietnamese Culinary Landscape." MA Thesis, Department of Geography, Queen's University.

Ignacio, Emily Noelle. 2005. Building Diaspora: Filipino Cultural Community Formation on the Internet. New Brunswick, NJ: Rutgers University Press.

Janer, Zilkia. 2007. “(IN)EDIBLE NATURE.” Cultural Studies 21(2-3): 385-405.

Jocano, F. Landa. 1967. “The beginnings of Filipino society and culture.” Philippine Studies 15(1): 9-40. 
Johnston, Josee and Shyonn Baumann. 2010. Foodies: Democracy and Distinction in the Gourmet Foodscape. New York, NY: Routledge.

Johnson, James P., Joseph Mark Munoz and Ilan Alon. 2007. "Filipino ethnic entrepreneurship: An integrated review and propositions." International Entrepreneurship and Management Journal 3(1): 69-85.

Kacen, Lea and Julia Chaitin. 2006. "The times are a changing: understanding qualitative research in ambiguous, conflictual and changing contexts." Qualitative Report 11(1): 209-228.

Kamphuis, Carlijn B. M., Tessa Jansen, Johan P. Mackenbach, and Frank J. van Lenthe. 2015. "Bourdieu's Cultural Capital in Relation to Food Choices: A Systematic Review of Cultural Capital Indicators and an Empirical Proof of Concept." PLOS One 10(8): 1-19.

Kelley, Ninette, and Michael Trebilcock. 2010. The Making of the Mosaic: A History of Canadian Immigration Policy (2nd ed.). Toronto, ON: University of Toronto Press.

Kelly, Casey R. 2014. "Bizarre Foods: White Privilege and the Neocolonial Palate.” Scholarship and Professional Work - Communication. Paper 97. (http://digitalcommons.butler.edu/ccom_papers/97)

Kelly, Phillip F. 2006. "Filipinos in Canada: Economic Dimensions of Immigration and Settlement." CERIS Working Paper No. 48. Toronto, ON: Joint Centre of Excellence for Research on Immigration and Settlement.

---. 2014. Understanding intergenerational social mobility: Filipino youth in Canada. IRPP Study 45(1): 1-40. (http://irpp.org/wp-content/uploads/assets/research/diversityimmigration-and-integration/filipino-youth/kelly-feb-2014.pdf)

Keshen, Jeff, and Nicole J. St-Onge. 1999. Ottawa: Making a Capital. Ottawa, ON: University of Ottawa Press.

Kim, Kwang Ok. 2015. Re-Orienting Cuisine: East Asian Foodways in the Twenty-First Century. Brooklyn, NY: Berghahn Books.

Kludt, Amanda. 2017. "Bourdain Says Filipino Food Will Be the Next Big Thing in America." Eater, June 7. Retrieved on July 11, 2017. (https://www.eater.com/2017/6/7/15753640/bourdain-filipino-food)

Knezevic, Irena. 2016. "Illicit food: Canadian food safety regulation and informal food economy." Critical Policy Studies 4(1): 410-425.

Knowles, Valerie. 2016. Strangers at Our Gates: Canadian Immigration and Immigration Policy, 1540-2015. Toronto, ON: Dundurn. 
Knowlton, Andrew. 2016. "Bad Saint Is the \#2 Best New Restaurant in America 2016." Bon Appetit Magazine, August 16. Retrieved on July 11, 2017. (http://www.bonappetit.com/story/bad-saint-washington-dc)

Kobayashi, Audrey. 2008. "A Research and Policy Agenda for Second Generation Canadians: Introduction." Canadian Diversity 6(2): 3-6.

Kong, Jacqui. 2011. "Feasting with the 'Other': Transforming the Self in Food Adventuring Television Programs." Asian American Literature: Discourses and Pedagogies 2(1): 4556.

Kraidy, Marwan M. 2002. "Hybridity in Cultural Globalization." Communication Theory 12(3): 316-339.

$\mathrm{Ku}$, Robert Ji-Song, Martin F. Manalansan IV, and Anita Mannur. 2013. Eating Asian America: A Food Studies Reader. New York, NY: NYU Press.

Larsen, Leif. 2016. "Chef Exposing Winnipeggers to Filipino Cuisine, 1 pop up dinner at a time." CBC News Manitoba, April 25.

(http://www.cbc.ca/news/canada/manitoba/winnipeg-chef-filipino-food-pop-up$1.3551149)$

Laquian, Eleanor R. 1973. A Study of Filipino Immigration to Canada, 1962-1973. Ottawa, ON: United Council of Filipino Associations in Canada.

---. 2011. "Filipinos.” The Canadian Encyclopedia, retrieved on March 30, 2017. (http://www.thecanadian encyclopedia.com/)

LeBesco, Kathleen and Peter Naccarato. 2008. "Introduction." Pp. 1-12 in Edible Ideologies: Representing Food and Meaning, edited by Kathleen LeBesco and Peter Naccarato. Albany, NY: State University of New York Press.

Levesque, Lia. 2017. “Canadian Food Habits, Attitudes Towards Meals Are Shifting: Dalhousie Study." Huffington Post, retrieved on March 30, 2017. (http://www.huffingtonpost.ca/2017/05/19/canadian-food-habits_n_16704852.html)

Li, Jun. 2008. "Ethical Challenges in Participant Observation: A Reflection on Ethnographic Fieldwork.” The Qualitative Report 13(1): 100-115.

Lichauco, Samantha. 2016. "Fat Not Allowed." PLUMP Magazine. Retrieved on June 13, 2017. (http://plump.ph/fat-not-allowed/)

Lindsay, Colin. 2007. The Filipino Community in Canada, 2001. Catalogue no. 89-621-XIE. Ottawa: Statistics Canada. 
Liu, Helen. 2016. "Beneath the white gaze: Strategic self-Orientalism among Chinese Australians." Human Relations 70(7): 781-804.

Llamzon, Teodoro A. 1968. "On Tagalog as Dominant Language." Philippine Studies 16(4): 729-749.

Locher, Julie L., William C. Yoels, Donna Maurer and Jillian van Ells. 2005. "Comfort Foods: An Exploratory Journey into the Social and Emotional Significance of Food." Food and Foodways 13(4): 273-297.

Long, Lucy M. 2004. "Culinary Tourism: A Folkloristic Perspective on Eating and Otherness." Pp. 20-50 in Culinary Tourism, edited by Lucy M. Long. Lexington, KY: The University Press of Kentucky.

Lopez, Joseph. 2016. "First Filipinos in Canada.” JLopezMB, retrieved on April 1, 2017. (http://jlopezmb.blogspot.ca/2016/03/first-filipinos-in-canada.html)

Lu, Shun and Gary Alan Fine. 1995. "The Presentation of Ethnic Authenticity: Chinese Food as a Social Accomplishment.” The Sociological Quarterly 36(3): 535-553.

Lusis, Tom. 2005. "Filipino immigrants in Canada: A literature review and directions for further research on second-tier cities and rural areas." Immigrant Labour Project, University of Guelph.

Maas, Marisha. 2005. "Transnational Entrepreneurship: Exploring Determinants and Impacts of a Dutch-based Filipino Immigrant Business." Asian and Pacific Migration Journal 14(12): 169-191.

---. 2008. "Door-to-door cargo agents: cultivating and expanding Filipino transnational space." Pp. 135-148 in Tales of Development: People, Power, and Space, edited by Paul Hebnick, Sef Slootweg, and Lothar Smith. Assen, Netherlands: Royal Van Gorcum.

Mabalon, Dawn Bohulano. 2013. "As American as Jackrabbit Adobo: Cooking, Eating, and Becoming Filipina/o American before World War II." Pp. 147-176 in Eating Asian America: A Food Studies Reader, edited by Robert Ji-Song Ku, Martin F. Manalansan and Anita Mannur. New York, NY: NYU Press.

Macalay, Raymund. 2015. "What is a Boodle Fight?" Ang Sarap. Retrieved on July 11, 2017. (http://www.angsarap.net/2015/05/21/what-is-a-boodle-fight/)

MacCannell, Dean. 1976. The Tourist: A New Theory of the Leisure Class. Oakland, CA: University of California Press.

MacLeod, Meredith. 2016. "Long Lineups in Frigid Temps as Jollibee Opens First Canadian 
Outpost." CTV News, December 16. Retrieved July 11, 2017.

(http://www.ctvnews.ca/canada/long-lineups-in-frigid-temps-as-jollibee-opens-firstcanadian-outpost-1.3206672)

Mahtani, Minelle. 2002. "Interrogating the Hyphen-Nation: Canadian Multicultural Policy and 'Mixed Race' Identities." Social Identities 8(1): 67-90.

Malek, John. 2016. "Filipinos in Canada before 1900.” Pilipino Express, retrieved April 4, 2017. (http://www.pilipino-express.com/history-a-culture/it-s-all-history/3525-filipinos-incanada-before-1900.html)

Manalansan, Martin F. 2013. "Beyond Authenticity: Rerouting the Filipino Culinary Diaspora." Pp. 288-302 in Eating Asian America: A Food Studies Reader, edited by Robert Ji-Song $\mathrm{Ku}$, Martin F. Manalansan and Anita Mannur. New York, NY: NYU Press.

Mannur, Anita. 2005a. “'Peeking Ducks' and 'Food Pornographers: Commodifying Culinary Chinese Americanness." Pp. 19-38 in Culture, Commodity, Identity: Chinese Diasporic Literatures in English, edited by Kam Louie and Tseen Khoo. Montreal, QC: McGillQueen's University Press.

---. 2005b. "Model Minorities Can Cook: Fusion Cuisine in Asian America." Pp. 72-94 in East Main Street: Asian American Popular Culture, edited by Shilpa Dave, Leilani Nishime and Tasha G. Oren. New York, NY: NYU Press.

---. 2007. "Culinary Nostalgia: Authenticity, Nationalism, and Diaspora." MELUS 32(4): 11-31.

---. 2009. Culinary Fictions: Food in South Asian Diasporic Literature. Philadelphia, PA: Temple University Press.

Manzanilla, Johsa. 2009. "Citizenship Notwithstanding: An analysis of social exclusion narratives by Filipino postcolonial diaspora in Winnipeg." Master's Thesis, Department of Human Rights, Development, and Social Justice (HDS). Erasmus University.

Marshall, Alison. 2014. "Bayanihan and Belonging: Filipinos in Manitoba." Manitoba History 76(1): 11-18.

---. 2015. "Stories of Bayanihan and Belonging: Filipinos in Manitoba, Part 2." Manitoba History 77(1): 13-22.

Matejowsky, Ty. 2007. "SPAM and Fast-food "Glocalization" in the Philippines." Food, Culture and Society 10(1): 23-41.

---. 2013. "The Incredible, Edible Balut: Ethnographic Perspectives on the Philippines' Favorite Liminal Food." Food, Culture and Society 16(3): 387-404.

Mayan, Maria J. 2016. Essentials of Qualitative Inquiry. New York, NY: Left Coast Press Inc. 
McElhinny, Bonnie, Lisa M. Davidson, John Paul C. Catungal, Ethel Tungohan, and Roland Sintos Coloma. 2012. "Spectres of (In)visibility: Filipina/o Labour, Culture, and Youth in Canada." Pp. 5-45 in Filipinos in Canada: Disturbing Invisibility, edited by Roland Sintos Coloma, Bonnie McElhinny, Ethel Tungohan, John Paul C. Catungal, and Lisa M. Davidson. Toronto, ON: University of Toronto Press.

McFerson, Hazel M. 2002. Mixed Blessing: The Impact of the American Colonial Experience on Politics and Society in the Philippines. Westport, CT: Greenwood Press.

McNamara, Keith, and Jeanne Batalova. 2015. "Filipino Immigrants in the United States." Migration Information. Retrieved February 28, 2017.

(http://www.migrationpolicy.org/article/filipino-immigrants-united-states)

McNeilly, Claudia. 2017. "How Filipino Food Is Becoming the Next Great American Cuisine." Vogue, June 1. Retrieved on July 11, 2017. (http://www.vogue.com/article/filipino-foodphilippines-cuisine-restaurants)

Melamed, Jodi. 2006. "The Spirit of Neoliberalism: From Racial Liberalsim to Neoliberal Multiculturalism." Social Text 24(4): 1-24

Mendoza, S. Lily. 2002. Between the homeland and the diaspora: The politics of theorizing Filipino and Filipino identities. New York, NY: Routledge.

Mendoza, S. Lily, and Jim Perkinson. 2003. "Filipino "Kapwa" in Global Dialogue: A Different Politics of Being-With the "Other."' Intercultural Communication Studies 7(4): 277-293.

Mercene, Floro L. 2007. Manila Men in the New World: Filipino Migration to Mexico and the Americas from the Sixteenth Century. Quezon City, Philippines: The University of Philippines Press.

Meredith, Paul. 1998. "Hybridity in the Third Space: Rethinking Bi-cultural Politics in Aotearoa/New Zealand." Presented at Te Oru Rangahau Maori Research and Development Conference, July 7-9, Massey University. Retrieved July 11, 2017. (http://lianz.waikato.ac.nz/PAPERS/paul/hybridity.pdf)

Merry, Sally Engle, and Susan Bibler Coutin. 2014. "Technologies of Truth in the Anthropology of Conflict: AES/APLA Presidential Address, 2013." American Ethnologist: Journal of the American Ethnological Society 41(1): 1-16.

Molz, Jennie Germann. 2004. "Tasting an Imagined Thailand: Authenticity and Culinary Tourism in Thai Restaurants.” Pp. 53-75 in Culinary Tourism, edited by Lucy M. Long. Lexington, KY: The University Press of Kentucky.

---. 2007. “Eating Difference: The Cosmopolitan Mobilities of Culinary Tourism.” Space and 
Culture 10(1): 77-93.

Nadal, Kevin L. 2011. Filipino American Psychology: A Handbook of Theory, Research, and Clinical Practice. Hoboken, NJ: John Wiley and Sons, Inc.

Nadal, Kevin L. and Jennifer Mozones. 2011. "Neuropsychological assessments and Filipino Americans: Cultural implications for practice." Pp. 47-70 in The Neuropsychology of Asian Americans, edited by Daryl E.M. Fujii. New York, NY: Taylor and Francis Group, LLC.

Narag, Raymund, and Sheila R. Maxwell. 2014. "Understanding cultural context when collecting field data: Lessons learned from field research in a slum area in the Philippines." Qualitative Research 14(3): 311-326.

Neuwirth, Gertrud, and Lynn Clark. 1981. "Indochinese Refugees in Canada: Sponsorship and Adjustment." The International Migration Review 15(1/2): 131-140.

Noh, Samuel, Ann H. Kim, and Marianne S. Noh. 2012. Korean Immigrants in Canada: Perspectives on Migration, Integration, and the Family. Toronto, ON: University of Toronto Press.

Obokata, Reiko. 2014. "Environmental Factors and Transnational Migration: A case study with Filipino newcomers in Ottawa, Canada." Master's thesis. Department of Geography, University of Ottawa. Ottawa, ON.

Okazaki, Sumie, E.J.R. David, and Nancy Abelmann. 2008. "Colonialism and the Psychology of Culture." Social and Personality Psychology Compass 2(1): 90-106.

Oldham, Gabriella. 2015. "Restaurants and Cuisine, Filipino American." Pp. 303-304 in Asian American History and Culture: An Encyclopedia, edited by Hping Ling and Allan W. Austin. New York, NY: Routledge.

Ong, Aihwa. 1995. "Women out of China: Traveling tales and traveling theories in postcolonial feminism." Pp. 350-372 in Women writing culture, edited by Ruth Behar and Deborah A. Gordon. Berkeley, CA: University of California Press.

---. 1996. "Cultural citizenship as subject making: Immigrants negotiate racial and cultural boundaries in the United States." Current Anthropology 37(5): 737-762.

---. 2006. Neoliberalism as Exception: Mutations in Citizenship and Sovereignty. Durham, NC: Duke University Press.

Orquiza, Rene Alexander Jr. 2013. "Lechon with Heinz, Lea and Perrins with Adobo: The 
American Relationship with Filipino Food, 1898-1946." Pp. 177-185 in Eating Asian America: A Food Studies Reader, edited by Robert Ji-Song Ku, Martin F. Manalansan and Anita Mannur. New York, NY: NYU Press.

Oum, Young Rae. 2005. "Authenticity and representation: cuisines and identities in KoreanAmerican diaspora." Postcolonial Studies 8(1): 109-125.

Pacho, Arturo. 1986. "The Chinese Community in the Philippines: Status and Conditions." Sojourn: Journal of Social Issues in Southeast Asia 1(1): 76-91.

Padgett, Deborah K. 2008. Qualitative Methods in Social Work Research. Thousand Oaks, CA: Sage.

Palanca, Clinton. 2016. "Filipino food is always the bridesmaid, never the bride." Esquire, November 28. Retrieved on July 11, 2017. (http://www.esquiremag.ph/culture/food-anddrink/filipino-food-international-a1515-20161128-lfrm2)

Pe-Pua, Rogelia 2006. "From Decolonizing Psychology to the Development of a CrossIndigenous Perspective in Methodology: The Philippine Experience." Pp. 109-137 in Indigenous and Cultural Psychology: Understanding People in Context, edited by Uichol Kim, Kuo-Shu Yang, and Kwang-Kuo Hwang. New York, NY: Springer.

Pe-Pua, Rogelia, and Elizabeth Protacio-Marcelino. 2000. "Sikolohiyang Pilipino (Filipino psychology): A legacy of Virgilio G. Enriquez.” Asian Journal of Social Psychology 3 (1): 49-71.

Pfeifer, Mark Edward. 1999. "Community, adaptation, and the Vietnamese in Toronto". Toronto, ON: University of Toronto.

Philippine Culinary Heritage Movement. 2017. In Facebook [Fan Page]. Retrieved July 12, 2017. (https://www.facebook.com/philippineculinaryheritagemovement/)

Philippine Statistics Authority. 2016. Total Number of OFWs Estimated at 2.2 Million (Results from the 2016 Survey on Overseas Filipinos). 2016 Survey on Overseas Filipinos. Philippine Statistics Authority reference no. 2017-129. Quezon City, Philippines.

Pido, Antonio J.A. 1986. The Pilipinos in America: Macro/micro dimensions of immigration and integration. Staten Island, NY: Center for Migration Studies.

Pijpers, Roos, and Marisha Maas. 2014. "Identity construction and 'coincidental' entrepreneurship among gay Filipino guesthouse owners in Amsterdam." Gender, Place and Culture 21(8): 996-1011.

Pitcher, Ben. 2014. Consuming Race. Oxon, New York: Routledge. 
Posadas, Barbara Mercedes. 1999. The Filipino Americans. Westport, CT: Greenwood Press.

Pratt, Geraldine. 2006. "Separation and reunification among Filipino families in Vancouver." Canadian Business and Current Affairs, Spring 2006.

Pratt, Geraldine et al. 2017. "Between Homes: Displacement and Belonging for SecondGeneration Filipino-Canadian Youths." Pp. 145-168 in Asian Canadian Studies Reader, edited by Roland Sintos Coloma and Gordon Pon. Toronto, ON: University of Toronto Press.

Pujol, Anton. 2009. "Cosmopolitan Taste: The Morphing of the New Catalan Cuisine." Food, Culture and Society 4(1): 437-455.

Reid, Lawrence A. 2005. "Tagalog and Philippine Languages." Pp. 3-4 in Encyclopedia of Linguistics edited by Phillip Stranzy. London, UK: Routledge.

Reisenleitner, Markus. 2001. "Tradition, Cultural Boundaries and the Construction of Spaces of Identity." Tradition, Cultural Boundaries, and Identity Formation in Central Europe and Beyond 1(1). (http://soi.journals.yorku.ca/index.php/soi/article/view/8052/7228)

Roces, Mina. 2014. "A Space in Social Memory - Filipina/o American Migrants as Community Historians, 1906-2010." Pp. 1-26 in Occasional Paper Series, edited by Jurgen Ruland, Judith Schlehe, Gunther Schulze, Sabine Dabringhaus, and Stefan Seitz. Freiburg, Germany: Southeast Asian Studies at the University of Freiburg.

Rodriguez, Robyn Magalit. 2010. Migrants for Export: How the Philippine State Brokers Labor to the World. Minneapolis, MN: University of Minnesota Press.

Rogando, Daniel Ray E. "Exotica Ilocandia: Photo Complication of Various Exotic Foods by Ilocano.” Undergraduate Dissertation, Department of Graphics Design and Multimedia, De La Salle University.

Ronquillo, Charlene, Geertje Boschma, Sabrina T. Wong, and Linda Quiney. 2011. "Beyond greener pastures: exploring contexts surrounding Filipino nurse migration in Canada through oral history." Nursing Inquiry 18(3): 262-275.

Rothblum, Esther and Sondra Solovay. 2009. The Fat Studies Reader. New York, NY: NYU Press.

Said, Edward W. 1993. Culture and Imperialism. New York, NY: Alfred A. Knopf.

---. [1987]2000. The Edward Said Reader. New York, NY: Vintage.

San Juan, Epifanio. Jr. 2001. “The Filipino Diaspora.” Philippine Studies 49(2): 255-264. 
---. 2002. Racism and Cultural Studies: Critiques of Multiculturalist Ideology and the Politics of Difference. Durham, NC: Duke University Press.

Schwartz-Shea, Peregrine, and Dvora Yanow. 2012. Interpretive Research Design: Concepts and Processes. New York, NY: Routledge.

Shome, Raka. 2012. "Mapping the Limits of Multiculturalism in the Context of Globalization." International Journal of Communication 6(1): 144-165.

Simmel, Georg. 1997. "Sociology of the Meal." Pp. 130-136 in Simmel on Culture, edited by David Frisby and Mike Feathersone. London, UK: Sage.

Sit, Michelle. 2008. "The Filipino 'exhibit' at the 1904 St. Louis World's Fair, Missouri." MAI Review 2(1): 1-5.

Siu, Lok. 2011. "Twenty-First Century Food Trucks: Mobility, Social Media, and Urban Hipness." Pp. 231-244 in Eating Asian America: A Food Studies Reader, edited by Robert Ji-Song Ku, Martin F. Manalansan IV and Anita Mannur. New York, NY: New York University Press.

Sprang, Rebecca L. 2000. The Invention of the Restaurant: Paris and Modern Gastronomic Culture. Cambridge, MA: Harvard University Press.

Stasiulis, Daiva K. 1980. "The Political Structuring of Ethnic Community Action: A Reformulation." Canadian Ethnic Studies/Etudes Ethniques au Canada 12(3): 19-44.

---. 2013. "Worrier Nation: Quebec's Value Codes for Immigrants." Politikon 40(1): 183-209.

Stasiulis, Daiva, and Abigail Bakan. 2005. Negotiating citizenship: Migrant women in Canada and the global system. Toronto, ON: University of Toronto Press.

Statistics Canada. 2013a. Winnipeg, Manitoba and Manitoba. National Household Survey (NHS) Profile. 2011 National Household Survey. Statistics Canada Catalogue no. 98-316-XWE. Ottawa, ON.

---. 2013b. Ottawa, CV, Ontario. National Household Survey (NHS) Profile. 2011 National Household Survey. Statistics Canada Catalogue no. 99-004-XWE. Ottawa, ON.

---. 2013c. Canada (Code 01). National Household Survey (NHS) Profile. 2011 National Household Survey. Statistics Canada Catalogue no. 99-004-XWE. Ottawa, ON.

---. 2013d. Toronto, CMA, Ontario (Code 535). National Household Survey (NHS) Profile. 2011 National Household Survey. Statistics Canada Catalogue no. 99-004-XWE. Ottawa, ON. 
---. 2013e. Vancouver, CMA, British Columbia (Code 933). National Household Survey (NHS) Profile. 2011 National Household Survey. Statistics Canada Catalogue no. 99-004-XWE. Ottawa, ON.

---. 2013f. "Generation status: Canadian-born children of immigrants." NHS in Brief, National Household Survey (NHS), 2011. (http://www12.statcan.gc.ca/nhs-enm/2011/as-sa/99010-x/99-010-x2011003_2-eng.pdf)

Stierand, Mark and Paul Lynch. 2008. "The art of creating culinary innovations." Tourism and Hospitality Research 8(4): 337-350.

Svennevig, Jennifer. 2001. "Abduction as a methodological approach to the study of spoken interaction." Norskrift, Institutt for nordistikk og litteraturvitenskap, Universitetet i Oslo 103(1): $1-22$.

Symons, Michael. 1994. "Simmel's Gastronomic Sociology: An overlooked essay." Food and Foodways 5(4): 333-351.

Tam, Ruth. 2015. "How it feels when white people shame your culture's food - then make it trendy." The Washington Post, August 31. Retrieved on July 2, 2017. (https://www.washingtonpost.com/posteverything/wp/2015/08/31/childhood-friendscalled-my-food-chinese-grossness-how-did-it-become-americas-hottest-food-trend/)

Tanaka, Shaun Naomi. 2008. "Consuming the 'Oriental Other', Constructing the Cosmopolitan Canadian: Reinterpreting Japanese Culinary Culture in Toronto's Japanese Restaurants." PhD Dissertation, Department of Geography, Queen's University.

Tastsoglou, Evangelia. 2008. "The Experiences of the Second-Generation Canadian Youth.” Special Issue of Canadian Ethnic Studies 40(2).

Teodoro, Noel V. 1999. "Pensionados and Workers: The Filipinos in the United States, 19031956." Asian and Pacific Migration Journal 8(1-2): 157-178.

Tongco, Ma. Dolores C. 2007. "Purposive Sampling as a Tool for Informant Selection." Ethnobotany Research and Applications 5(1): 147-158.

Treasury Board of Canada Secretariat. 2016. Report on Plans and Priorities 2016-17. Ottawa: Government of Canada. Retrieved on July 11, 2017. (https://www.canada.ca/content/dam/canada/tbs-sct/migration/ip-pi/reportsrapports/rpp/2016-2017/tbd-eng.pdf)

Turgeon, Laurier and Madeleine Pastinelli. 2002. "'Eat the World": Postcolonial Encounters in Quebec City's Ethnic Restaurants." Journal of American Folklore 115(456): 247-268. 
Uy, Amy A. 2012. "Food Trucks Invade Manila." GMA News, December 17. Retrieved on March 30, 2017. (http://www.gmanetwork.com/news/lifestyle/food/286721/food-trucksinvade-manila/story/)

Vachon, Marc, and Wes Toews. 2008. "A Geography of the Filipino Migration to Winnipeg." Canadian Journal of Urban Research 17(1):107-29.

Vergara, Benito. 2009. Pinoy Capital: The Filipino Nation in Daly City. Philadelphia, PA: Temple University Press.

Vineberg, Robert. 2010. "The Role of Immigration in Ottawa's Historic Growth and Development: A Multi-City Comparative Analysis of Census and Immigration Data." Ottawa Local Immigration Partnership. Ottawa, ON: OLIP-PLIO.

Volery, Thierry. 2007. "Ethnic entrepreneurship: A theoretical framework.” Pp. 30-41 in Handbook of Research on Ethnic Minority Entrepreneurship:A Co-evolutionary View on Resource Management, edited by Leo-Paul Dana. Cheltenham, UK: Edward Elgar Publishing.

Wacquant, Loic. 2007. "Pierre Bourdieu.” Pp. 261-277 in Key Sociological Thinkers, edited by Rob Stones. New York, NY: MacMillan. (http://loicwacquant.net/assets/Papers/PIERREBOURDIEU-Stones2007.pdf)

Waldinger, Roger, Howard Aldrich, and Robin Ward. 1990. "Opportunities, Group Characteristics, and Strategies." Pp. 13-48 in Ethnic Entrepreneurs: Immigrant Business in Industrial Societies, edited by Roger Waldinger, Howard Alrich, and Robin Ward. Newbury Park, CA: Sage Publications.

Walia, Harsha. 2010. "Transient servitude: migrant labour in Canada and the apartheid of citizenship.” Race and Class 52(1): 71-84.

Warde, Alan. "Eating Globally: Cultural Flows and the Spread of Ethnic Restaurants." Pp. 299316 in The Ends of Globalization: Bringing Society Back in, edited by Don Kalb. Lanham, ML: Rowman and Littlefield Publishers, Inc.

Waters, Erica 2017. "Let's Talk About Body Shaming in the Philippines." Nextshark Asia. Retrieved on June 13, 2017. (https://nextshark.com/lets-talk-body-shaming-philippines/)

Wessel, Ginette. 2012. "From Place to NonPlace: A Case Study of Social Media and Contemporary Food Trucks." Journal of Urban Design 4(1): 511-531.

Westbrook, Laura. 2008. "Mabuhay Pilipino! (Long Life!): Filipino Culture in Southeast Louisiana." Folklife in Louisiana: Louisiana's Living Traditions. Retrieved April 3, 2017. (http://www.louisianafolklife.org/LT/Articles_Essays/pilipino1.html) 
Wiley, Sophia. 2016. "Becoming Visible: Oral Histories of Filipino Americans in California." MA Thesis, Department of Anthropology, California State University Northridge.

Winant, Howard. 2006. "Race and racism: Towards a global future." Ethnic and Racial Studies 29(5):986-1003.

Winter, Elke. 2007. "Bridging Unequal Relations, Ethnic Diversity, and the Dream of Unified Nationhood: Multiculturalism in Canada.” Zeitschrift fur Kanada-Studien 1(1): 38-57.

World Bank. 2011. Migration and Remittances Factbook, 2011. Washington, DC: World Bank.

Xu, Wenying. 2008. Eating Identities: Reading Food in Asian American Literature. Honolulu, HI: University of Hawai'i Press.

Yanow, Dvora, and Peregrine Schwartz-Shea. 2009. "Interpretive Research: Characteristics and Criteria.” Revenue Internationale de Psychoscociologie 35(15): 29-38.

Yinger, John Milton. 1985. "Ethnicity.” Annual Review of Sociology 11(1): 151-180.

Yu, Wan. 2016. "U.S. Asians: Migration and Settlements." Pp. 279-296 in Race, Ethnicity, and Place in a Changing America (3rd ed.), edited by John W. Frazier, Eugene L. Tettey-Fio, Norah F. Henry. New York, NY: SUNY Press.

Zappia, Corina. 2015. "Filipino: The Five-Step Plan." Gastronomica: The Journal of Critical Food Studies 15(2): 57-64.

Zhou, Min, and Mingang Lin. 2005. "Community Transformation and the Formation of Ethnic Capital: Immigrant Chinese Communities in the United States." Journal of Chinese Overseas 1(2): 260-284 


\section{APPENDIX A: LIST OF TERMS AND TRANSLATIONS ${ }^{21}$}

\section{Philippine Culinary Terminology 2223}

Adobo: A dish of meat, seafood or vegetables cooked in vinegar and spices. Most commonly used meats are chicken or pork. Spices and sauces typically include soy sauce, black pepper and bay leaves.

Afritada: A meat stew made with green peppers, onions, tomatoes and potatoes. Most commonly used meats are chicken or pork.

Alat: Salty.

Anghang: Spicy.

Asim: Sour.

Atchara: Pickled fruits or vegetables. Common ingredients are green papaya and carrots. Eaten as a condiment

Baboy: Pork.

Baka: Beef.

Balut: A fertilized duck embryo. The common practice is to eat from the shell and dipped in a sawsawan made of vinegar, chilies and garlic sprinkled with salt. Balut is a popular pulutan food to be eaten with alcohol.

Bagoong: Small shrimps preserved and fermented in brine. Eaten as a salty condiment with other foods.

Baon: A "packed lunch" or meal to be eaten outside the home (i.e: at a picnic).
Burro: Fermented shrimp or meat preserved in brine or salt, pickled green fruits; or shrimp fermented with rice.

Caldareta: A stew traditionally made with goat meat simmered with tomato sauce vegetables (tomatoes, potatoes, olives, bell peppers and carrots) and liver paste. A popular variation of caldareta is made with beef in lieu of goat.

Champorado: A glutinous rice porridge made with cacao or chocolate tablets served with milk. It is commonly eaten and paired with tuyo at breakfast time.

Dinakdakan: An Ilocano dish made with boiled and grilled pork meat and pork innards which commonly uses the pig's face, ears, and liver. It is simmered in pork brains to give it a creamy texture. Commonly eaten as a pulutan.

Dinuguan: A dish commonly made with pork innards and coagulated pork blood seasoned with vinegar, garlic, salt, and chilies. Commonly eaten with puto. Colloquially known among second generation Filipinos as "chocolate meat" due to its appearance.

Dugo: Blood.
Ensaymada: A sweet roll/brioche usually buttered and topped with granulated sugar, sometimes with cheese.

Hapunan: A meal eaten in the evening.

Inasal: Originating from the Bacolod region of the Philippines, inasal means to "charbroil", most commonly chicken. It is traditionally marinated in a mixture of lime, vinegar, pepper, and annatto.

Inihaw: To grill or roast over a fire.

Isaw: Grilled innards, typically intestines, marinated and skewered. Commonly eaten as a street food or pulutan.

Kamayan: Refers to the practice of eating with one's hands. In contemporary times, it refers to meals eaten with one's hands over a lavish spread of food on a table adorned with banana leaves.

Kare-kare: A peanut-based stew commonly made with vegetables (eggplants, long beans, bok choy and banana hearts commonly) with ox tail and honeycomb tripe.

${ }^{21}$ The terminology referenced on this page are based off of the Tagalog language.

${ }^{22}$ The culinary terminology are loosely derived from the works of acclaimed Philippine culinary historian Doreen G. Fernandez (1988, 1993, 1994), her co-authored works with Edilberto Alegre (1990) and Jonathan Best (2000). Additionally, Gilda Cordero-Fernando (1976) and Kirshenblatt-Gimblett (2003).

${ }^{23}$ The dishes featured on this list are described according to the dominant mode of preparation. It is important to be aware of the many variations that exist elsewhere in the Philippines. 
Kinilaw: A dish made by marinating uncooked seafood in vinegar seasoned with salt, pepper, and chopped chilies. Similar to ceviche.

Lugaw: Rice porridge seasoned with garlic, fish sauce and ginger. Variations include goto (made with innards, such as beef tripe) and arroz caldo (chicken). Similar to the Cantonese congee.

Lumpia: Refers to rolled foods, similar to egg rolls. There are variations such as lumpia shanghai which are small egg rolls stuffed with ground meat (i.e., pork and shrimp) with vegetables then deep fried and lumpia sariwa which are fresh rolls made with a crepe wrapper stuffed with vegetables, ground meat, ground tofu, and served with a peanut sauce.

Lutong Bahay: Homemade cooking or home-style cooking. Can also refer to comfort food.

Mechado: A dish made with larded beef marinated in vinegar, soy sauce, garlic, spices (black pepper, bay leaf), fish sauce, vegetables (commonly bell peppers, onions and carrots) and tomatoes. Slowly braised until tender. Similar to a North American beef stew.

Menudo: A stew made with pork meat or chicken, with sausage, potatoes, carrots, peas, tomato sauce and raisins.

Merienda: A mid-day snack/meal. Either in the morning or afternoon.

Pait: Bitter.

Palayok: A round-bottomed clay cooking vessel.

Pancit: Stirfried noodles. There are different variations. Most commonly includes meat and vegetables seasoned with fish sauce and garlic as the basis.

Pan de coco: Sweet bread roll stuffed with coconut jam
Pan de sal: Sweet bread roll commonly eaten in the mornings with coffee.

Papaitan: A soup made of offal (traditionally made with goat, but usually with beef), which is seasoned with onions, garlic, ginger, and lastly, the core ingredient, goat bile which gives it the bitter taste.

Patis: Fish sauce.

Puto: Steamed sweet rice cakes.

Pulutan: Foods that are eaten alongside alcohol.

Sabaw: Broth.

Sawsawan: A catch-all term for dipping sauce. A common sawsawan is made with vinegar, chilies and garlic.

Silog: A term to refer to Filipino breakfasts. Silog is prefaced with the main meat featured (i.e.: tapa) and becomes tapsilog. A silog has a meat or seafood, fried eggs, and garlic fried rice.

Silogan: A place that specialises in silogs.

Sinangag: Garlic fried rice.

Sinigang: A soup made with meat or seafood, with vegetables in a sour broth, commonly tamarindbased.

Siomai: A steamed dumpling made with pork and shrimp and eaten with a sawsawan of calamansi and soy sauce.

Siopao: A large steamed meat bun. Common fillings are sweet pork (asado) or ground pork meatballs with egg yolk (bola-bola).
Sisig: A dish made with pork (most commonly a pork's head) and pork liver, seasoned with calamansi, chili peppers, and a raw egg. Sometimes mayonnaise is included. A popular appetiser and pulutan.

Suka: Vinegar.

Sorbetes: A frozen dessert akin to ice cream made with a grinder.

Tanghalian: A meal eaten at mid-day, or a lunch.

Tapa: Cured beef marinated in soy sauce, sugar and vinegar.

Tocino: Sweet cured pork.

Tuyo: It is usually referred to as a catch-all for dried preserved fish.

Ube: Purple yam. Popularly used in desserts.

Umagahan: A meal eaten to break the morning fast. 


\section{APPENDIX B: INTERVIEW QUESTIONS}

$\underline{\text { Interview Questions }}$

Title of Project: Serving Resistance on the Menu: The Cultural Politics of Filipino Cuisine in Winnipeg and Ottawa

Researcher: Gazel Manuel

Supervisor: Dr. Xiaobei Chen

Introductory Questions: Restaurant-Related

1) What is the name of your/this restaurant?

$\rightarrow$ Can you tell me a bit about the inspiration behind the name?

2) How would you describe kind of food do you serve at your restaurant?

3) Tell me more about the menu items.

4) IF a 'turo-turo' style restaurant (take-out): Does your selection change frequently, or does it remain relatively the same?

5) What are your best-sellers?

6) Are the foods you serve at this restaurant something you would serve at home? Parties?

7) Who are the main clientele at your restaurant?

8) What is your role in the restaurant? Describe your day-to-day duties in the restaurant.

9) Why did you choose the restaurant industry as your line of work?

10) From your observations, how does your restaurant generate business?

$\underline{\text { Restaurant-Specific Questions (Cultural) }}$

1) Would you define your restaurant as more traditional (authentic), or more modern? Or neither? Which is more important to you? Which one do you think generates more interest/customers, in your opinion?

2) Thinking about your work life or personal life, has there ever been a moment where nonFilipinos have complained, or made negative remarks about the restaurant's food, or Filipino food in general? 
3) Have you ever had to adapt the food to follow certain tastes or dietary restrictions? (People not liking the ingredients, allergies, diets such as veganism/vegetarianism)

Atmosphere-Related Questions

Ask in conjunction with observations made about the restaurant space! Ask about the concept, and decisions; if applicable.

1) Open-ended question: Can you tell me about [uniform/décor/etc. related to space and atmosphere of restaurant]?

Filipino Cuisine Questions

1) How would you describe Filipino cuisine?

2) There are regional differences in Filipino cuisine. How would you classify your restaurant? Does it cater to a specific region?

3) Do you think Filipino cuisine is 'mainstream?' Why or why not? If not, could it ever be mainstream?

4) Have you ever seen Filipino cuisine/food featured in the media? If so, could you recall what you remember?

5) Are there foods from the Philippines that you do not see in restaurants in Canada? $\rightarrow$ IF YES, why do you think there isn't any?

6) What kind of foods do you wish you could have from the Philippines but you cannot easily get or have in Canada?

7) What Filipino foods do you think are the most popular?

$\rightarrow$ Why do you think that it's so popular?

8) What Filipino foods do you think are the least popular?

$\rightarrow$ Why do you think that it's not very popular?

9) Do you think Filipino foods can be considered 'upscale'? Why or why not?

10) Filipinos are the $3^{\text {rd }}$ largest ethnic group in Canada, yet there aren't many Filipino restaurants in Canada. What are your thoughts on this?

\section{$\underline{\text { Last remarks }}$}

1) This concludes the interview. Are there other things you would like to discuss? This could be previous points, or things we haven't discussed in this interview. 


\title{
APPENDIX C: LETTER OF INVITATION
}

\author{
Carleton \\ U N I V E R S I T Y \\ Canada's Capital University
}

\section{Letter of Invitation for Research Study}

Title: Serving Resistance on the Menu: The Cultural Politics of Filipino Cuisine in Winnipeg and Ottawa

Date of ethics clearance: October 20, 2016

Ethics Clearance for the Collection of Data Expires: October 31, 2017

$10 / 20 / 2016$

Dear Sir or Madam,

My name is Gazel Manuel and I am a Master's student in the department of Sociology and Anthropology at Carleton University. I am working on a research project under the supervision of Prof. Xiaobei Chen.

I am writing to you today to invite you to participate in a study on ethnic identity formation through practices of multicultural eating. This study aims to examine the perspective of producers of ethnic food, and how food is used to express or denote one's ethnic identity in a multicultural society such as Canada.

This study involves one 60 minute interview that will take place in a mutually convenient, safe location. With your consent, interviews will be audio-recorded. Once the recording has been transcribed, the audio-recording will be destroyed.

While this project does involve some professional and emotional risks, care will be taken to protect your identity. This will be done by keeping all responses anonymous and allowing you to request that certain responses not be included in the final project.

You will have the right to end your participation in the study at any time, for any reason, up until March 1, 2017. If you choose to withdraw, all the information you have provided will be destroyed.

All research data, including audio-recordings and any notes will be encrypted. Any hard copies of data (including any handwritten notes or USB keys) will be kept in a locked cabinet at Carleton University. Research data will only be accessible by the 
researcher and the research supervisor.

This ethics protocol for this project was reviewed by the Carleton University Research Ethics Board, which provided clearance to carry out the research. Should you have questions or concerns related to your involvement in this research, please contact:

REB contact information:

Professor Louise Heslop, Chair

Professor Andy Adler, Vice-Chair

Research Ethics Board

Carleton University

511 Tory

1125 Colonel By Drive

Ottawa, ON K1S 5B6

Tel: 613-520-2517

ethics@carleton.ca

There will be no compensation provided in this interview. However, if you would like to participate in this research project, or have any questions, please contact me at or gazel.manuel@carleton.ca

Sincerely,

Gazel Manuel 


\section{APPENDIX D: CONSENT FORM}

Carleton

U N I V E R S I T Y

Canada's Capital University

\section{Consent Form for Research Study}

Title: Serving Resistance on the Menu: The Cultural Politics of Filipino Cuisine in Winnipeg and Ottawa

Date of ethics clearance: October 20, 2016

Ethics Clearance for the Collection of Data Expires: October 31, 2017

\section{I} choose to participate in a study on (insert research subject here). This study aims to study ethnic identity formation through practices of multicultural eating. More specifically, this study examines the perspective of producers of ethnic food, and how food is used to express or denote one's ethnic identity in a multicultural society such as Canada.

The researcher for this study is Gazel Manuel in the department of Sociology and Anthropology at Carleton University. She is working under the supervision of Dr. Xiaobei Chen in the department of Sociology and Anthropology at Carleton University.

This study involves one 60 minute interview. With your consent, interviews will be audio-recorded. Once the recording has been transcribed, the audio-recording will be destroyed.

During this study, I will take precautions to protect your identity. This will be done by keeping all responses anonymous and allowing you to request that certain responses not be included in the final project. Should you experience any distress during the interview, you will be provided with contact information for counseling services available nearby.

You have the right to end your participation in the study at any time, for any reason, up until March $1^{\text {st }}, 2017$. You can withdraw by phoning or emailing the researcher or the research supervisor. If you withdraw from the study, all information you have provided will be immediately destroyed.

All research data, including audio-recordings and any notes will be encrypted. Any hard copies of data (including any handwritten notes or USB keys) will be kept in a locked cabinet at Carleton University. Research data will only be accessible by the researcher and the research supervisor. 
Once the project is completed, all research data will be kept for five years and potentially used for other research projects on this same topic. At the end of five years, all research data will be securely destroyed. (Electronic data will be erased and hard copies will be shredded.)

If you would like a copy of the finished research project, you are invited to contact the researcher to request an electronic copy which will be provided to you.

The ethics protocol for this project was reviewed by the Carleton University Research Ethics Board, which provided clearance to carry out the research. Should you have questions or concerns related to your involvement in this research, please contact:

REB contact information:

Professor Louise Heslop, Chair

Professor Andy Adler, Vice-Chair

Research Ethics Board

Carleton University

511 Tory

1125 Colonel By Drive

Ottawa, ON K1S 5B6

Tel: 613-520-2517

ethics@carleton.ca

Researcher contact information:

Name : Gazel Manuel

Department: Sociology

Carleton University

Tel:

Email: gazel.manuel@carleton.ca
Supervisor contact information:

Name: Dr. Xiaobei Chen

Department: Sociology

Carleton University

Tel: $613-520-2600 \times 3990$

Email:xiaobei.chen@carleton.ca

Do you agree to be audio-recorded: Yes No

Signature of participant

Date

Signature of researcher

Date 


\section{APPENDIX E: CUREB CERTIFICATE OF APPROVAL}

\section{Carleton}

UNIVERSITY

Canada's Capital University

Research Compliance Office

511 Tory $\mid 1125$ Colonel By Drive

| Ottawa, Ontario K1S 5B6

613-520-2600 Ext: 4085

ethics@carleton.ca

\section{CERTIFICATION OF INSTITUTIONAL ETHICS CLEARANCE}

Ethics clearance for the following research has been cleared by the Carleton University Research Ethics Board (CUREB-A) at Carleton University. CUREB-A is constituted and operates in compliance with the Tri-Council Policy Statement: Ethical Conduct for Research Involving Humans (TCPS2).

Ethics Protocol Clearance ID: Project \# 105445

Faculty Supervisor: Xiaobei Chen, Carleton University

Research Team: Xiaobei Chen (Primary Investigator)

Gazel Manuel (Student Researcher)

Study Title: Serving Resistance on the Menu: The Cultural Politics of Filipino Cuisine in Winnipeg and Ottawa [Gazel Manuel]

\section{Funding Source (If applicable):}

Effective: October 20, 2016

Expires: October 31, 2017.

Restrictions:

This certification is subject to the following conditions:

1. Clearance is granted only for the research and purposes described in the application.

2. Any modification to the approved research must be submitted to CUREB-A. All changes must be approved prior to the continuance of the research.

3. An Annual Application for the renewal of ethics clearance must be submitted and cleared by the above date. Failure to submit the Annual Status Report will result in the closure of the file. If funding is associated, funds will be frozen.

4. A closure request must be sent to CUREB-A when the research is complete or terminated.

5. Should any participant suffer adversely from their participation in the project you are required to report the matter to CUREB-A. 
6. It is the responsibility of the student to notify their supervisor of any adverse events, changes to their application, or requests to renew/close the protocol.

7. 7. Failure to conduct the research in accordance with the principles of the Tri-Council Policy Statement: Ethical Conduct for Research Involving Humans 2nd edition and the Carleton University Policies and Procedures for the Ethical Conduct of Research may result in the suspension or termination of the research project.

Please email the Ethics Coordinators at ethics@carleton.ca if you have any questions. If a researcher requires a certificate with a signature, they may contact ethics@carleton.ca to have one generated.

CLEARED BY:

Andy Adler, PhD, Chair, CUREB-A

Shelley Brown, PhD, Vice-Chair, CUREB-A

\section{DATE:}

October 20, 2016 